\title{
TESTS AND ANALYSES OF 1/4-SCALE UPGRADED NINE-BAY REINFORCED CONCRETE BASEMENT MODELS
}

\author{
by \\ Stanley C. Woodson \\ Structures Laboratory \\ DEPARTMENT OF THE ARMY \\ Waterways Experiment Station, Corps of Engineers \\ PO Box 631 \\ Vicksburg, Mississippi 39180-0631
}
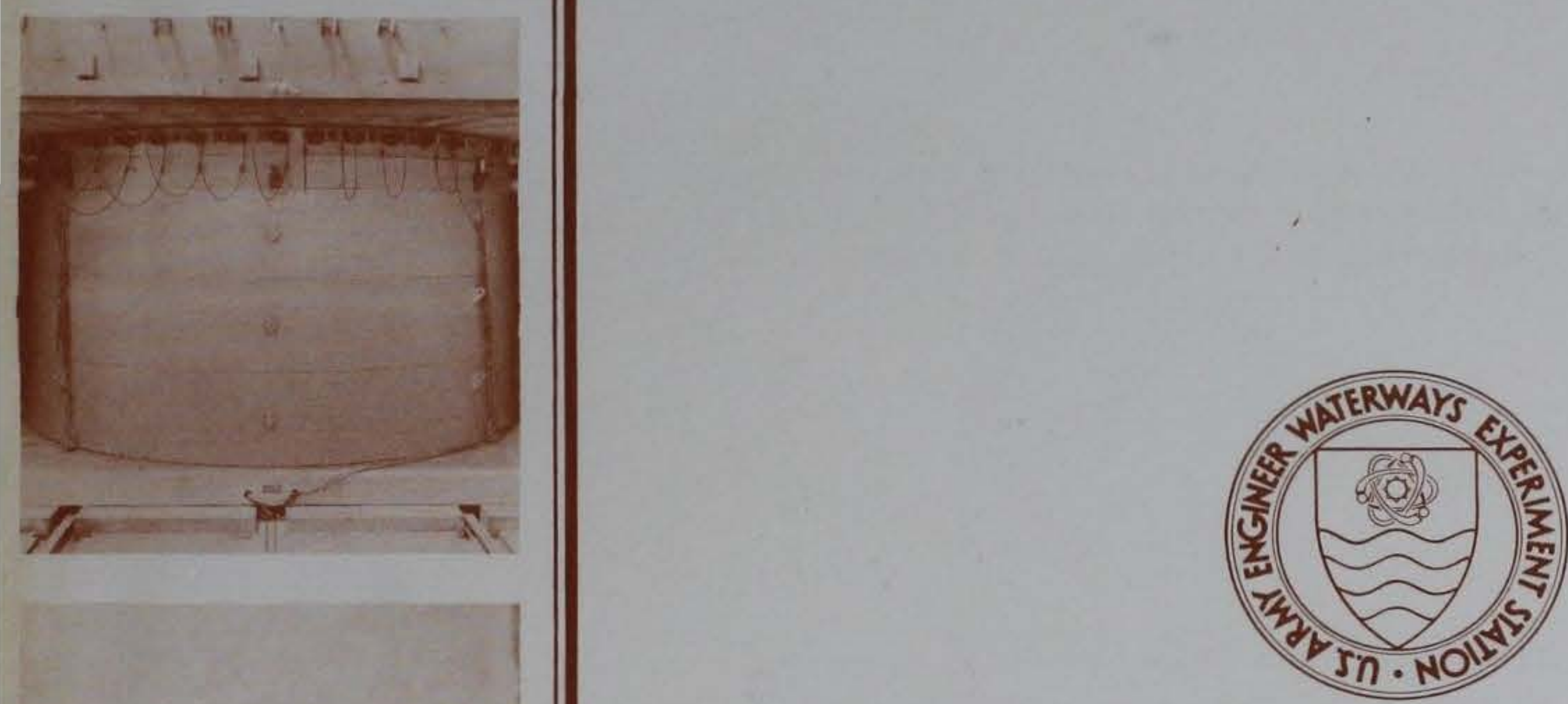

May 1984

Final Report

Approved For Public Release: Distribution Unlimited

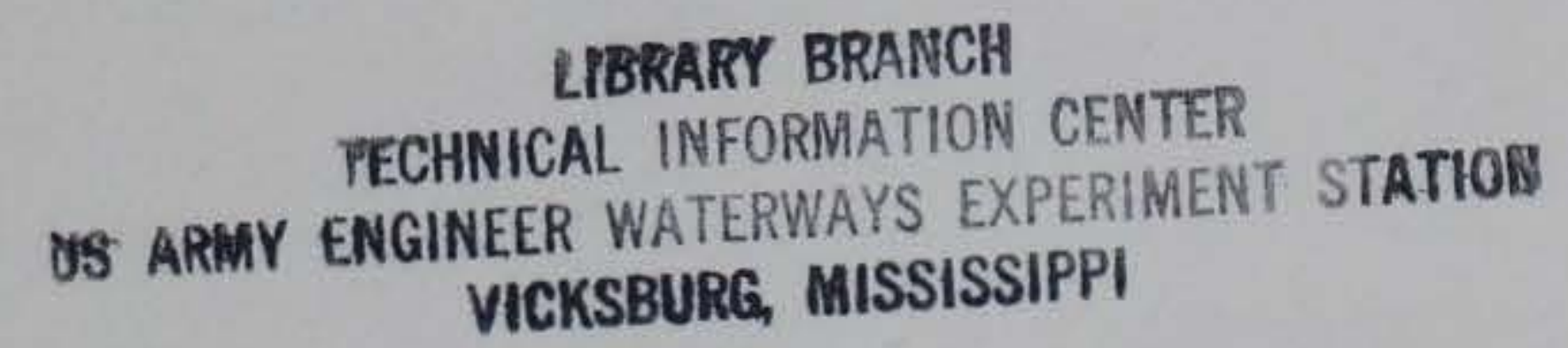

Prepared for

Federal Emergency Management Agency Washington, DC 20472 


\title{
TESTS AND ANALYSES OF 1/4-SCALE UPGRADED NINE-BAY REINFORCED CONCRETE BASEMENT MODELS
}

\author{
by \\ Stanley C. Woodson \\ Structures Laboratory \\ DEPARTMENT OF THE ARMY \\ Waterways Experiment Station, Corps of Engineers \\ PO Box 631 \\ Vicksburg, Mississippi 39180-0631
}

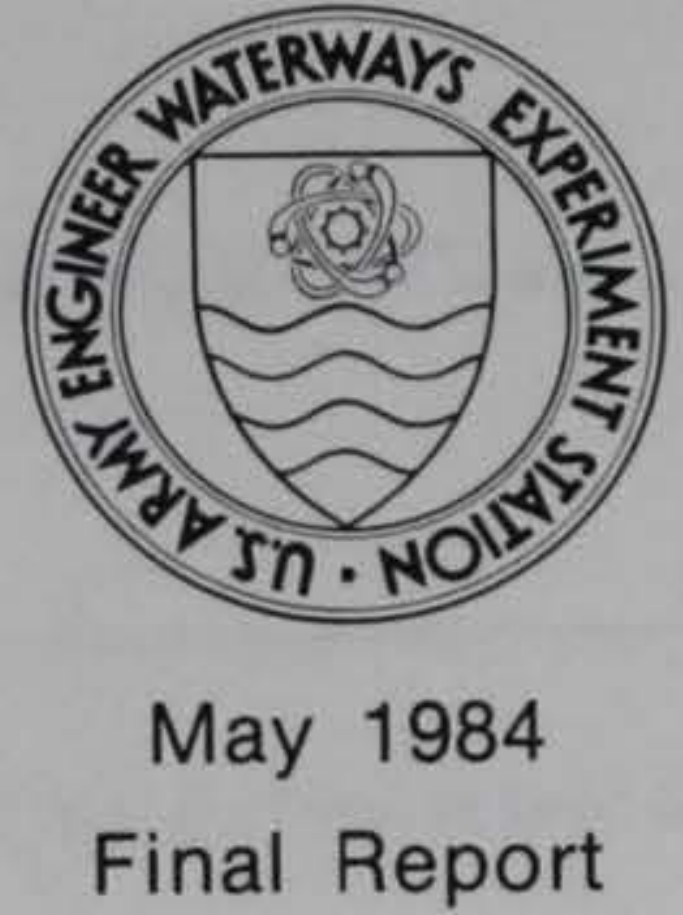

Approved For Public Release; Distribution Unlimited

This report has been reviewed in the Federal Emergency Management Agency and approved for publication. Approval does not signify that the contents necessarily reflect the views and policies of the Federal Emergency Management Agency. 
Unclassified

SECURITY CLASSIFICATION OF THIS PAGE (Whan Data Entored)

\begin{tabular}{|c|c|}
\hline REPORT DOCUMENTATION PAGE & $\begin{array}{l}\text { READ INSTRUCTIONS } \\
\text { BEFORE COMPLETING FORM } \\
\end{array}$ \\
\hline $\begin{array}{l}\text { 1. REPORT NUMBER } \\
\text { Technical Report SL-84-6 }\end{array}$ & 3. RECIPIENT'S CATALOG NUMBER \\
\hline \multirow[t]{2}{*}{$\begin{array}{l}\text { 4. TITLE (and Subtü) } \\
\text { TESTS AND ANALYSES OF 1/4-SCALE UPGRADED NINE- } \\
\text { BAY REINFORCED CONCRETE BASEMENT MODELS }\end{array}$} & $\begin{array}{l}\text { 5. TYPE OF REPORT \& PERIOD COVERED } \\
\text { Final report }\end{array}$ \\
\hline & 6. PERFORMING ORG. REPORT NUMBER \\
\hline $\begin{array}{l}\text { 7. AUTHOR(o) } \\
\text { Stanley C. Woodson }\end{array}$ & 8. CONTRACT OR GRANT NUMBER(0) \\
\hline $\begin{array}{l}\text { 9. PERFORMING ORGANIZATION NAME AND ADDRESS } \\
\text { US Army Engineer Waterways Experiment Station } \\
\text { Structures Laboratory } \\
\text { PO Box 631, Vicksburg, Mississippi 39180-0631 }\end{array}$ & $\begin{array}{l}\text { 10. PROGRAM ELEMENT, PROJECT, TASK } \\
\text { AREA \& WORK UNIT NUMEERS }\end{array}$ \\
\hline \multirow{2}{*}{$\begin{array}{l}\text { 11. CONTROLLING OFFICE NAME AND ADDRESS } \\
\text { Federal EmergenCy Management Agency } \\
1725 \text { I. St. N. W. (M. Bldg.) } \\
\text { Washington, DC } 20472\end{array}$} & $\begin{array}{l}\text { 12. REPORT DATE } \\
\text { May } 1984\end{array}$ \\
\hline & $\begin{array}{l}\text { 13. NUMBER OF PAGES } \\
132\end{array}$ \\
\hline \multirow[t]{2}{*}{ 14. MONITORING AGENCY NAME \& ADDRESS(II different from Controlling Office) } & $\begin{array}{l}\text { 15. SECURITY CLASS. (of thio roport) } \\
\text { Unclassified }\end{array}$ \\
\hline & $\begin{array}{l}\text { 15a. DECLASSIFICATION/DOWNGRADING } \\
\text { SCHEDULE }\end{array}$ \\
\hline
\end{tabular}

\section{DISTRIBUTION STATEMENT (of this Roport)}

Approved for public release; distribution unlimited.

17. DISTRIBUTION STATEMENT (of the abstract ontered in Block 20, if different from Report)

\section{SUPPLEMENTARY NOTES}

Available from National Technical Information Service, 5285 Port Royal Road, Springfield, Virginia 22161.

19. KEY WORDS (Continue on reverse side If nocessary and identily by block number)

Basement model

Static loading

Flat plate model

Two-way slab model

Reinforced concrete

Upgrading

\section{ABSTRACT (Continue an roverse stith if necoseary and identity by block number)}

Methods that can be used to increase (upgrade) the blast resistance of existing two-way reinforced concrete slab systems to a value near $50-p s i$ overpressure from a 1 -mt weapon were evaluated.

Two nine-bay prototype structures, a flat plate and a two-way slab with beams, were designed in accordance with the 1977 ACI Code. Each structure had a basement area 60 feet square. A $1 / 4-$ scale model of each prototype was

(Continued) 


\section{ABSTRACT (Continued).}

constructed, upgraded with 4 - by 4 -inch timber posts, and statically tested in the Large Blast Load Generator at the U. S. Army Engineer Waterways Experiment Station. The timber posts placement scheme was based upon yield-line analyses, a study of moment-thrust interaction diagrams for sections of the slabs, and punching shear evaluations. The upgraded flat plate was tested first, and the upgrading scheme was then modified for the slab with beams model. The flat plate was upgraded at locations $1 / 4$ of the span length, and the two-way slab with beams structure was upgraded at locations $1 / 3$ of the span length.

The flat plate model and the slab with beams model withstood approximate static overpressures of 79 and $40 \mathrm{psi}$. Allowing some plastic deformation from a long duration load such that the peak dynamic load capacity approaches static capacity indicates that required hardness can be achieved through simple upgrading techniques. The flat plate test indicated that the $1 / 4-s p a n-1$ ength spacing was conservative for a required 50-psi overpressure capacity. The ability of the upgraded flat plate to deflect without punching shear failure occurring at the upgrading columns allowed the model to withstand overpressures greater than expected.

Rupture occurred in the two-way slab with beams model. The ruptured area was approximately 40 inches square, and was the consequence of either an upgrading column punching into the slab or the slippage of the column such that it no longer supported the slab. The test indicated that the $1 / 3-s p a n-1$ ength spacing of upgrading columns was inadequate for a 50-psi overpressure requirement. 


\section{PREFACE}

This study was conducted during the period April 1981 through March 1982 by members of the staff of the U. S. Army Engineer Waterways Experiment Station (WES) under the sponsorship of the Federal Emergency Management Agency (Interagency Agreement No. EMW-E-0337).

The investigation was conducted under the general supervision of Mr. Bryant Mather, Chief of the Structures Laboratory (SL), and Mr. J. T. Ballard, Chief of the Structural Mechanics Division, SL. Mr. W. L. Huff was the Project Manager of the study. Mr. S. C. Woodson supervised the experiments, conducted the analyses, and prepared this report. Acknowledgment is given to $\mathrm{Mr}$. C. D. Norman for providing analytical aid.

The Director of WES during the conduct of this investigation was COL Tilford C. Creel, CE. Technical Director was Mr. Fred R. Brown. 
CONVERSION FACTORS, INCH-POUND TO SI (METRIC) UNITS OF

MEASUREMENT

CHAPTER 1 INTRODUCTION

1.1 Background

1.2 Objectives

1.3 Scope

CHAPTER 2 SELECTION OF SLAB SYSTEM AND DESIGN OF PROTOTYPE SYSTEM AND SCALE MODELS

2.1 Design Requirements of Prototype . . . . . . . . . . . 10

2.2 Selection of the Slab Systems.................. 10

2.3 Design Procedure and Calculations for the Prototype Design . . . 11

2.3.1 Determination of Prototype Design Loads . . . . . . . . 11

2.3.2 Determination of Prototype Design Flexural Moments . . . . 12

2.3.3 Determination of Slab Thickness . . . . . . . . . 13

2.3.3.1 Control of Deflections ........... 13

2.3.3.2 Shear Transfer ............. 14

2.3.4 Beam Design .................. . . . 15

2.3.4.1 Reinforcement for Flexural Resistance...... 16

2.3.4.2 Reinforcement for Shear Resistance . . . . . 17

2.3.5 Slab and Beam Reinforcement Details . . . . . . . . 18

2.3.5.1 Beam Reinforcement Details . . . . . . . . 18

2.3.5.2 Slab Reinforcement Details for Two-Way Slab

With Beams .............. 18

2.3.5.3 Slab Reinforcement Details for Flat Plate... . 19

2.3.6 Column and Wall Design and Reinforcement Details . . . . 19

2.3.6.1 Column Design ............. 19

2.3.6.2 Wall Design.............. 20

2.4 Design of the Models . . . . . . . . . . . . . . 20

2.4.1 Description and Dimensions . . . . . . . . . . 20

2.4.2 Slab Reinforcement ................ 21

2.4.3 Beam Reinforcement ................ 21

2.4.4 Column Reinforcement ................ 21

2.4.5 Wall Reinforcement ................ 21

2.5 Design of the Upgrading System . . . . . . . . . . . 22

CHAPTER 3 EXPERIMENTAL PROCEDURES . . . . . . . . . . . . . . . . 46

3.1 Materials ................... . . 4 46

3.1.1 Concrete................... . . 46

3.1.2 Reinforcement ................. 46

3.1.3 Material Tests.................. 46

3.2 Construction of the Model ............... . 47

3.2.1 Base Slab .................. 47

3.2.2 Formwork for Model Structures ........... 47 
3.2.3 Placing the Reinforcement............. 48

3.2.3.1 Flat Plate Model .................. 48

3.2.3.2 Two-Way Slab with Beams Model ......... 49

3.2.4 Casting the Model .................. 49

3.2.5 Curing the Mode1, Removal of Formwork, and Condition of Model .................... 50

3.3 Testing Procedure ..................... 51

3.3.1 Preparation of Test Specimen .............. . . . 51

3.3.2 Loading Device ....................... . . . . . 52

3.3.3 Placement of Model and Backfill ............ 52

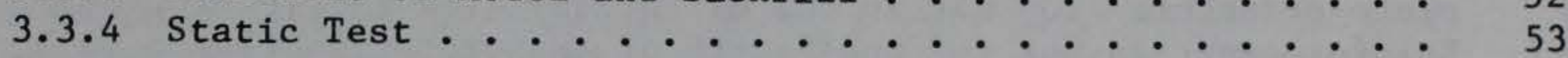

3.4 Instrumentation . . . . . . . . . . . . . . . . . . . . . . . . . . . . 54

3.4.1 Pressure Measurements ............... . . 54

3.4.2 Deflection Measurements ............. . . 54

3.4.3 Soil Stress Measurements .............. . 54

3.4.4 Strain Measurements . . . . . . . . . . . . 54

CHAPTER 4 EXPERIMENTAL RESULTS . . . . . . . . . . . . . . 75

4.1 Flat Plate Model .................. 75

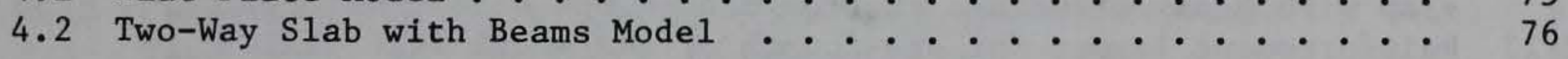

CHAPTER 5 DISCUSSION OF THE TEST RESULTS . . . . . . . . . . . . . 84

5.1 Flat Plate Model ................... . . . 84

5.2 Two-Way Slab with Beams Model . . . . . . . . . . . 87

CHAPTER 6 CONCLUSIONS AND RECOMMENDATIONS . . . . . . . . . . . . 91

6.1 Conclusions .......................... 91

6.2 Recommendations ................... . . . . 93

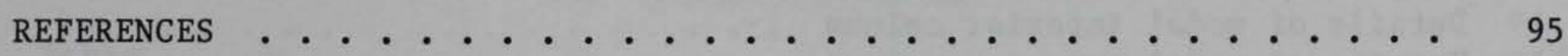

APPENDIX A DATA FROM THE UPGRADED FLAT PLATE MODEL TEST • • • • • • • 97

APPENDIX B DATA FROM THE UPGRADED TWO-WAY SLAB WITH BEAMS

MODEL TEST . . . . . . . . . . . . . . . 113

APPENDIX C REVIEW OF PREVIOUS STUDIES OF UPGRADED SLABS . . . . . . . 131

C.1 Upgraded One-Way Slabs . . . . . . . . . . . 131

C.2 Upgraded Two-Way Slabs .............. 131 
Figure

2.1 Geometry of prototype....................

2.2 Two-way slab with beams prototype............. . . 25

2.3 Prototype concrete beam reinforcement details . . . . . . . 26

2.4 Reinforcement layout for one-fourth of the prototype slab with beams structure (top mat in one direction)

2.5 Reinforcement layout for one-fourth of the prototype slab with beams structure (bottom mat in one direction)

2.6 Reinforcement layout for one-fourth of the prototype flat plate structure (top mat in one direction)

2.7 Reinforcement layout for one-fourth of the prototype flat plate structure (bottom mat in one direction) . . . . . . . 30

2.8 Flat plate model suspended from crane.............. 31

2.9 Cross-section of one-half of flat plate model . . . . . . . 32

2.10 Cross-section of one-half of two-way slab with beams model . . 33

2.11 Reinforcement layout for one-fourth of the model two-way slab with beams structure (top mat in one direction)

2.12 Reinforcement layout for one-fourth of the model two-way slab with beams structure (bottom mat in one direction)

2.13 Reinforcement layout for one-fourth of the model flat plate structure (top mat in one direction) . . . . . . . . . 36

2.14 Reinforcement layout for one-fourth of the model flat plate structure (bottom mat in one direction) ........... 37

2.15 Details of reinforcement in column area of flat plate model . . 38

2.16 Details of reinforcement near top of the flat plate model walls..................... 39

2.17 A-beam reinforcement details . . . . . . . . . . . . 40

2.18 B-beam reinforcement details ............... . 41

2.19 Details of model interior column . . . . . . . . . . . 42

2.20 Details of model exterior column ............... 43

2.21 Model wall details .................... . 44

2.22 Model entranceway details . . . . . . . . . . . . 45

3.1 Base slab...................... 56

3.2 Details of base slab edge and slab to model wall connection... 57

3.3 Inverted base slab ready to be cast . . . . . . . . . 58

3.4 Flat plate model inner formwork .............. . 59

3.5 Two-way slab with beams model inner formwork ......... . 60

3.6 Flat plate model bottom reinforcement mat in place . . . . . . 60

3.7 Column reinforcement steel .............. 61

3.8 Wall reinforcement mat .................. 61

3.9 Completed steel placement at interior column area . . . . . . 62

3.10 Completed steel placement of flat plate model . . . . . . . . 62

3.11 Two-way slab with beams model (wall reinforcement in place) . . . 63

3.12 Completed steel placement of two-way slab with beams model . . 63

3.13 View of reinforcement near column area . . . . . . . . 64

3.14 Close-up view of beam-column connection . . . . . . . . . . 64

3.15 Casting the flat plate model ............... . 65

3.16 Location of voided areas of two-way slab with beams model . . . 66

3.17 Model with structural tubing sections in place ........ 67

3.18 Large Blast Load Generator . . . . . . . . . . . . . . . 68

3.19 Instrumentation and upgrading layout of flat plate model . . . 69 
3.20 Instrumentation and upgrading layout of two-way slab with beams model...................... 70

3.21 Interface pressure gage mounts in place............. . 71

3.22 Strain gages in place in flat plate slab .......... 71

4.1 Top view of posttest flat plate model . . . . . . . . . . 77

4.2 General yield line pattern on undersurface of flat plate model slab . . . . . . . . . . . . . . . . . 77

4.3 Visible yield line cracks and shear results in flat plate model . . . . . . . . . . . . . . . . . . 78

4.4 Punching shear at interior column ............. 78

4.5 Posttest view of upgrading columns in flat plate model . . . . 79

4.6 Compressed wedges in flat plate model test . . . . . . . . . 79

4.7 Top view of posttest two-way slab with beams model . . . . . . 80

4.8 General yield line pattern on undersurface of two-way slab with beams model . . . . . . . . . . . . . . . 80

4.9 Undersurface of posttest two-way slab with beams model . . . . 81

4.10 Short crack extending from column . . . . . . . . . . . 81

4.11 Debris at ruptured area . . . . . . . . . . . . . . 82

4.12 Beam and upgrading columns adjacent to ruptured area . . . . . 82

4.13 Compressed wedges in two-way slab with beams model test . . . . 83

5.1 Load-deflection curve for wooden upgrading column . . . . . . . 89

5.2 Moment diagram for continuous beam with uniform load . . . . . 89

5.3 Moment-thrust interaction diagram (support conditions, low thrust region of diagram) . . . . . . . . . . . . . . 90

5.4 Moment-thrust interaction diagram (midspan conditions, low thrust region of diagram) . . . . . . . . . . . . . 90

\section{LIST OF TABLES}

3.1 Results of concrete cylinder tests for flat plate model.....

3.2 Results of concrete cylinder tests for two-way slab with beams model ....................... 73

3.3 Results of static tensile tests on Dl wire reinforcement . . . 74 
Inch-pound units of measurement used in this report can be converted to SI (metric) units as follows:

Multiply
cubic feet
feet
inches
kips (force)
kips (force) per square inch
pounds (force)
pounds (force) per foot
pounds (force) per square foot
pounds (force) per inch
pounds (force) per square inch
pounds (mass)
pounds (mass) per cubic foot
square inches
mils
tons (nuclear equivalent of

Fahrenheit degrees

$\frac{\text { By }}{0.02831685}$
0.3048
2.54

4448.222

6.894757

4.448222

14.59390

0.04788026

175.1268

0.006894757

0.4535924

16.01846

6.4516

0.0254

4189.0

$5 / 9$
To Obtain

cubic metres

metres

centimetres

newtons

megapascals

newtons

newtons per metre

kilopascals

newtons per metre

megapascals

kilograms

kilograms per cubic metre square centimetres

millimetres

megajoules

Celsius degrees or Kelvins*

* To obtain Celsius (C) temperature readings from Fahrenheit (F) readings, use the following formula: $C=(5 / 9)(F-32)$. To obtain Kelvin (K) readings, use: $K=(5 / 9)(F-32)+273.15$. 
Methods that can be used to increase (upgrade) the blast resistance of existing two-way reinforced concrete slab systems to a value near 50-psi overpressure from a $1-\mathrm{mt}$ weapon were evaluated.

Two nine-bay prototype structures, a flat plate and a two-way slab with beams, were designed in accordance with the 1977 ACI Code. Each structure had a basement area 60 feet square. A 1/4-scale model of each prototype was constructed, upgraded with 4- by 4-inch timber posts, and statically tested in the Large Blast Load Generator at the U. S. Army Engineer Waterways Experiment Station. The timber posts placement scheme was based upon yield-line analyses, a study of moment-thrust interaction diagrams for sections of the slabs, and punching shear evaluations. The upgraded flat plate was tested first, and the upgrading scheme was then modified for the slab with beams model. The flat plate was upgraded at locations $1 / 4$ of the span length, and the two-way slab with beams structure was upgraded at locations $1 / 3$ of the span length.

The flat plate model and the slab with beams model withstood approximate static overpressures of 79 and 40 psi. Allowing some plastic deformation from a long duration load such that the peak dynamic load capacity approaches static capacity indicates that required hardness can be achieved through simple upgrading techniques. The flat plate test indicated that the $1 / 4-$ span-length spacing was conservative for a required 50-psi overpressure capacity. The ability of the upgraded flat plate to deflect without punching shear failure occurring at the upgrading columns allowed the model to withstand overpressures greater than expected.

Rupture occurred in the two-way slab with beams model. The ruptured area was approximately 40 inches square, and was the consequence of either an upgrading column punching into the slab or the slippage of the column such that it no longer supported the slab. The test indicated that the 1/3-span-length spacing of upgrading columns was inadequate for a 50-psi overpressure requirement. 


\section{TESTS AND ANALYSES OF 1/4-SCALE UPGRADED NINE-BAY}

\section{REINFORCED CONCRETE BASEMENT MODELS}

\section{CHAPTER 1}

INTRODUCTION

\subsection{BACKGROUND}

The Federal Emergency Management Agency (FEMA) has the responsibility of maintaining an appropriate civil defense program for the United States. Currently known as Crisis Relocation Planning (CRP), this program would call for the following actions during a time of developing international crisis when a nuclear war is imminent:

1. Moving the majority of the population away from potential target areas into surrounding host areas within 2 to 3 days.

2. Moving people initially into public and private buildings in the host areas and then, if necessary, into shelters (mostly expedient-type).

3. Keeping key workers and officials behind in the target areas to operate important industries and government positions until just before an attack as well as providing cover for them in a hardened shelter within quick access from the target area.

This report is related to Part 3 of the CRP. It has been estimated that a hardened shelter within quick access of a target area would be in an overpressure range of $50 \mathrm{psi}$ * or less from a l-mt weapon. There are several concepts for development of keyworker shelters. One is called "Upgrading," in which basements in existing buildings are upgraded with additional structural members in order to withstand a peak overpressure of $50 \mathrm{psi}$. Another concept is called "Slanting," in which the government provides funding for the additional design and construction costs in strengthening a new building to withstand $50 \mathrm{psi}$. The newest concept requires the development of a dedicated shelter system. Under this concept specially designed blast shelters would be constructed near keyworkers.

Very few existing civil defense shelters are capable of withstanding

* A table of factors for converting inch-pound units of measurement to metric (SI) units is presented on page 6. 
50 psi. Although slanted buildings, or dedicated shelters, are preferred and some construction has begun, it will be several years before enough shelters will be available. Over the past few years the emphasis has been on developing upgrading methods that could immediately be used to implement CRP in the event of a nuclear war.

Some earlier studies (see Appendix C) revealed the possibility of increasing the load capacity of one-way and two-way reinforced concrete floor slabs through use of proper upgrading methods. The upgrading of portions of two-way slabs indicated a high probability that two-way slabs may be upgraded to withstand overpressures near 50 psi. However, it was concluded that the two-way slab portions did not properly model a two-way slab floor and that additional research was needed to investigate the effects of upgrading two-way slabs.

\subsection{OBJECTIVES}

The objectives of this study were to (1) design and construct two 1/4-scale reinforced concrete two-way slab models representing economical basement ceiling systems typical of existing reinforced concrete buildings in the United States and (2) evaluate methods that can be used to increase (upgrade) the blast resistance of existing two-way reinforced concrete slab systems, represented by the models, to a value near the CRP requirement of 50-psi peak overpressure from a 1-Mt weapon.

\section{$1.3 \mathrm{SCOPE}$}

The general structural behavior of two-way reinforced concrete slab systems was considered in the selection of a geometrical configuration for the prototype structures. The prototype structures each consisted of a basement area 60 feet square having a reinforced concrete two-way slab roof with three 20-foot spans in each direction. Therefore, each prototype structure consisted of nine bays and was large enough to reasonably represent an actual structure. Effort was made to develop a prototype design which properly simulated actual structure boundary conditions. Reinforced concrete walls and columns cast monolithically with the slab helped to impose the proper boundary conditions.

The prototype structures were designed according to the 1977 ACI Code (Reference 1). Principles of engineering similitude were applied to the 
prototype structures' design details, resulting in the development of design details for the 1/4-scale models.

The models were upgraded with wooden posts. Pretest analyses were performed to develop an upgrading scheme which would increase the overpressure load capacity of the models to a value near $50 \mathrm{psi}$. The upgraded models were statically tested in the Large Blast Load Generator (LBLG) at the Waterways Experiment Station (WES), which can sustain static loads up to 1000 psi. 


\section{CHAPTER 2}

\section{SELECTION OF SLAB SYSTEM AND DESIGN OF PROTOTYPE SYSTEM AND SCALE MODELS}

\subsection{DESIGN REQUIREMENTS OF PROTOTYPE}

The following two basic requirements were to be satisfied in the design of the prototype slab system:

1. The ceiling must be representative of a below-grade basement of a reinforced concrete building.

2. The design must conform to the requirements of the 1977 ACI Code (Reference 1).

In accordance with basic requirements, the following decisions were made prior to design of the slab system:

1. The prototype structure was to consist of three 20-foot spans in each direction in order to include corner, exterior, and interior slab panels. The configuration was complex enough to reasonably represent basement shelters that exist throughout the nation. The symmetry of the configuration simplified the modeling of the prototype.

2. The perimeter of the slab was to be supported with reinforced concrete walls and columns. Four reinforced concrete columns would support the interior region of the slab, one column located at each corner of the center panel. The walls and columns were to be cast monolithically with the slab in order to produce a considerable degree of fixity at the slab's boundary.

3. The material properties assumed in the design of the slab were to include a minimum steel yield strength of 60,000 psi and a concrete compressive strength of 4000 psi.

\subsection{SELECTION OF THE SLAB SYSTEMS}

Tolman, Lyday, and Hill (Reference 2) summarize various characteristics of National Fallout Shelter Survey (NFSS) facilities based on a national field survey of a random sample of NFSS facilities performed in 1972. The surveyed sample consisted of 219 buildings within the Continental United States. Tolman reveals that the most prevalent first-floor system is an ordinary concrete slab on cast-in-place concrete beams, while the ordinary concrete slab on steel beams system occurs less frequently. The third most common floor system is a concrete slab with one-way ribbed joists. Fourth most frequent is a 
one-way concrete slab with concrete joists. Occurring at a slightly less frequency than the one-way concrete slab is a two-way concrete slab without

beams. Approximately 54 percent of the two-way concrete slab floor systems do not have drop panels and are known as flat plate floor systems. The two-way floor systems composing the remaining 46 percent do have drop panels and are known as flat slabs.

A two-way reinforced concrete slab with reinforced concrete beams was chosen as one floor system type to be modeled in this study, since it was the most prevalent system in Tolman's investigation. A flat plate floor system was selected as the other system to be modeled, since it was the most prevalent two-way floor system without beams in Tolman's study.

Tolman also categorizes the 219 surveyed NFSS buildings in terms of number of stories. The category having the largest percentage (15.8) of buildings is that of two-story buildings. Therefore, the designs of the two prototypes in this study were based upon loading conditions incurred by basements of two-story structures.

\subsection{DESIGN PROCEDURE AND CALCULATIONS FOR THE PROTOTYPE DESIGN}

\subsubsection{Determination of Prototype Design Loads}

In the strength method of the 1977 ACI Code, service loads are increased sufficiently by factors to obtain design loads. The load factors are 1.4 for dead loads and 1.7 for live loads. The design (factored) floor loading for the two floors of the two-story prototype structure consisted of a 140-psf dead load and a 200-psf live load.

The BOCA Basic Building Code (Reference 3) defines the minimum design roof loading in section 711.1. The code states that the roof shall be designed for a live load of $30 \mathrm{psf}$ in areas subject to snow loads. Since most of the United States receives some snow, the 30-psf load was adopted for this study. The factored roof live load of 51 psf and the factored roof dead load of 140 psf constituted a total design roof load of 191 psf.

Section 714.11 of Reference 3 specifies that on buildings that are 50 feet or less in height the wind pressure on exposed vertical surfaces shall be assumed to be 15 psf. Section 714.2 of Reference 3 calls for a distribution of the wind force with the assumption that two-thirds of the wind pressure acts as a normal pressure on the windward side while one-third of the pressure acts as a normal outward suction on the leeward side. 
Section 9.2 .2 of the 1977 ACI Code specifies a load factor of 1.3 to be used in the determination of design wind loads. Therefore, the design wind loads on the prototype structure were $1.3 \times 10$ psf $=13$ psf on the windward side and $1.3 \times 5$ psf $=6.5$ psf as suction on the leeward side.

In the determination of design loading on the basement walls of the prototype structure, it was assumed that active earth pressures would exist from a soil having a unit weight $\gamma$ of $100 \mathrm{psf}$ and an angle of internal friction $\phi$ of 35 degrees. Peck, Hanson, and Thornburn (Reference 4) discuss the active earth pressure $P_{A}$ which may be expressed as

$$
P_{A}=1 / 2 K_{A} \gamma H^{2}
$$

where

$\mathrm{P}_{\mathrm{A}}=$ active earth pressure

$\mathrm{K}_{\mathrm{A}}=$ coefficient of active earth pressure equivalent to $\tan ^{2}\left(45^{\circ}-\phi / 2\right)$

$\gamma=$ unit weight of soil

$\mathrm{H}=$ height of vertical wall

For the assumed soil conditions and a wall height of 12 feet, the resultant force of the active earth pressure has a magnitude of 1944 pounds per foot of wall length acting at a distance of 4 feet from the bottom edge of the wall. Section 9.2.4 of the 1977 ACI Code specifies that a load factor of 1.7 be applied to lateral earth pressures. Application of the load factor yields a resultant design load of 3305 pounds per foot of wall length. The assumed distribution of this resultant is triangular as discussed in Reference 4.

\subsubsection{Determination of Prototype Design Flexural Moments}

The design flexural moments were obtained from a moment distribution performed on the prototype structure in accordance with Chapter 13 of the 1977 ACI Code. Section 13.7 of the code describes the equivalent frame method used in the design of the prototype structure which calls for a division of the structure into equivalent frames on column lines taken longitudinally and transversely through the building. Each frame consisted of a row of equivalent columns and slab-beam strips bounded laterally by the center line of the panels on each side of the center line of columns. The frames adjacent and parallel to an edge of the structure were bounded by that edge and the center line of the adjacent panels. 
Due to the symmetry of the nine-bay prototype, only two moment distribution analyses were required in the determination of design flexural moments. In reference to Figure 2.1, the geometry and loading characteristics of all inner frames were identical, as was the case for all outer frames. Therefore, a moment distribution was performed on an inner frame and on an outer frame.

Section 13.2 of the ACI Code subdivides the inner and outer frames into column strips and middle strips. A column strip is a design strip with a width on each side of a column center line equal to one-fourth of the span length measured center-to-center of supports. A middle strip is a design strip bounded by two column strips; see Figure 2.1. The significance of column and middle strips is reflected in section 13.7 .7 .5 of the ACI Code where provisions are given for distribution of the moments determined from the equivalent frame moment distribution analysis to column and middle strips, thereby designating design moments for all portions of the slab.

\subsubsection{Determination of Slab Thickness}

\subsubsection{Control of Deflections}

Section 9.5 of the ACI Code stipulates the minimum slab thickness allowed for a slab subjected to flexure, based upon deflection control, by presenting the following equation:

$$
h=\frac{\ell_{n}\left(800+0.005 f_{y}\right)}{36000+5000 \beta\left[\alpha_{m}-0.5\left(1-\beta_{s}\right)\left(1+\frac{1}{\beta}\right)\right]}
$$

where

$\mathrm{h}=\mathrm{slab}$ thickness

$\theta_{n}=$ length of clear span in long direction of two-way construction

$\mathrm{f}_{\mathrm{y}}=$ yield strength of steel reinforcement

$\beta=$ ratio of clear spans in long to short direction of two-way slabs $\beta_{S}=\begin{aligned} & \text { ratio of length of continuous edges to total perimeter of a slab } \\ & \text { panel }\end{aligned}$

$\alpha_{m}=$ average value of the ratios of flexural stiffness of beam section to flexural stiffness of a width of slab bounded laterally by center line of adjacent panel on each side of beam for all beams on edges of a panel. 
Equation 2.1 yielded a value of 7.22 inches for the flat plate prototype structure. Section 9.5.3.3 requires an increase in the minimum thickness by 10 percent in panels having a discontinuous edge. The 10 percent increase resulted in a slab thickness of 7.94 inches. Therefore, a thickness of 8 inches was used to satisfy the deflection control requirements.

Equation 2.1 and section 9.5.3.3 of the ACI Code stipulate a minimum allowable slab thickness of 6.42 inches for the two-way slab with beams prototype structure. A thickness of 8 inches was chosen for use in the prototype design procedure since it satisfied the deflection control requirements and was the minimum thickness that could be accurately modeled by a 1/4-scale model without construction difficulties.

\subsubsection{Shear Transfer}

The thickness of the slab is directly related to the slab's punching shear strength in the vicinity of concentrated loads or reactions. Section 11.11.2 of the ACI Code presents a design equation for determination of shear strength of two-way slabs without shear reinforcement as follows:

$$
v_{c}=\left(2+\frac{4}{\beta_{c}}\right) \sqrt{f_{c}^{\prime}} b_{o} d
$$

where

$$
\begin{aligned}
\mathrm{V}_{c}= & \text { nominal shear strength provided by concrete } \\
\beta_{c}= & \text { ratio of long side to short side of concentrated load or reaction } \\
& \text { area } \\
f_{c}^{\prime}= & \text { specified compressive strength of concrete } \\
b_{0}= & \text { perimeter of critical section which need not approach closer than } \\
& d / 2 \text { to perimeter of concentrated load or reaction area } \\
d= & \text { distance from extreme compression fiber to centroid of longitu- } \\
& \text { dinal tension reinforcement }
\end{aligned}
$$

Section 11.11 .2 also specifies that the value determined by Equation 2.2 be limited to that determined by the following expression:

$$
v_{c}=4 \sqrt{f_{c}^{\prime}} b_{o} d
$$

Each of the two slab systems in this study had a $\beta_{c}$ value of 1.0 , 
requiring the use of Equation 2.3. With a slab thickness of 8 inches, a design concrete compressive strength of $4000 \mathrm{psi}$, and an effective depth of 6.85 inches, Equation 2.3 yielded a value of 186.1 kips for a critical section accompanying a 20-inch-square interior column. Equation $11-1$ of the ACI Code gives the required relationship between the slab's shear strength and the applied shear force as follows:

$$
\mathrm{v}_{\mathrm{u}} \leq \phi \mathrm{v}_{\mathrm{n}}
$$

where

$\mathrm{V}_{\mathrm{u}}=$ factored shear force at section considered

$\phi=$ strength reduction factor with value of 0.85 for shear conditions

$\mathrm{V}_{\mathrm{n}}=$ nominal shear strength of slab equivalent to $\mathrm{V}_{\mathrm{c}}$ in slabs without shear reinforcement

The force $V_{u}$ based upon the design loads presented in article 2.3.1 is:

$$
\mathrm{v}_{\mathrm{u}}=(340 \mathrm{psf})\left[(20 \mathrm{ft})^{2}-\left(\frac{26.85}{12}\right)^{2}\right]=134.3 \text { kips }
$$

Application of Equation 2.5 yields the expression:

$$
\begin{gathered}
134.3 \text { kips } \leq(0.85)(186.1 \text { kips }) \\
\text { or }
\end{gathered}
$$

134.3 kips $\leq 158.2$ kips

which is a true mathematical statement. Therefore, the slab thickness of 8 inches satisfied the punching shear transfer requirements for a slab system with 20-inch-square interior columns and the given loads.

\subsubsection{Beam Design}

Each of the nine panels of the two-way slab with beams prototype was bounded on all sides not coincident with the basement walls by reinforced concrete beams. Section 13.7.7.5 of the ACI Code allows beams between supports 
to be proportioned to resist 85 percent of column strip moments if the value of $a\left(l_{2} / \ell_{1}\right)$ is equal to or greater than 1.0 , where:

$\alpha=$ ratio of flexural stiffness of beam section to flexural stiffness of a width of slab bounded laterally by center lines of adjacent panels (if any) on each side of the beam

$\theta_{1}=$ length of span in direction that moments are being determined, measured center-to-center of supports $\theta_{2}=\begin{aligned} & \text { length of span transverse to } \ell_{1} \text {, measured center-to-center of } \\ & \text { supports }\end{aligned}$

In order to allow maximum use of the beams in the floor system, they were designed to resist the maximum allowed moments equivalent to 85 percent of the column strip moments. Therefore, the beams were sized to minimum dimensions that would yield a value of $\alpha$ equal to or greater than 1.0 for an 8 -inchthick slab with $\ell_{1}$ equal to $\ell_{2}$. The overall cross-sectional dimensions of the beams were determined to be 10 by 21 inches. All beams had an effective flange width $b_{e}$ equal to 55 inches as prescribed by section 8.10 .2 of the 1977 ACI Code.

\subsubsection{Reinforcement for Flexural Resistance}

The two-way slab with beams prototype structure consisted of two types of beams in relation to reinforcement steel ratio and placement as well as moment capacity. Figure 2.2 shows the locations of the two beam types distinguished by the labels: A-beam and B-beam. Each A-beam was identical in design to all A-beams, and each B-beam was identical to all B-beams. The reinforcement steel used for design of the prototype beams consisted of hypothetical steel bars whose geometrical characteristics were derived from the scaling-up of reinforcement steel selected for use in model construction in this study. The properties and characteristics of the modeling steel are discussed in Section 3.1 .2 of this report; however, for purposes of prototype design it was only necessary to know that two sizes of steel reinforcement bars were available with each having a yield stress of $60 \mathrm{ksi}$. The two bar sizes may be referred to as PD1 and PD3 bars, respectively, having cross-sectional areas of $0.18 \mathrm{in}^{2}$ and $0.48 \mathrm{in}^{2}$.

Negative moment steel reinforcement was required at each end of the typical A-beam. The nominal negative moment strength $M_{n}^{-}$required of the A-beam was $1,909.0$ in-kips. The requirement was satisfied with an $M_{n}^{-}$value of 1,994.5 in-kips provided by the beam reinforced with four PD3 bars. The 
accompanying negative steel ratio $\rho^{-}$was equal to 0.01011 which was equivalent to $0.354 \rho_{b}$ where

$\rho_{b}=$ reinforcement ratio producing balanced strain conditions such that tension reinforcement reaches the strain corresponding to its specified yield strength $f_{y}$ just as concrete in compression reaches its assumed ultimate strain of 0.003 .

Positive moment steel was required in the A-beam to provide it with a nominal positive moment strength $\mathrm{M}_{n}^{+}$of 784.55 in-kips. The requirement was satisfied with an $M_{n}^{+}$value of 784.63 in-kips provided by the beam reinforced with four PDl bars. The positive steel ratio $\rho^{+}$was equal to 0.003830 which was between the minimum ratio value of 0.00333 and the maximum ratio value of 0.02138 , respectively, allowed by sections 10.5 .1 and 10.3 .3 of the 1977 ACI Code.

The ends of the typical B-beam were required to provide different nominal negative moment strengths. The end of the beam that was supported at the interior column was required to provide an $M_{n}^{-}$value equivalent to that required by the A-beam since both beams joined at the interior support. Therefore, the interior end of the B-beam was designed identically to the end of the A-beam in respect to negative moment area reinforcement steel. However, the end of the B-beam supported by an exterior column at the basement wall was required to provide a nominal negative moment strength of $2,164.0$ in-kips. The requirement was satisfied with an $M_{n}^{-}$value of $2,302.2$ in-kips provided by the beam reinforced with five PD3 bars. The beam cross-section had a $\rho^{-}$value of 0.01326 .

Positive moment steel was required in the B-beam to provide it with a nominal positive moment strength of 722.50 in-kips. The requirement was satisfied with an $M_{n}^{+}$value of 784.63 in-kips provided by the beam reinforced with four PD1 bars. The steel ratio $\rho^{+}$had a value of 0.003830 .

\subsubsection{Reinforcement for Shear Resistance}

Shear reinforcement was required in all beams in accordance with section 11.5 of the 1977 ACI Code. The shear reinforcement used in the prototype design consisted of stirrups that were perpendicular to the axis of the member and were bent PD1 bars. Section 11.5.5.1 of the ACI Code requires shear reinforcement in flexural beam members where factored shear force $V_{u}$ exceeds one-half the shear strength provided by the concrete $\phi \mathrm{V}_{c}$.

In the A-beam, $V_{u}$ had a value of 42.95 kips at the face of the support 
and decreased linearly to a value of zero near midspan of the beam. The strength provided by the concrete $\phi \mathrm{V}_{c}$ had a value of $20.43 \mathrm{kips}$. Therefore, shear stirrups were required throughout much of the beam where the linear function of $V_{u}$ was greater than $(0.5)(20.43 \mathrm{kips})=10.22 \mathrm{kips}$.

The value of $V_{u}$ in the B-beam at the face of the exterior support (column at basement wall) was 45.29 kips, and it linearly decreased to zero near the midspan of the beam. Since one-half of the shear strength provided by the concrete was $9.68 \mathrm{kips}$, shear stirrups were required throughout much of the beam.

\subsubsection{Slab and Beam Reinforcement Details}

The detailing of the reinforcement in the beams of the prototype two-way slab with beams is presented in section 2.3.5.1. The detailing of the reinforcement for the slab portions of the two-way slab with beams and the flat plate are respectively presented in sections 2.3 .5 .2 and 2.3.5.3.

\subsubsection{Beam Reinforcement Details}

Figure 2.3 presents the reinforcement details for A-beams and B-beams. Each beam was reinforced with top PD3 bars in the negative moment area and with bottom PDI bars in the positive moment area. The shear stirrups were PD1 bars.

Section 12.12.1 of the ACI Code requires that at least one-third of the positive moment reinforcement extend into the support at least 6 inches. Each A-beam and each B-beam contained 4 PDI bars in the positive moment region. Therefore, two PDI bars were required to extend into the support in each beam.

Section 12.13 of the ACI Code specifies embedment details for negative moment reinforcement in beams. Standard hooks were required to develop negative steel embedment length in each prototype beam at a column support.

As presented in section 2.3.4.2 above, shear reinforcement was required in each beam. The stirrups were spaced according to the provisions of section 11.5 of the ACI Code. Stirrups located near an interior column in A-beams and B-beams were spaced at the maximum allowable spacing of 9.5 inches on center (o.c.). However, the maximum allowable spacing of the stirrups located in shear regions at the exterior columns in the B-beams was 9.0 inches o.c.

2.3.5.2 Slab Reinforcement Details for Two-Way Slab With Beams

After the slab thickness had been determined as in section 2.3.3, the 
flexural reinforcement could be proportioned. Since the beams of the prototype were designed to resist the maximum allowable percentage of moments in accordance with section 13.7.7.5 of the ACI Code, the slab portions of the column strips were required to resist only 15 percent of the column strip moments. The middle strip slab portions were required to resist the full middle strip moments. The required moment capacities were satisfied in each region of the slab by use of either PD1 or PD3 bars. Section 10.5.3 of the ACI Code sets the minimum reinforcement ratio $\rho$ equivalent to 0.0018 . The minimum value of $\rho$ was applicable in column strip slab portions adjacent to beams. The column strip slab portions required relatively low moment capacities since they were to resist 15 percent of the column strip moments, thus requiring the minimum steel ratio.

Section 13.4.8.4 of the ACI Code refers to a figure which presents the minimum reinforcement bar lengths for the slab reinforcement. The reinforcement layouts for one-fourth of the prototype in one direction are shown in Figures 2.4 and 2.5 herein for the top and bottom mats, respectively.

\subsubsection{Slab Reinforcement Details for Flat Plate}

After the slab thickness had been determined as in section 2.3.3, the flexural reinforcement could be proportioned. The minimum steel ratio value $\rho$ prescribed by section 10.5 .3 of the ACI Code to be 0.0018 was approached in some regions of the flat plate. PD1 and PD3 bars were used in the prototype design.

Section 13.4.8.4 of the ACI Code refers to a figure which presents the minimum reinforcement bar lengths for the flat plate reinforcement. The reinforcement layouts for one-fourth of the prototype in one direction are shown in Figures 2.6 and 2.7 herein for the top and bottom mats, respectively.

\subsubsection{Column and Wall Design and Reinforcement Details}

\subsubsection{Column Design}

As presented in section 2.3.3.2, a 20-inch square interior column was adequate for shear transfer between the slab and column. Although an 18-inch square column would have been adequate for shear transfer, the 20-inch dimension was chosen for modeling purposes.

The calculated axial column load on the interior column was 348.4 kips, and the column moment was 76.7 in-kips in each span direction. Reference 5 is 
a design aid that was used for the column design. Application of the loadmoment strength interaction diagrams on page 77 of Reference 5 revealed that the 20-inch square interior column was adequate when reinforced in accordance with the 1977 ACI Code minimum steel ratio. Section 10.9 .1 of the code requires that the area of longitudinal reinforcement be not less than 0.01 times the gross area of the section. Therefore, eight PD3 bars were required as longitudinal reinforcement.

PD1 bars were used for lateral ties in the column. The ties were spaced at 10 inches in accordance with the maximum allowable spacing presented in section 10.14 .8 .5 of the 1977 ACI Code.

The prototype exterior column was 30 inches square due to shear perimeter requirements. The calculated axial column load on the exterior column was 174.2 kips, and the column moment was 1,892.3 in-kips. Application of the load-moment strength interaction diagrams of Reference 5 revealed that the 30-inch square exterior column was adequate when reinforced with the 1977 ACI Code minimum steel ratio. Therefore, twenty PD3 bars were required as longitudinal reinforcement. PDl bars were used for lateral ties and were spaced at 12 inches.

\subsubsection{Wall Design}

For a 12-inch thick wall, the effects of slenderness had to be considered in accordance with section 10.11 of the 1977 ACI Code. The moment magnification factor of 1.0055 increased the design moment to a value of 15,900 in$\mathrm{lb} / \mathrm{in}$, and the design axial wall load was $283.3 \mathrm{lb} / \mathrm{in}$. A resulting steel ratio of 0.00365 was required. PD3 bars were spaced at 11 inches o.c. in both faces of the wall to satisfy the steel ratio requirement.

Horizontal reinforcement was required in the prototype wall at the minimum steel ratio of 0.0020 in accordance with section 10.15 of the 1977 ACI Code. To satisfy the steel ratio requirement, PD3 bars were spaced at 18 inches o.c. in both faces of the wall.

\subsection{DESIGN OF THE MODELS}

\subsubsection{Description and Dimensions}

Each of the 1/4-scale models of the prototypes were designed to be cast as a monolithic unit consisting of the slab, columns, walls, and beams in the case of the two-way slab with beams model; see Figure 2.8. The bases of the 
walls were bolted to a rigid base slab, which served as the floors and footings of the model basement structures.

The prototype dimensions were divided by four in order to obtain the dimensions of the model. The cross-sections of one-half of the flat plate model and one-half of the two-way slab with beams model are shown in Figures 2.9 and 2.10 , respectively.

\subsubsection{Slab Reinforcement}

The material properties of the reinforcement steel wire used in models are discussed in section 3.1 .2 of this report. The nominal cross-sectional areas were $0.0113 \mathrm{in.}^{2}$ and $0.03 \mathrm{in.}^{2}$ for the wire herein referred to as D1 and D3 wire, respectively.

The spacings of the reinforcement steel in the models were one-fourth of that for their respective prototype structures. The slab reinforcement layouts for one-fourth of the two-way slab with beams model in one direction are shown in Figures 2.11 and 2.12 for the top and bottom mats, respectively. The slab reinforcement layouts for one-fourth of the flat plate model in one direction are shown in Figures 2.13 and 2.14 for the top and bottom mats, respectively. Cross-sectional details of the slab reinforcement are shown in Figures 2.15 and 2.16 .

\subsubsection{Beam Reinforcement}

The beams of the two-way slab with beams model were reinforced with D1 and D3 wire. The reinforcement spacings were one-fourth of the prototype reinforcement spacings. Reinforcement details for the model A-beam and B-beam are shown in Figures 2.17 and 2.18, respectively.

\subsubsection{Column Reinforcement}

The columns of the models were reinforced longitudinally with D3 wire, and the lateral ties were D1 wire. The spacings of the reinforcement were one-fourth of the spacings in the prototype design. Details of the model interior column and the model exterior column are presented in Figures 2.19 and 2.20, respectively.

\subsubsection{Wall Reinforcement}

The walls of the models were reinforced with D3 wire. The spacings of the reinforcement were one-fourth of the prototype wall design spacings. 
Figure 2.21 shows details of the placement of the wall reinforcement.

An entrance was provided at the center of one wall of each model to provide access into the model structure. The entrance was framed with 60 No. 4 grade steel reinforcement bars enclosed by No. 3 bar stirrups. Details of the entrance are shown in Figure 2.22.

\subsection{DESIGN OF THE UPGRADING SYSTEM}

As discussed in Chapter 1, the objective of upgrading the nine-bay models was to strengthen the model slabs to withstand overpressures near 50 psi. Woodson and McVay (Reference 6) indicated that it might be possible to upgrade waffle slabs and flat plate slabs to withstand overpressures near 50 psi, using wooden upgrading columns. The study discussed in Reference 6 utilized composite wooden upgrading columns consisting of four 4- by 4-inch dimensioned timbers. Since the models were 1/4-scale structures, a composite wooden column was represented by a single 4- by 4-inch dimensioned timber. Previous studies have not involved upgraded nine-bay structures with concrete columns and walls. Preliminary analyses were required to develop an upgrading system for the two models.

Effort was taken to design a placement spacing scheme for the upgrading columns that would harden the structures as required but not harden them to great excess. A ductile flexural-type failure was considered to be more desirable than a brittle shear-type failure. The types of design calculations and analyses performed for different spacings of the upgrading columns included: yield-line analyses, punching shear evaluations, and a study of moment-thrust interaction diagrams generated by the computer program called Reinforced Concrete Column Analysis (Reference 7). In the yield-line analyses and in the generation of the interaction diagrams, the slabs were considered to be continuous over the upgrading columns which were considered to act as simple supports. After the design analyses were performed on various spacings, a spacing of 15 inches o.c. (60 inches in the prototype) was chosen for the upgrading columns in the flat plate model structure. Since each panel or bay of the model structure was $60 \mathrm{in}^{2}$, the 15 -inch spacing allowed the placement of a line of upgrading columns in line with the concrete column lines.

A spacing of 20 inches ( 80 inches in the prototype) was used in the twoway slab with beams model. Different reinforcement steel ratios among the two model types as well as the assumption that the reinforced concrete beams would 
serve as boundaries to yield lines were factors contributing to the requirement of a spacing different from that used in the flat plate model. The twoway slab with beams model was tested after the flat plate model was tested. As discussed in section 5.1, the 15-inch spacing was conservative for the flat plate model. Considering the results of the flat plate model test and that the assumptions used in the design of the spacing scheme for the flat plate model were conservative, a 20-inch o.c. spacing was used for the upgrading columns in the two-way slab with beams model. The 20-inch spacing allowed the placement of upgrading columns along the beam lines. 


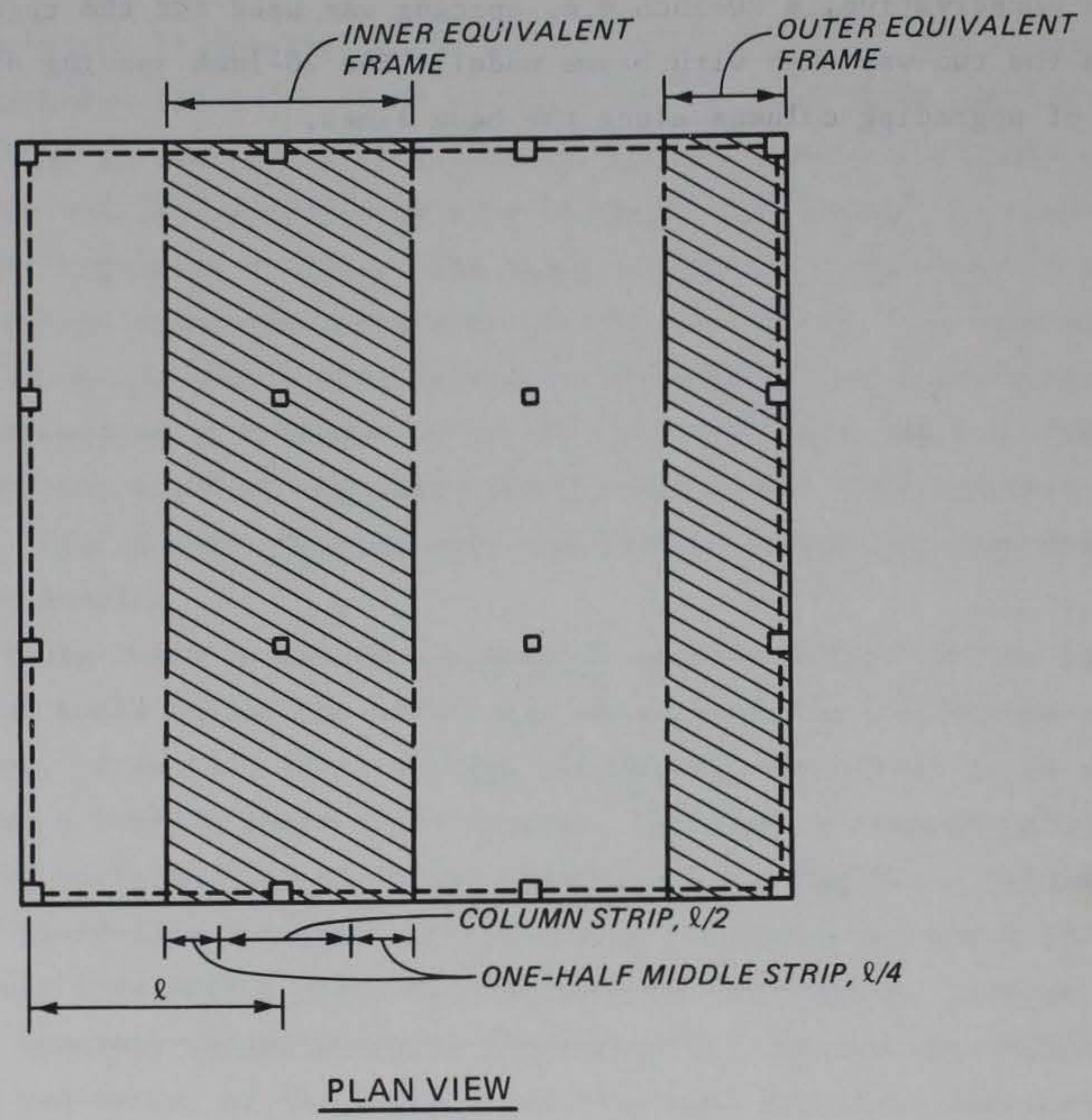

Figure 2.1 Geometry of prototype. 


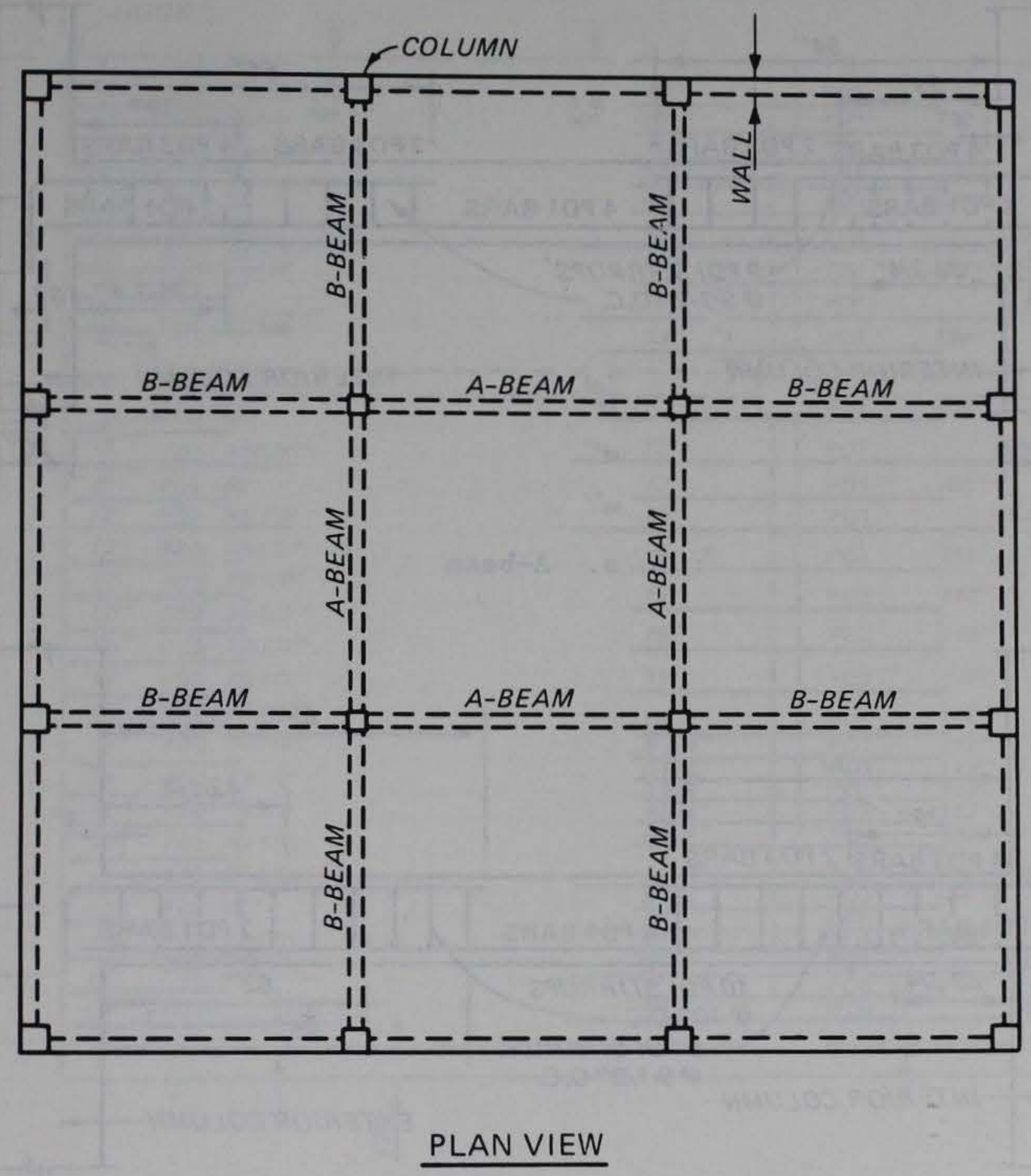

Figure 2.2 Two-way slab with beams prototype. 


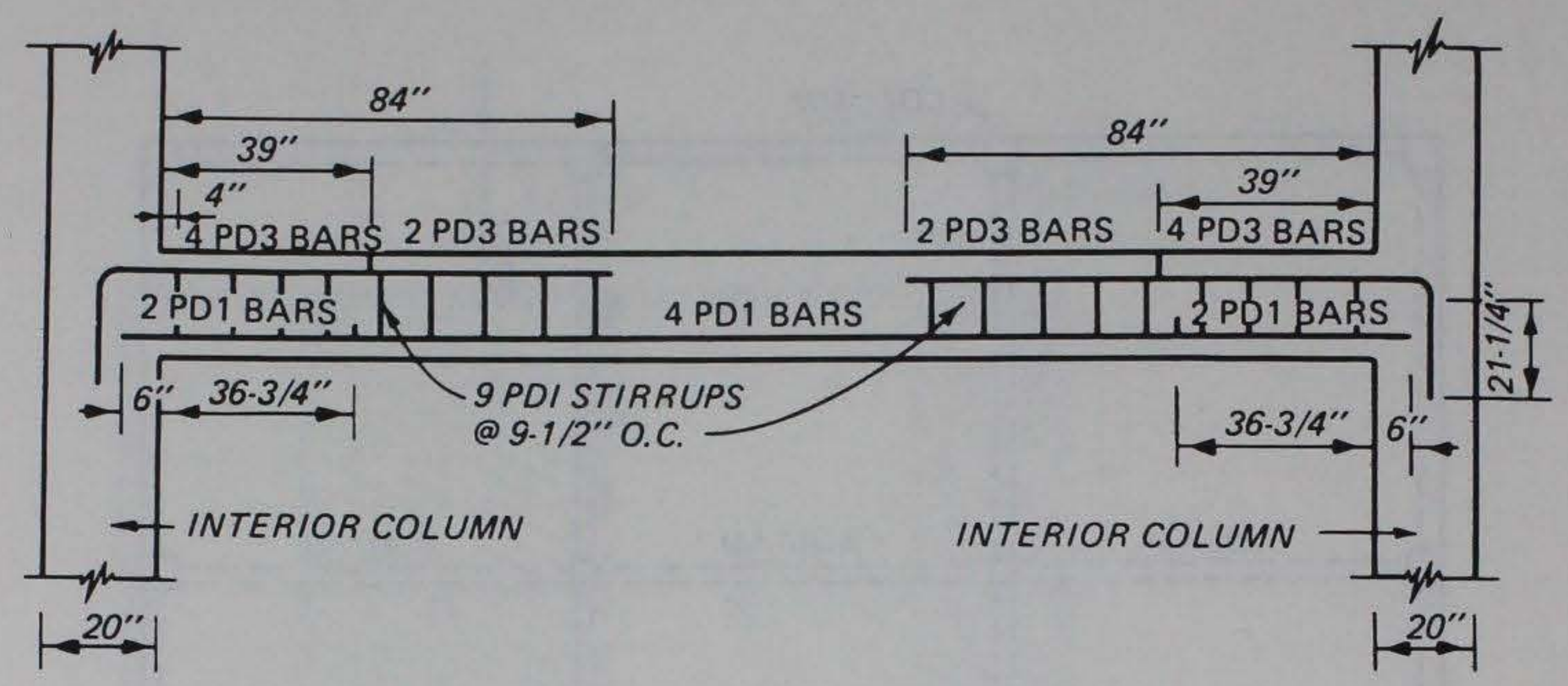

a. A-beam

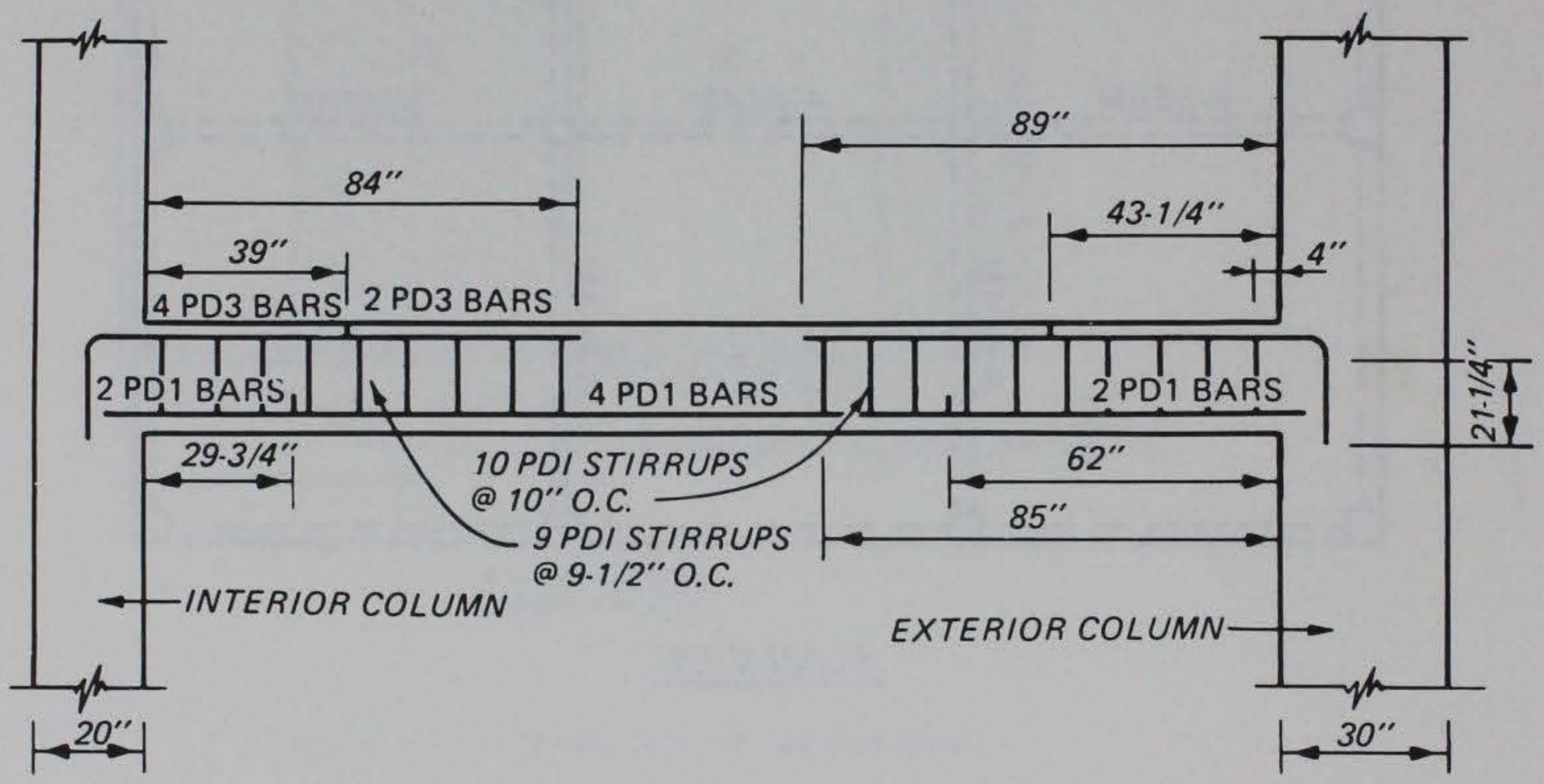

$$
\text { b. B-beam }
$$

Figure 2.3 Prototype concrete beam reinforcement details. 


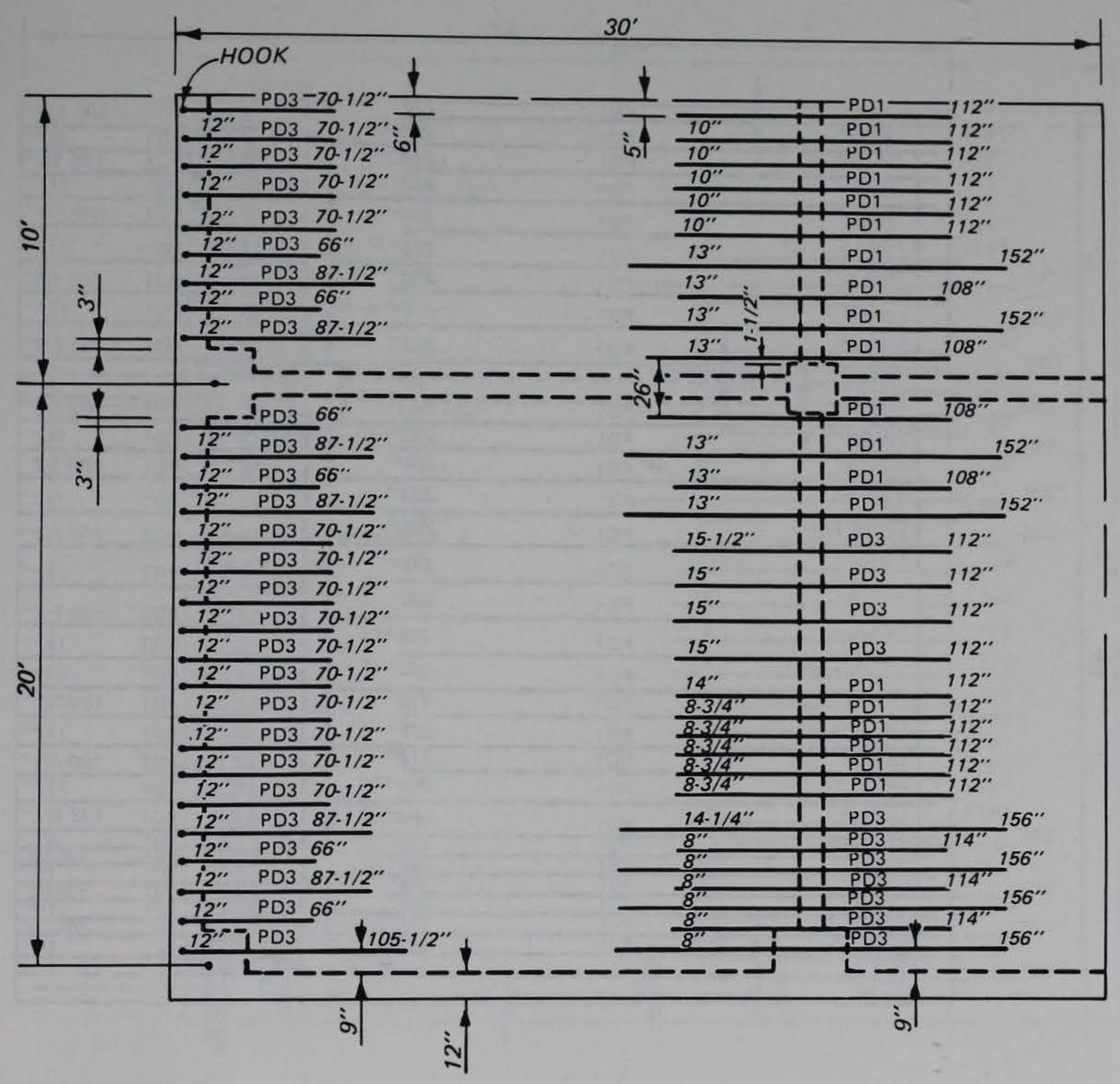

Figure 2.4 Reinforcement layout for one-fourth of the prototype slab with beams structure (top mat in one direction). 


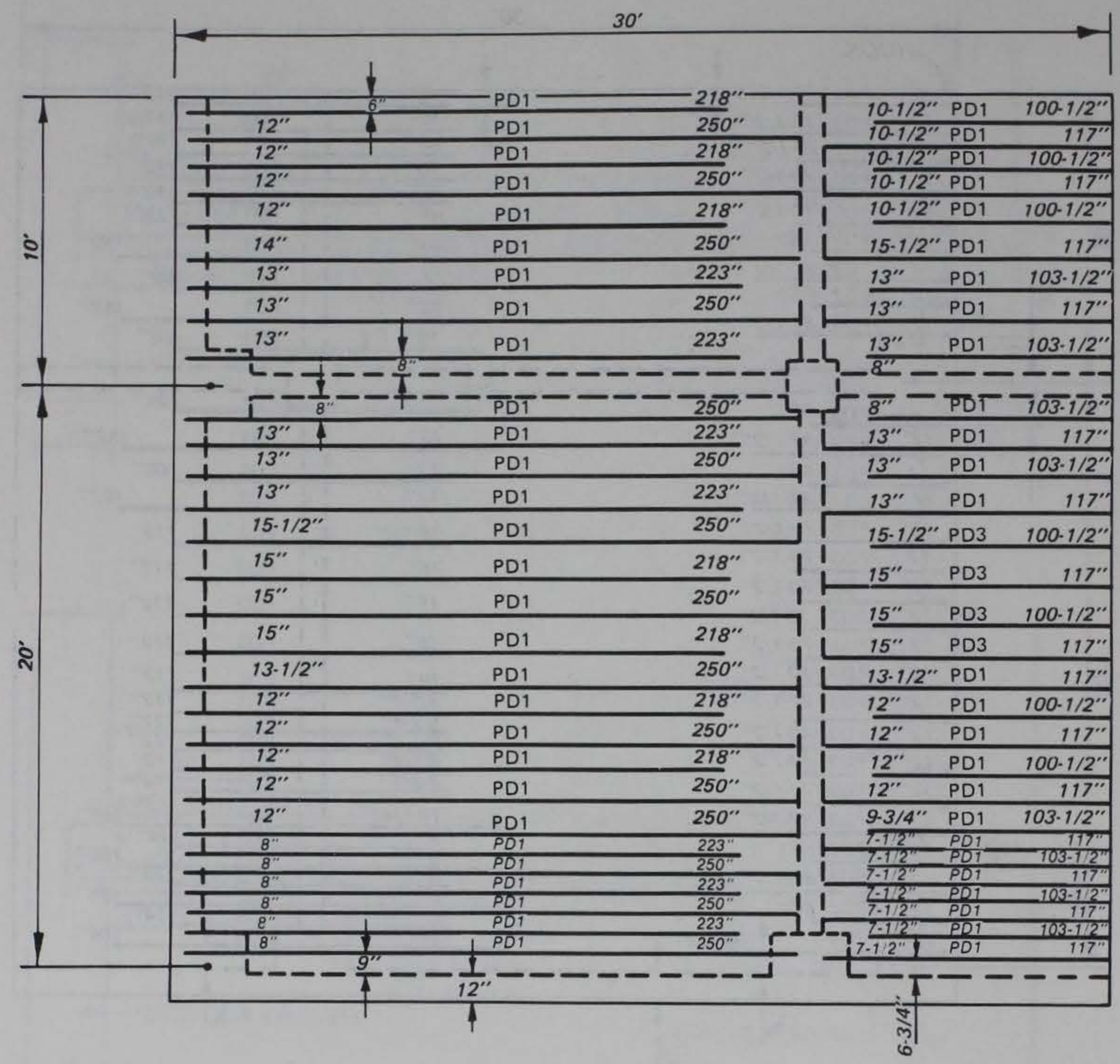

Figure 2.5 Reinforcement layout for one-fourth of the prototype slab with beams structure (bottom mat in one direction). 


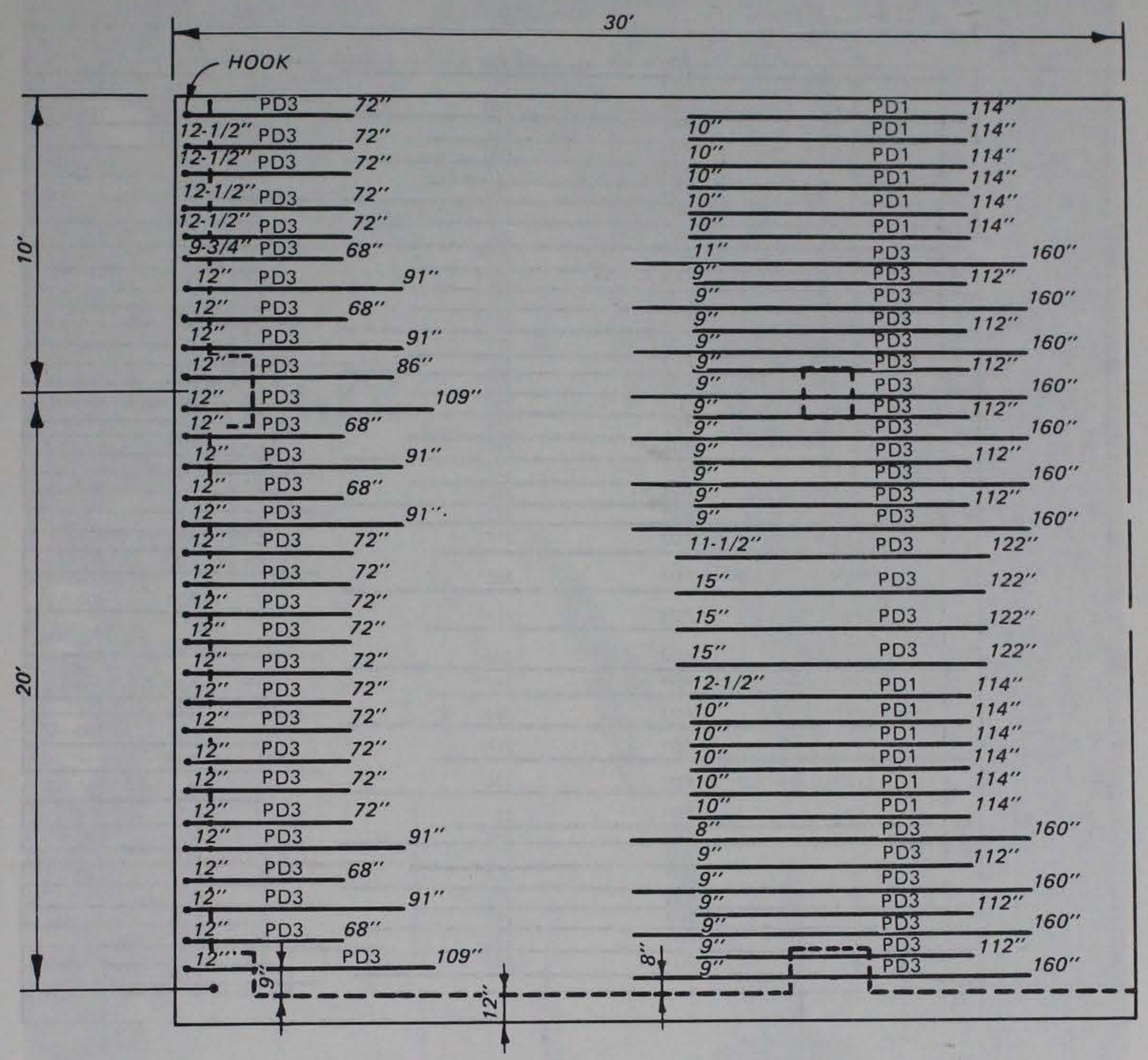

Figure 2.6 Reinforcement layout for one-fourth of the prototype flat plate structure (top mat in one direction). 


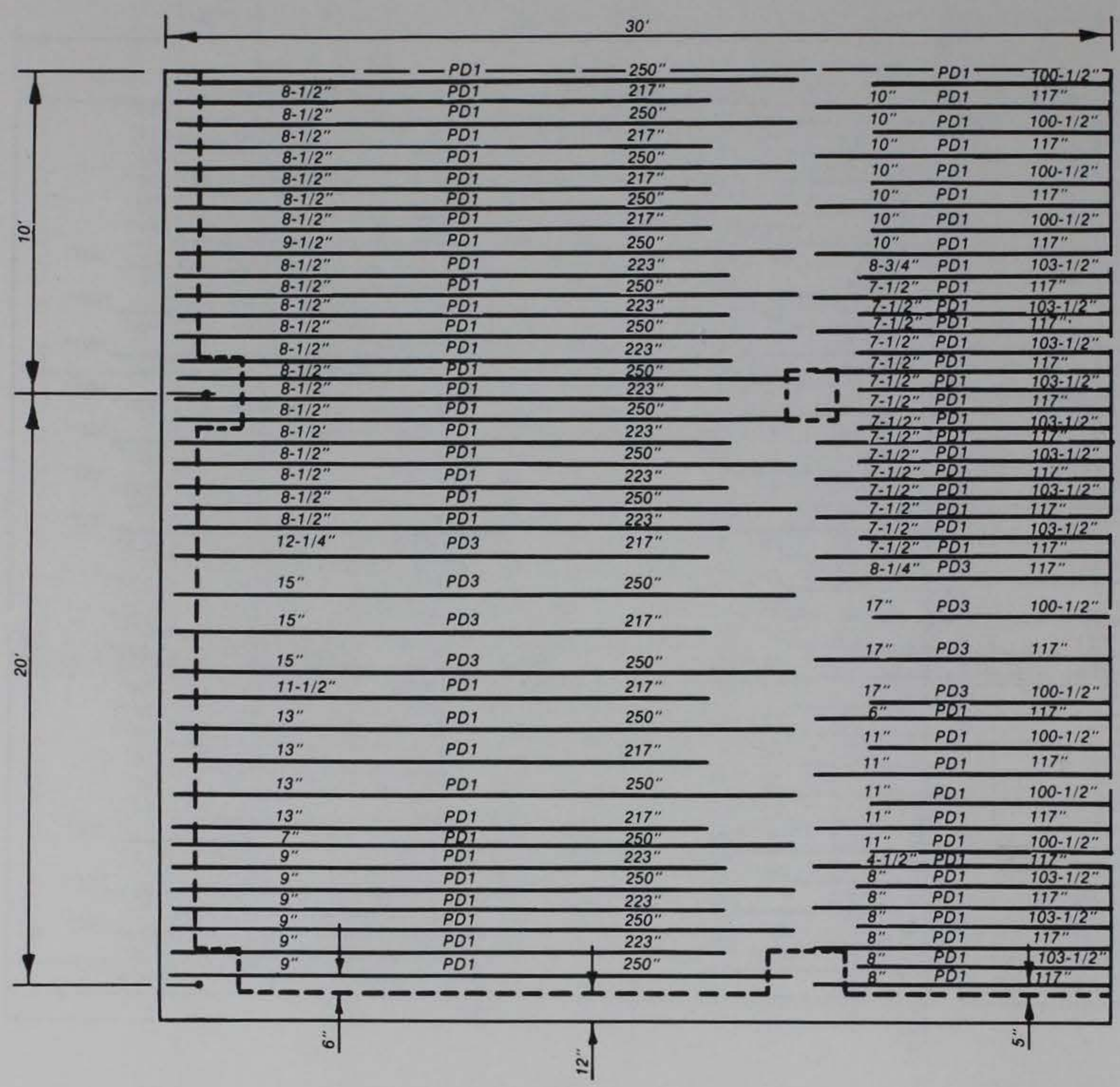

Figure 2.7 Reinforcement layout for one-fourth of the prototype flat plate structure (bottom mat in one direction). 


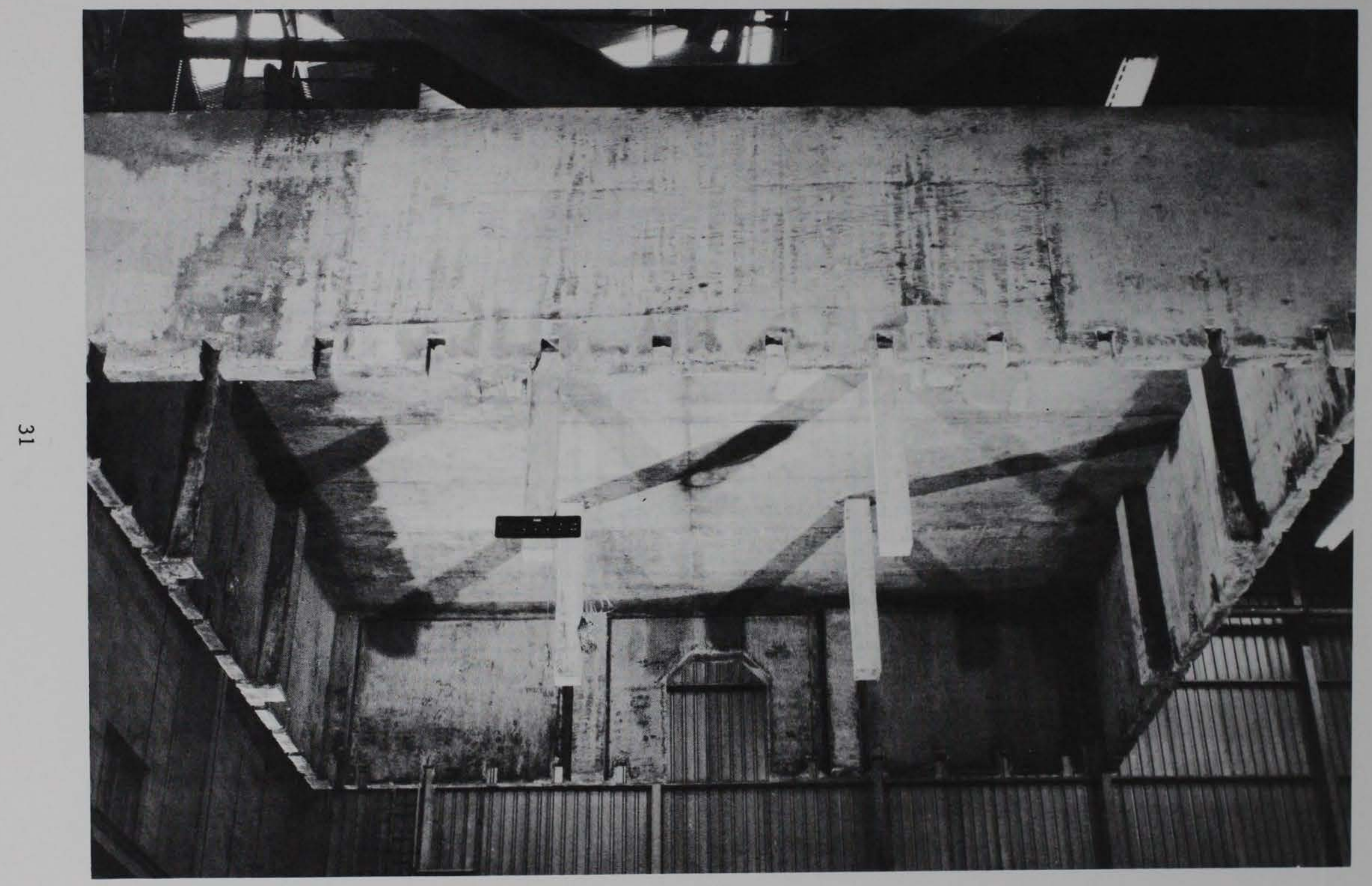

Figure 2.8 Flat plate model suspended from crane. 


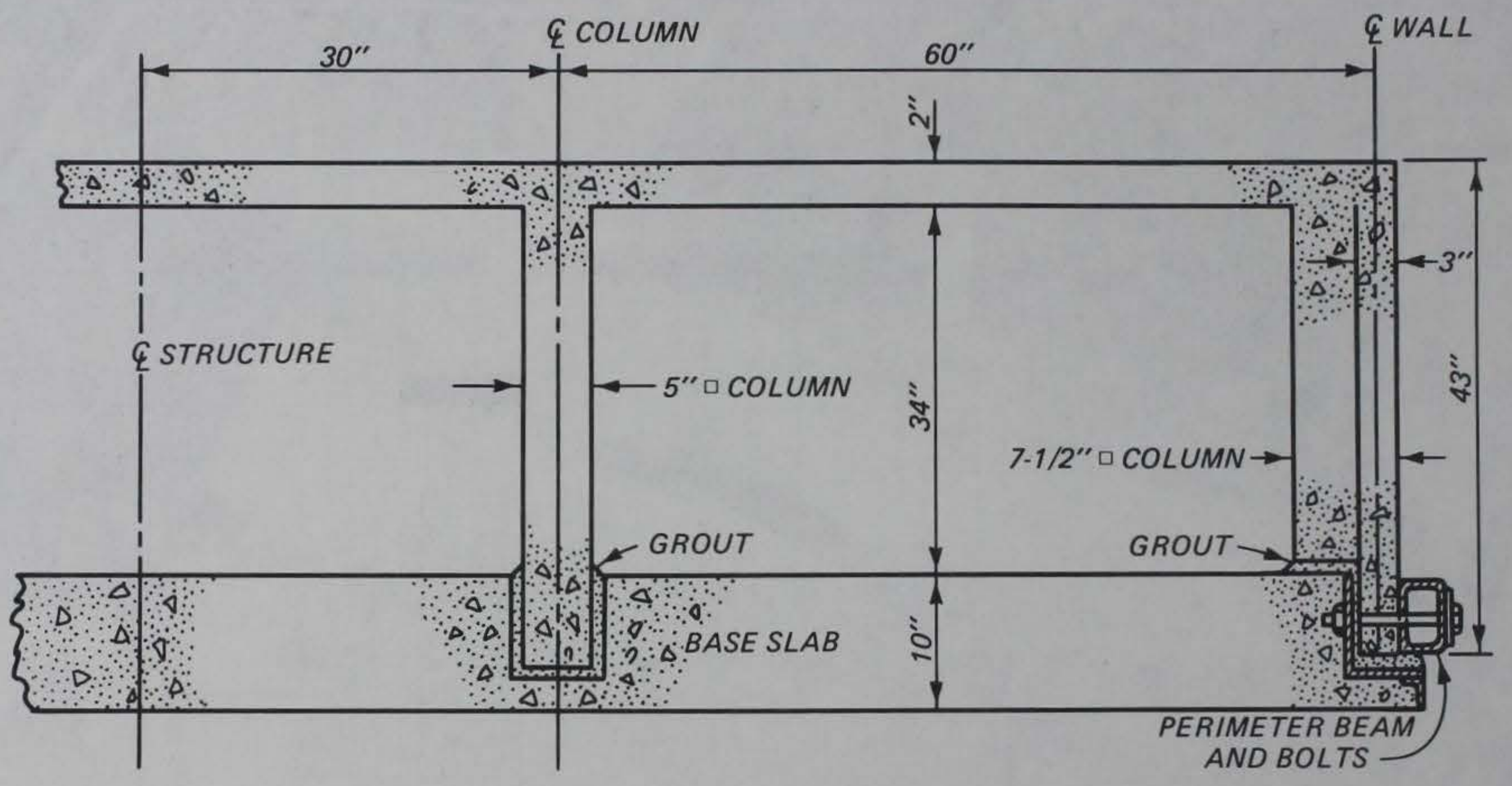

Figure 2.9 Cross-section of one-half of flat plate model. 


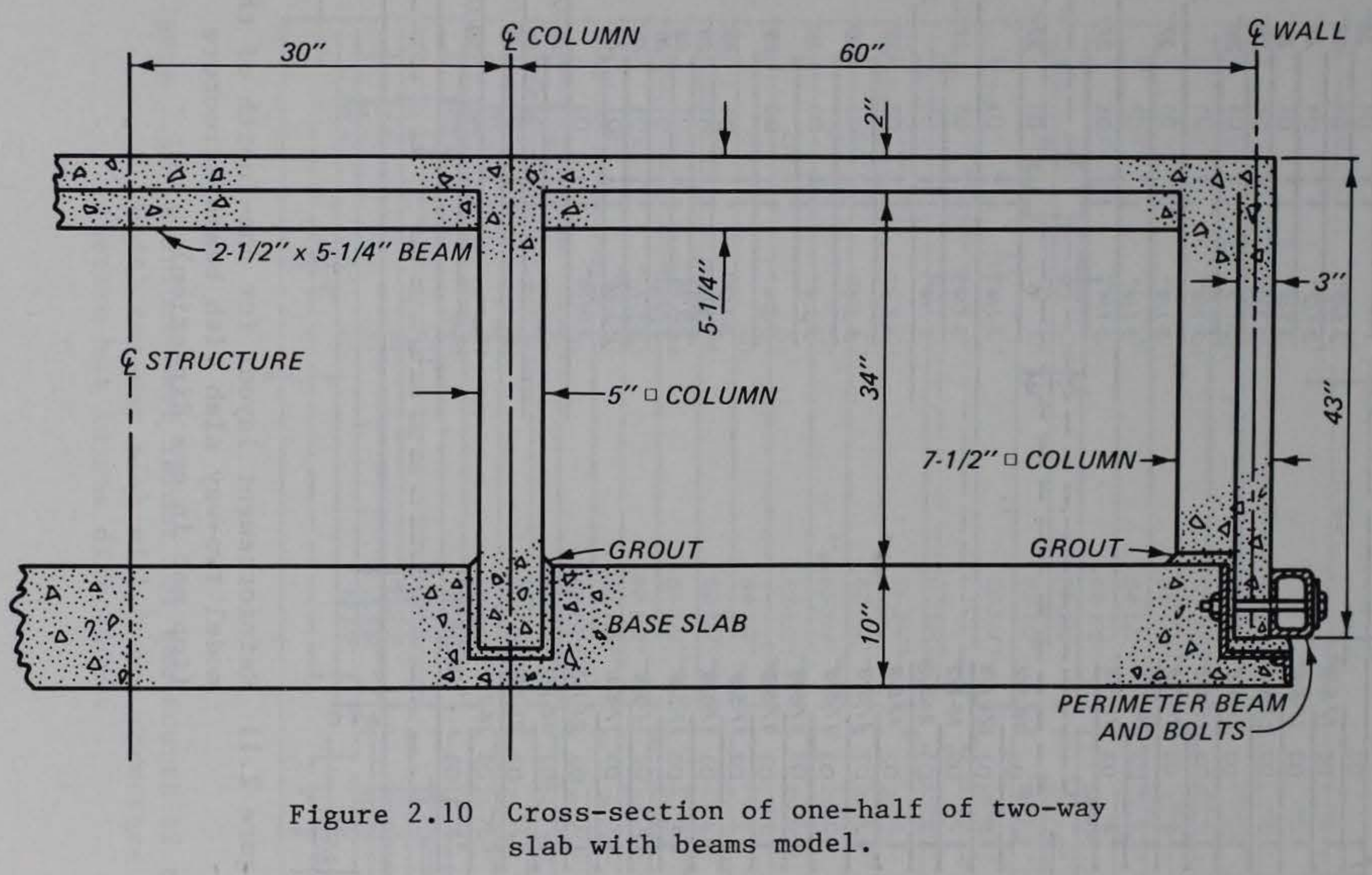




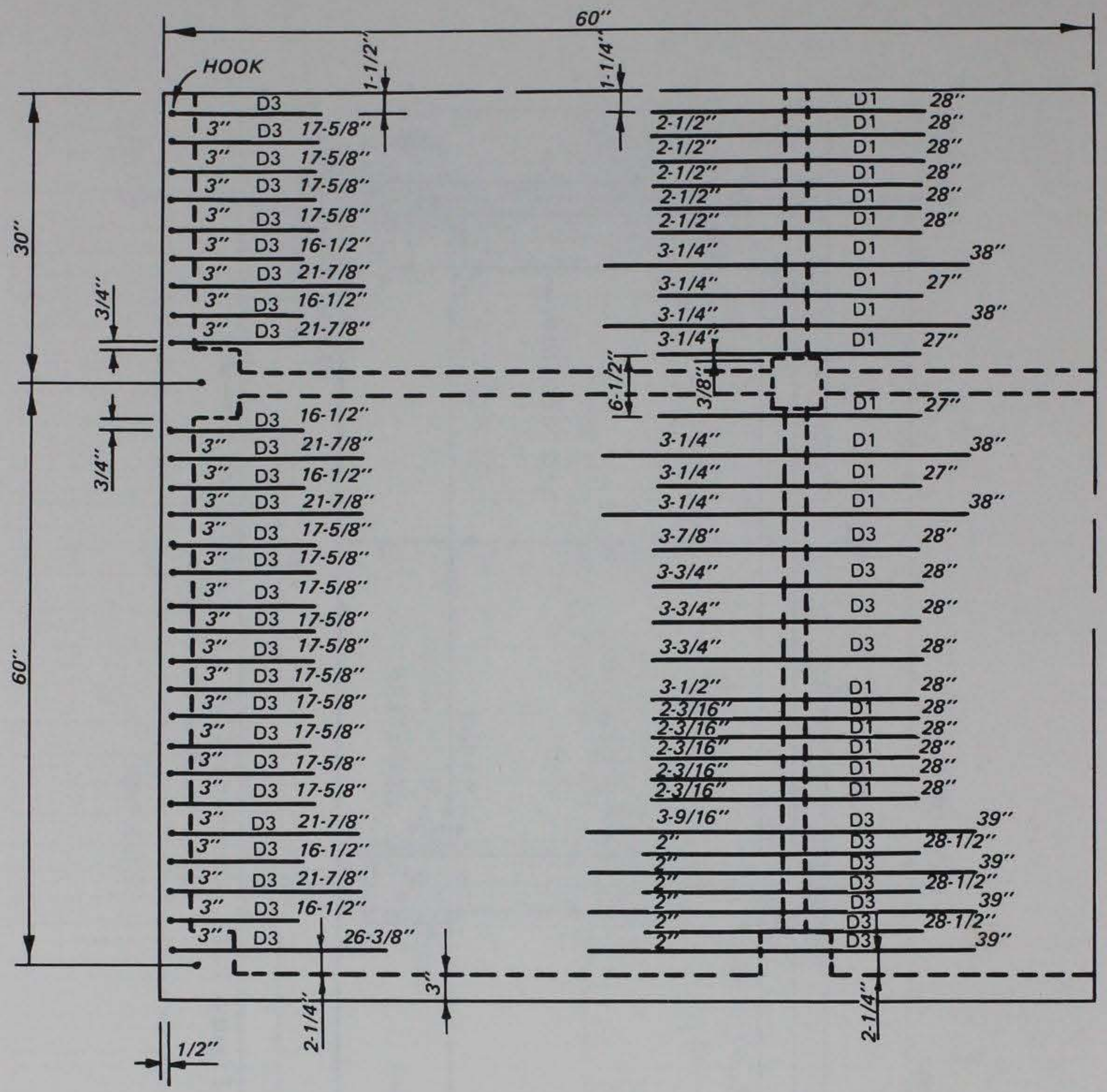

Figure 2.11 Reinforcement layout for one-fourth of the model two-way slab with beams structure (top mat in one direction). 


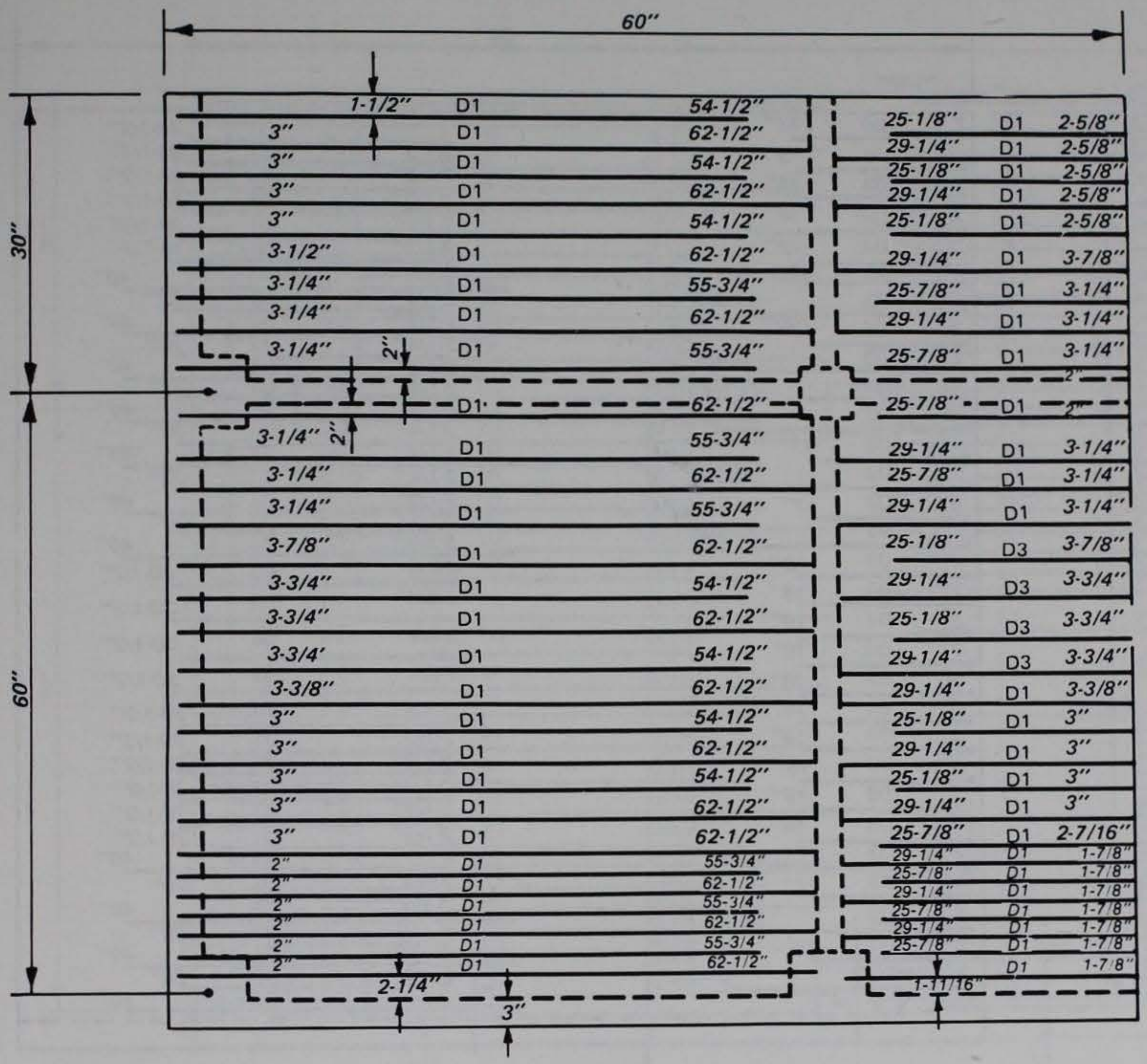

Figure 2.12 Reinforcement layout for one-fourth of the model two-way slab with beams structure (bottom mat in one direction). 


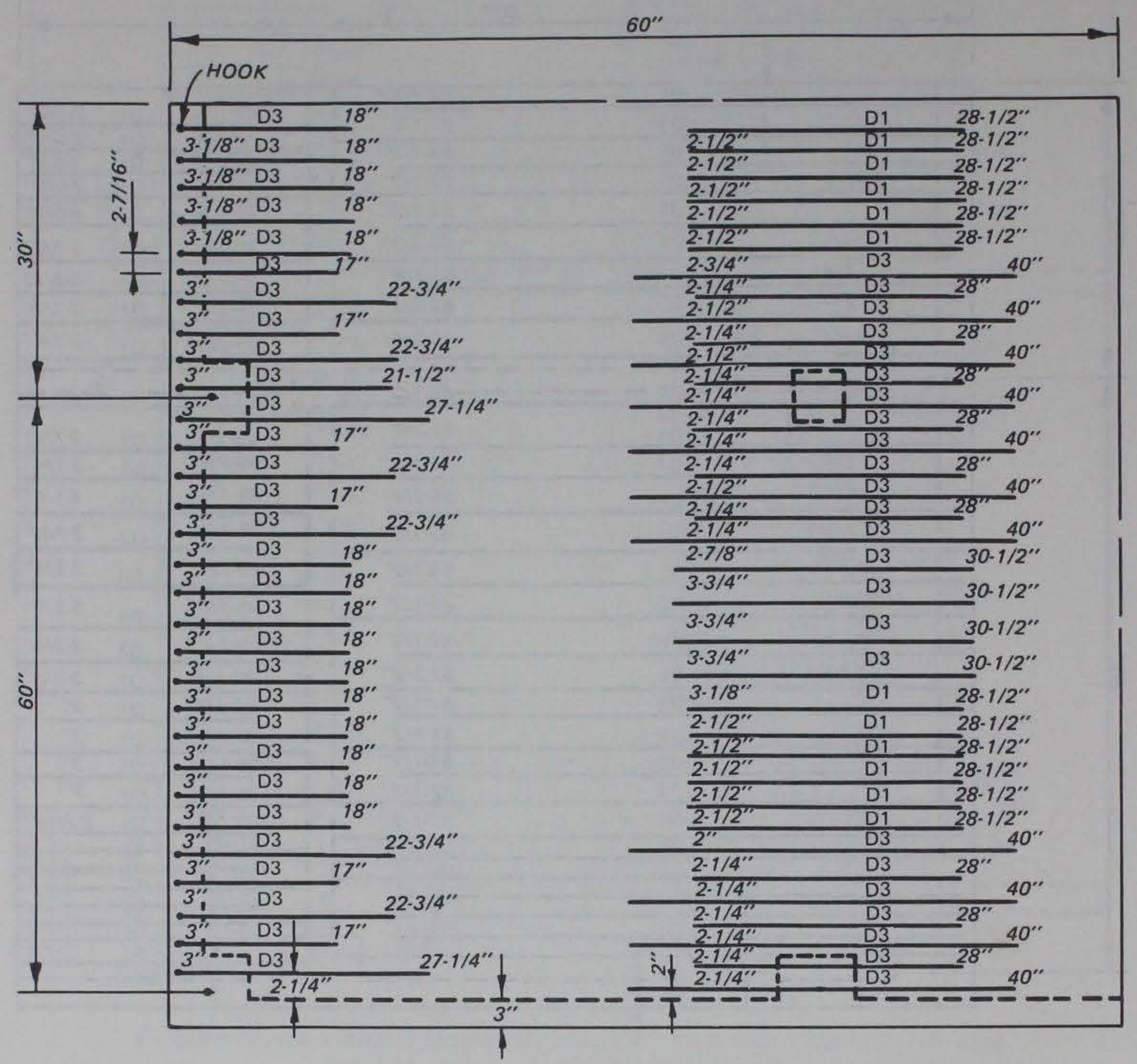

Figure 2.13 Reinforcement layout for one-fourth of the model flat plate structure (top mat in one direction). 


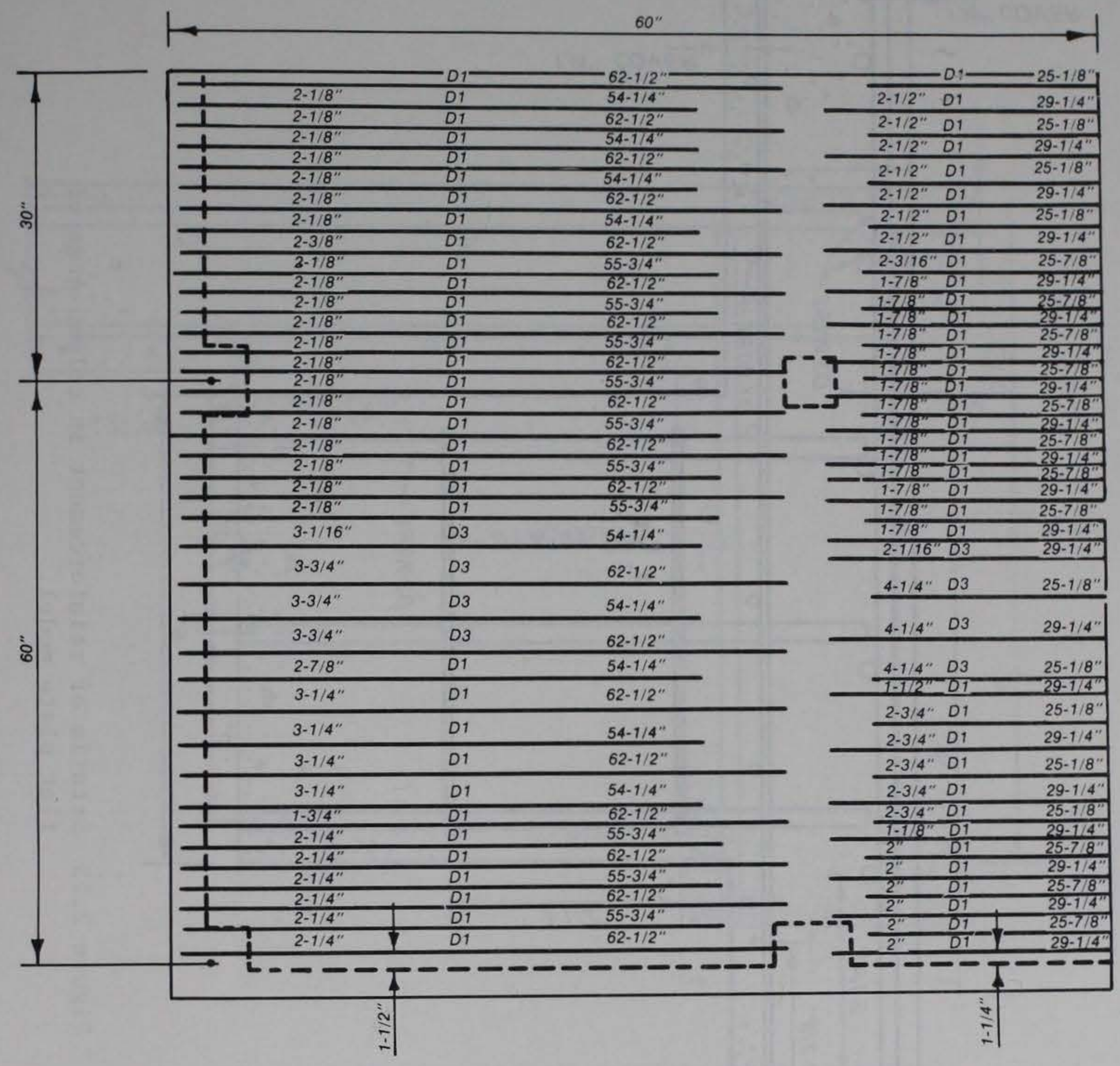

Figure 2.14 Reinforcement layout for one-fourth of the model flat plate structure (bottom mat in one direction). 


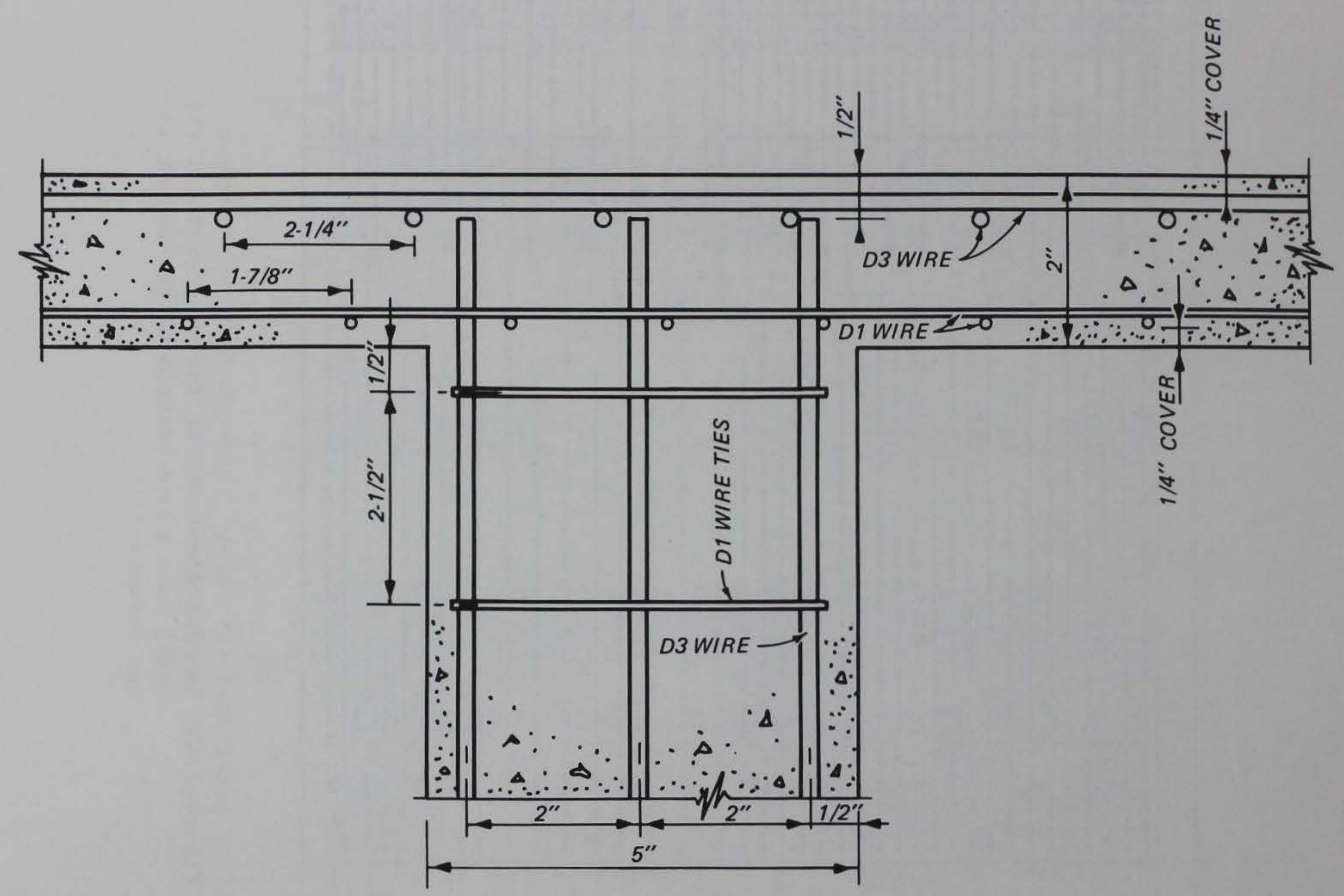

Figure 2.15 Details of reinforcement in column area of flat plate model. 


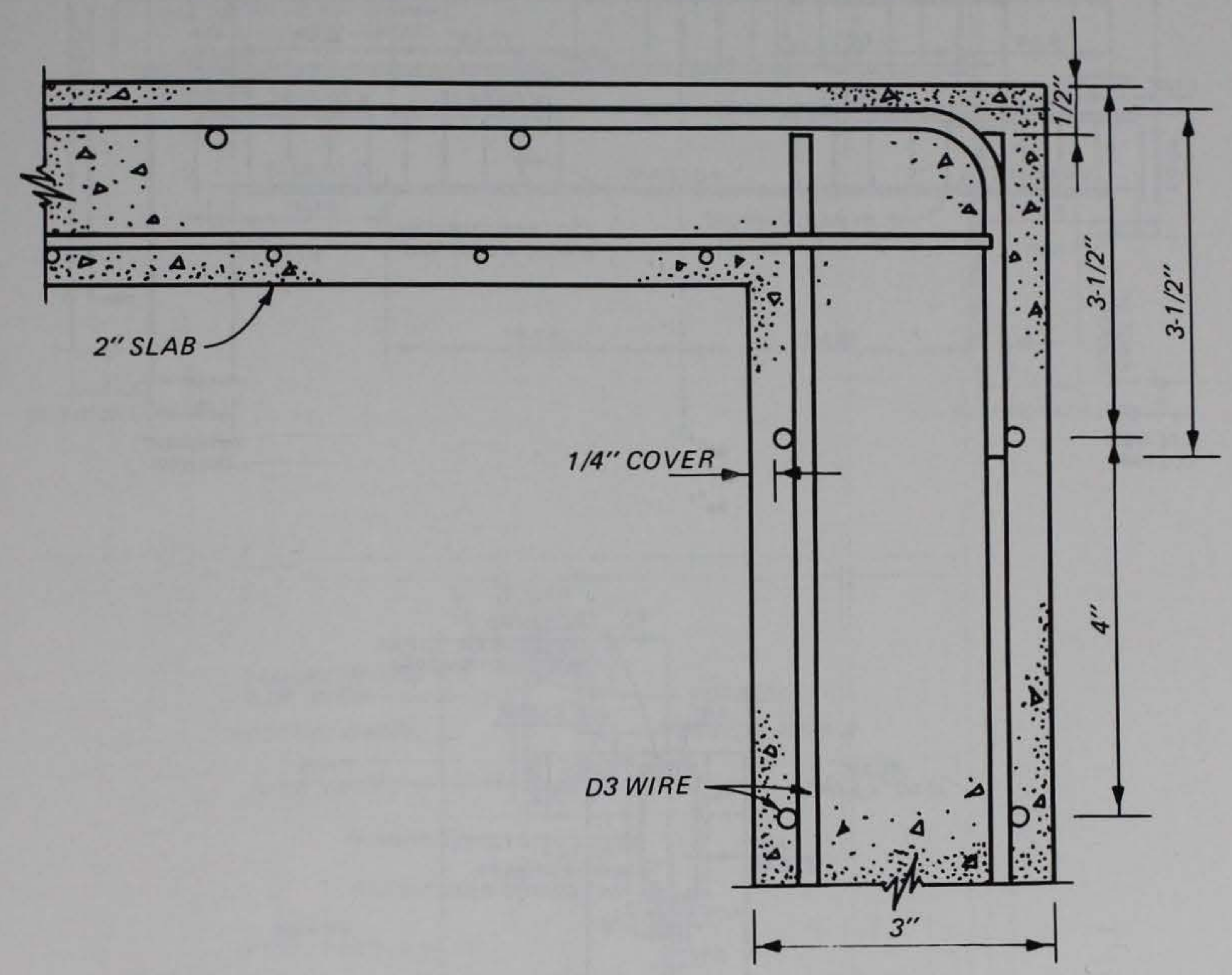

Figure 2.16 Details of reinforcement near top of the flat plate model walls. 

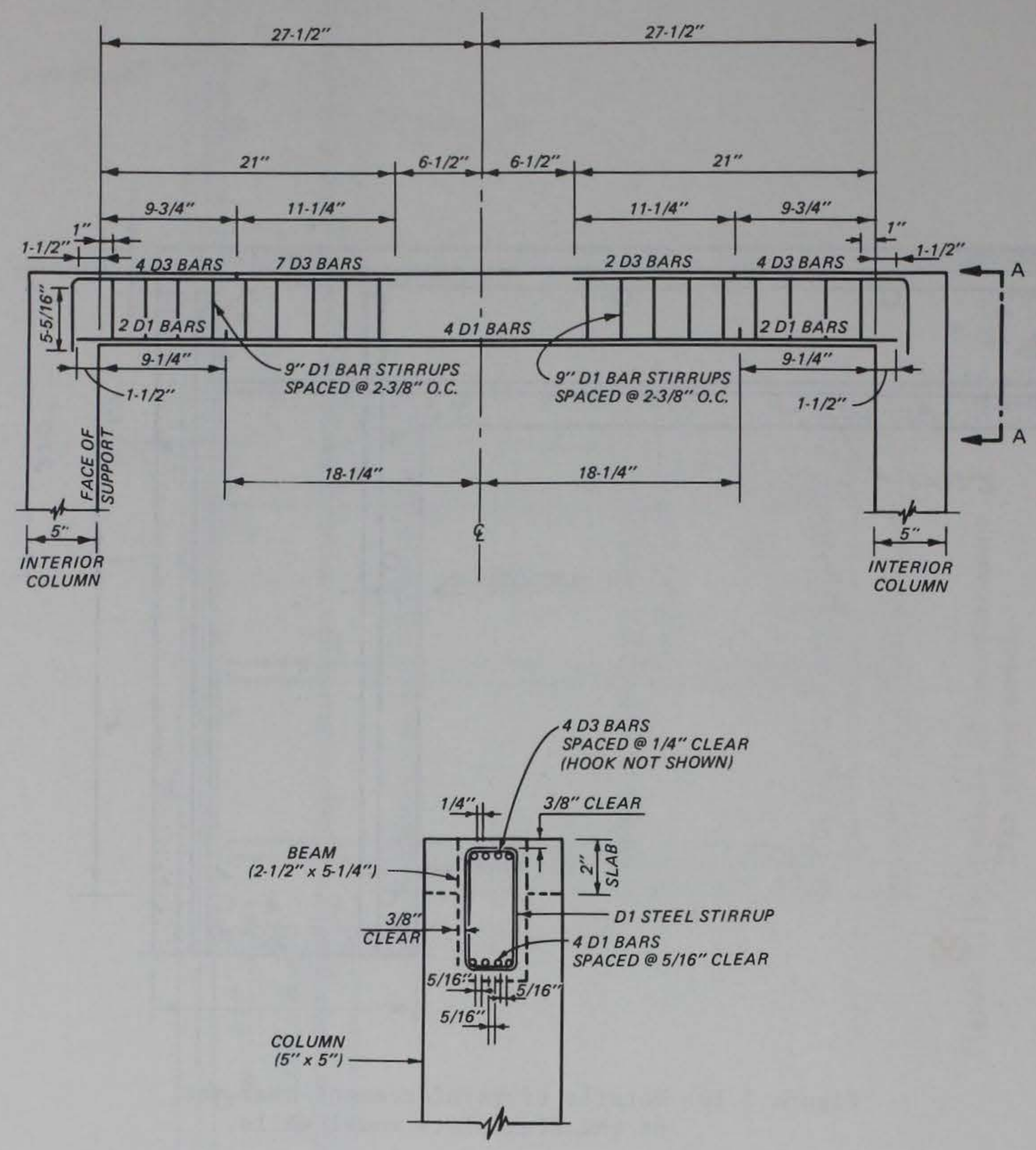

SECTIONA-A

Figure 2.17 A-beam reinforcement details. 

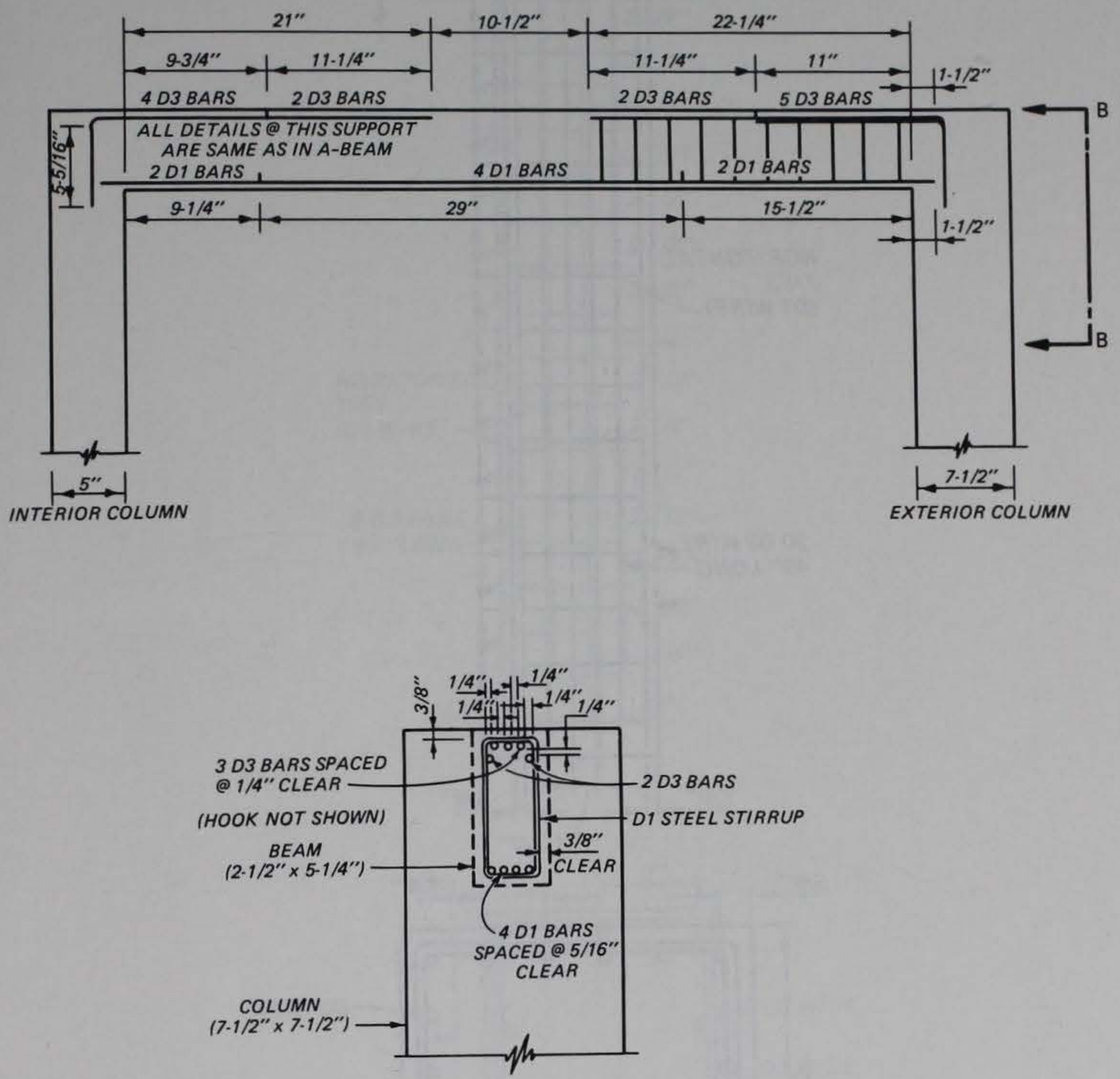

\section{SECTION B-B}

Figure 2.18 B-beam reinforcement details. 


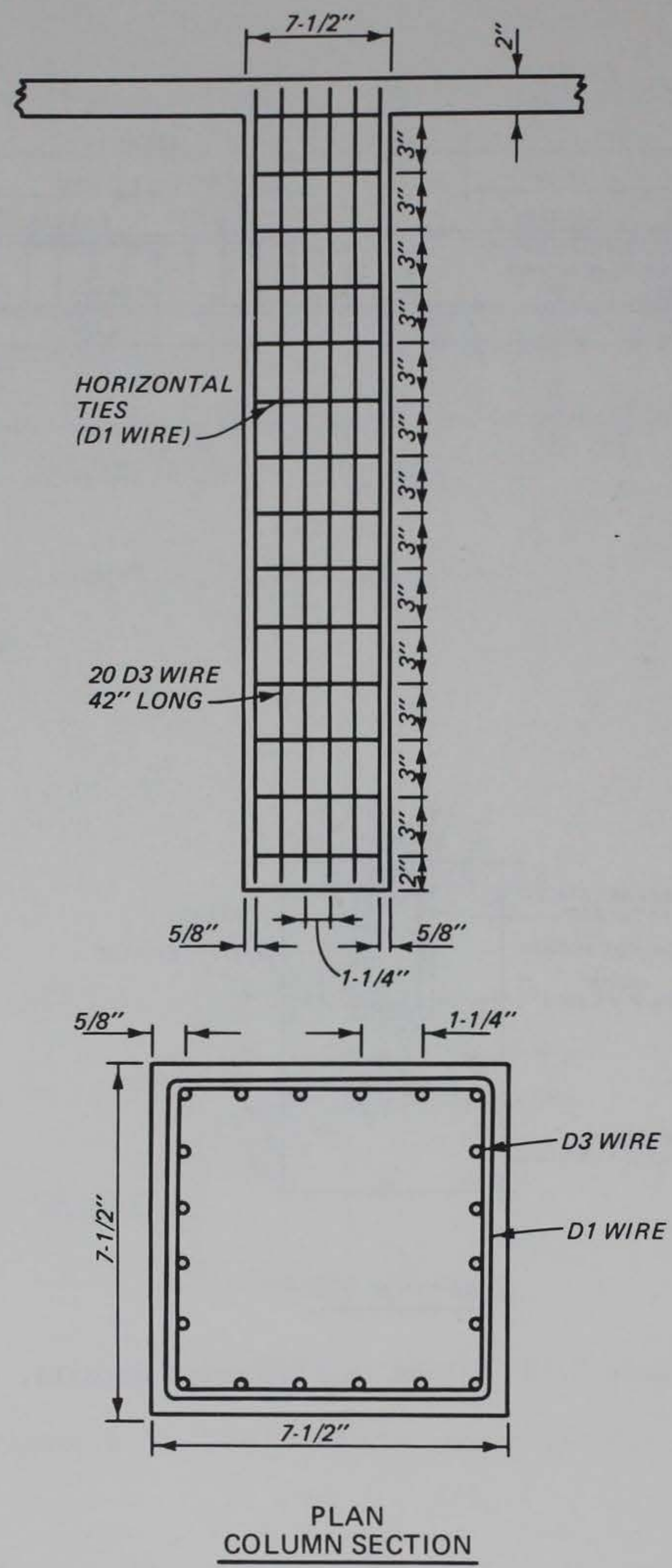

Figure 2.19 Details of model interior column. 

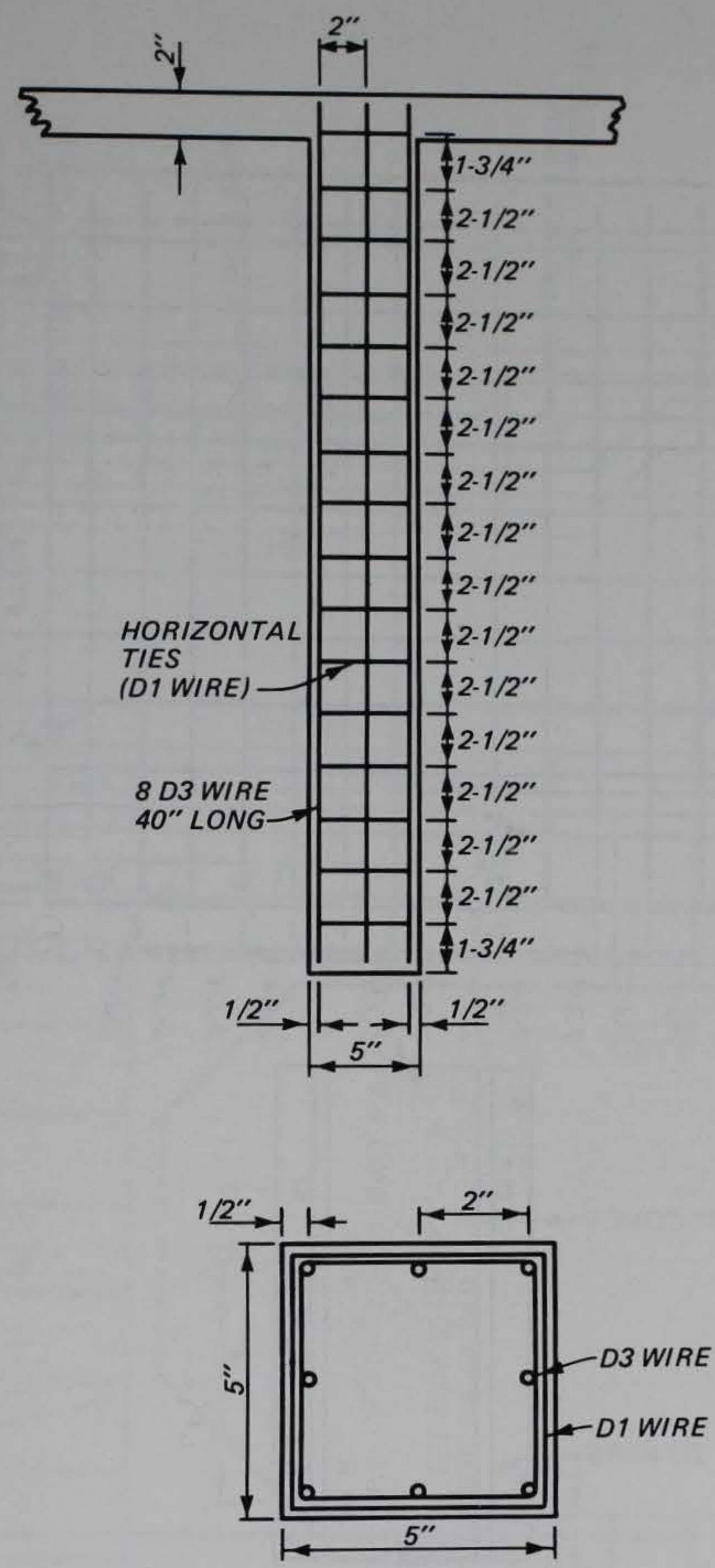

\section{COLUMN SECTION}

Figure 2.20 Details of model exterior column. 


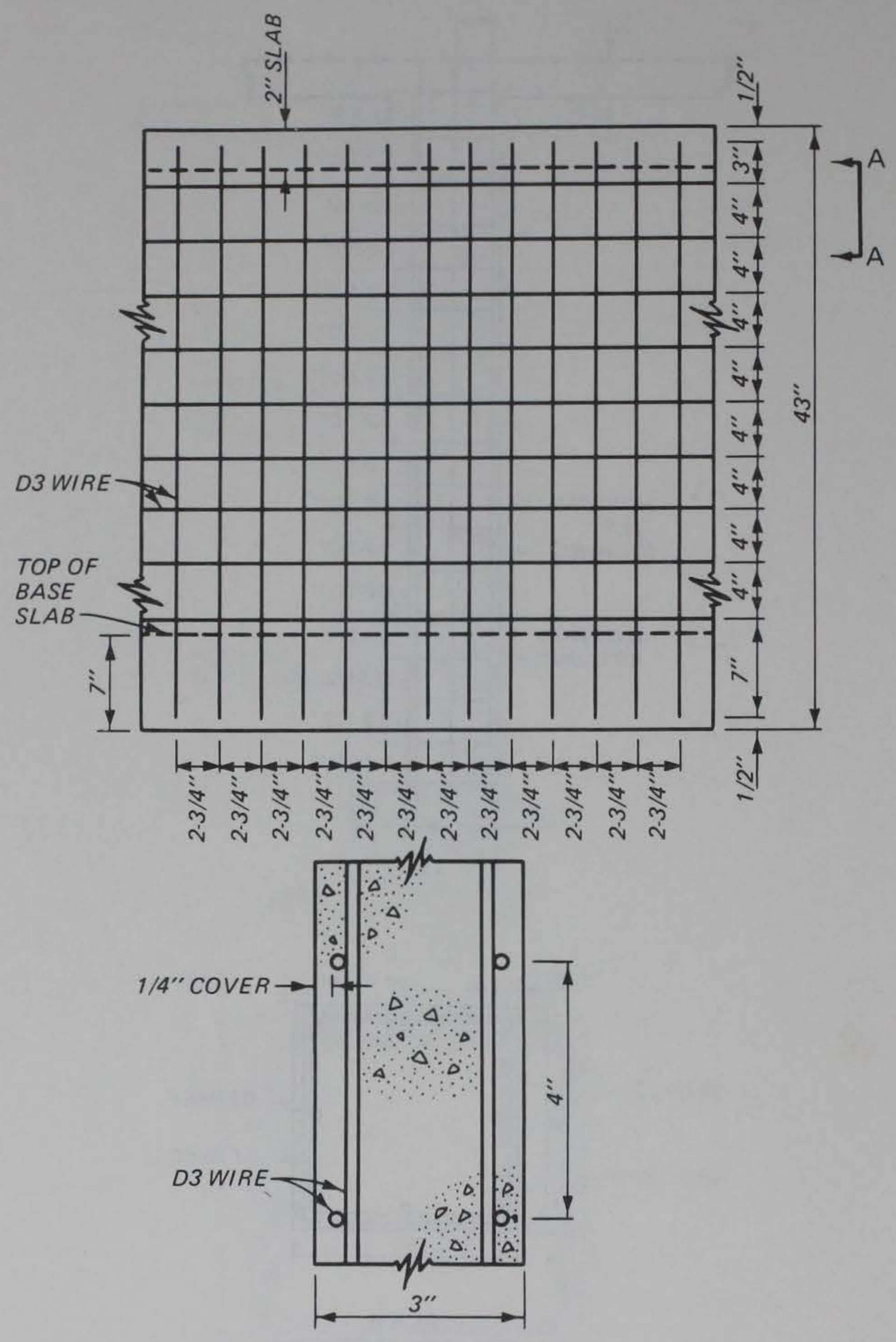

SECTION A-A: WALL SECTION

Figure 2.21 Mode1 wall details. 

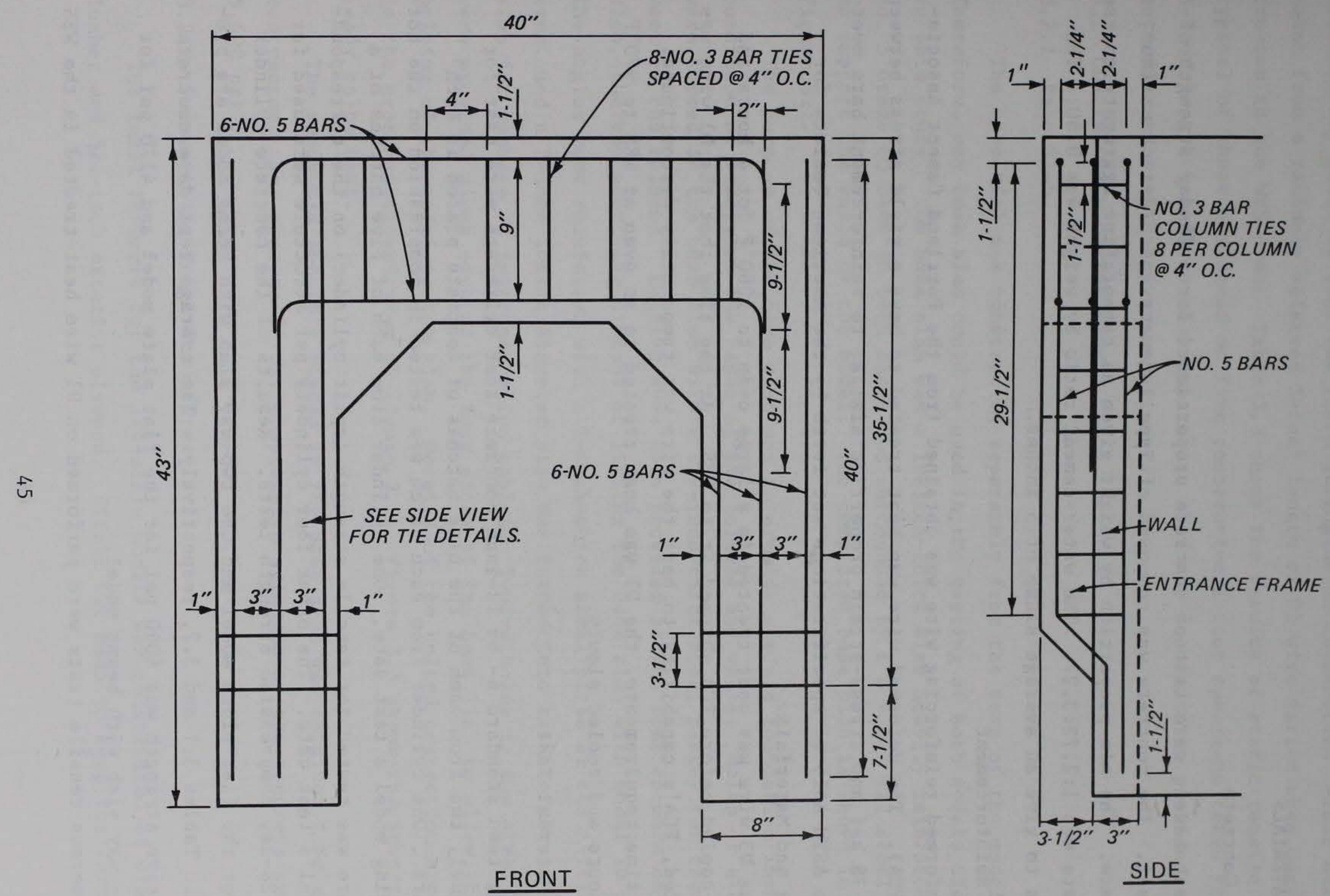

FRONT

Figure 2.22 Model entranceway details. 


\section{CHAPTER 3}

\section{EXPERIMENTAL PROCEDURES}

\subsection{MATERIALS}

\subsubsection{Concrete}

Both models were cast of concrete proportioned for a 28-day strength of 4,000 psi. The concrete was composed of Type I cement and 3/8-inch maximum aggregate. The mix proportion by weight given as cement:fine aggregate:coarse aggregate was $1: 2.72: 3.27$. The water-cement ratio by weight was 0.60 . The $\operatorname{mix}$ was to give an average slump of 5 inches.

\subsubsection{Reinforcement}

Deformed reinforcing wire was obtained from the Portland Cement Association (PCA). The deformed wire was heat treated to have a yield stress between 60 and $78 \mathrm{ksi}$ and stress-strain properties similar to reinforcement bars meeting the ASTM A615-81 specifications set forth by the American Society for Testing and Materials.

The D3 wire was heat treated in a large oven to $1060^{\circ} \mathrm{F}$ for 4 hours and slowly cooled before PCA shipped it to WES. At the time that the D1 wire was requested, PCA's capability to heat the wire was temporarily discontinued. Due to time requirements, the D1 was heat treated in an oven at WES to $970^{\circ} \mathrm{F}$ for 4 hours and cooled slowly.

\subsubsection{Material Tests}

Eighteen standard 6- by 12-inch concrete test cylinders were cast for each model, two from each of the nine batches of concrete placed in each structure. One cylinder from each batch was tested in compression on the corresponding model's test date. One cylinder from each of five batches of a structure was tested for tensile strength (split cylinder) on the corresponding model's test date. The other four cylinders per structure were used for 7- and 28-day compression strength tests. Results of the concrete cylinder tests for the flat plate model and the two-way slab with beams model are presented in Tables 3.1 and 3.2, respectively. The average test date concrete compressive strength was 4060 psi for the flat plate model and 4170 psi for the two- way slab with beams model.

Numerous tensile tests were performed on D1 wire heat-treated in the WES 
oven because a trial-and-error procedure was used to determine the heating temperature that would anneal the steel to required specifications. It was consistently observed that the yield strengths of consecutive 1-foot sections taken from a randomly selected 5-foot length of D1 wire varied when heat treated in the WES oven. Table 3.3 shows the results of static tensile tests typical of those performed on five consecutive 1 -foot specimens taken from a 5-foot length heated to the temperature that was concluded to provide results satisfactory for the given experiments.

\subsection{CONSTRUCTION OF THE MODEL}

\subsubsection{Base Slab}

The base slab was constructed separately from the rest of the model. Therefore, one base slab could be used in the testing of both models discussed in this study. The base slab was a 10-inch-thick slab heavily reinforced with No. 5 Grade 60 bars in both faces and surrounded by L $8 \times 6 \times 1 / 2$ steel angles to support the walls of the model. The completed base slab is shown in Figure 3.1.

The purpose of the base slab was to provide a rigid foundation imposing a condition of fixity at the bases of the columns and walls. Holes or slots were formed in the base slab with a 1/2-inch-thick steel plates for the placement of the columns. Lifting eyes were provided at the four corners of the slab, thereby providing a means of lifting the base slab with model in place. The angles were reinforced with a 1-inch-thick steel plate at the lifting eyes, and a 2-inch inside diameter pipe was formed into each corner of the slab for passage of instrumentation cables. Twelve holes in the steel angles were provided along each of the four sides of the base slab to allow the bolting of the model to the slab. Details of the bolted connection are shown in the cross-sectional view of Figure 3.2. Figure 3.3 shows the inverted slab ready to be cast.

The ready-mix concrete placed in the base slab was obtained from a local contractor. The average 28-day compressive strength of the concrete was 5,600 psi.

\subsubsection{Formwork for Model Structures}

The inner formwork for the 1/4-scale models was constructed of dimension lumber and 3/4-inch exterior plywood. Effort was made to keep the formwork 
dimensions within a tolerance of $1 / 16 \mathrm{inch}$. The inner wall forms were split vertically at the center of each of the model's four sides, which simplified removal. The foundation of the formwork was a platform constructed of dimension lumber and plywood. The interior formwork for the flat plate model during construction is shown in Figure 3.4. After placement of the plywood sheeting, the levelness of the slab-form surface was checked at approximately 80 locations. The slight variations over the $1 / 16$-inch tolerance were corrected by shimming of the formwork.

Figure 3.5 shows the inner formwork for the two-way slab with beams model prior to placement of the plywood sheeting. Shimming of the formwork also leveled the two-way slab with beams model within the $1 / 16$-inch tolerance. Figure 3.5 also shows the blockouts placed along the base of the model's walls to form slots in the walls to allow passage of bolts for fastening the model to the base slab. Blockouts were also placed at the bases of the corner columns to form slots for the lifting eyes of the base slab.

\subsubsection{Placing the Reinforcement}

\subsubsection{Flat Plate Model}

The bottom reinforcement mat of the flat plate model was constructed in place on the formwork. The model reinforcement steel was tied together with stovepipe wire manufactured by the Modern Wire Company. Reinforcement steel to be instrumented was not put in place at this phase. Pieces of steel bar, $1-1 / 2$ to 2 inches, were tied to the bottom of the mat to lift it off the formwork and allow space for $1 / 4$ inch of concrete cover. Figure 3.6 shows the bottom mat of the flat plate model with some of the spacers in place.

The wall and column steel was placed on the formwork when the slab bottom mat was completed. The column cages and the mats for the wall steel, shown in Figures 3.7 and 3.8 respectively, were prefabricated. The instrumented reinforcement in the interior columns was tied into position with the rest of the column steel since their addition at a later time would be difficult. The column steel shown in Figure 3.7 was typical of the exterior columns, and the column on the left was partially discontinued at the base, as were all corner columns, to accompany the lifting eyes of the base slab. Sheet metal spacers, 3 inches in length, were used to position the wall steel mats in each face at the proper depth. To complete the wall reinforcement, the heavy reinforcement around the entrance was placed into position. The entrance reinforcement was 
identical to that of the two-way slab with beams model shown in Figure 3.11 .

The top steel mat of the flat plate model was prefabricated in sections, such as a section at a column area, and pieced together on the formwork. Sheet metal spacers were used to maintain the proper depth of the top mat. Figure 3.9 shows the top mat in position over an interior column. The hooks of the top mat were tied to the wall reinforcement to prevent them from moving during placement of the concrete. Remaining instrumented reinforcement wire was tied into position to finalize the placement of all required steel. Figure 3.9 shows some reinforcement instrumented with strain gages at an interior column area. Figure 3.10 is an overall view of the flat plate model with steel placement completed and the outer wall forms in position and partially braced.

3.2.3.2 Two-way Slab with Beams Model

The two-way slab with beams model was constructed after construction and testing of the flat plate model. Therefore, the experience gained in construction of the flat plate model was useful in making the construction phase of the second model more efficient. The wall and column steel was first to be placed on the formwork in a manner similar to the procedure used for the flat plate model. The outer wall forms were then placed into position. Figure 3.11 shows the model prior to the outer wall form being placed over the entrance, allowing a view of the steel around the entrance. The beam reinforcement was prefabricated and placed into position. The bottom mat for each of the nine panels was prefabricated, as were sections of the top mat. Instrumented reinforcement was included. The mats were tied into position with sheet metal spacers being used to ensure that the mats were placed at the proper depth. Figure 3.12 shows the model with all reinforcement in place. Figure 3.13 is a view of the completed steel placement at an interior column area, and Figure 3.14 is a close-up view of a beam-column connection.

\subsubsection{Casting the Mode1}

Each model was cast in one continuous operation over a period of about 5 hours. The concrete was mixed in batches of $12 \mathrm{ft}^{3}$, and nine batches were required for each model.

An aluminum catwalk supported by the outer wall forms of the model provided access to the top of the model. The concrete was placed with hand 
shovels and vibrated with an internal vibrator. Figure 3.15 shows the casting operation in process on the flat plate model.

After the concrete had been placed and vibrated, the top surface was screeded with a 6 - by 12 -inch aluminum structural tubing section, and the surface was finished several hours later.

\subsubsection{Curing the Model, Removal of Formwork, and Condition of Model}

A layer of polyethylene was placed over the surface of the model for 14 days to maintain moisture content in the slab. The formwork was then removed, allowing the model to air-cure until testing.

Inspection of the flat plate model revealed that it was free of visible voids. The only visible cracks were minor cracks extending from the blockouts formed to provide slots for the base slab lifting eyes.

Inspection of the two-way slab with beams model revealed minor cracks at the blockouts similar to those in the flat plate model. Three of the nine panels exhibited honeycomb-like voids on the bottom surface. The voids covered a near circular surface area in each of the three panels which was approximately $2-1 / 2$ feet in diameter. Figure 3.16 shows which panels had the voids. The voids existed in the concrete cover of the panel's bottom reinforcement steel and were not expected to be of structural significance to the test program. However, the voids were filled with grout for aesthetic purposes and for formation of a smooth surface in the event of crack formations expected to occur during testing of the model.

Mixture proportions for the grout used to fill the voids based upon a $1-\mathrm{ft}^{3}$ volume were as follows:

$\begin{array}{lc}\text { Type I cement } & 49.81 \text { pounds } \\ \text { Fine sand } & 52.99 \text { pounds } \\ \text { Water } & 26.48 \text { pounds } \\ \text { Powdered aluminum } & 1.06 \text { grams } \\ \text { Calcium chloride } & 1.0 \text { pounds }\end{array}$

The calcium chloride agent stimulated the curing process to aid in the placement of the grout on the slab undersurface.

Three beams of the two-way slab with beams model also had void areas. Figure 3.16 shows the locations of the voids. Two of the void sections covered a length of approximately 6 inches along the beam, and the other void 
section affected a length of the beam approximately equal to 3 inches. Voids in 6-inch-long sections affected the most of the width and depth of the beam over the 6-inch length. Voids in the 3-inch-long section affected only an upper quarter of the beam over the 3-inch length.

The void sections in the beams were repaired by the removal of the loose concrete in the sections and the placement of grout. Forms were built around the void sections, and the grout was pumped into the voids through small holes drilled into the beam from the top surface of the model slab. The mixture proportions for the grout were the same as those previously mentioned to fill the voids on the undersurface of the slab, except for the calcium chloride ingredient. Calcium chloride was not in the grout used to repair the beams. The grout had a 7-day compressive strength of 3,435 psi and a 13-day (structure test day) compressive strength of 4,085 psi.

\section{3 TESTING PROCEDURE}

\subsubsection{Preparation of Test Specimen}

The model was placed on the base slab by lifting the model at the four lifting points provided at the corner columns. To prevent deflection of the model slab during the lifting process, two sections of 5 - by $3-$ by $3 / 8-i n c h$ structural tubing were used as beams spanning from wall to wall of the model as shown in Figure 3.17. Bolts were passed through the tubing sections and into lifting eyes in each of the four interior columns.

After the model was in place on the base slab, grout was placed in the voids beneath the interior columns. Two days after the grout was placed beneath the interior columns, the structural tubing sections were removed from the interior columns. As in the detail in Figure 3.2, the two tubing sections, along with two additional sections, were bolted against the lower edges of the model's walls with high-strength bolts. The bolts extended into the base slab and were greased to inhibit the occurrence of bonding with grout that later surrounded the bolts. The bolts were only tightened to the degree required to support the weight of the tubing sections. Grout was then placed in the voids between the model's walls and the base slab as shown in Figure 3.2.

The grout was required to have a 7-day strength of at least 4,000 psi to ensure that it would not crush under load prior to the crushing of the concrete composing the model. The mixture proportions for the grout used were 
the same as those presented in section 3.2 .5 that were used to fill the voids on the undersurface of the panels. Test cylinders were taken from the grout batches to allow determination of the grout's compressive strength. The 7-day compressive strength was approximately 6,000 psi. After the 7-day strength was attained the bolts along the base of the walls were tightened.

The described procedure used in joining the model to the base slab was applied to both the flat plate model and the two-way slab with beams model. However, additional effort was required in preparation of the two-way slab with beams specimen since it was tested after the flat plate specimen and the same base slab was used for both models. The additional effort consisted of the removal of the flat plate specimen and the grout which filled voids between the specimen and the base slab.

\subsubsection{Loading Device}

The two models were tested in the Large Blast Load Generator (LBLG) 1ocated at WES. The LBLG (Figure 3.18) is a large three-dimensional device designed primarily to test underground protective structures subjected to pressures simulating those generated by both kiloton and megaton nuclear devices. Pressures up to about 500 psi, having rise times and durations similar to megaton size nuclear weapons, can be reproduced in the generator. Static loads up to 1,060 psi can be substained. The LBLG has two basic components: the central firing station and the test chambers. The central firing station is a massive, posttensioned, prestressed concrete, reaction structure designed to resist the dynamic or static loads generated in the test chamber. The two test chambers are cylindrical steel bins, each having a 23-foot OD and a 22foot 10-inch ID, that contain the test media and test structures. A test chamber consists of three C-rings that stack to a height of $10 \mathrm{feet}$, one B-ring that is capable of containing 15 firing tubes during dynamic loadings, and one A-ring that is a telescoping-type lid.

\subsubsection{Placement of Model and Backfill}

Prior to placement of the model in the LBLG test chamber, a fairly uniform sand was used to fill the chamber to an elevation at which the base slab would be placed. The sand backfill was placed at a density of approximately $96 \mathrm{lb} / \mathrm{ft}^{3}$ and was leveled to provide a uniform support for the model's base slab. 
The model with base slab was lifted at the four lifting eyes of the base slab and placed in the test chamber. A steel entranceway box approximately 3 feet square and 4 feet deep was placed adjacent to the model's access hole. The steel entranceway box was open at the top and at the side adjacent to the model to allow access to the model. The test chamber was then backfilled to an elevation 4-1/2 inches above the surface of the model slab.

The remaining instrumentation transducers were placed into position, and the electrical leads for all transducers were connected to cables running from the instrumentation room adjacent to the LBLG. The cables passed through the base slab and the base of the test chamber. The wooden upgrading columns were also wedged into position before the entranceway box was closed with a lid. Then the soil cover, specimen, and test chamber were sealed as required for the static test.

\subsubsection{Static Test}

Water pressure was used to apply a uniform load for the static tests. It was necessary to seal the specimen and soil cover from the water. A 6-milthick layer of polyethylene was placed over the soil surface and taped to the sides of the chamber. A 0.035 -inch-thick polyurethane diaphragm was placed atop the polyethylene and glued to the chamber's side to form a water seal.

After the water seal had been completed, the top ring and lid of the test chamber were installed, and the chamber was moved into the Central Firing Station (CFS). The air void above the model was then filled with water.

Water pressure for loading was obtained by passing tap water through a pressure regulator. The water pressure in the water mains at the time of testing was approximately 79 psi. Before the pressure was applied, calibration steps were recorded for the instrumentation transducers. Water pressure was then applied to the specimen at a rate of approximately $6 \mathrm{psi} / \mathrm{min}$. One water pressure transducer, one slab deflection transducer, and one Bourdontype mechanical pressure gage connected to the water chamber above the model were monitored throughout the test.

In the case of the flat plate model, the test was terminated at a loading pressure of approximately 79 psi when the maximum commercial water line pressure was reached. In the case of the two-way slab with beams model, the test was terminated when the water sealing membrane ruptured and the monitored water pressure transducer indicated a sudden decrease in loading pressure 
after reaching a value of approximately 39.5 psi.

The test chamber was then rolled out of the CFS so that the top ring, lid, and sealing membranes could be removed. After removal of the soil cover, the specimen was examined and photographed. The model was then removed from the test chamber.

\subsection{INSTRUMENTATION}

Experimental data were collected during each test with electronic transducers; they were then recorded on magnetic tape and digitized for plotting with a computer. Figures 3.19 and 3.20 show the instrumentation layouts for the flat plate model and the two-way slab with beams model, respectively.

\subsubsection{Pressure Measurements}

The loading pressure in each of the two tests was measured with two pressure gages mounted in the "B" ring of the LBLG to measure the applied pressure in the cavity above the specimen.

Three interface pressure gages were used in each test to measure the load applied normal to a wall of the model at the locations shown in Figures 3.19 and 3.20. Figure 3.21 is a view of the mounts used to encase the interface pressure gages in place in the model wall prior to placement of concrete.

\subsubsection{Deflection Measurements}

Deflections were measured in the models with ten Trans-Tek linear variable displacement transducers mounted in each model. Eight of the deflection gages were used to measure slab deflections, and two were used to measure wall deflections in each model.

\subsubsection{Soil Stress Measurements}

Five soil stress gages were used in each of the two tests to allow investigation of load transfer through the soil cover and backfill. Three of the gages were placed on a 1/4-in.-thick layer of soil on top of the model slab's surface. The remaining two gages were placed in the soil backfill approximately 12 inches from the model wall at the depths shown in Figures 3.19 and 3.20 .

\subsubsection{Strain Measurements}

Ten strain gages were used in the flat plate model test, and twelve strain gages were used in the two-way slab with beams model to measure strains 
in the reinforcement steel. In each model, two of the gages were mounted on vertical wall reinforcement steel, and four gages were mounted on the vertical reinforcement steel in one of the interior columns. The remaining strain gages were mounted on reinforcement steel in the model slab. The strain gages were placed in pairs with one gage on a top reinforcement bar and one on a nearby bottom reinforcement bar in parallel alignment. Figure 3.22 shows strain gages in place in the flat plate model slab. The gages were bounded to the bars with a heat-curing epoxy after the bar had been cleaned and lightly sanded. Lead wires were then attached to the strain gages, and the locations were waterproofed with synthetic rubber compounds. 


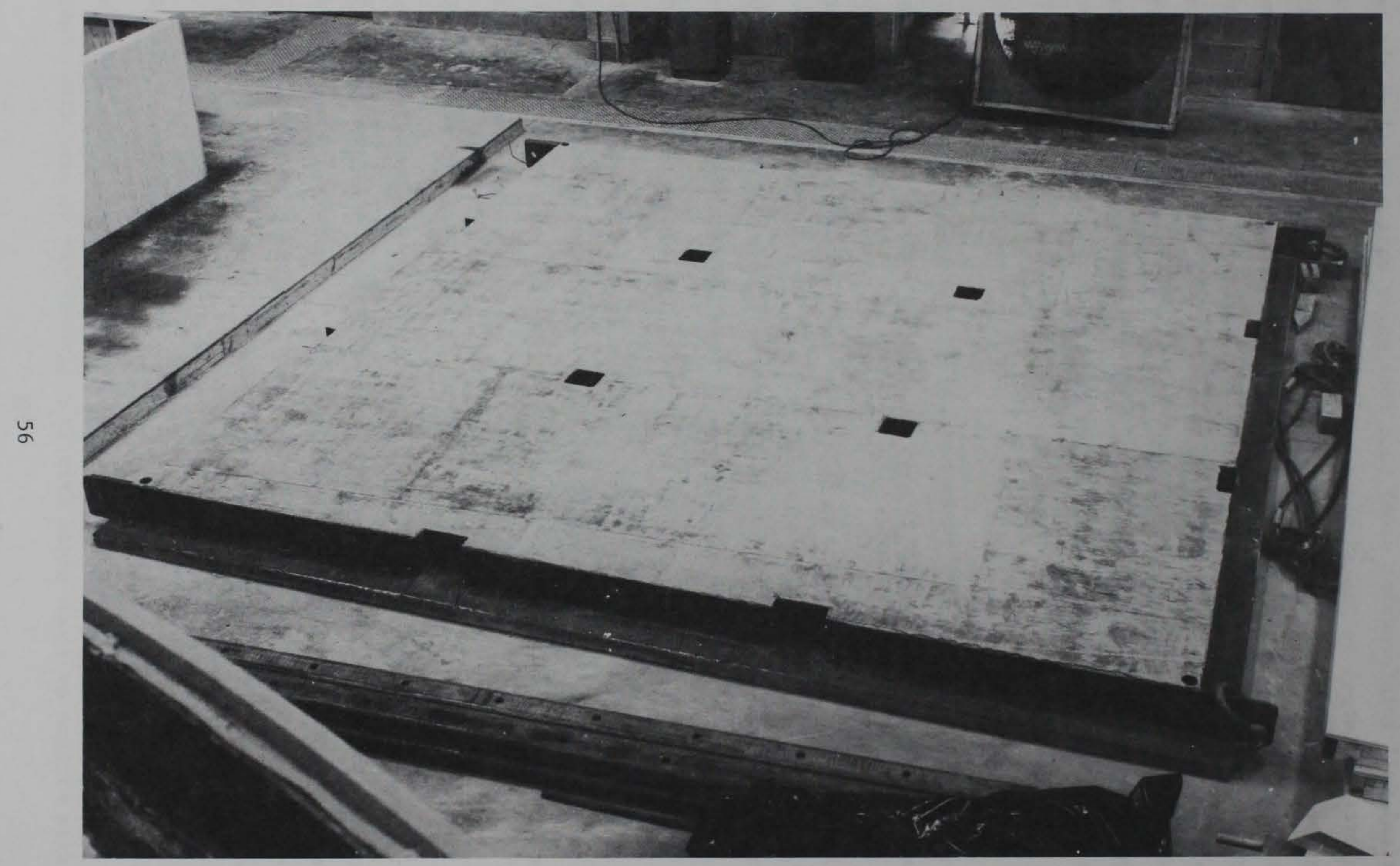

Figure 3.1 Base slab. 


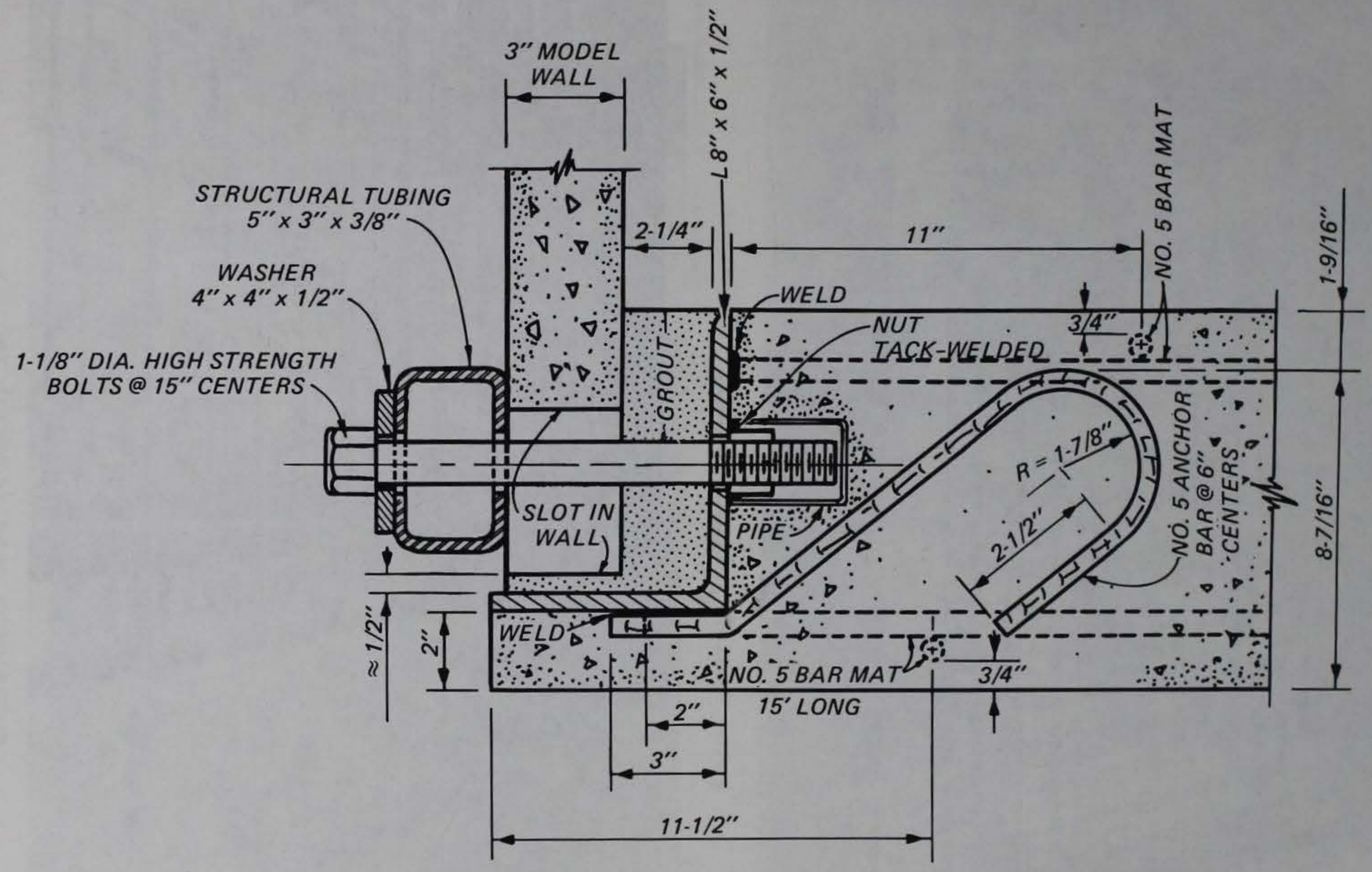

Figure 3.2 Details of base slab edge and slab to model wall connection. 


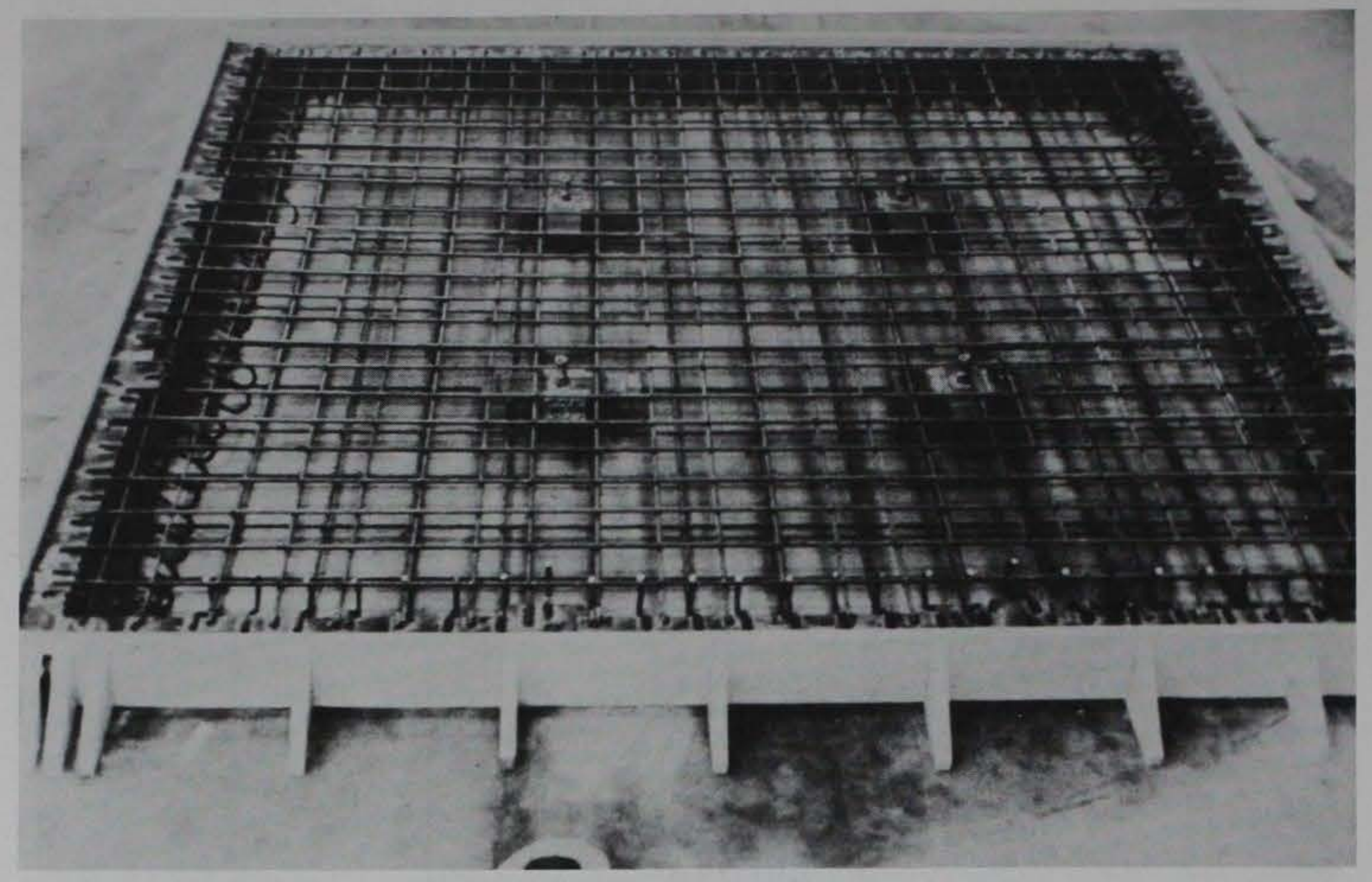

a. Overall view

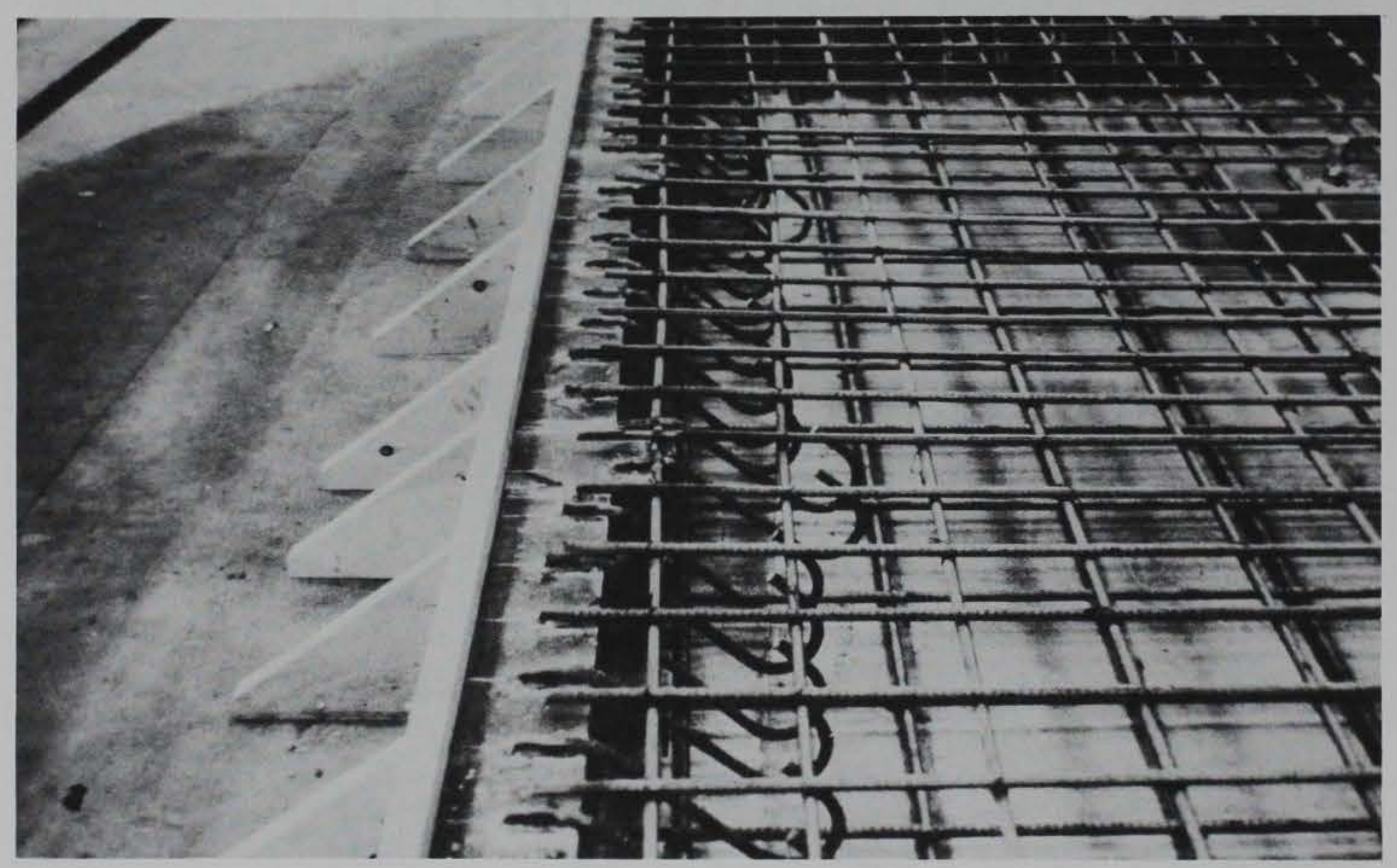

b. Edge detail showing anchor bars

Figure 3.3 Inverted base slab ready to be cast. 


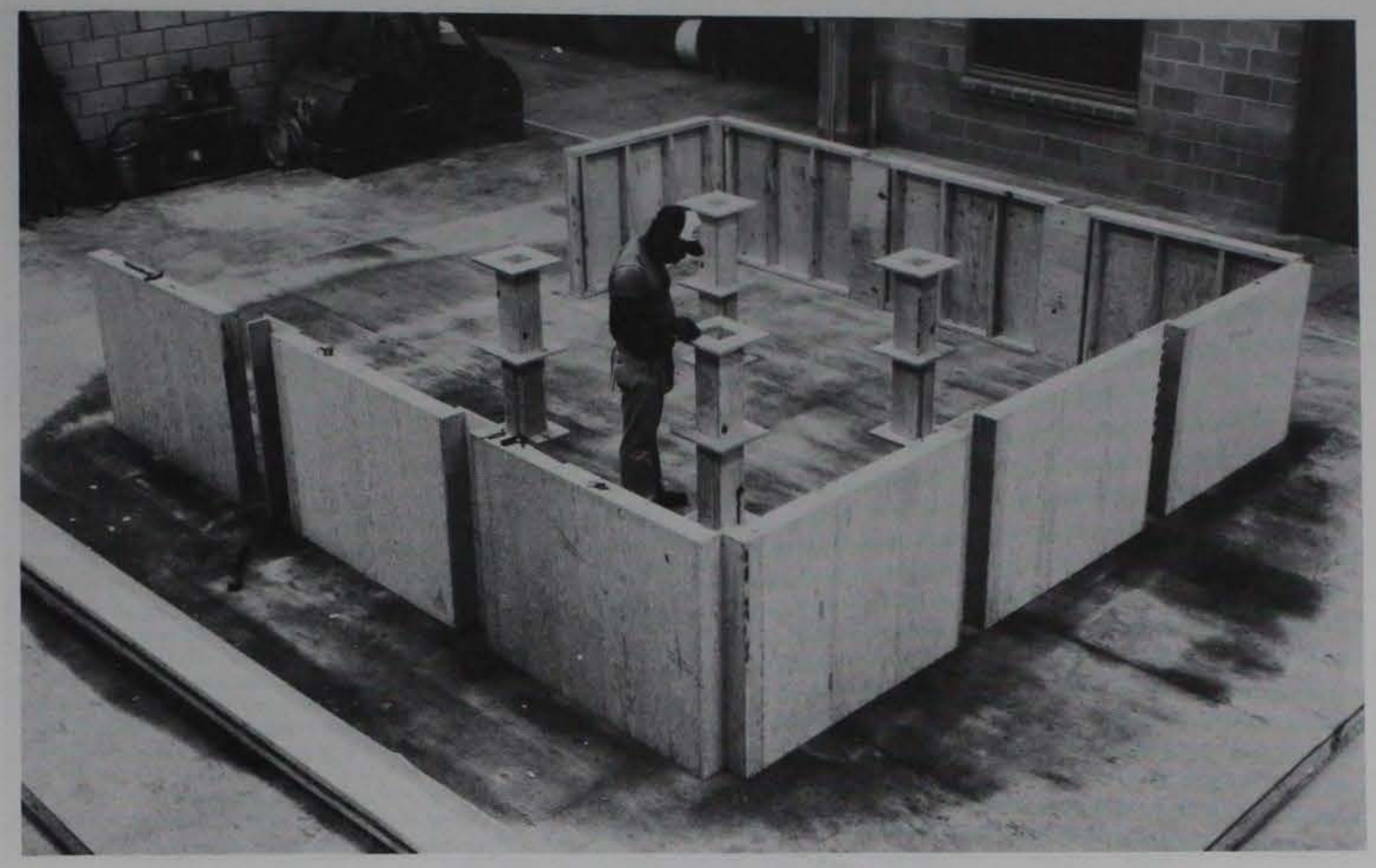

a. Phase showing interior column forms

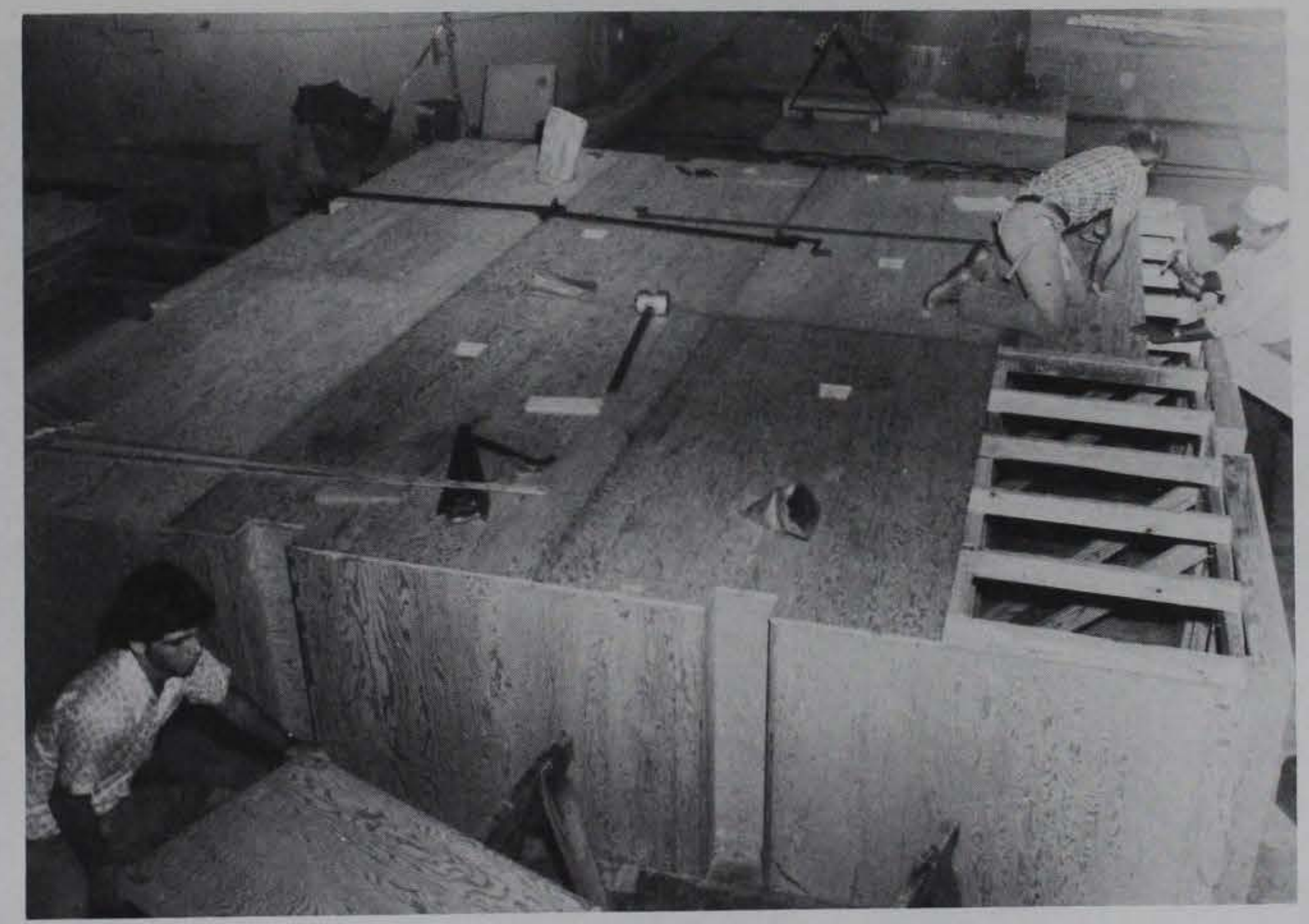

b. Inner formwork near completion

Figure 3.4 Flat plate model inner formwork. 


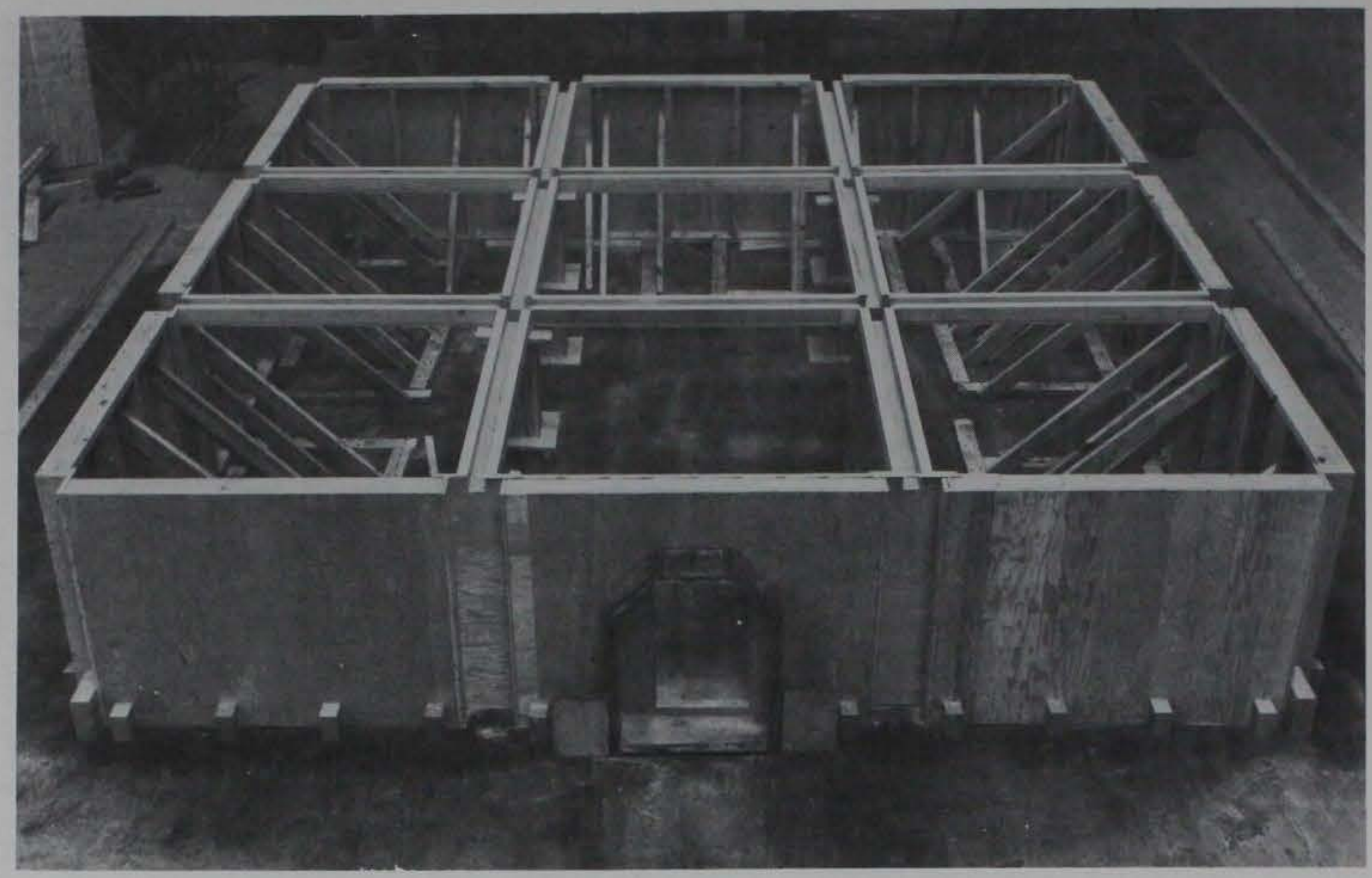

Figure 3.5 Two-way slab with beams model inner formwork.

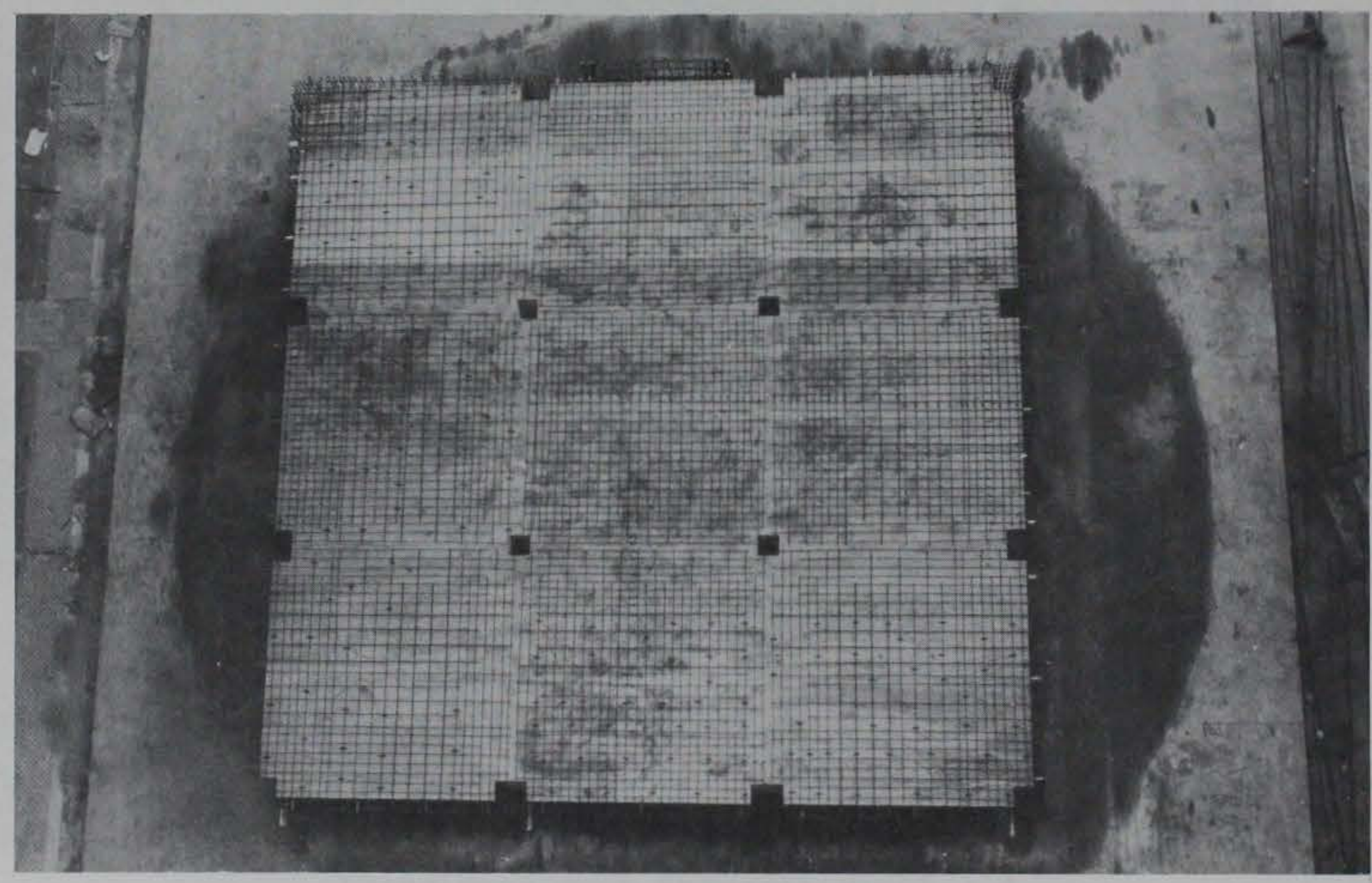

Figure 3.6 Flat plate model bottom reinforcement mat in place. 


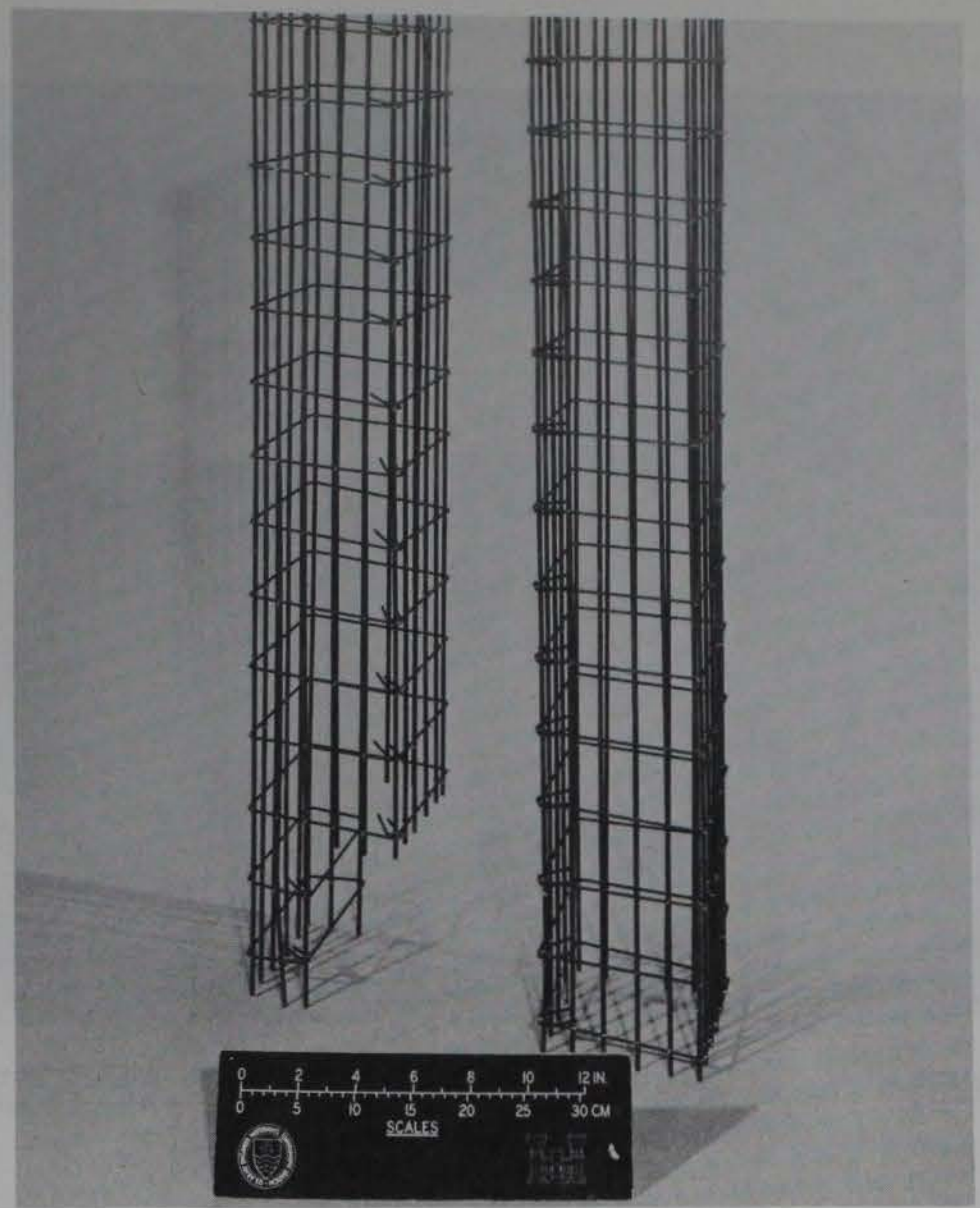

Figure 3.7 Column reinforcement steel.

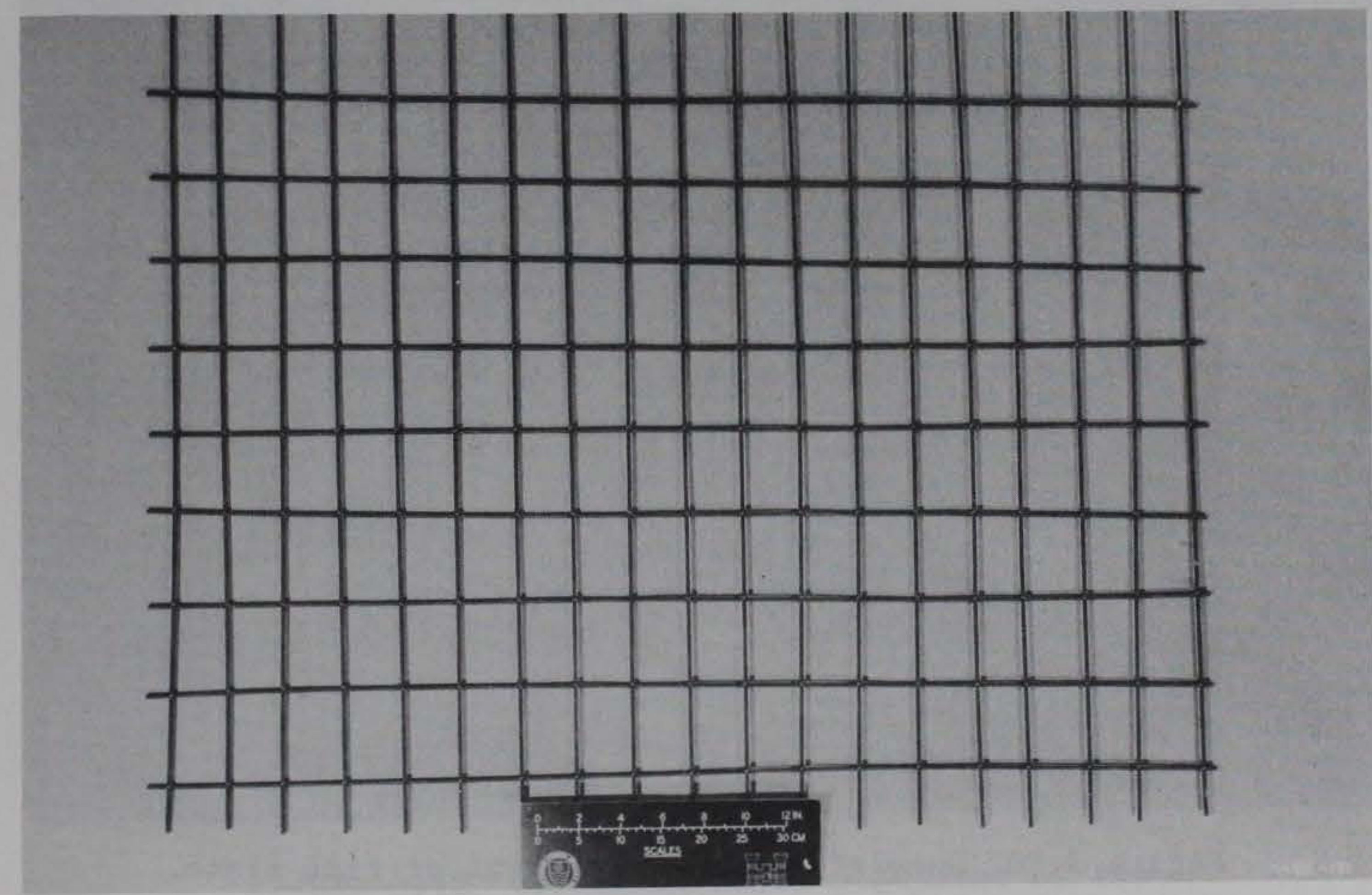

Figure 3.8 Wa11 reinforcement mat. 


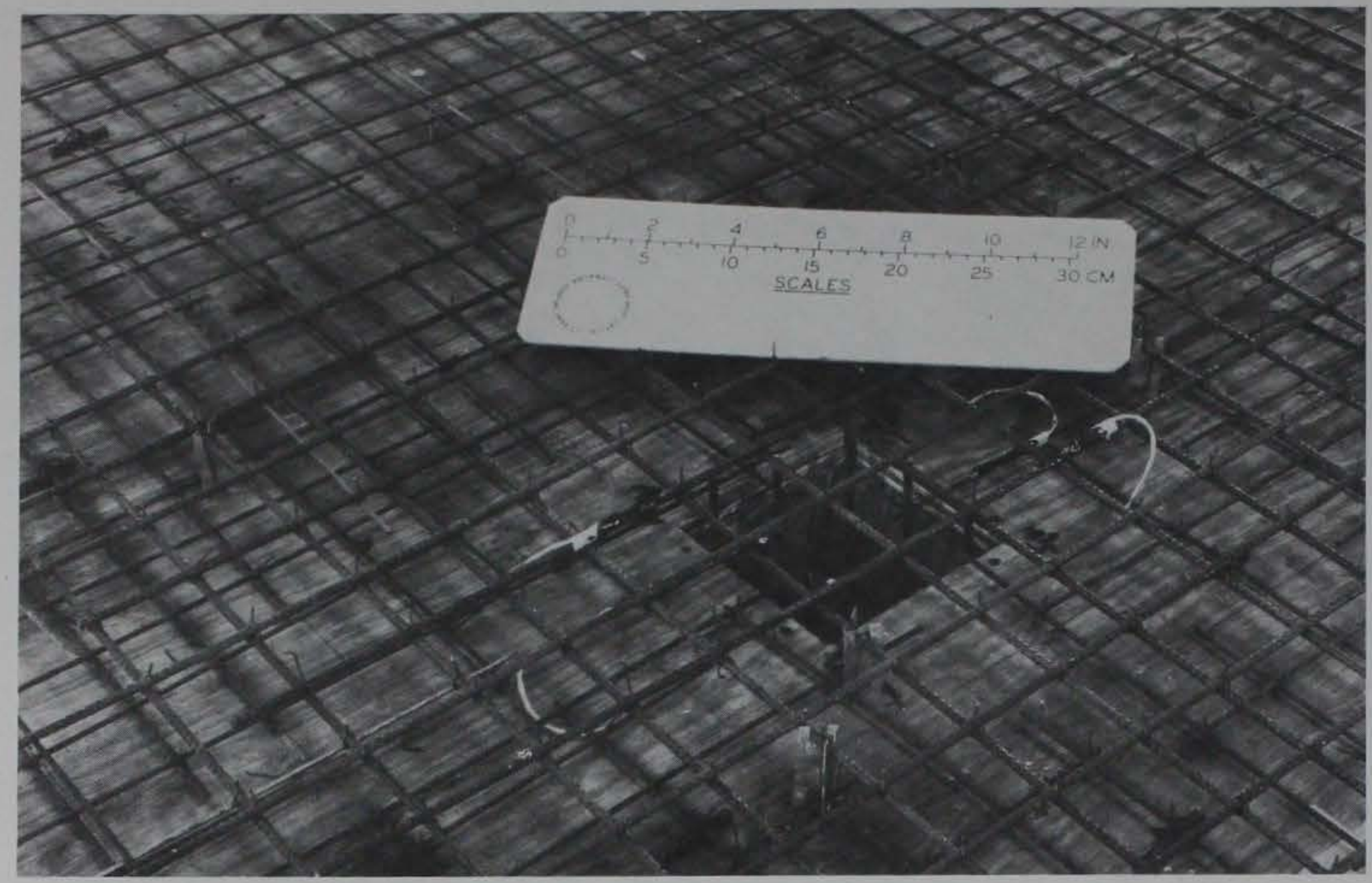

Figure 3.9 Completed steel placement at interior column area.

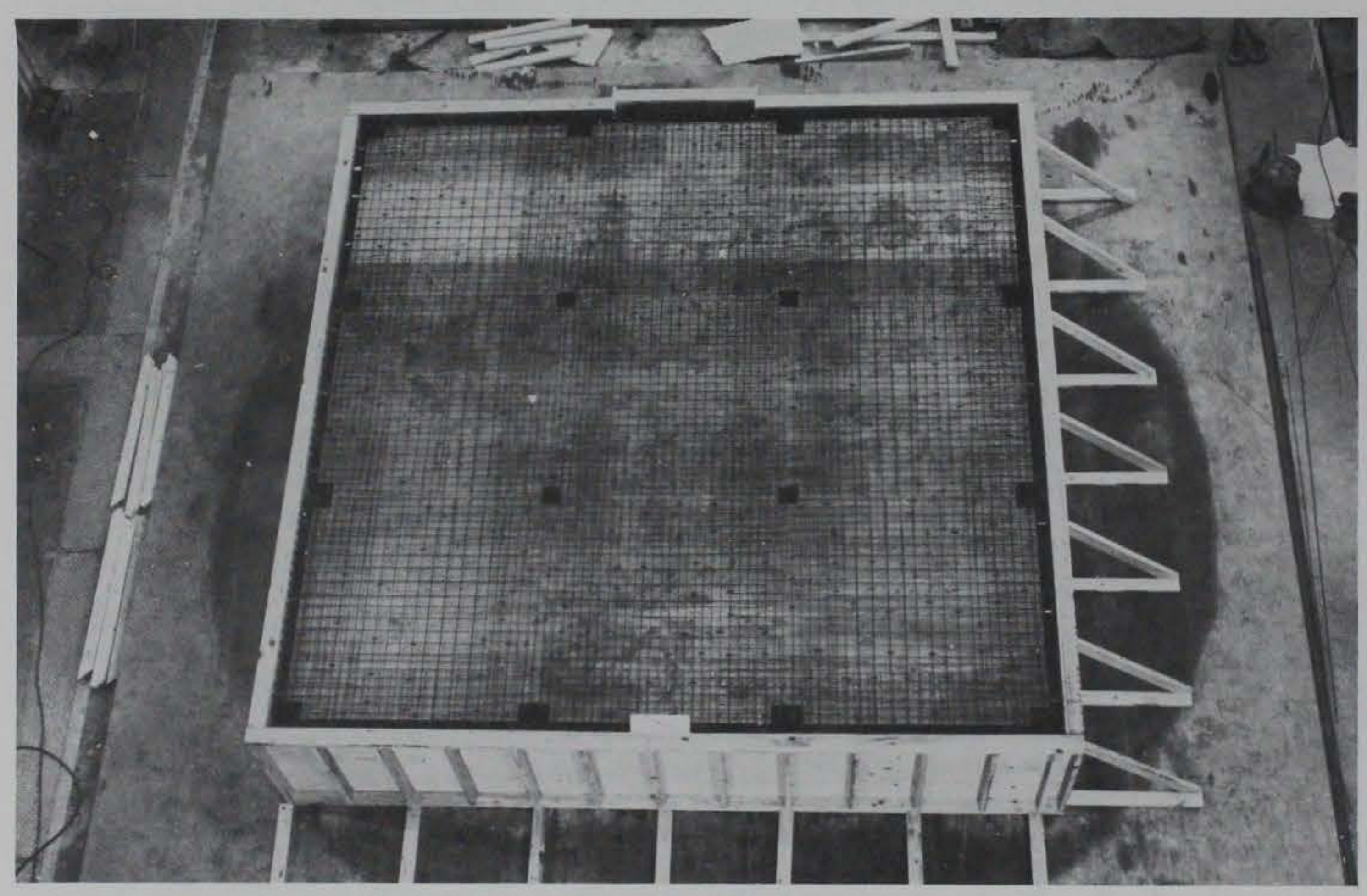

Figure 3.10 Completed steel placement of flat plate model. 


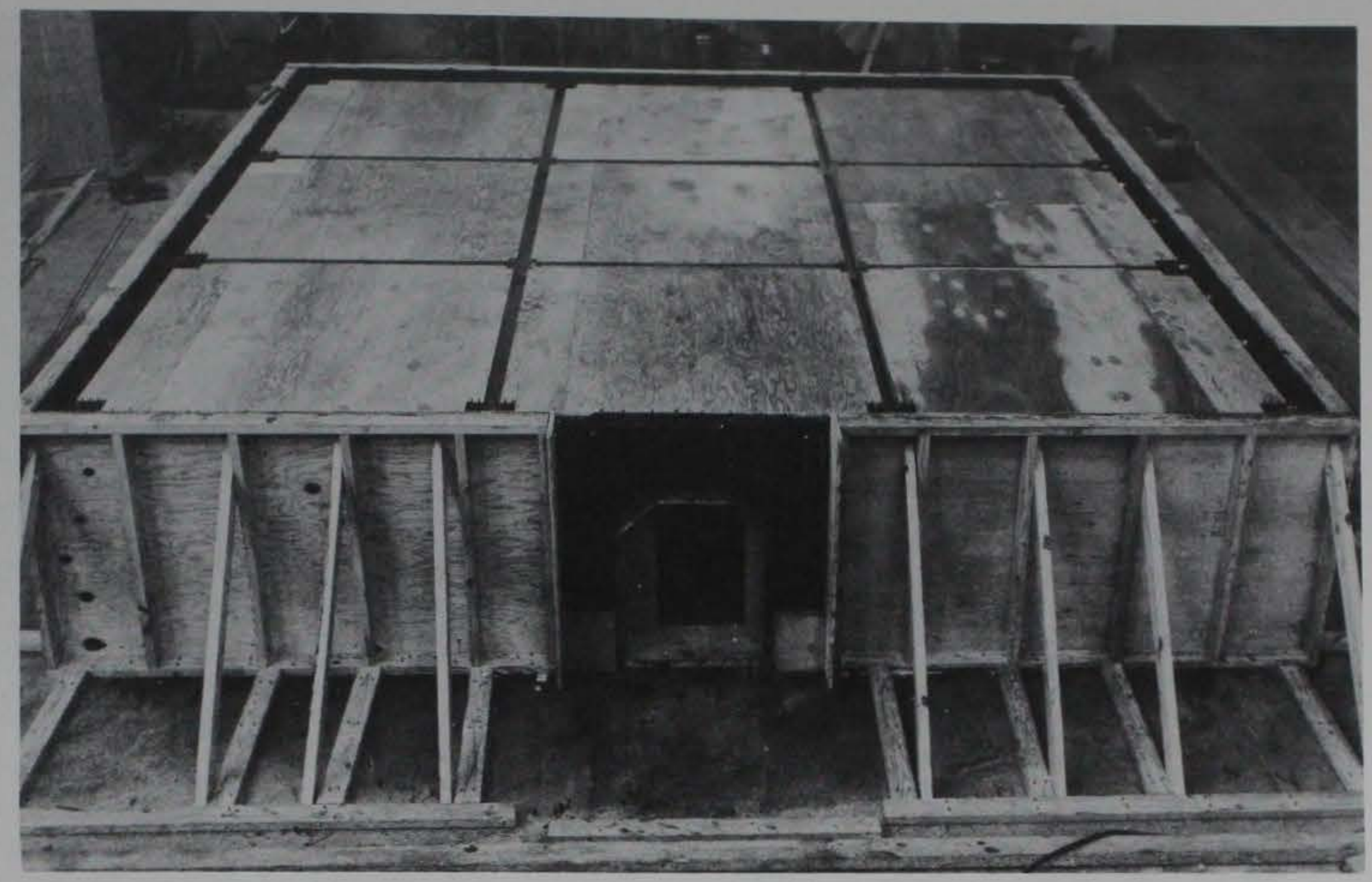

Figure 3.11 Two-way slab with beams model (wall reinforcement in place).

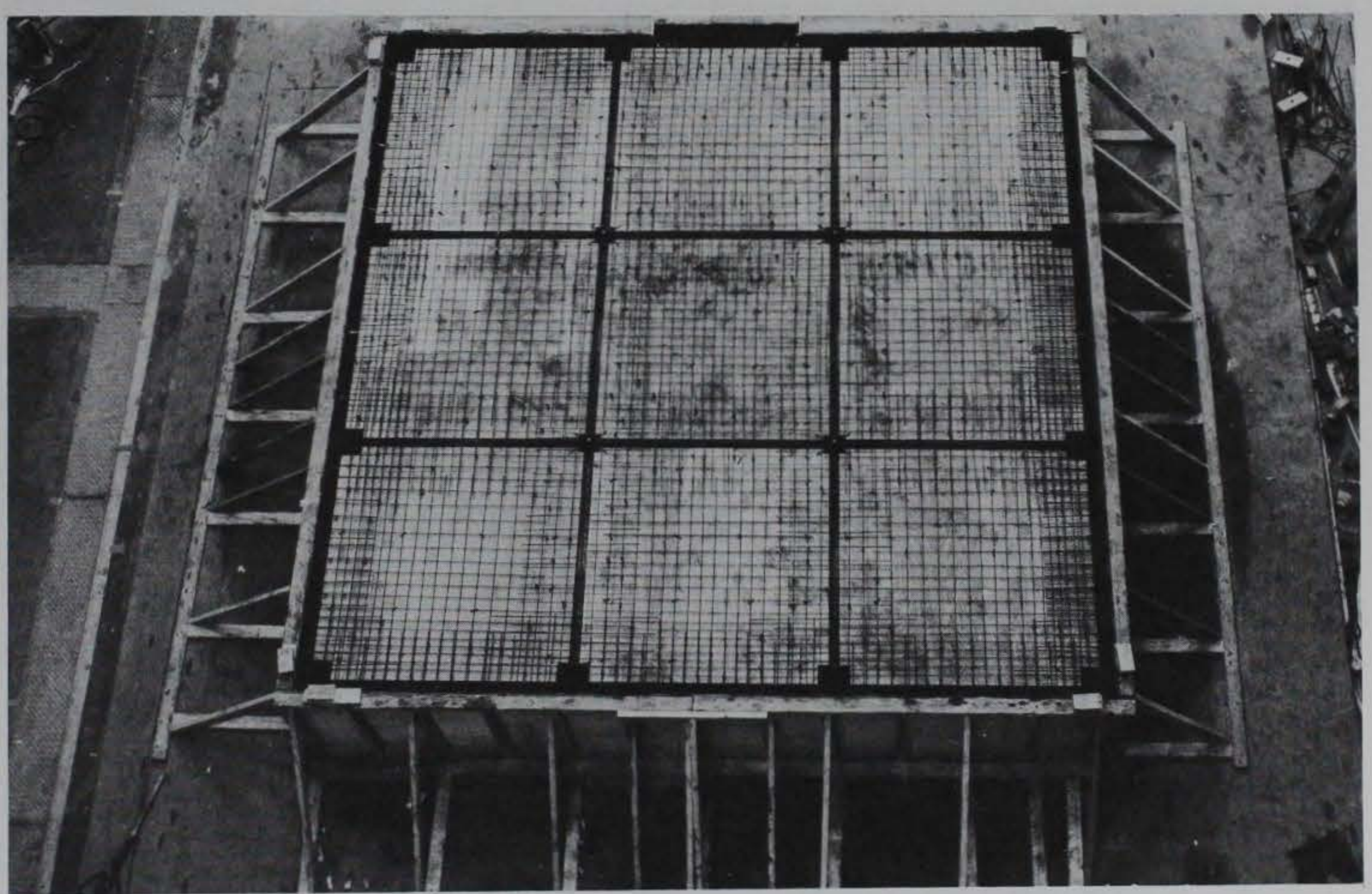

Figure 3.12 Completed steel placement of twoway slab with beams model. 


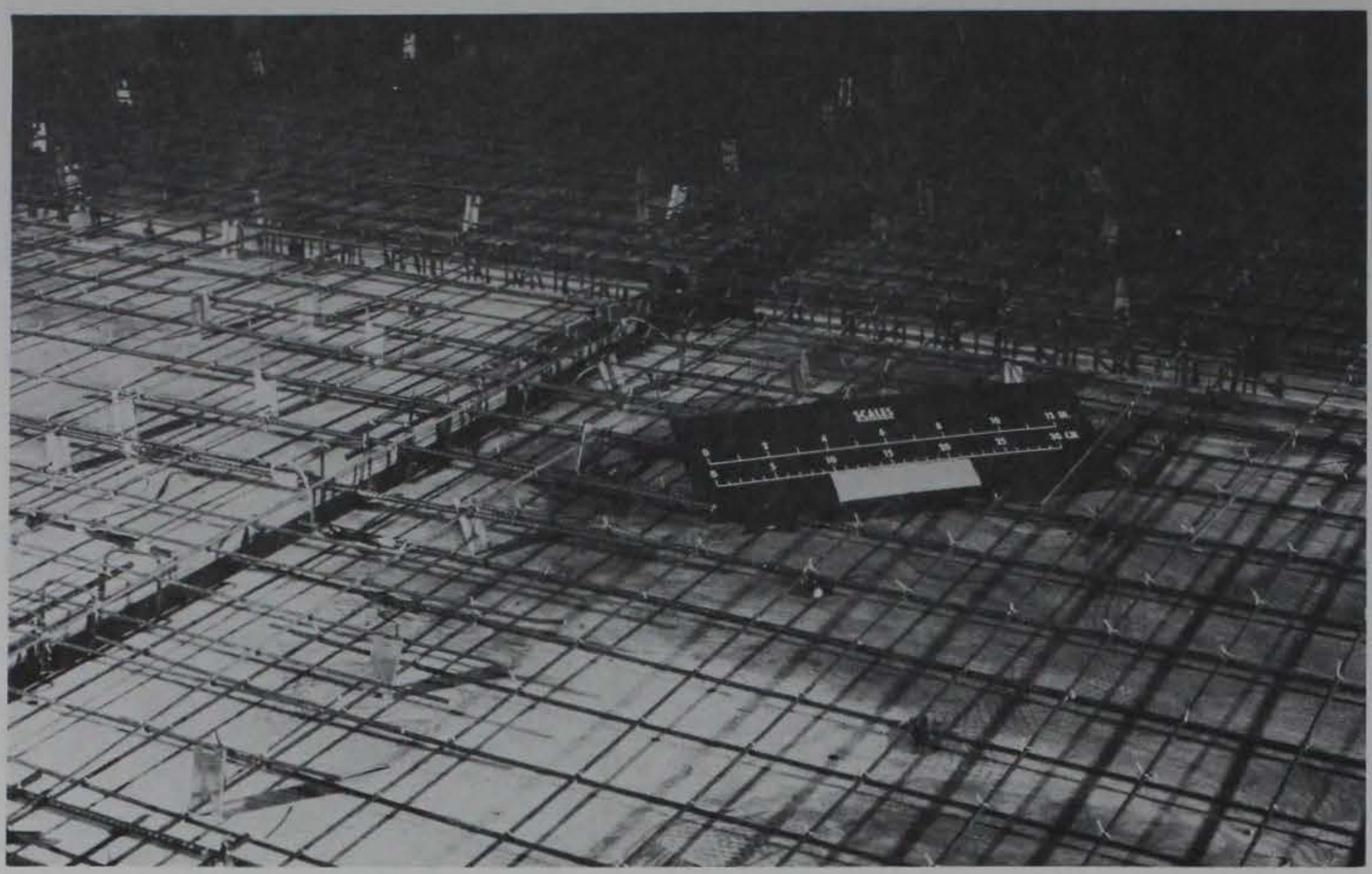

Figure 3.13 View of reinforcement near column area.

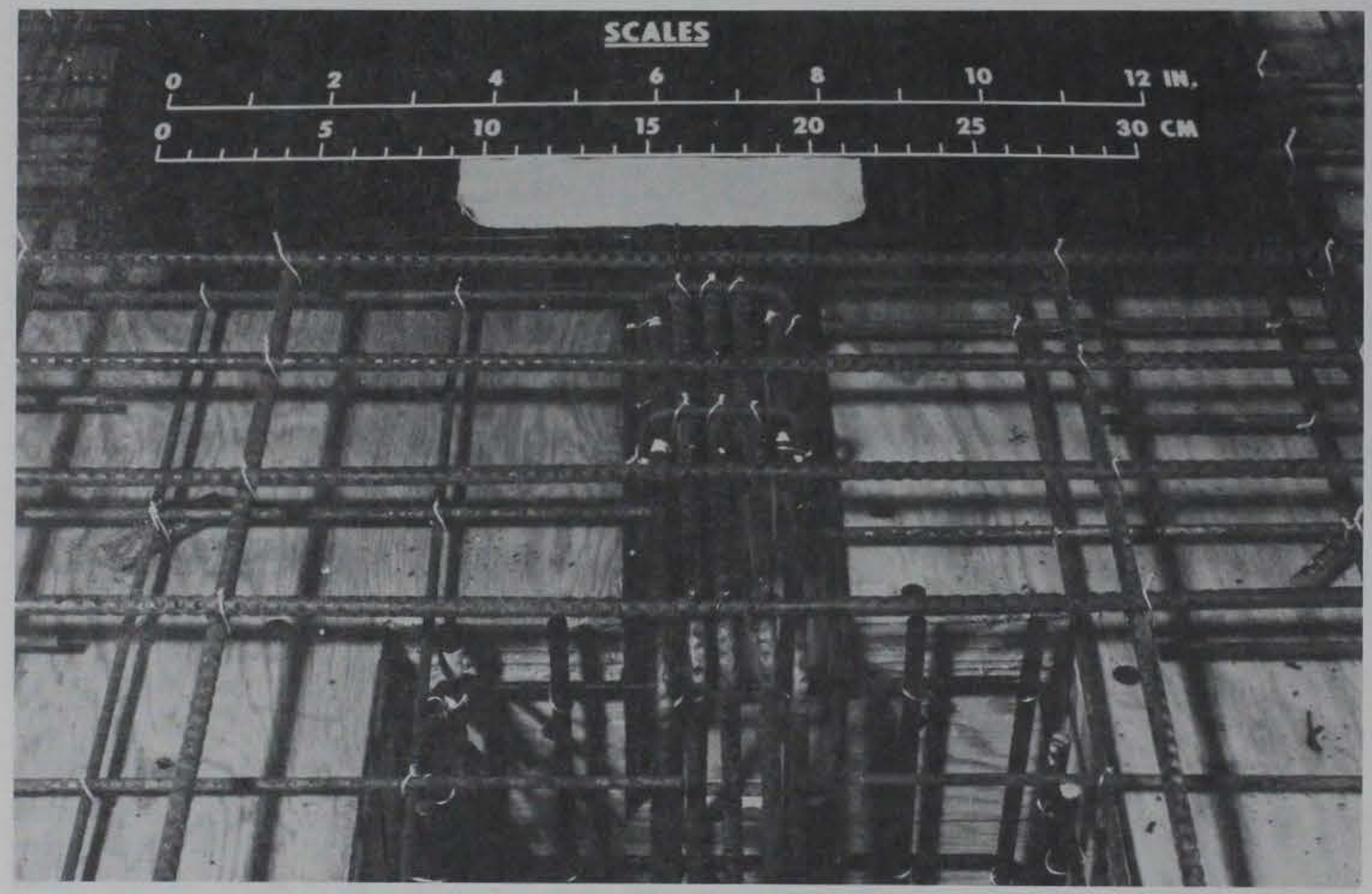

Figure 3.14 Close-up view of beam-column connection. 


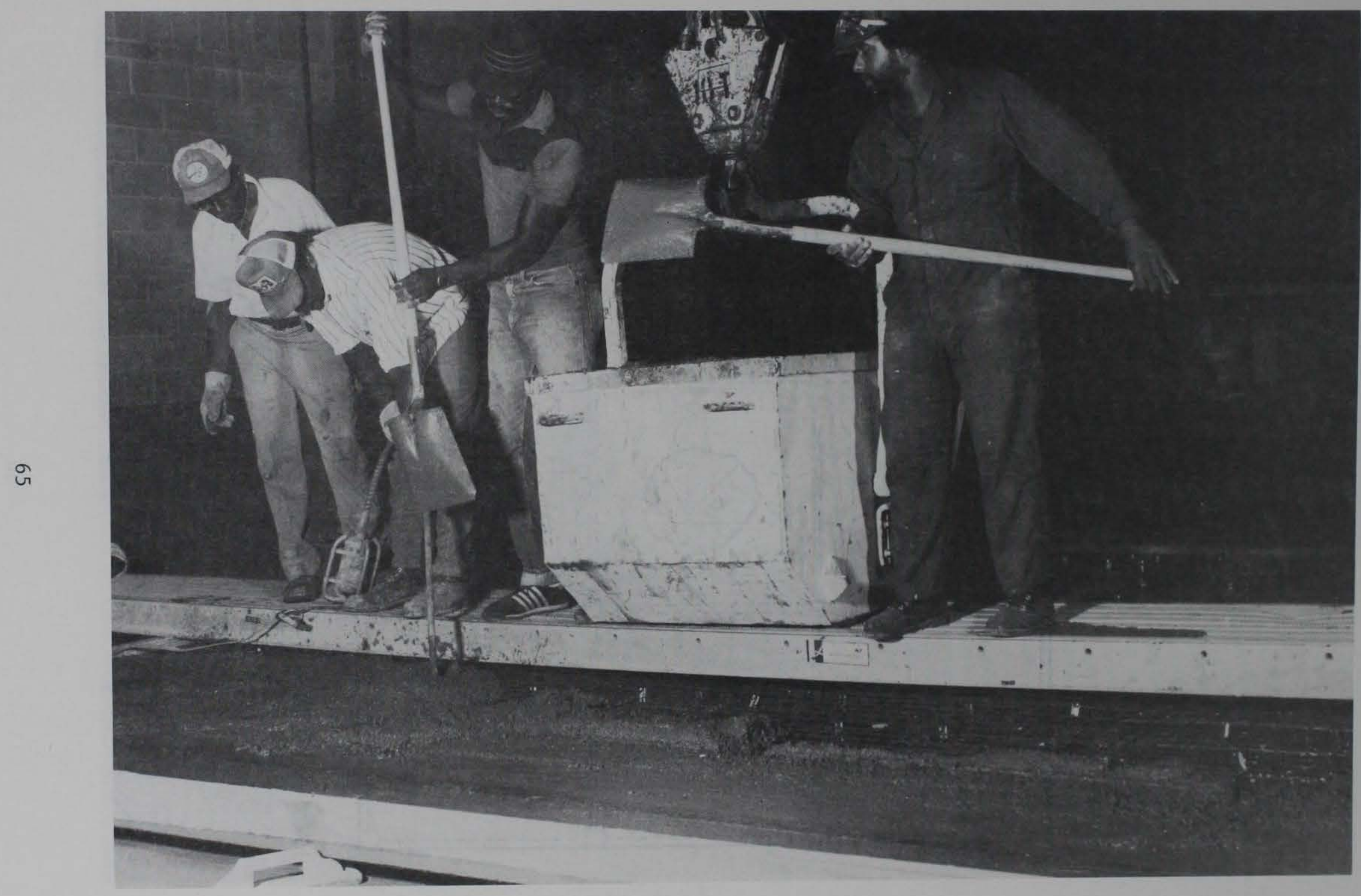

Figure 3.15 Casting the flat plate model. 


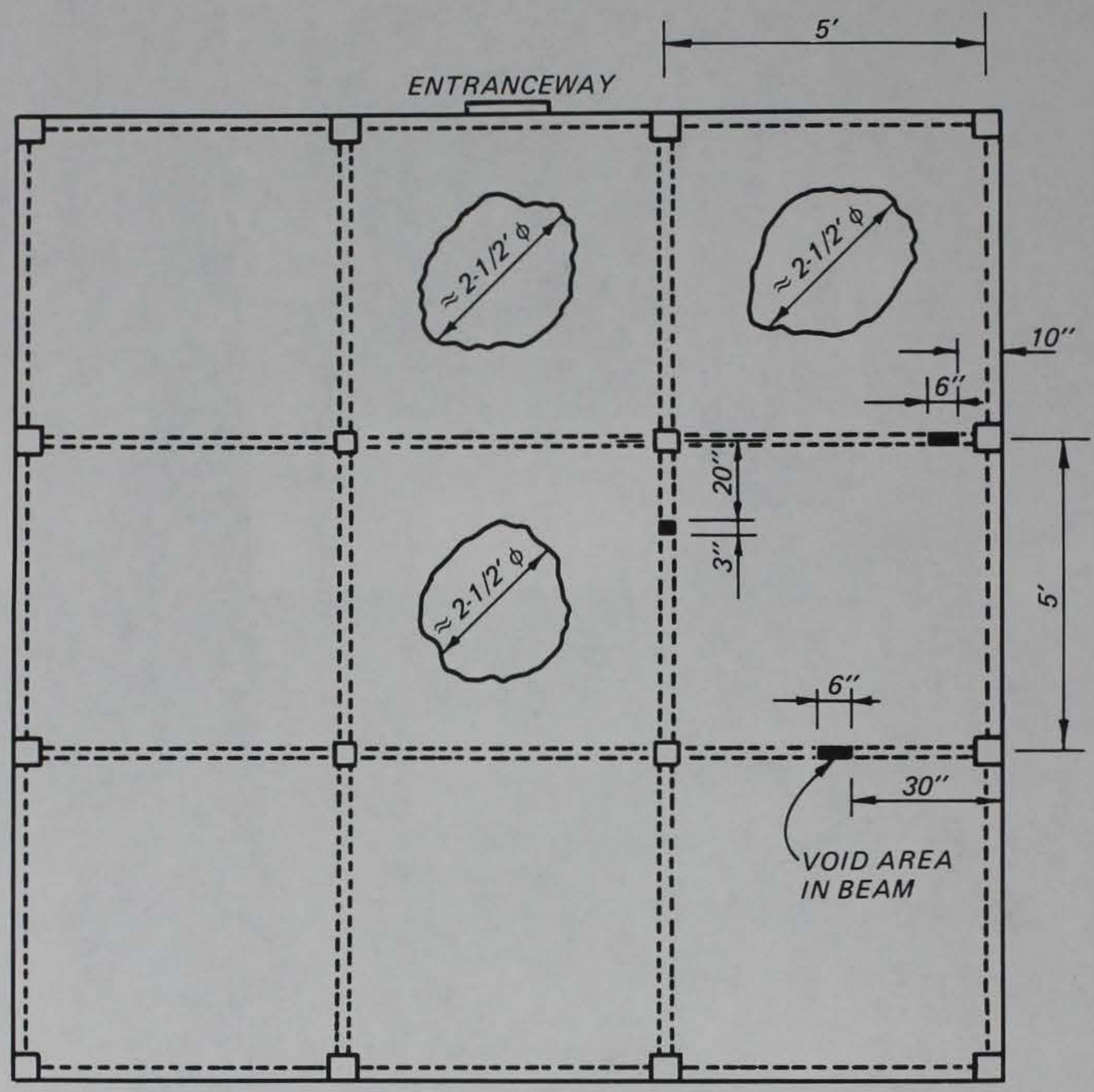

Figure 3.16 Location of voided areas of two-way slab with beams model. 


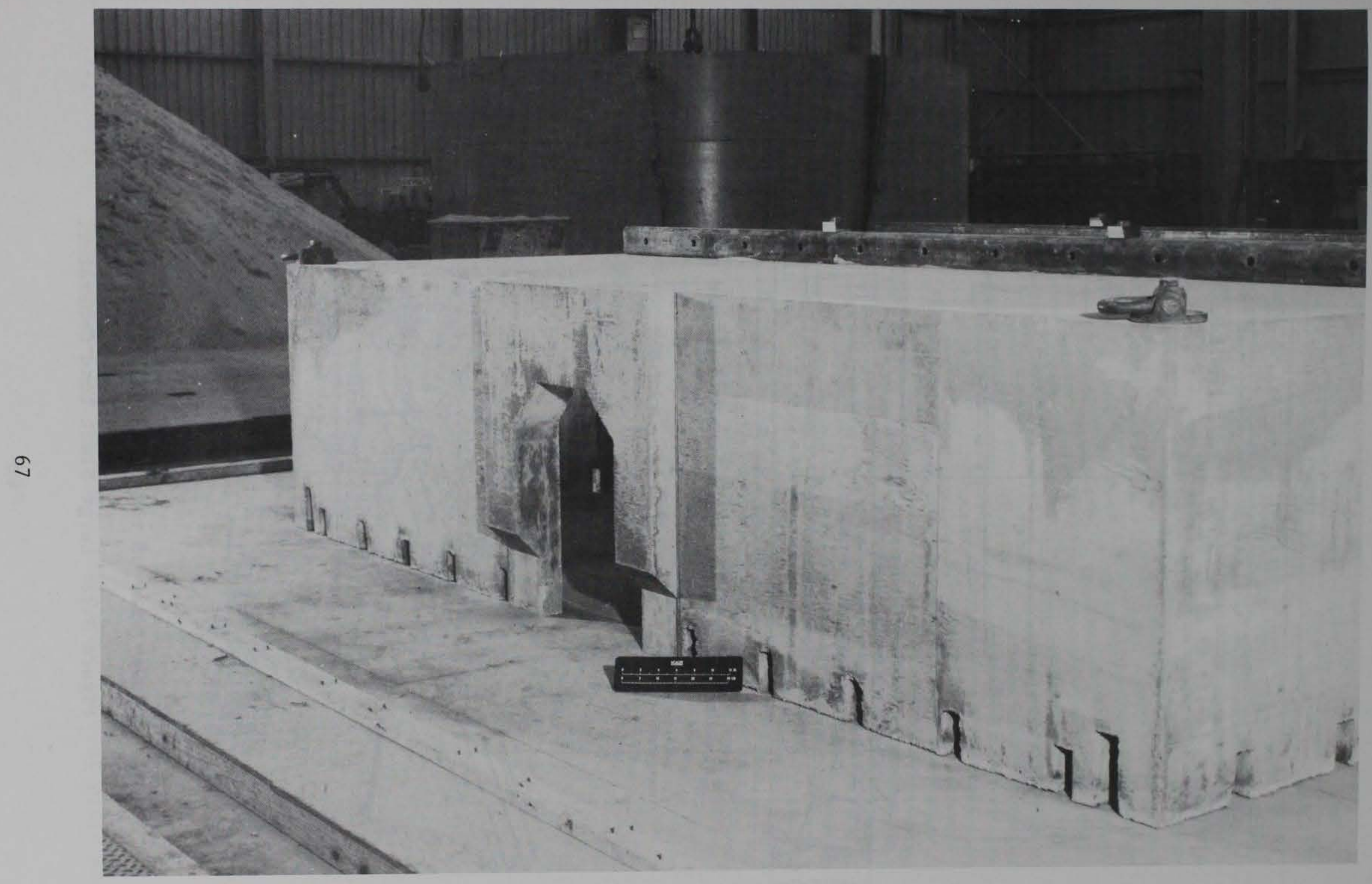

Figure 3.17 Model with structural tubing sections in place. 


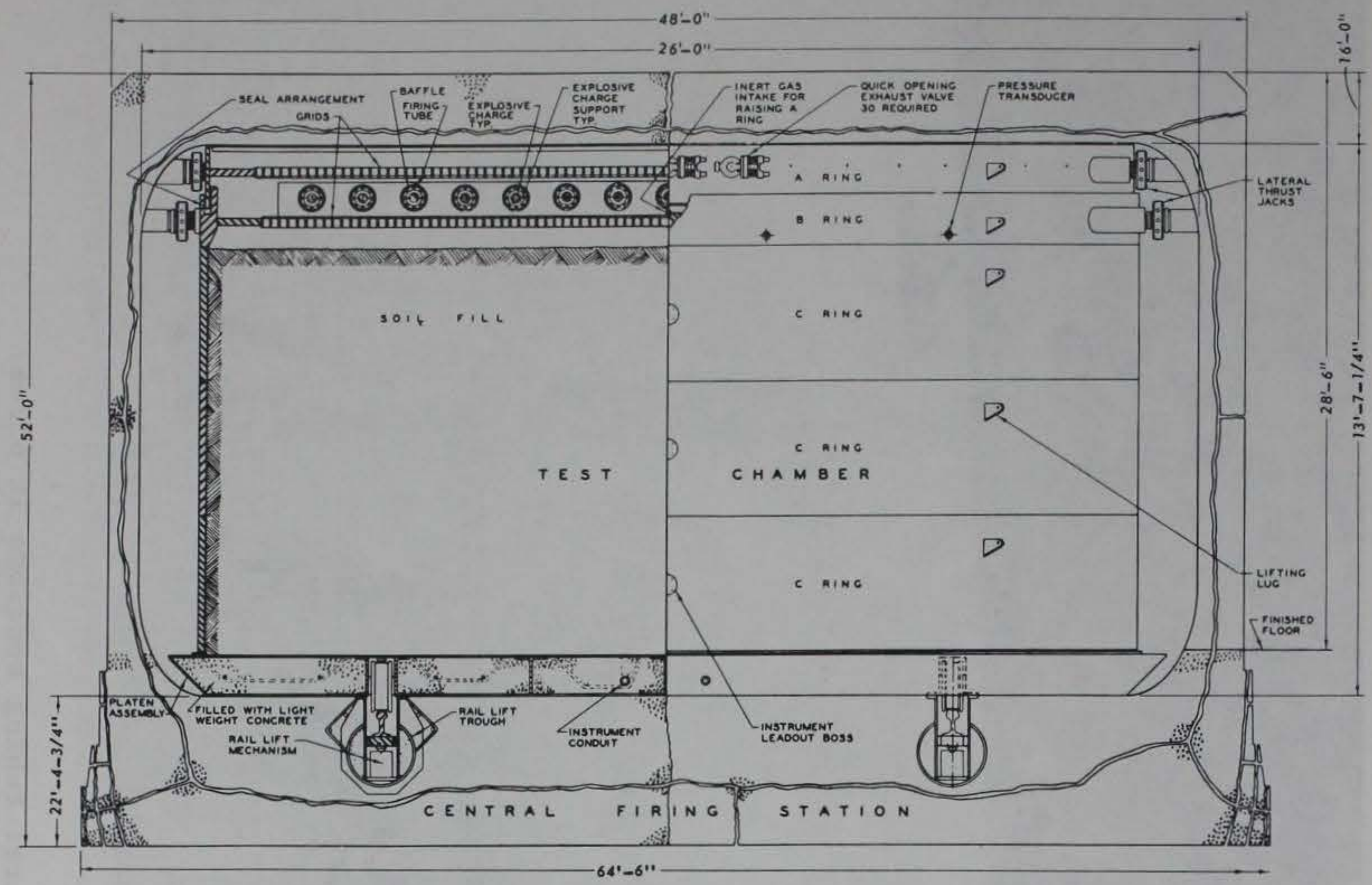

a. Half-section of the Large Blast Load Generator.

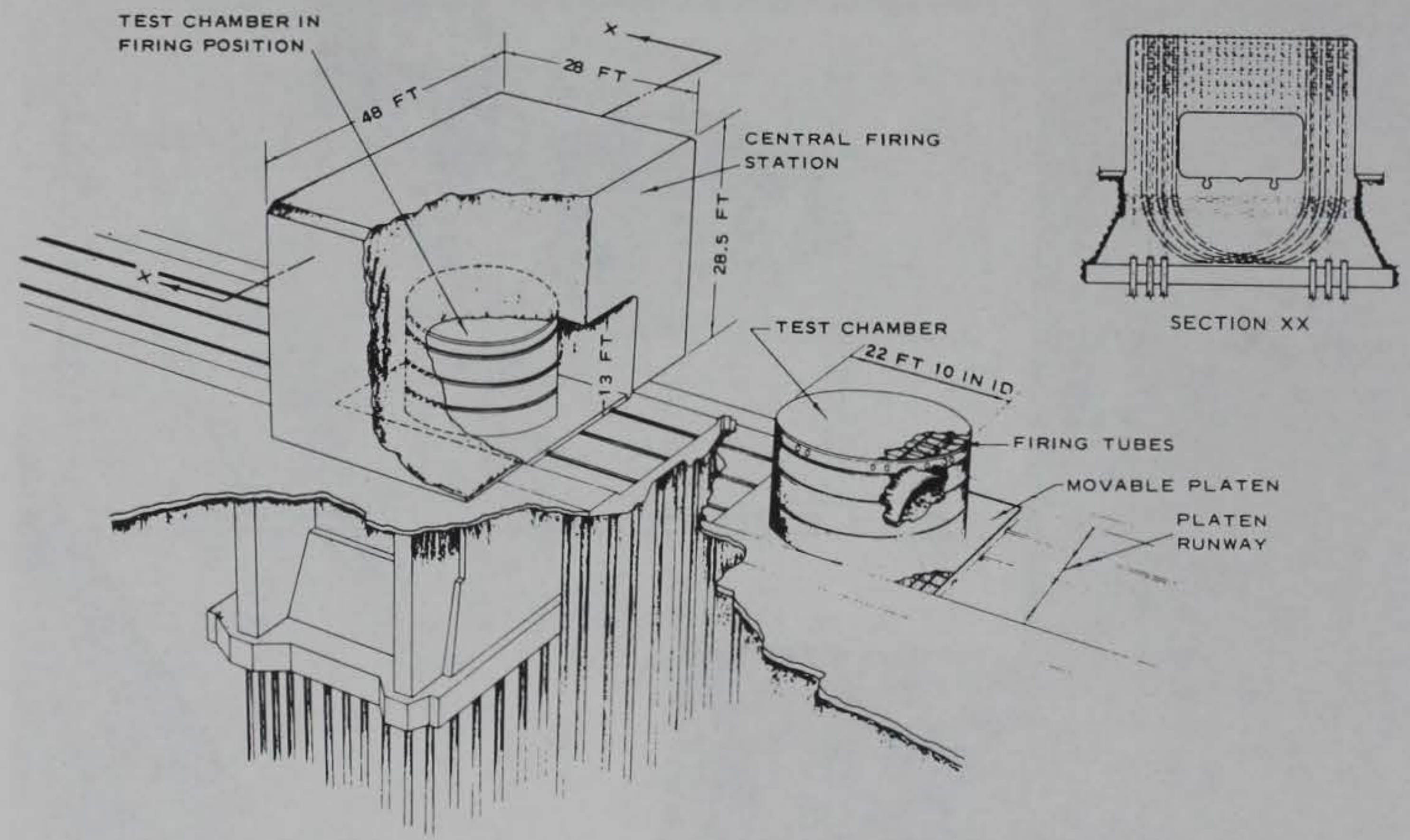

b. Cutaway view of the Large Blast Load Generator.

Figure 3.18 Large Blast Load Generator. 


\section{LEGEND}

-- - $4 \times 4$ (3-1/2" × 3-1/2") UPGRADING POST (SPACED @ 15" O.C.)

D-- CONCRETE COLUMN

- - DEFLECTION GAGE

--- SOIL STRESS GAGE

--- INTERFACE PRESSURE GAGE

I---- STRAIN GAGE

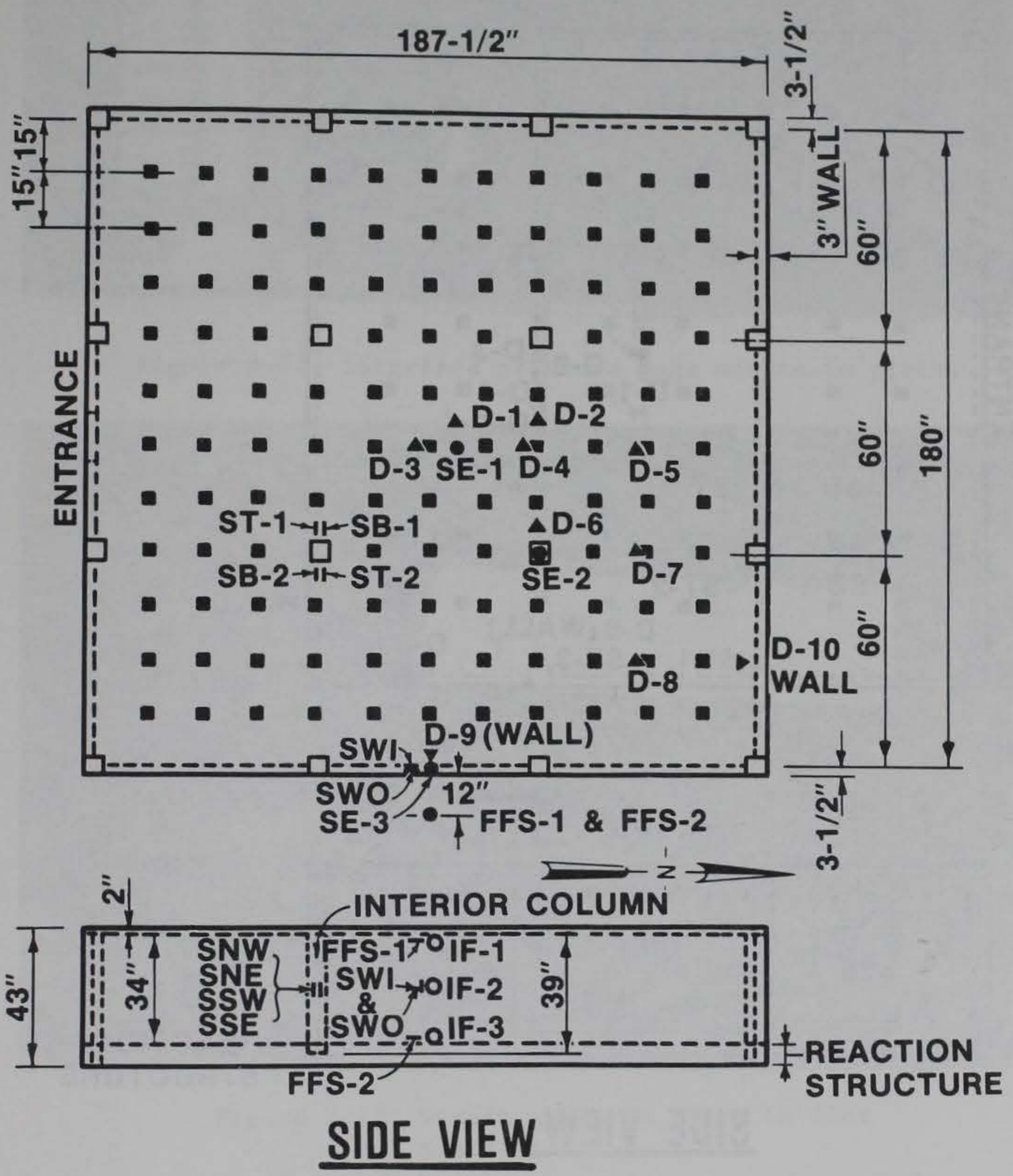

Figure 3.19 Instrumentation and upgrading layout of flat plate model. 


\section{LEGEND}

-- $4 \times 4\left(3-1 / 2 " \times 3-1 / 2^{\prime \prime}\right)$ UPGRADING POST (SPACED @ 20" O.C.)

D- - CONCRETE COLUMN

- - - DEFLECTION GAGE

- - - - SOIL STRESS GAGE

- -- -- INTERFACE PRESSURE GAGE

I-- -- STRAIN GAGE
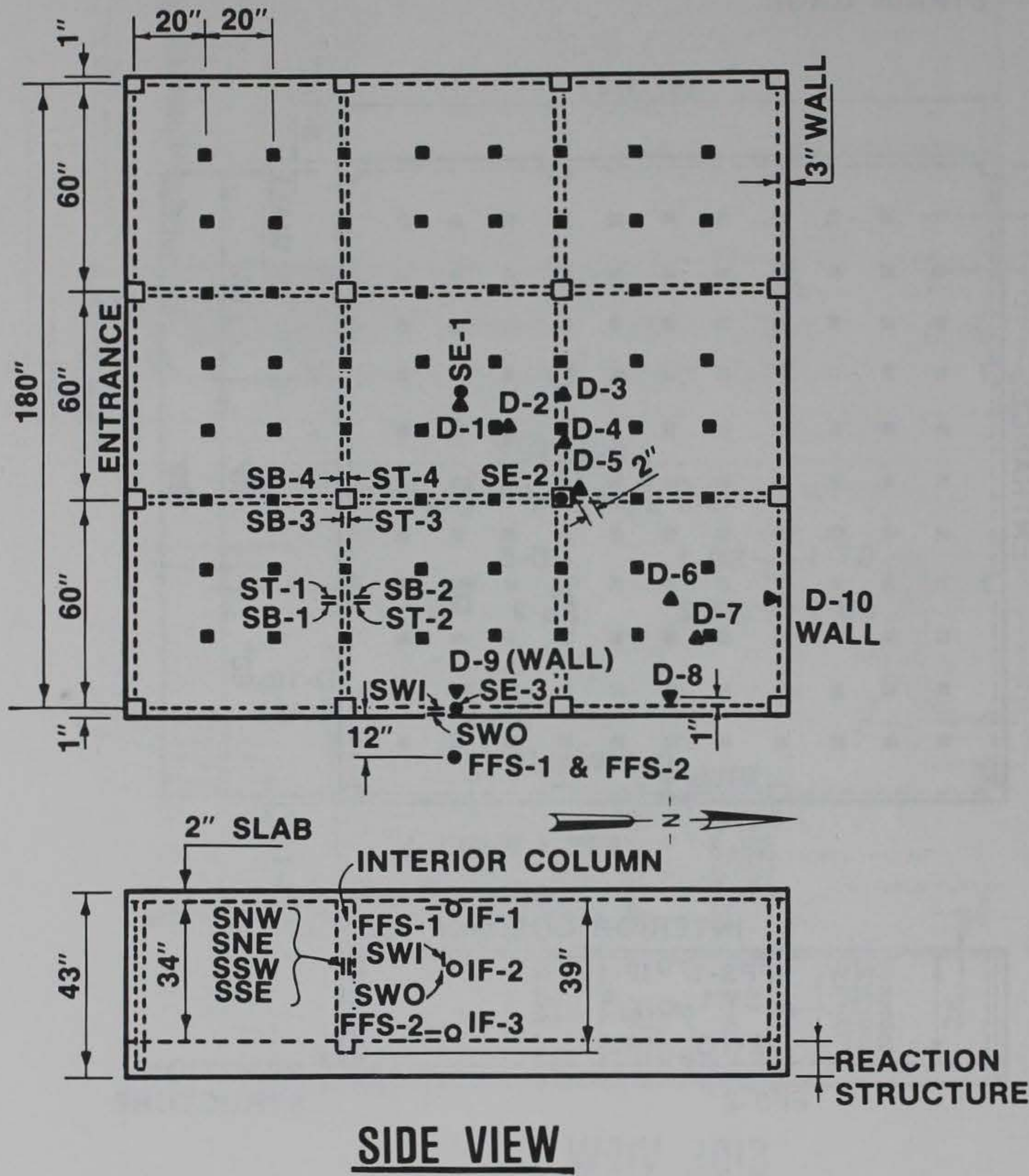

Figure 3.20 Instrumentation and upgrading layout of two-way slab with beams model. 


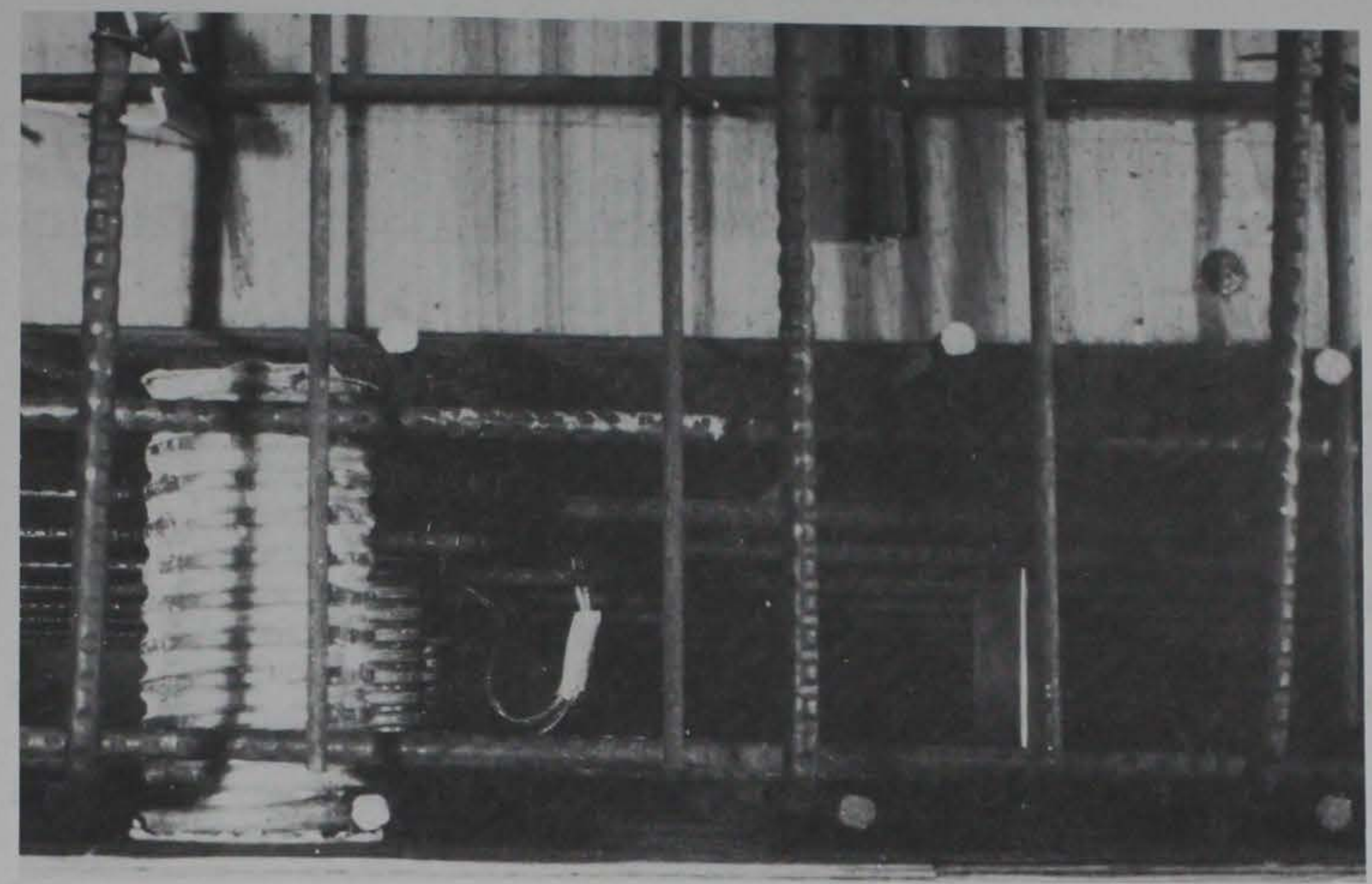

Figure 3.21 Interface pressure gage mounts in place.

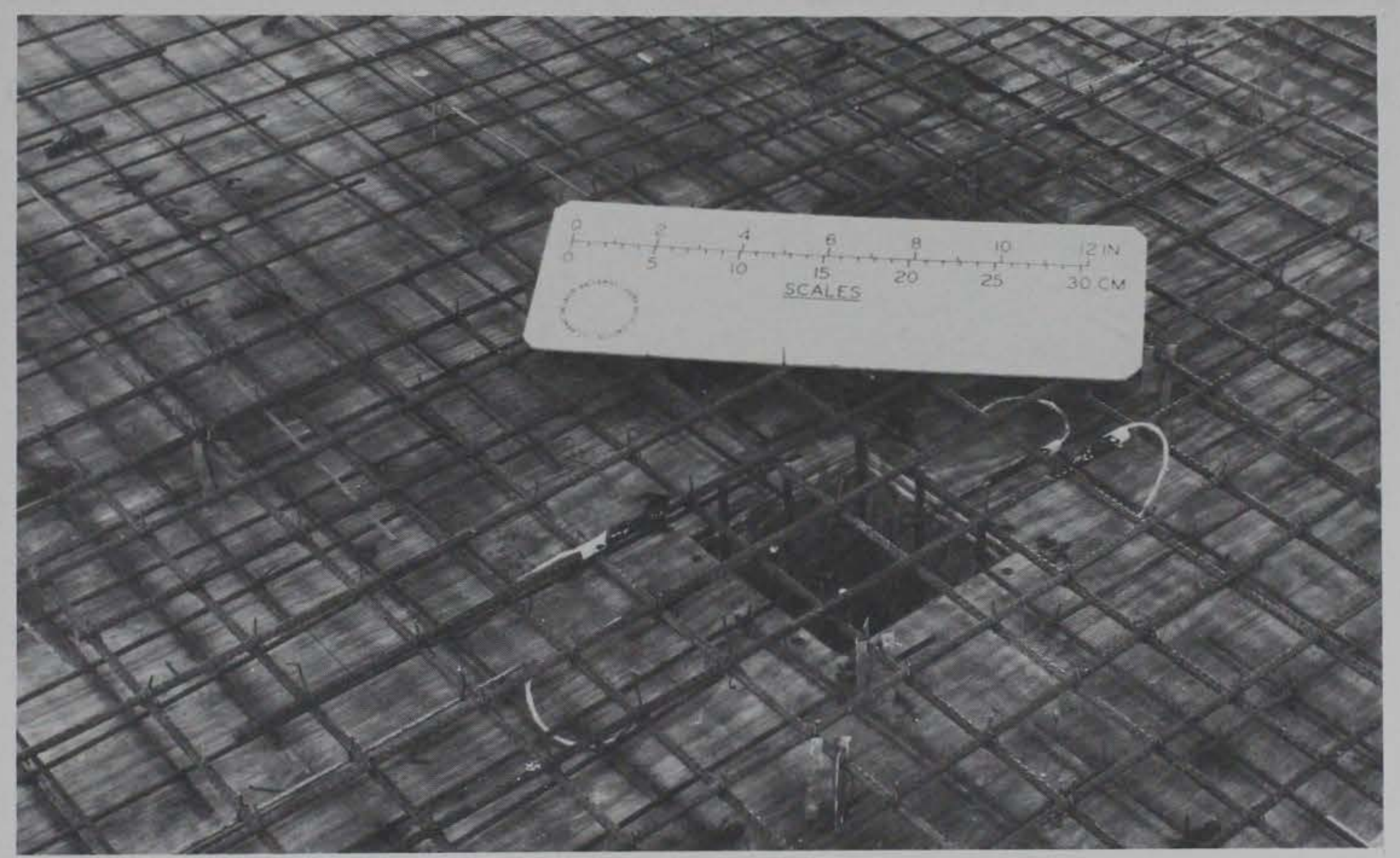

Figure 3.22 Strain gages in place in flat plate slab. 
Table 3.1 Results of Concrete Cylinder Tests

for Flat Plate Model

\begin{tabular}{|c|c|c|c|}
\hline $\begin{array}{c}\text { Concrete } \\
\text { Batch } \\
\end{array}$ & $\begin{array}{l}\text { Age, * } \\
\text { days }\end{array}$ & $\begin{array}{l}\text { Compressive } \\
\text { Strength, psi } \\
\end{array}$ & $\begin{array}{c}\text { Splitting } \\
\text { Tensile } \\
\text { Strength, psi } \\
\end{array}$ \\
\hline 1 & $\begin{array}{r}28 \\
124\end{array}$ & $\begin{array}{l}3500 \\
3960\end{array}$ & \\
\hline 2 & $\begin{array}{r}28 \\
124\end{array}$ & $\begin{array}{l}3520 \\
4050\end{array}$ & \\
\hline 3 & $\begin{array}{r}7 \\
124\end{array}$ & $\begin{array}{l}2870 \\
3960\end{array}$ & \\
\hline 4 & $\begin{array}{r}28 \\
124\end{array}$ & $\begin{array}{l}3550 \\
4210\end{array}$ & \\
\hline 5 & $\begin{array}{l}124 \\
124\end{array}$ & 4090 & 365 \\
\hline 6 & $\begin{array}{l}124 \\
124\end{array}$ & 3960 & 365 \\
\hline 7 & $\begin{array}{l}124 \\
124\end{array}$ & 4120 & 360 \\
\hline 8 & $\begin{array}{l}124 \\
124\end{array}$ & 4170 & 390 \\
\hline 9 & $\begin{array}{l}124 \\
124\end{array}$ & 4000 & 340 \\
\hline
\end{tabular}

* 124-day age corresponds to structure's test date. 
Table 3.2 Results of Concrete Cylinder Tests

for Two-way Slab with Beams Model

\begin{tabular}{|c|c|c|c|}
\hline $\begin{array}{c}\text { Concrete } \\
\text { Batch } \\
\end{array}$ & $\begin{array}{l}\text { Age,* } \\
\text { days }\end{array}$ & $\begin{array}{l}\text { Compressive } \\
\text { Strength, psi } \\
\end{array}$ & $\begin{array}{c}\text { Splitting } \\
\text { Tensile } \\
\text { Strength, psi } \\
\end{array}$ \\
\hline 1 & $\begin{array}{r}7 \\
84\end{array}$ & $\begin{array}{l}2900 \\
4320\end{array}$ & \\
\hline 2 & $\begin{array}{l}28 \\
84\end{array}$ & $\begin{array}{l}3660 \\
4260\end{array}$ & \\
\hline 3 & $\begin{array}{l}28 \\
84\end{array}$ & $\begin{array}{l}3590 \\
4050\end{array}$ & \\
\hline 4 & $\begin{array}{l}28 \\
84\end{array}$ & $\begin{array}{l}3910 \\
4210\end{array}$ & \\
\hline 5 & $\begin{array}{l}84 \\
84\end{array}$ & 4170 & 330 \\
\hline 6 & $\begin{array}{l}84 \\
84\end{array}$ & 4260 & 310 \\
\hline 7 & $\begin{array}{l}84 \\
84\end{array}$ & 4300 & 330 \\
\hline 8 & $\begin{array}{l}84 \\
84\end{array}$ & 4070 & 335 \\
\hline 9 & $\begin{array}{l}84 \\
84\end{array}$ & 3870 & 285 \\
\hline
\end{tabular}

* 84-day age corresponds to structure's test date. 
Table 3.3 Results of Static Tensile Tests on D1 Wire Reinforcement

\begin{tabular}{cc}
\hline Specimen & Yield Stress, psi \\
\cline { 2 - 2 } 1 & 66,800 \\
2 & 66,600 \\
3 & 67,920 \\
4 & 72,300 \\
5 & 75,700 \\
\hline
\end{tabular}




\section{EXPERIMENTAL RESULTS}

The results of the tests are presented in this chapter and in the appendix. A general description of the data produced and of the performance of each specimen and accompanying instrumentation is presented herein. Further discussion and analyses of the results are presented in Chapter 5.

\subsection{FLAT PLATE MODEL}

Recorded data from the flat plate model test are presented in Appendix A.

The model was statically loaded with water pressure until the maximum pressure attainable from the commercial water line was reached at approximately 79 psi. Figure 4.1 is an overhead view of the flat plate model in the LBLG with the water-sealing membranes and soil cover removed. The cracks are darkened with black markers for photographic purposes. Figure 4.1 also shows cracking and punching results at the four interior concrete column locations. Yield lines formed along the walls and exterior columns, and results of shearing action can be seen along the wall in the bottom right corner of Figure 4.1. A yield line also formed along a row of upgrading columns in the bottom right panel as seen in Figure 4.1 .

Positive bending moment yield line cracks formed on the undersurface of the flat plate model. Figure 4.2 shows the general pattern of the yield line formations on the undersurface of the model slab, as indicated by the broken lines. A photographic view of the yield line cracks is shown in Figure 4.3. Figure 4.3 also shows the underside of the corner where shear failure occurred as marked in the top view of Figure 4.1. The photograph in Figure 4.3 was taken after the removal of a row of upgrading columns that was positioned halfway between the row of upgrading columns shown and the wall. Therefore, the marked yield line formed at midspan between the upgrading columns shown and the removed row. The shear failure which occurred along the wall can be seen in Figure 4.3.

Figure 4.4 is a typical close-up view of the results of the punching shear that occurred at the interior columns. Figure 4.5 shows that the wooden upgrading columns did not punch into the flat plate slab. However, the 
upgrading columns did compress the wooden wedges beneath the columns as shown in the posttest view of wedges in Figure 4.6 .

\subsection{TWO-WAY SLAB WITH BEAMS MODEL}

Recorded data from the two-way slab with beams model test are presented in Appendix B. Figure 4.7 is a posttest overhead view of the model in the LBLG after removal of the soil cover. The photograph shows the ruptured area that caused a sudden loss in loading pressure and termination of the test. Also shown in Figure 4.7 are numerous yield lines, most of which occurred along beam lines. Positive bending moment yield line cracks formed on the undersurface of the model slab. Figure 4.8 shows the general pattern of the yield line formations on the undersurface as indicated by the broken lines. A photographic view of a typical yield line is shown in Figure 4.9. The yield line occurred along midspan of the span between two rows of upgrading columns. Figure 4.9 also shows that the wooden columns did not punch into the slab or beams. None of the upgrading columns which remained standing after the test punched into the slab. All of the columns did remain standing except for those directly under the ruptured area and those near the ruptured area that were knocked down by the debris. As shown in Figures 4.8 and 4.10 , a short crack extended diagonally from one of the interior concrete columns.

Figures 4.11 and 4.12 are close-up views of the ruptured area. Figure 4.11 shows some of the concrete debris hanging by reinforcement. Figure 4.12 shows that two sides of the ruptured area were along adjacent beams.

Although the wedges beneath the wooden upgrading columns were compressed during loading, the magnitude of the compression of the wedges was not as great as that of the wedges in the flat plate model test. Figure 4.13 shows a pair of wedges from the two-way slab with beams model test. 


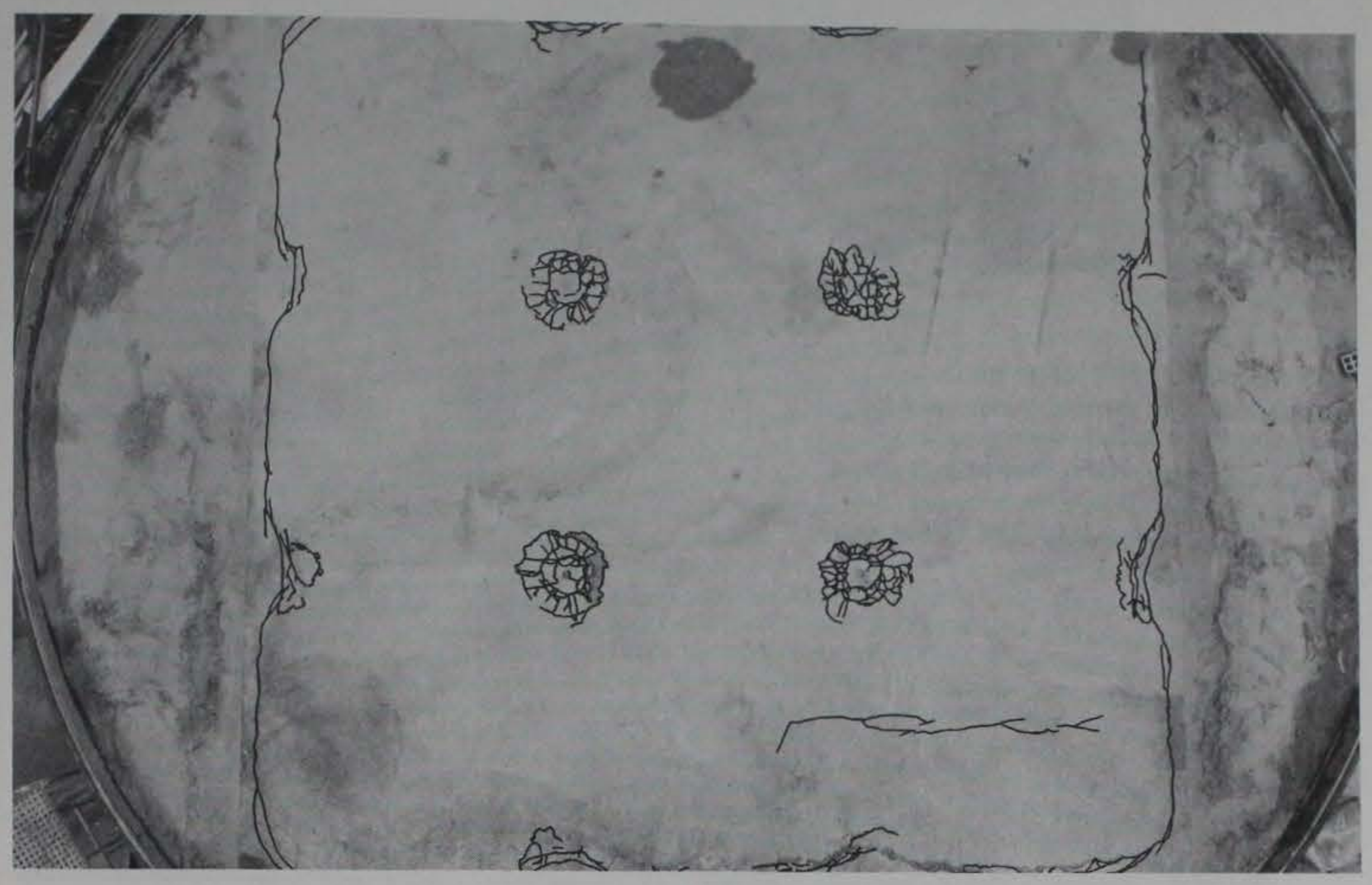

Figure 4.1 Top view of posttest flat plate model.

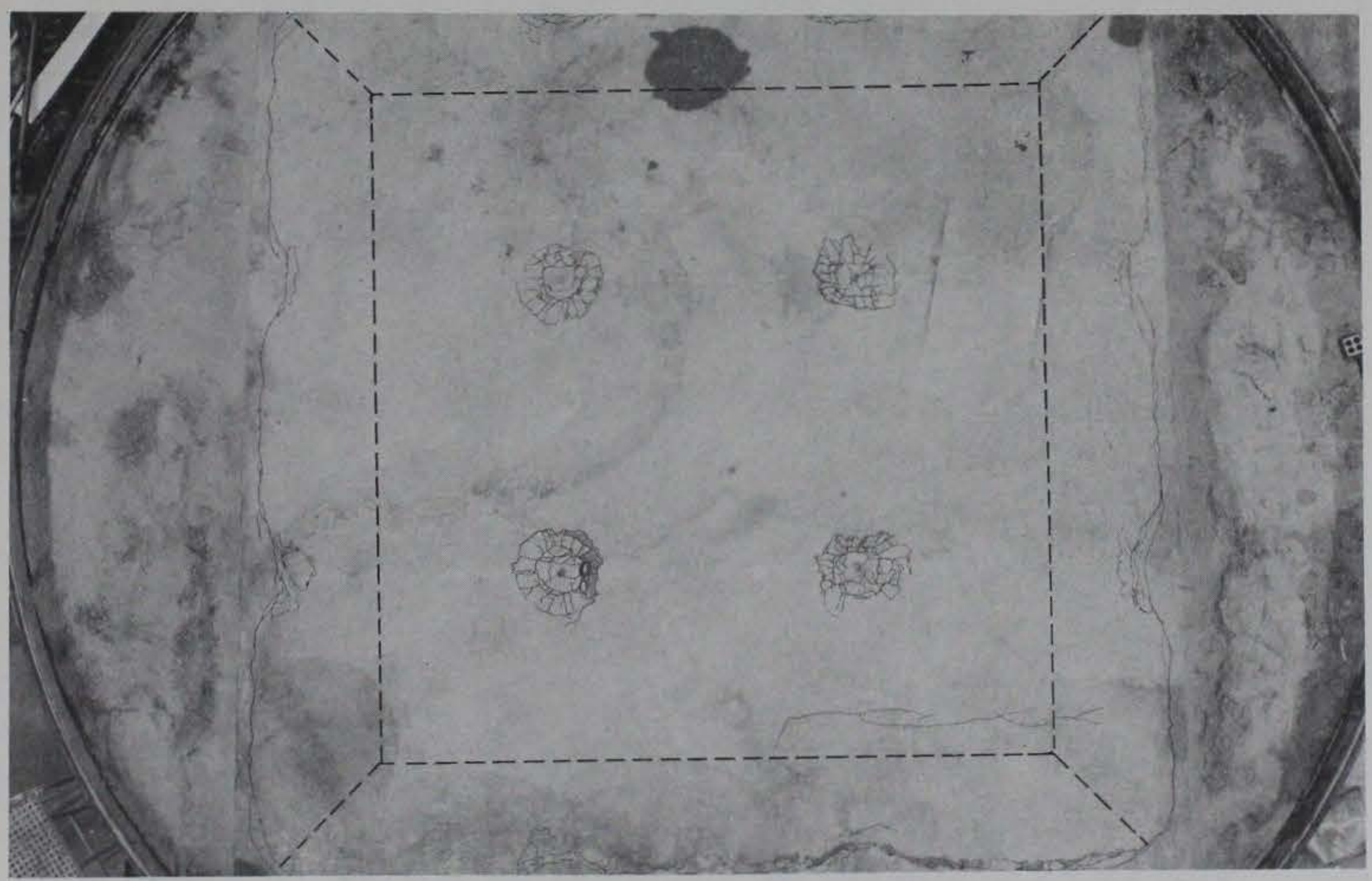

Figure 4.2 General yield line pattern on undersurface of flat plate model slab. 


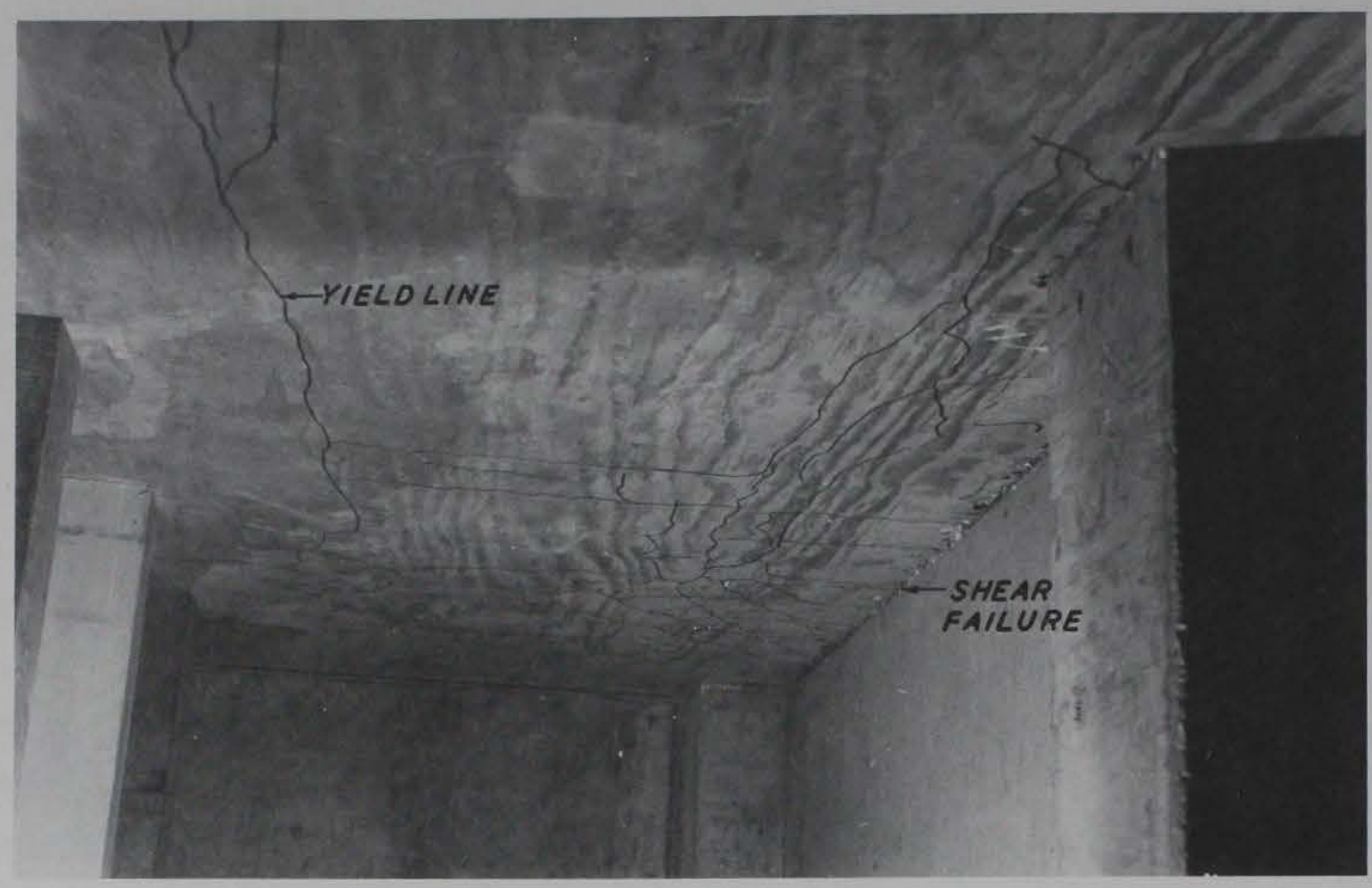

Figure 4.3 Visible yield line cracks and shear results in flat plate model.

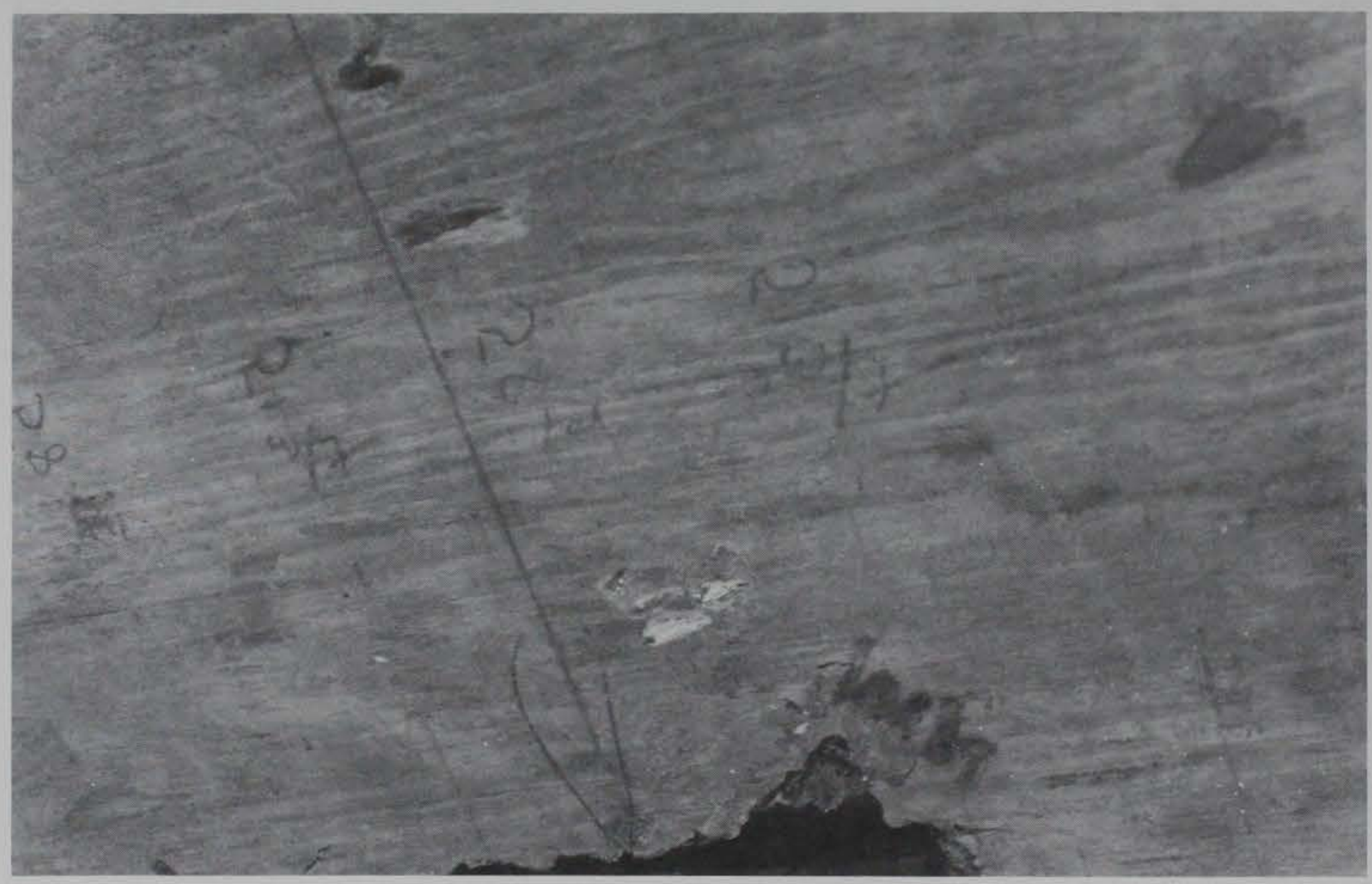

Figure 4.4 Punching shear at interior column. 


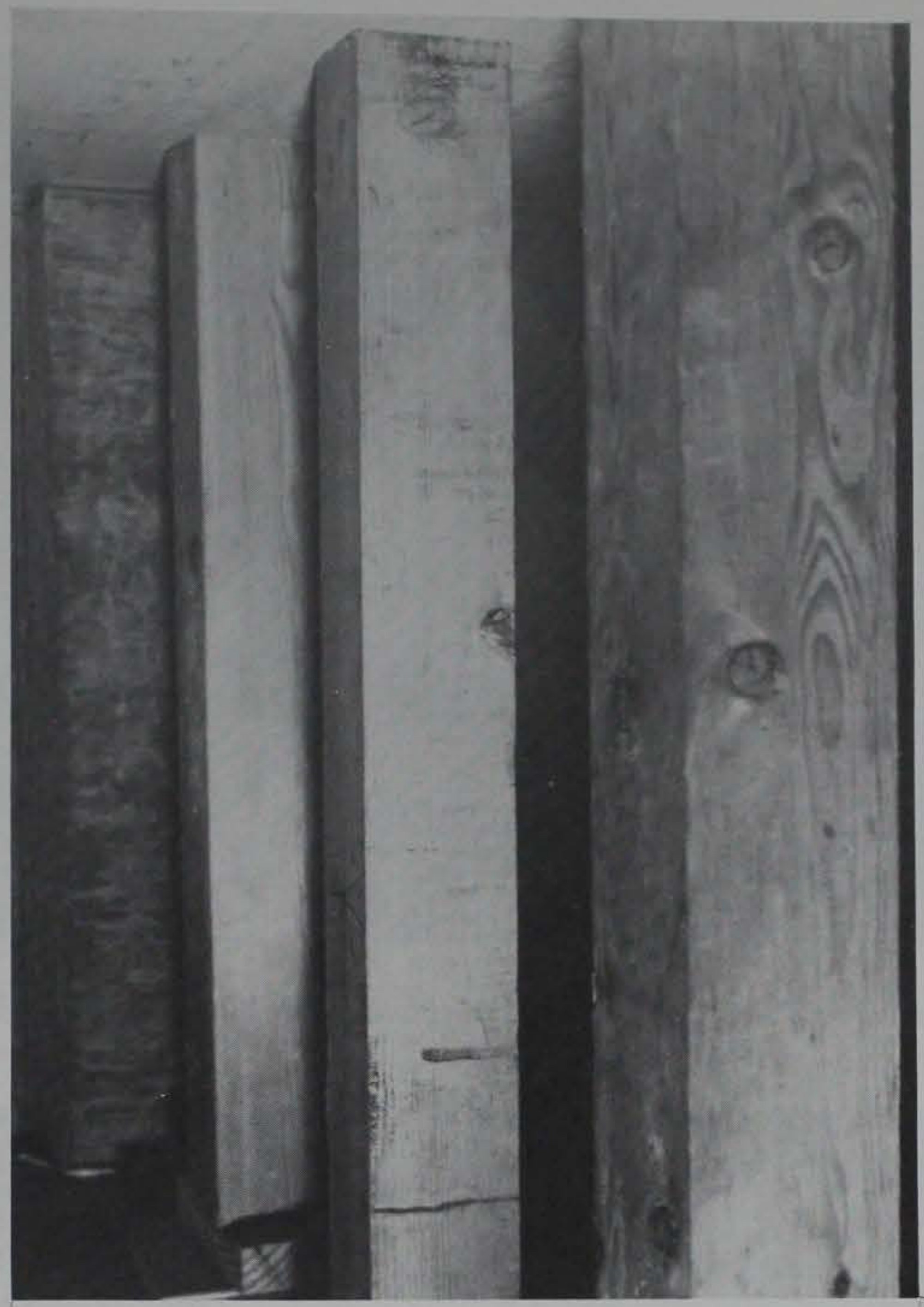

Figure 4.5 Posttest view of upgrading columns in flat plate model.

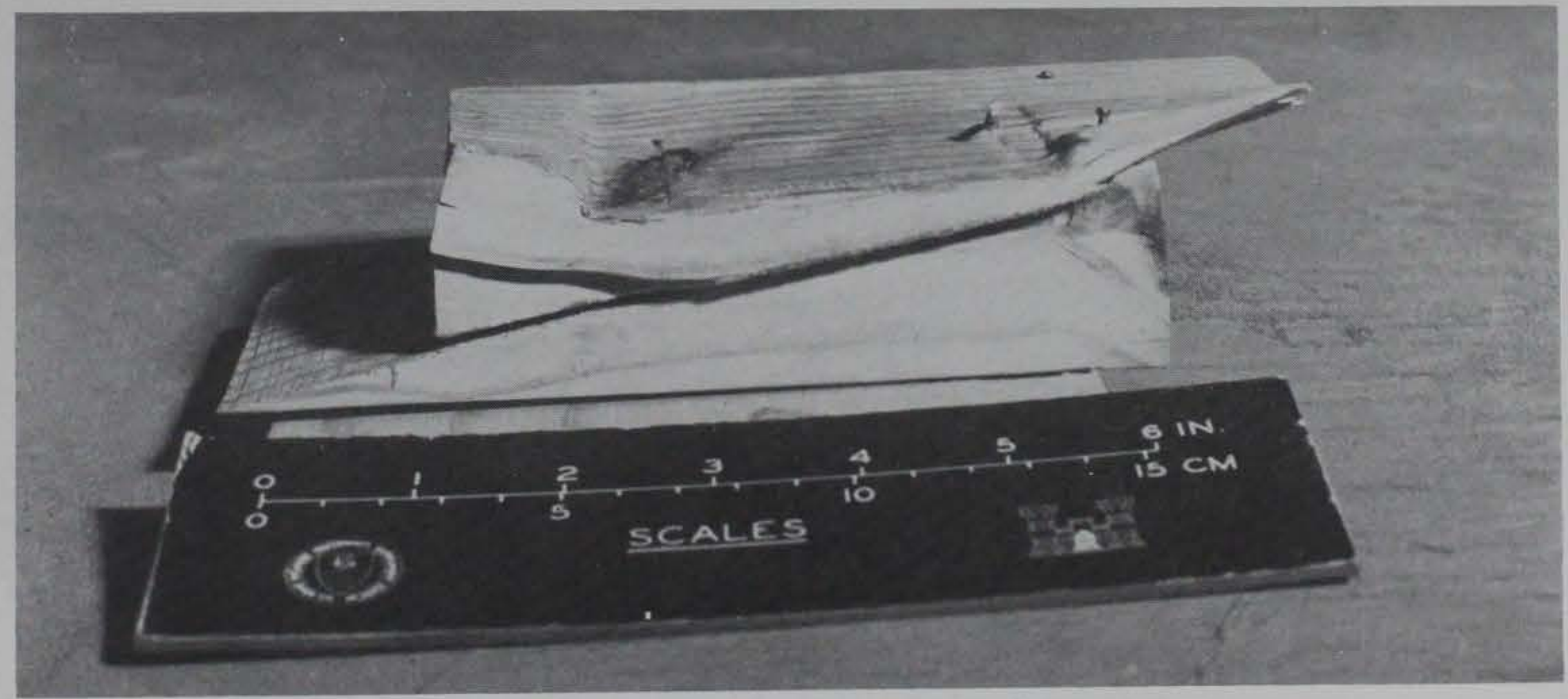

Figure 4.6 Compressed wedges in flat plate model test. 


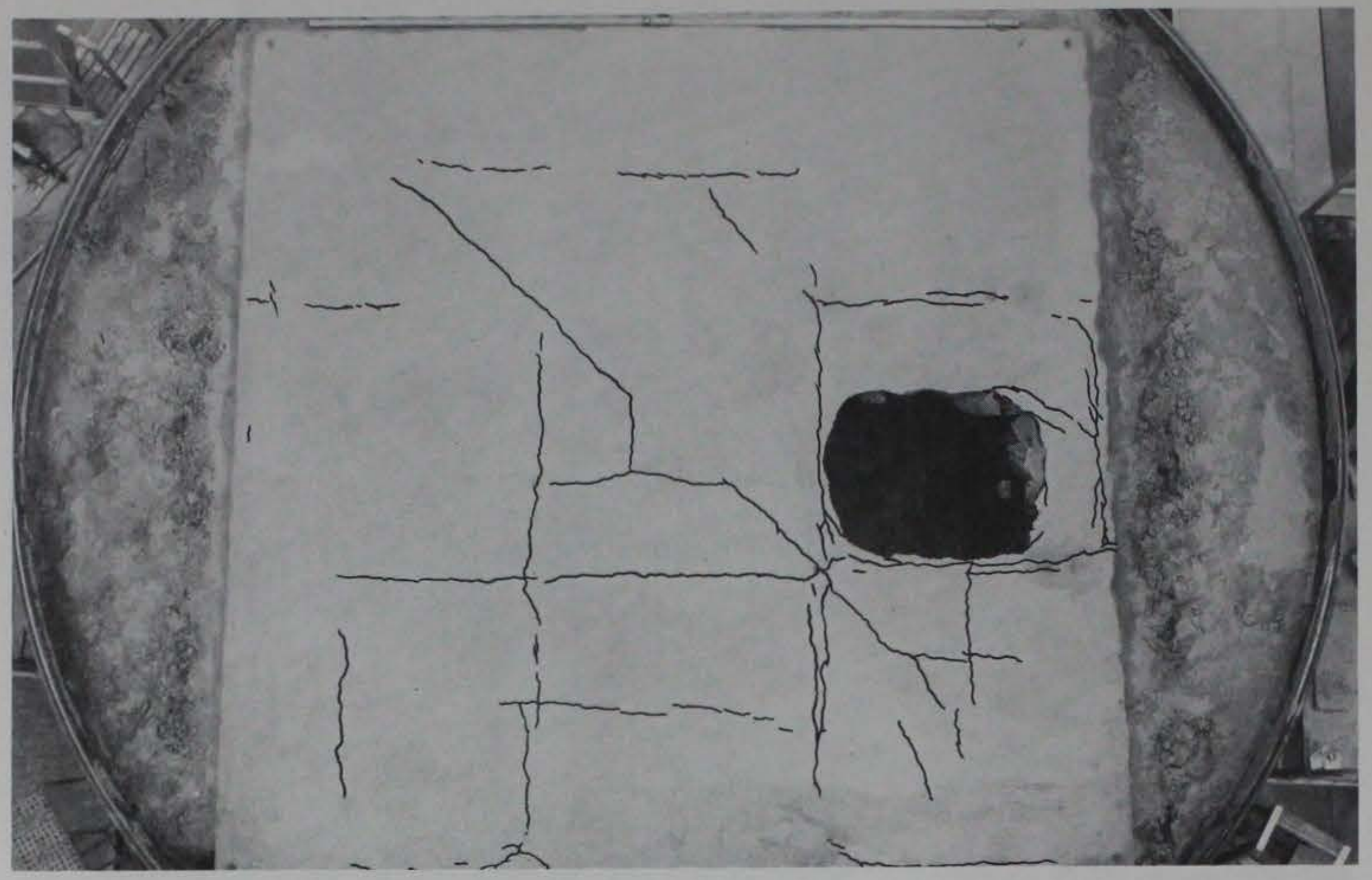

Figure 4.7 Top view of posttest two-way slab with beams model.

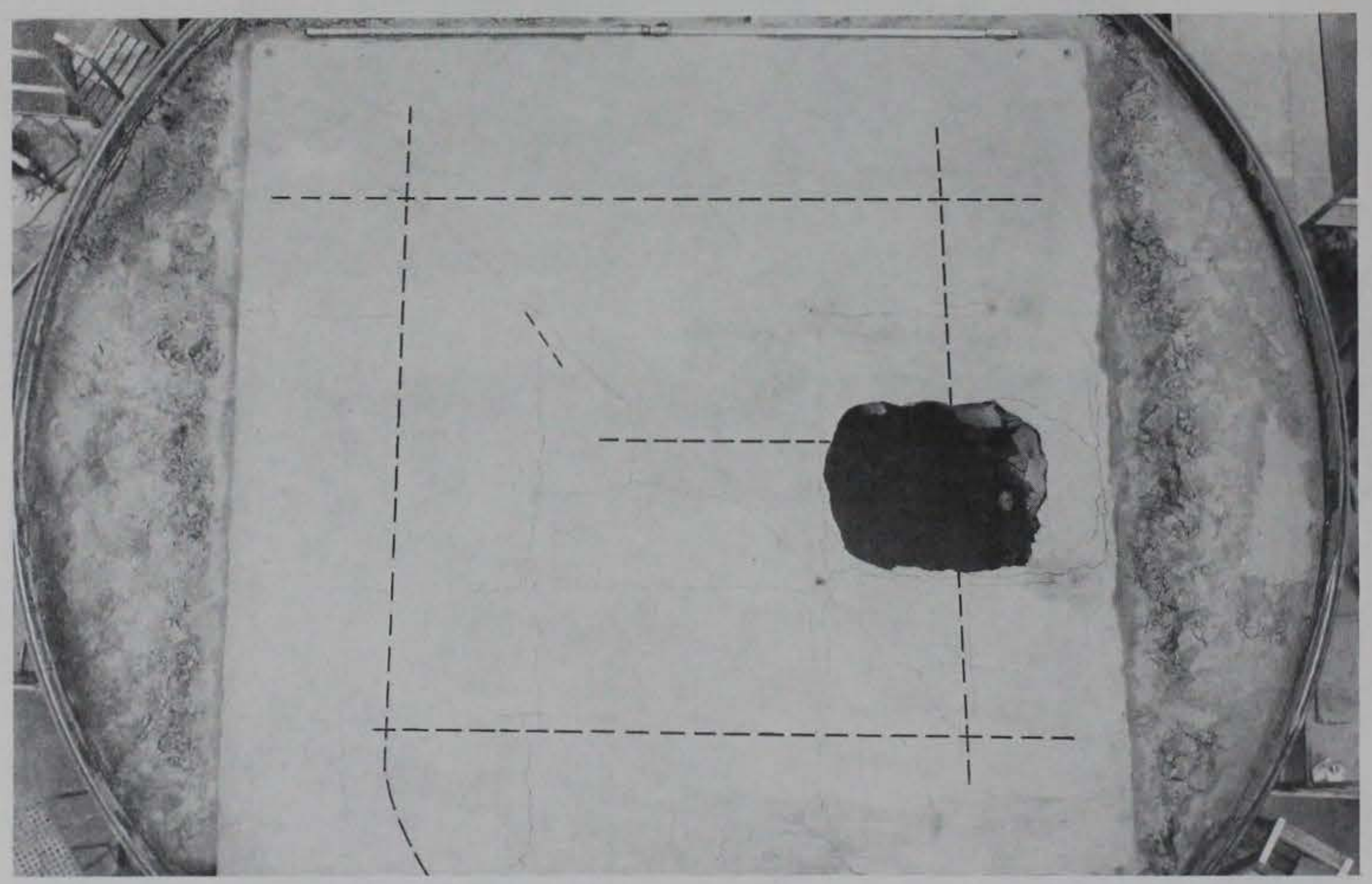

Figure 4.8 General yield line pattern on undersurface of two-way slab with beams model. 


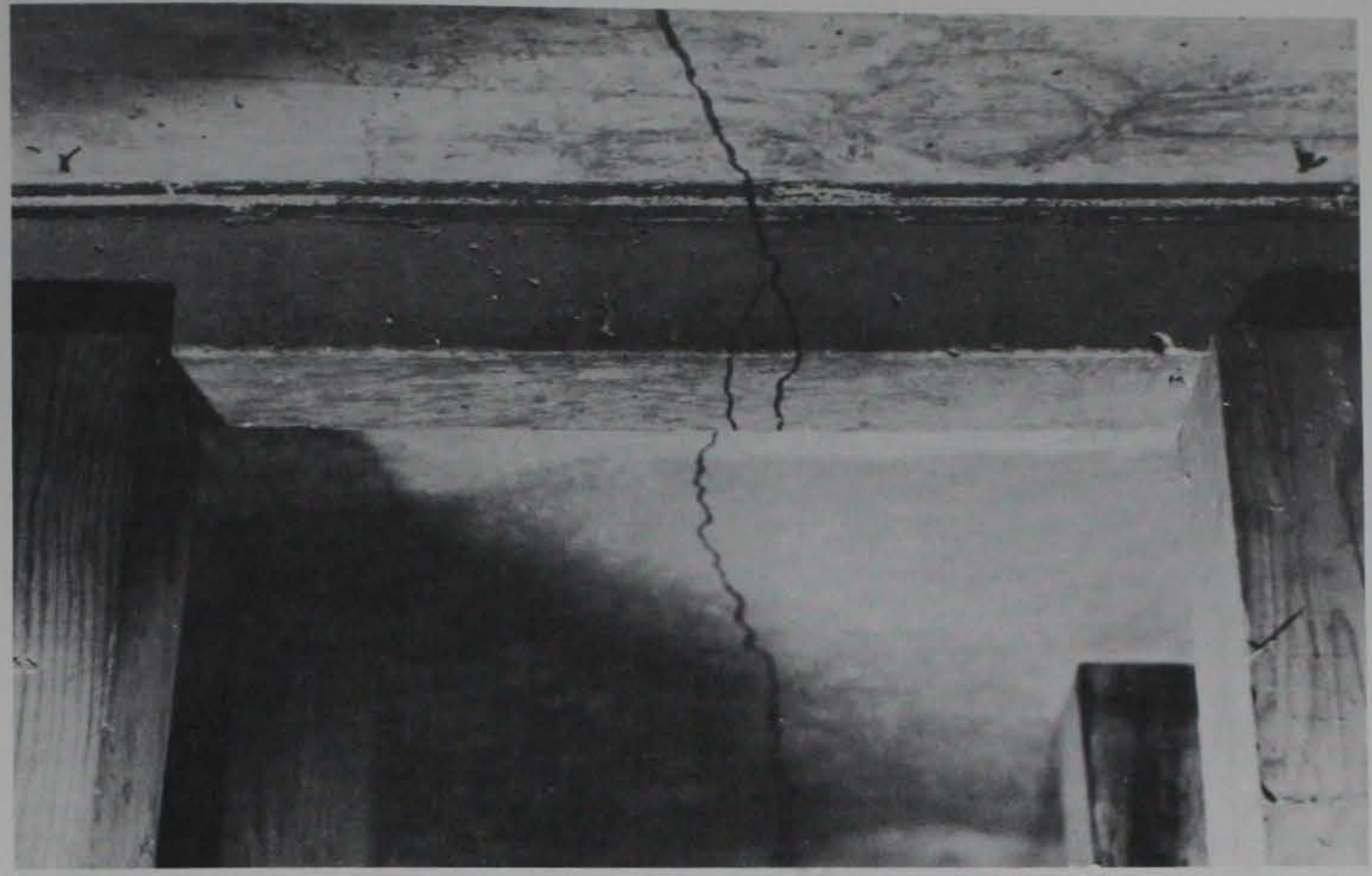

Figure 4.9 Undersurface of posttest two-way slab with beams model.

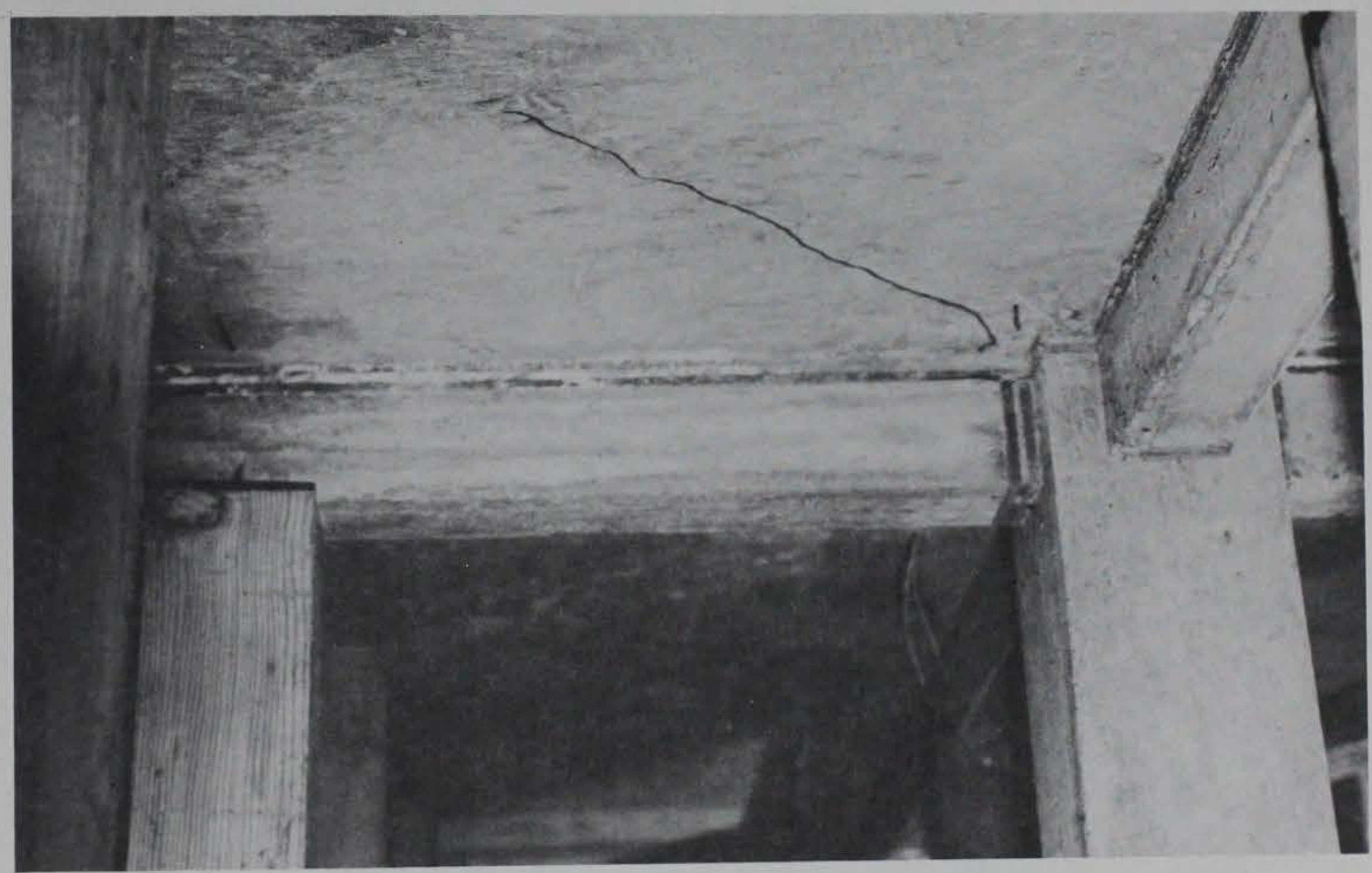

Figure 4.10 Short crack extending from column. 


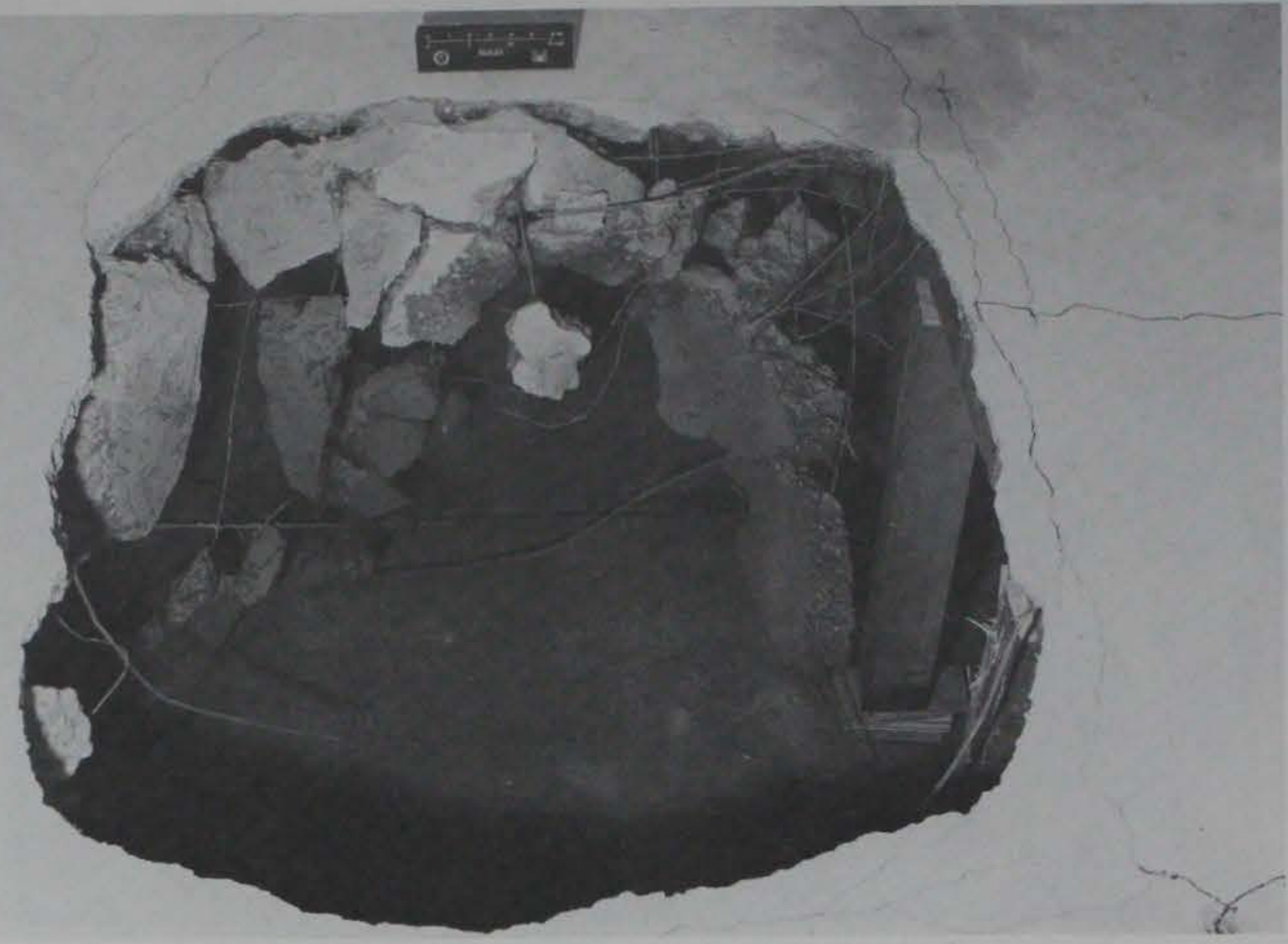

Figure 4.11 Debris at ruptured area.

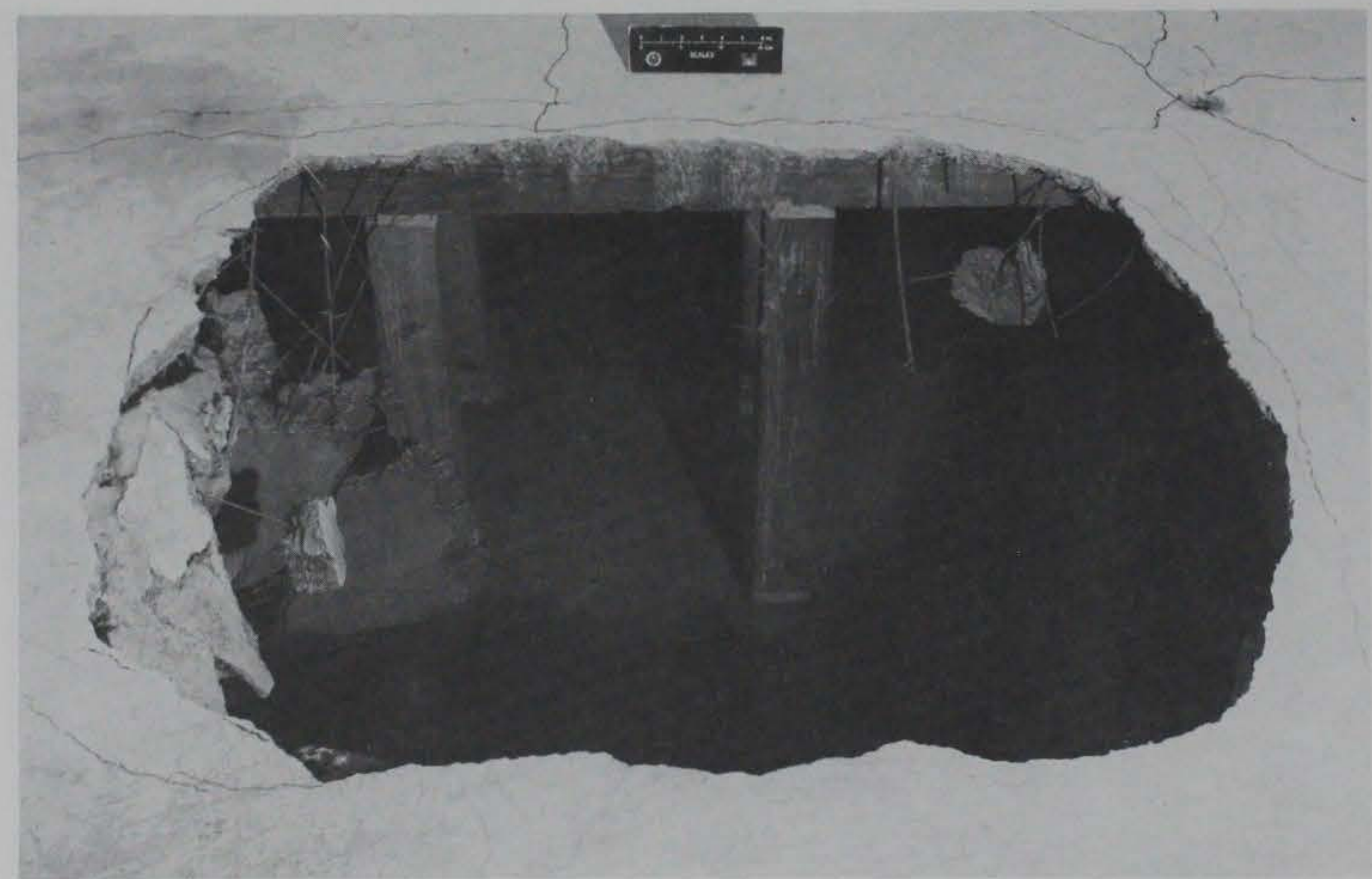

Figure 4.12 Beam and upgrading columns adjacent to ruptured area. 


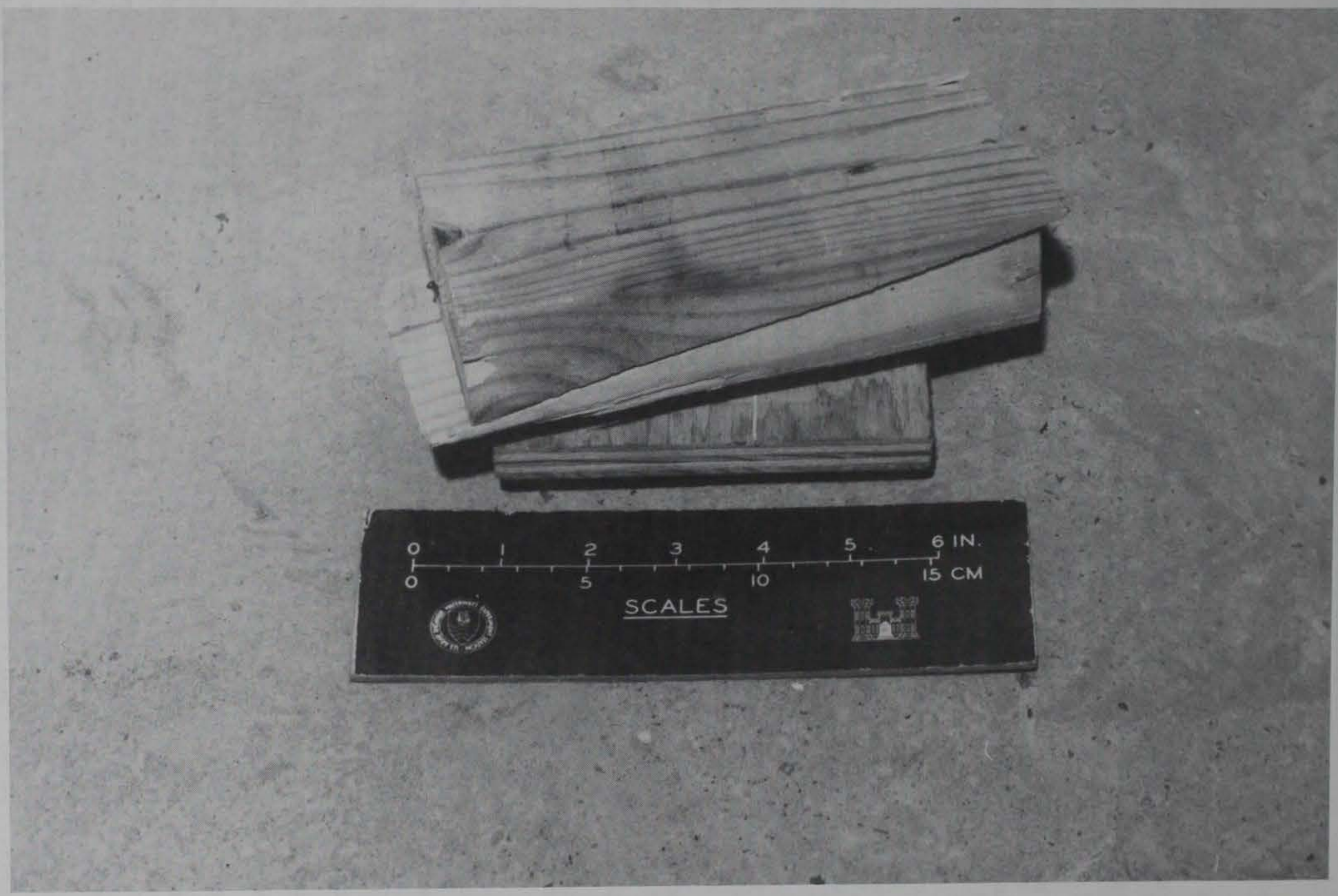

Figure 4.13 Compressed wedges in two-way slab with beams model test. 


\subsection{FLAT PLATE MODEL}

When the water pressure loading reached a value of approximately 40 psi abrupt changes occurred in the data measured by the slab deflection gages, the strain gages in the slab at an interior concrete column, and the soil-stress gage SE-2 located over an interior concrete column. The deflection data revealed an increase in the rate of deflection of the slab under a constant rate of loading. The strains measured by the strain gages ST2 and SB2 decreased to a value of zero strain. The data indicated that the interior concrete columns had punched into the structure's roof slab.

Since the loading measured by the SE- 2 gage reached a value of 80 psi when the water loading pressure was $40 \mathrm{psi}$, it is evident that soil arching did occur in the 4-1/2-inch-thick soil layer. Evidence that soil arching occurred is also revealed by data measured by the soil-stress gage SE-1. Figure 3.19 shows that the SE-1 gage was located at midspan of the span between two upgrading columns on the model's center panel. Figure A.16 in the appendix shows that the loading pressure measured by the SE-1 gage was 32 psi when the water loading pressure was 40 psi.

Although punching shear failure occurred at the concrete columns, it did not occur at the wooden upgrading columns. The wooden wedges used to secure the upgrading columns in place compressed, allowing the slab to move downward, thereby redistributing load to the concrete columns. The load-deflection behavior of the wooden upgrading columns was investigated by the loading of two specimens in an 0lson Universal Testing Machine. The specimens were wedged into place to simulate the conditions of placement in the model. Figure 5.1 shows the load-deflection curve for the two specimens.

Deflection gage D3 measured the deflection of an upgrading column near the location of the soil-stress gage SE-1. Figure A.5 in the appendix indicates that the upgrading column had deflected approximately 0.15 inch when the water loading pressure of $40 \mathrm{psi}$ was reached. Figure 5.1 shows that the $0.15-$ inch deflection corresponded to a column load of approximately 24 kips or 24,000 pounds. Under conditions of uniform loading, the column load would be expressed by 


$$
P=w l^{2}
$$

where

$$
\begin{aligned}
& P=\text { column load (pounds) } \\
& w=\text { slab load (psi) } \\
& \ell=\text { upgrading column spacing (inches) }
\end{aligned}
$$

For an upgrading column spacing of 15 inches and a uniform load of 32 psi as measured by the SE-1 gage, equation 5.1 yields a column load of 7,200 pounds or 7.2 kips. The value of 7.2 kips is 30 percent of the column load of 24 kips determined from deflection data. Even though soil-stress gages were not placed at upgrading column locations, it is evident that soil arching did occur over the 15-inch spans between upgrading columns.

Deflection gages D4, D5, D7, and D8 measured the deflections at other upgrading columns in the model at the locations shown in Figure 3.19. The deflections measured by the D4, D5, D7, and D8 gages when the water loading pressure was $40 \mathrm{psi}$ were $0.08,0.16,0.15$, and $0.20 \mathrm{inch}$, respectively. Application of Figure 5.1 yields approximate column loads of 14.5 kips, 24.9 kips, 24.0 kips, and 27.7 kips in the upgrading columns at the D4, D5, D7, and D8 gage locations, respectively. Therefore, it is implied that upgrading columns at different locations in the model structure experienced different loads due to load redistribution through the soil layer and different load capacities of the roof slab at different regions of the model.

As shown in Figure 5.2, consideration of the slab acting as a continuous beam simply supported by the wooden upgrading columns and with fixed ends at the walls and concrete columns includes the assumption that the midspan and support moment values be equivalent to $w l^{2} / 24$ and $w \ell^{2} / 12$, respectively where

$$
\begin{aligned}
& w=\text { uniform load } \\
& l=\text { span between upgrading columns }
\end{aligned}
$$

Figure 5.3 shows the moment-thrust interaction diagram for support conditions in a 15- by 15-inch section of the slab at the region of the slab where yield lines occurred as shown in Figure 4.1. The load path plotted on Figure 5.3 is for the moments and thrusts applied at the upgrading columns based upon the expression for moment, $w l^{2} / 12$. The load path intersected the interaction diagram, indicating the initiation of yielding behavior at moment and thrust values compatible with a slab surface load of approximately 6 psi. The 
initiation of yielding at the upgrading columns allowed the 15-inch span between the upgrading columns to behave as a simply supported member with concentrated moments at the supports. Figure 5.4 shows the low thrust region of the moment-thrust interaction diagram for midspan conditions at the region of the slab where yield lines occurred. The load path plotted in Figure 5.4 is based upon thrusts and moments determined from wall and roof pressure records. The change in slope of the load path reflects the early formation of plastic hinges at supports. The load path intersected the interaction diagram, indicating the initiation of yielding behavior at moment and thrust values compatible with a slab surface load of approximately 21 psi. Yield-line analyses had predicted that yield would occur at a uniform load of approximately 30 psi. Data records indicate that plastic deformation was continuing to occur when the test was terminated at a water pressure loading of 79 psi.

The uniform surface load $w$ used to define the load path for midspan conditions was determined for the data measured by the SE-1 gage shown in Figure A.16 in the appendix. As shown in Figure 3.19, the SE-1 gage was located between two upgrading columns in the center panel of the model. Soil-stress gages were not located in the exterior panels. Figure A.16 indicates that the water loading pressure was approximately 23 psi when the slab surface load was $21 \mathrm{psi}$ and that the slab surface load was approximately 56 psi when the water loading pressure was $79 \mathrm{psi}$. According to Figure A.16, the slab surface load of 30 psi predicted by yield-line analysis corresponds to a water pressure loading of 37 psi.

If yield occurred at a water pressure load of $23 \mathrm{psi}$, the structure withstood an additional $56 \mathrm{psi}$ before the test was terminated. If yield occurred at a water pressure of $37 \mathrm{psi}$, the structure withstood an additional $42 \mathrm{psi}$ before the test was terminated. The large values of additional loading after yield implied by the beam theory analysis and the yield-line analysis indicate that the analyses did not accurately predict the behavior of the upgraded model. The error in the analytical results may be explained by the assumptions used in their development. The load was assumed to be uniform over a continuous member spanning over simple supports and with fixed ends. However, as previously discussed, a redistribution of the load occurred over the model's surface, and in-plane thrust loads were present in the slab. Some two-way action occurred as the upgrading columns deflected, and flexibility of the walls allowed some rotation at the assumed fixed ends. 


\subsection{TWO-WAY SLAB WITH BEAMS MODEL}

A 20-inch spacing was chosen for the upgrading columns in the two-way slab with beams test. As expected, data indicated that the thrust in the slab was similar to the thrust in the flat plate model for any given overpressure loading. It is evident from strain gage data that changes in the structure's response behavior began to occur at an overpressure loading of approximately 15 psi. Strain gages in the slab reinforcement steel near and perpendicular to the beams showed considerable increase in the rate of tension strains for a constant rate of water pressure loading. The strain gages in the beams and near the interior column indicated low values of strain as was the case for the flat plate test prior to punching shear failure at the column when the water loading pressure was about 40 psi.

At an overpressure of approximately $22 \mathrm{psi}$, the deflection data and the soil-stress data indicated that the rate of deflections was increasing and that soil-arching was occurring. When the water loading pressure reached a value of approximately 39.5 psi, punching shear failure had not occurred at the concrete columns. The presence of the beams joining the columns increased the shear area beyond that which existed in the flat plate model test. Therefore, punching shear failure at the concrete columns was avoided although the upgrading column spacing was greater than that used in the flat plate test. However, rupture did occur in an exterior bay. The ruptured area was bounded on two sides by beams and seemed to follow rows of upgrading columns on the other two sides. The location was such that the center of the rupture area was supported by one upgrading column. It is probable that either punching shear failure occurred at the upgrading column or the upgrading column slipped out of position leaving the slab unsupported over a span of 40 inches.

Criswell (Reference 8) studied the behavior of slab-column connections subjected to static loadings. Criswell indicated that the ACI Code expression for shear strength underestimates by 25 percent the shear strength in connections having a $\mathrm{r} / \mathrm{d}$ ratio of 2 where

$$
\begin{aligned}
& r=\text { square column side dimension } \\
& \mathrm{d}=\text { effective depth of the slab }
\end{aligned}
$$

The $\mathrm{r} / \mathrm{d}$ ratio in the current study is 2.1 ; therefore, Criswe 11 's results may be appropriate. If the ACI Code underestimates the shear strength by 25 percent, a punching shear force capacity of approximately 18.6 kips would be 
expected. Deflection measurements were taken at an upgrading column which was probably loaded similarly to the upgrading column at the ruptured area. Application of the deflection data to the previously mentioned load-deflection curve developed from two upgrading column specimens indicates that the column load at the time the slab ruptured was approximately $28.8 \mathrm{kips}$.

Criswell also states that punching shear failure is likely to occur at connections where general flexural yielding has occurred. Such flexural-shear failures occurred in some tests at less than 60 percent of the shear capacity calculated according to the ACI Code. In the current study, 60 percent of the calculated shear strength is equivalent to approximately $8.4 \mathrm{kips}$. A corner bay next to the bay where rupture occurred showed several yield lines beginning to congest near an upgrading column, indicating that the slab may have been susceptible to flexural shear failure. If flexural shear failure did occur at the ruptured area, the data records imply that it occurred at a shear capacity approximately 165 percent of that calculated according to the ACI Code. 


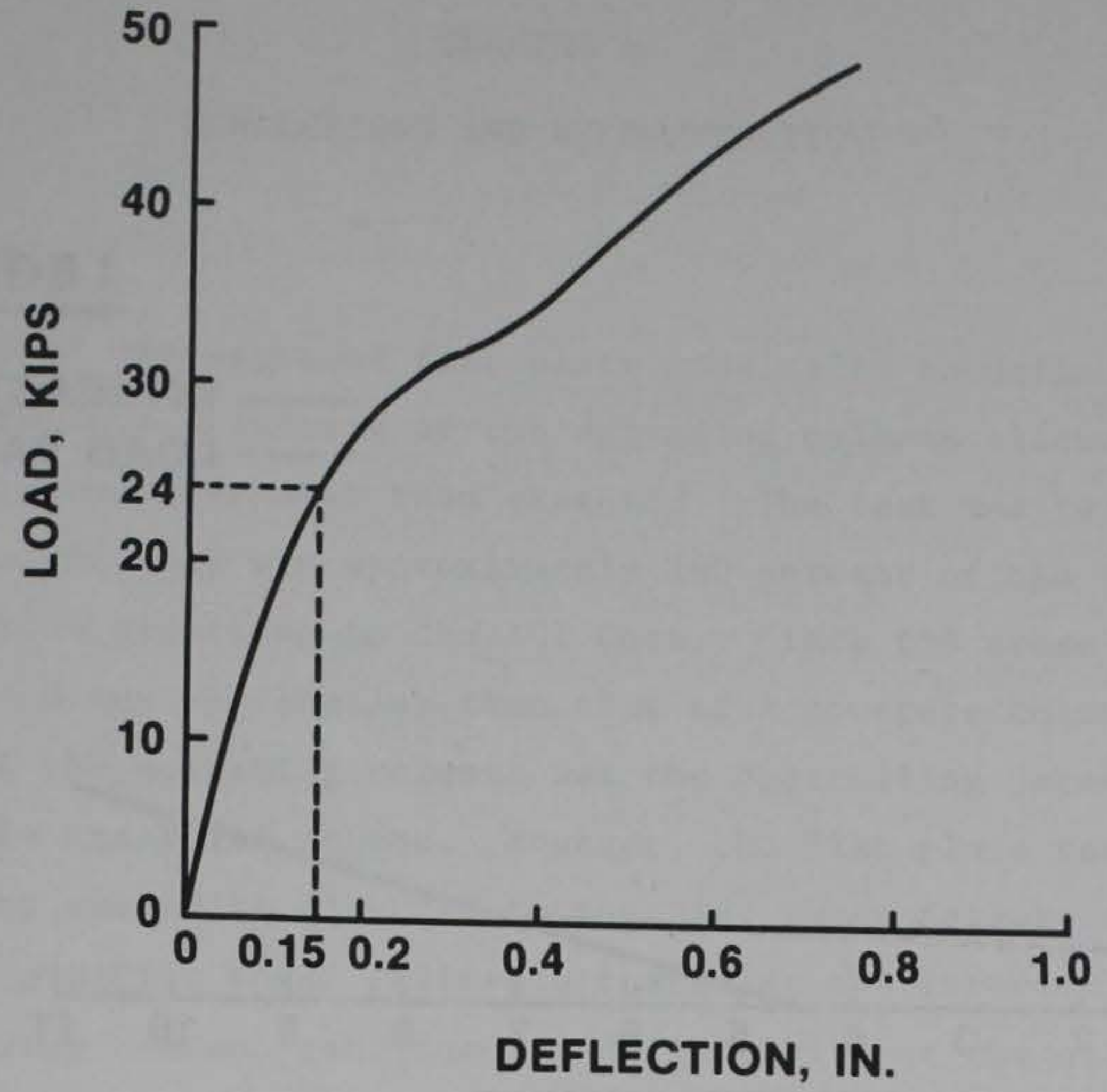

Figure 5.1 Load-deflection curve for wooden upgrading column.
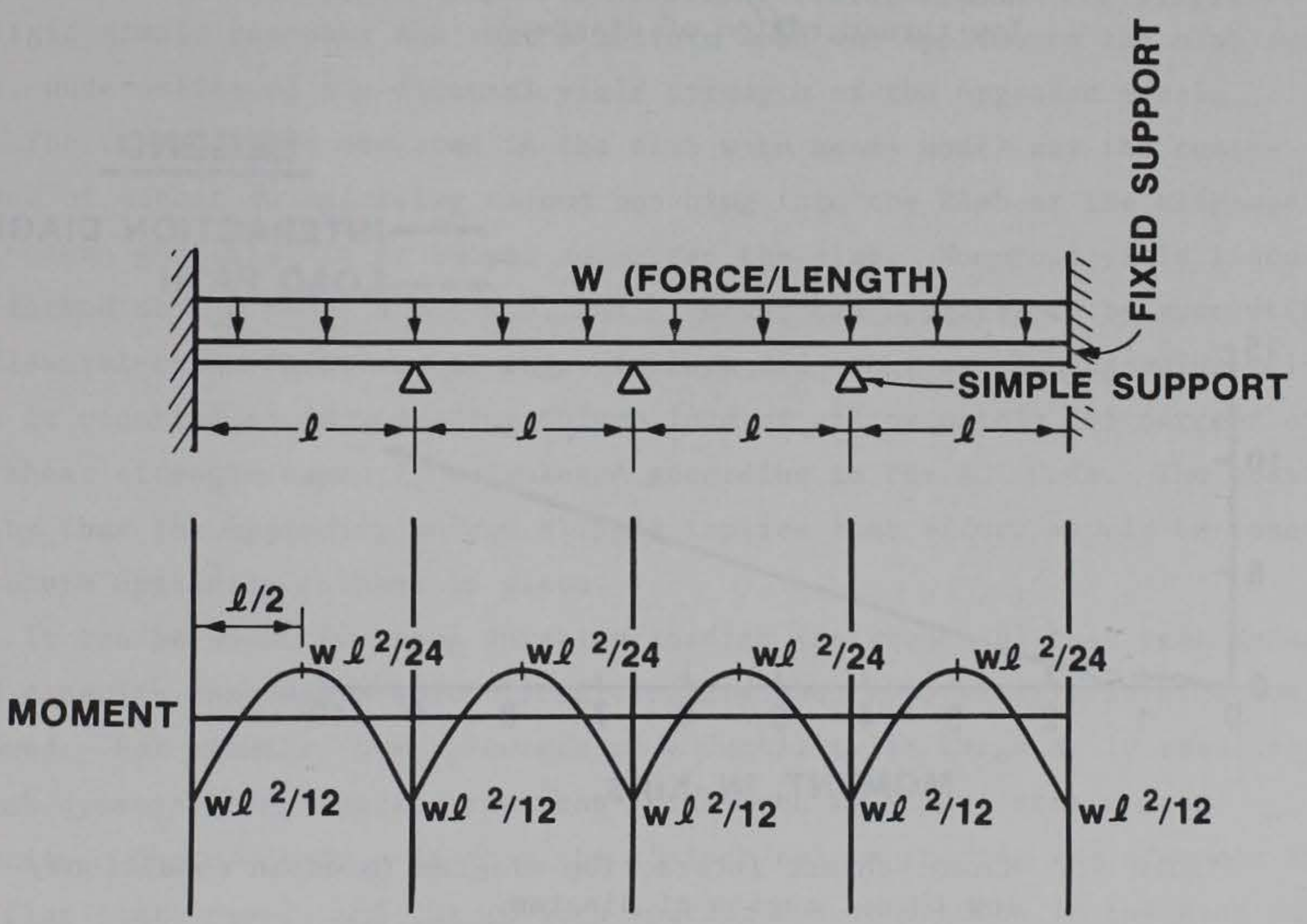

Figure 5.2 Moment diagram for continuous beam with uniform load. 


\section{LEGEND}

INTERACTION DIAGRAM

LOAD PATH

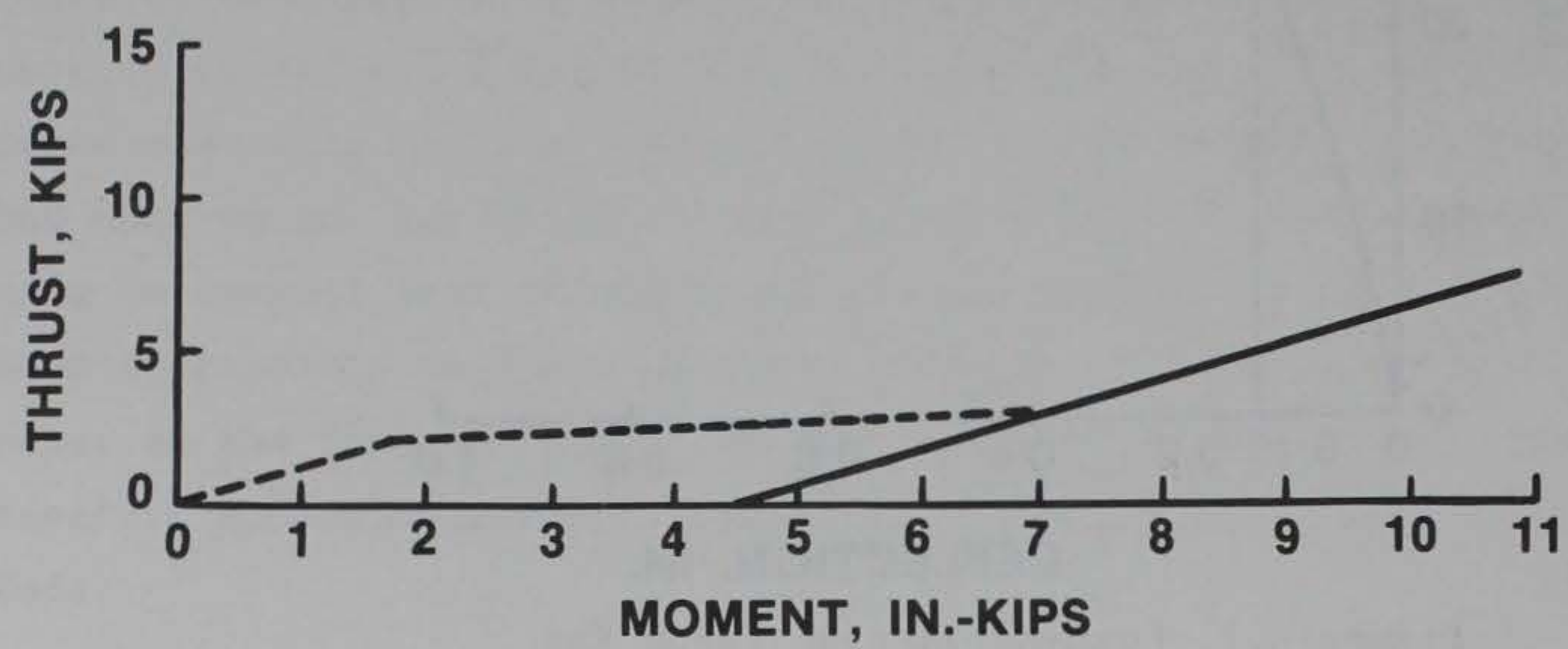

Figure 5.3 Moment-thrust interaction diagram (support conditions, low thrust region of diagram).

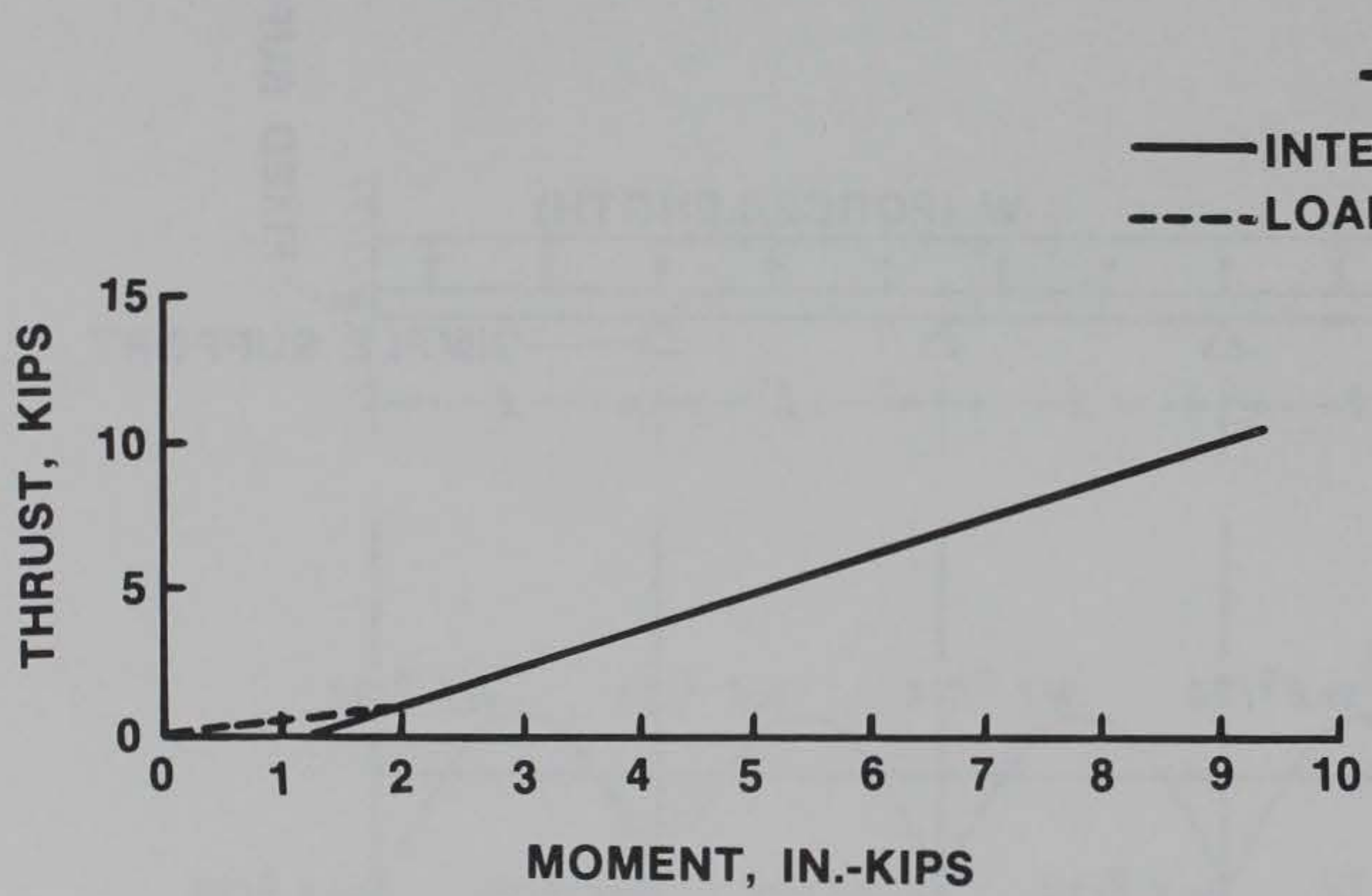

Figure 5.4 Moment-thrust interaction diagram (midspan conditions, low thrust region of diagram). 


\section{CHAPTER 6}

\section{CONCLUSIONS AND RECOMMENDATIONS}

\subsection{CONCLUSIONS}

The ability of the upgraded flat plate model slab to deflect without punching shear failure occurring at the upgrading columns allowed the model to withstand overpressures greater than expected. The test was terminated when the upgrading column load was approximately 190 percent of the shear strength capacity calculated according to the ACI Code. Since the cross-sectional area of an upgrading column was smaller than that of a concrete column, punching shear failure at the upgrading columns was the controlling parameter used in the design of the upgrading scheme. However, the flat plate test indicated that more concern should be directed to punching shear failure at the concrete columns. After punching shear failure occurred at the interior concrete columns, the upgrading columns continued to deflect without the occurrence of punching shear, thereby allowing flexural yield to occur. Yield-line analyses, which were based upon the assumptions that the upgrading columns behaved as rigid simple supports and that a uniform load was applied to the slab surface, underestimated the flexural yield strength of the upgraded model.

The rupture that occurred in the slab with beams model was the consequence of either an upgrading column punching into the slab or the slippage of the column such that it no longer supported the slab. Numerous yield lines had formed on the model's surface, and a corner bay appeared to be susceptible to flexural-shear failure. If shear failure did occur at the upgrading column, it occurred at an upgrading column load of approximately 165 percent of the shear strength capacity calculated according to the ACI Code. The possibility that the upgrading column slipped implies that effort should be taken to secure upgrading columns in place.

It can be shown for long duration loading (Reference 9) that peak dynamic load capacity approaches static load capacity when some plastic deformation is allowed. For example, the allowance of a ductility as large as 10 results in a peak dynamic load capacity that can be as much as $95 \%$ of static load capacity. The indication is that the 15 -inch column spacing was adequate in the flat plate model, and the 20 -inch spacing was inadequate in the slab with beams model for a CRP requirement of an overpressure load capacity of 50 psi. 
The 15-inch spacing was equivalent to $1 / 4$ of the span length, and the 20-inch spacing was equivalent to $1 / 3$ of the span length. Both spacing schemes allowed uniform spacing throughout the model with upgrading columns located along concrete column and/or beam lines. The flexural strength of the slabs of the flat plate model was greater than that of the slab with beams model due to the design requirements of the ACI Code. It is expected that the capacity of a similar flat plate model upgraded at a spacing of 20 inches would be greater than the approximate 40-psi capacity of the slab with beams model, assuming that flexural-shear failure occurred in the slab with beams model test. However, punching shear failure occurred at the interior concrete columns of the flat plate model at an overpressure of about 40 psi. A 20-inch spacing might allow the punching shear failure to occur at a lower overpressure and to be devastating to the structural integrity of the model. Therefore, spacing of upgrading columns at a spacing $1 / 4$ of the span length was conservative, and a spacing $1 / 3$ of the span length would probably be inadequate in the flat plate structure. Any uniform spacing between $1 / 3$ and $1 / 4$ of the span length would require the same number of upgrading columns as required by the $1 / 4-$ span-length spacings, if upgrading columns are to be placed along concrete column and beam lines. In the case of implementation of $\mathrm{CRP}$ during an international crisis, the use of uniform spacing would simplify the upgrading procedure. Therefore, it is implied from the degree of analysis performed in this study that a spacing of upgrading columns equivalent to $1 / 4$ of the span length be used in flat plate structures. The degree of conservatism observed in the test in this study may be considered as a margin of safety. The study discussed in Reference 6 indicates that a dynamically tested upgraded waffle slab structure has an overpressure load capacity approximately 77 percent of a similar upgraded statically tested structure. Therefore, the margin of safety in the static test may be required in order to ensure a peak overpressure capacity of 50 psi under dynamic loadings.

As in the flat plate structure, the results of this study imply that a spacing of upgrading columns equivalent to $1 / 4$ of the span length should be used in two-way reinforced concrete slab with beams structures. The test indicated that the 1/3-span-length spacing was inadequate. It is reasonable to expect that the 1/4-span-length spacing would be adequate and probably conservative for the statically applied overpressure of 50 psi. However, some two-way slab with beams structures may not be as thick as the 8-inch-thick 
slabs modeled by the nine-bay model. A thinner slab would be more susceptible to the occurrence of shearing action at the concrete and upgrading columns.

The interaction of the upgrading columns and the soil cover with the concrete structure allowed a redistribution of the applied overpressure load. In-plane thrusts in the slab contributed to the significant increase in shear strength beyond that calculated according to the ACI Code. The results of the tests are not appropriate for structures upgraded with rigid columns. Since soil-arching was a factor which influenced the loading characteristics of the tests, the results are not appropriate for structures that are not covered by a soil medium of sufficient depth to allow soil-arching to occur.

\subsection{RECOMMENDATIONS}

The study by Woodson and McVay (Reference 6) indicates that buckling of full-scale composite wooden upgrading columns may be critical to an upgraded slab system. Emphasis is again placed on the need to develop techniques for increasing the buckling resistance of a composite wooden column to ensure that the column loads experienced in the current study can be sustained under fullscale conditions. The possibility that an upgrading column in the two-way slab with beams model test slipped from position emphasizes the need for additional effort in securing upgrading columns in place.

The interaction of the soil cover and the upgrading columns with the nine-bay concrete structure results in an upgraded structure that is complex in an analytical sense. The analysis presented in this report does not fully evaluate the response of the upgraded structures. An analysis using finite element methods is needed to provide a better understanding of the behavior of the upgraded nine-bay structures. The tests in this study provide data useful for the development of finite element computer models which could be used to analyze various upgrading column spacings and placement schemes.

The current study deals with flat plate structures and two-way slab with beams structures. A structure which is similar in construction to the flat plate structure is the flat slab structure. An analytical study similar to the previously mentioned finite element study is needed to apply the test results to flat slab structures. The results of the current study are not applicable to structures having slabs with decking, which are typically thin slabs. The behavior of upgraded slabs with decking should be investigated by tests. Since the slabs are thin, 1/4-scale modeling of such slabs in nine-bay 
structures would not be feasible. A 1/2-scale to full scale one-bay or twobay structure could be tested in the LBLG at WES, or a multibay structure could be field tested using a High Explosive Simulation Technique (HEST) (Reference 10). A HEST is an airblast simulator that can reproduce the peak overpressure, rate of pressure decay, overpressure duration, and shock front velocity for a given nuclear yield and range.

In accordance with the concept of upgrading basements in existing buildings, research is needed to determine the effect of nuclear blast loading of the aboveground structure on the upgraded basement. During the time required to publish this report, plans were being made by FEMA to investigate the building-basement interaction. 
1. American Concrete Institute; Building Code Requirements for Rein forced Concrete, ACI 318-77, 1977, Detroit, Mich.

2. D. F. Tolman, R. O. Lyday, and E. L. Hill; "Statistical Classification Report, Estimated Characteristics of NFSS Inventory," December 1973, Research Triangle Institute, Research Triangle Park, N. C.

3. Building Officials Conference of America; The BOCA Basic Building Code/1970, Fifth Edition, 1969, Chicago, Ill.

4. R. P. Peck, W. E. Hanson, T. H. Thornburn; Foundation Engineering, Second Edition, 1974, John Wiley and Sons, Inc., New York, N. Y.

5. American Concrete Institute; Design Handbook, Volume 2-Columns, Pub1ication SP-17A(78), 1978, Detroit, Mich.

6. S. C. Woodson and M. K. McVay; "Tests and Evaluation of Upgraded Flat Plate and Waffle-Slab Floor Systems," December 1983, U. S. Army Engineer Waterways Experiment Station, Vicksburg, Miss.

7. S. A. Mahin and V. V. Bertero; "RCCOLA, A Computer Program for Reinforced Concrete Column Analysis, User's Manual and Documentation," 1977 , Department of Civil Engineering, University of California, Berkeley, Calif.

8. M. E. Criswe11; "Strength and Behavior of Reinforced Concrete SlabColumn Connections Subjected to Static and Dynamic Loadings," Technical Report No. N-70-1, 1970, U. S. Army Engineer Waterways Experiment Station, Vicksburg, Miss.

9. J. M. Biggs; Structural Dynamics, McGraw-Hill Inc., 1964.

10. S. A. Kiger; "User of a Foam HEST to Simulate Low-Yield Nuclear Overpressures," Miscellaneous Paper SL-81-12, 1981, U. S. Army Engineer Waterways Experiment Station, Vicksburg, Miss.

11. M. K. McVay; "Tests and Analysis of One-Way Reinforced Concrete Floor Slabs," Technical Report No. SL-81-4, 1981, U. S. Army Engineer Waterways Experiment Station, Vicksburg, Miss.

12. Concrete Reinforcing Steel Institute; CRSI Handbook Based Upon the 1977 ACI Building Code; 3rd Edition, 1978; Chicago, I11. 
APPENDIX A

DATA FROM THE UPGRADED FLAT PLATE MODEL TEST 
Figure A.1

UPGRADED FLAT PLATE

$P-1$

MGXIMUM
44.7233

CHANNEI NO. 1 16955 2

02/11/82 R0339

$\stackrel{\infty}{\infty}$

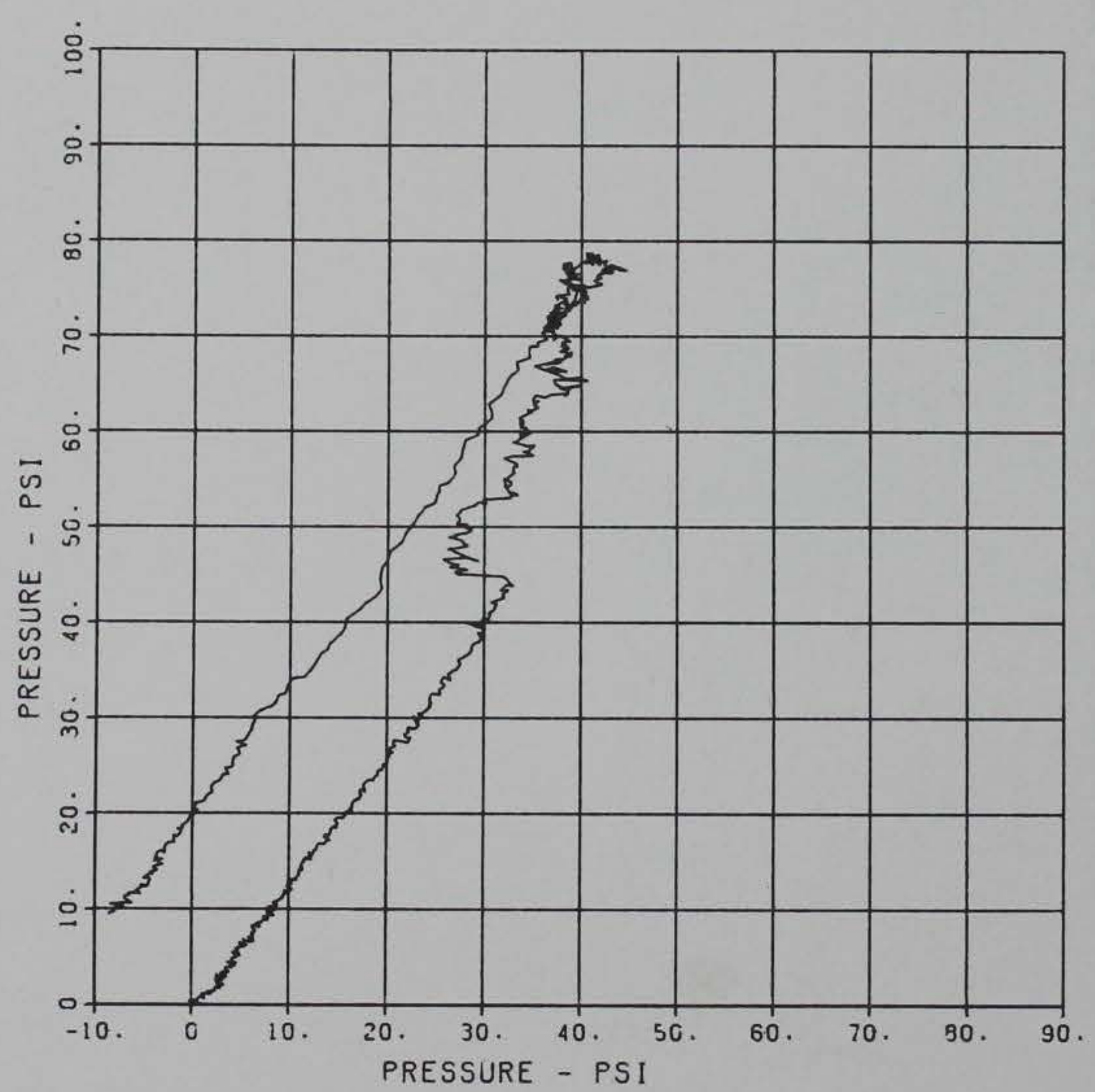

Figure A.2

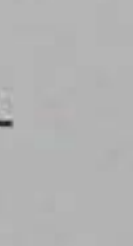

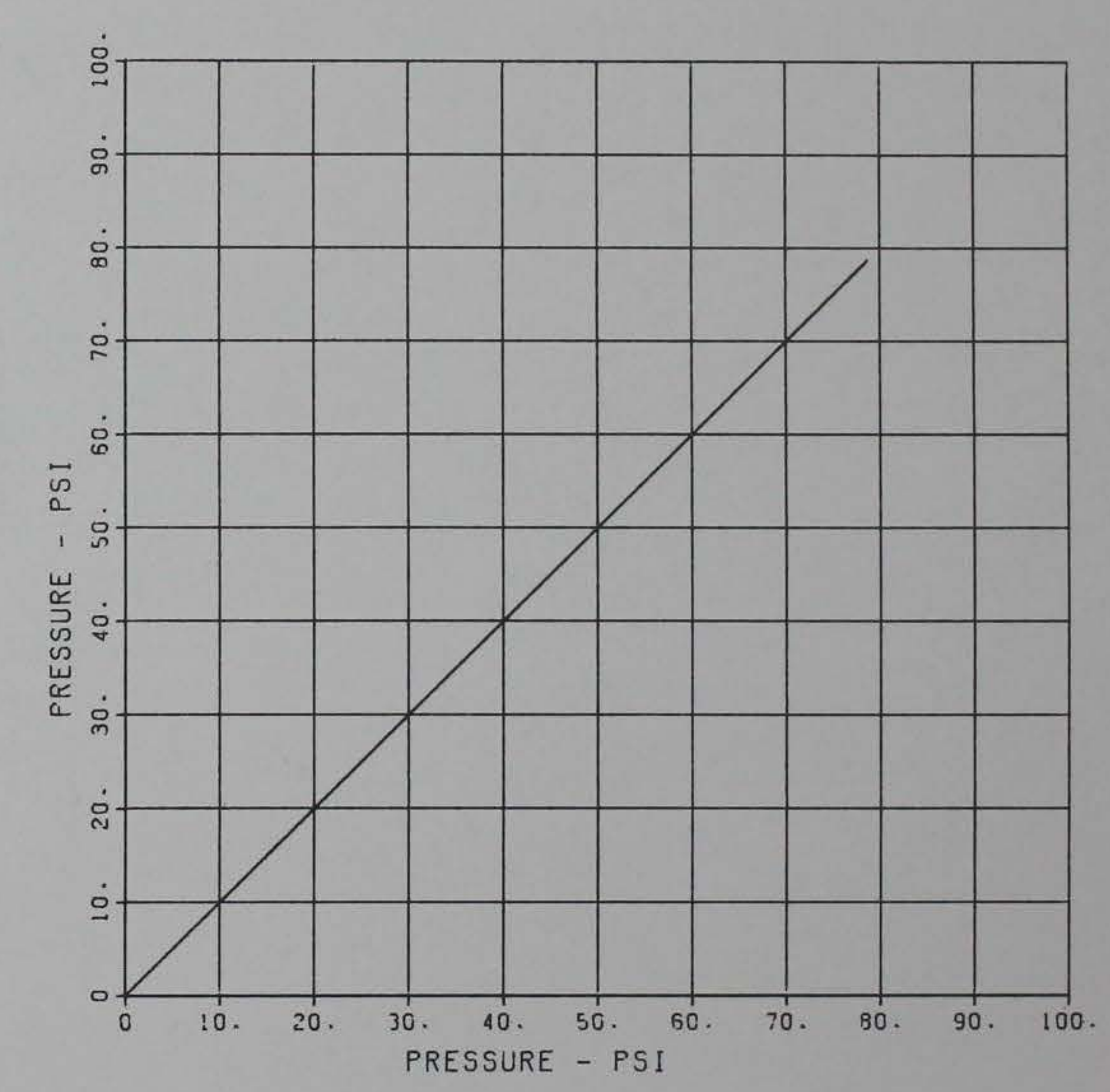


Figure A. 3

$:$

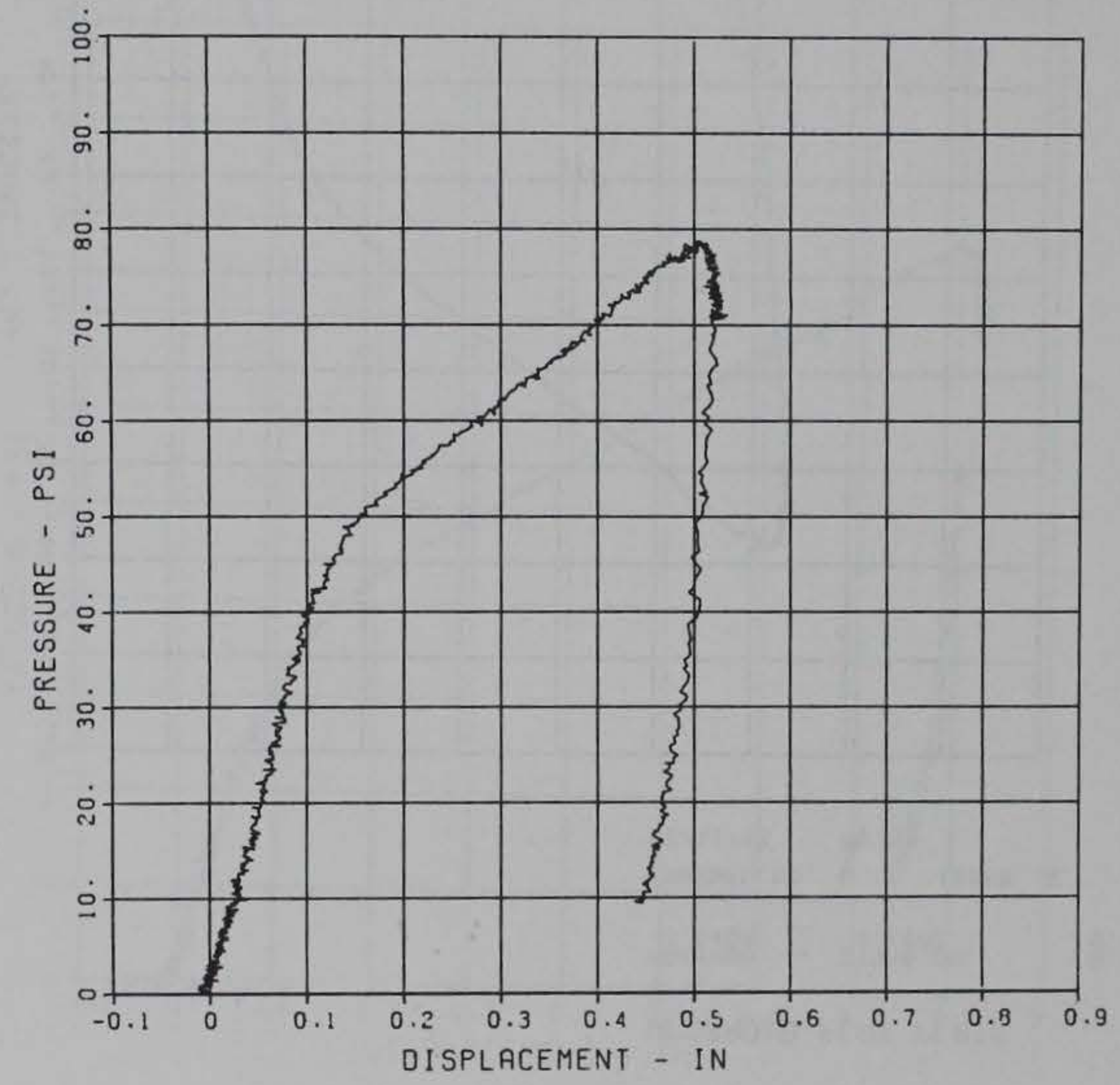

Figure A. 4

D-1

MAXIMUM

FLAT PLATE

IGMA $C A L$
3.5486

${ }_{0.6}^{\text {CAL VAL }}$

CHANNEL NO. $3 \quad 169552$

$02 / 11 / 82$

R0389

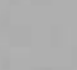

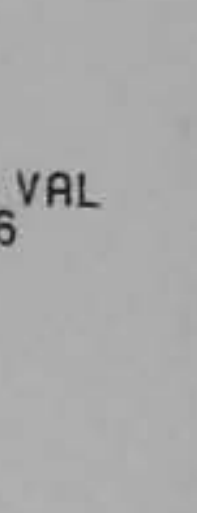

UPGRADED FLAT PLATE
D-2

MgXIMUM
0.4945
SI.2BA CAL

CHANNEL NO \& $46955 \quad 2$

02/11/82 R0359

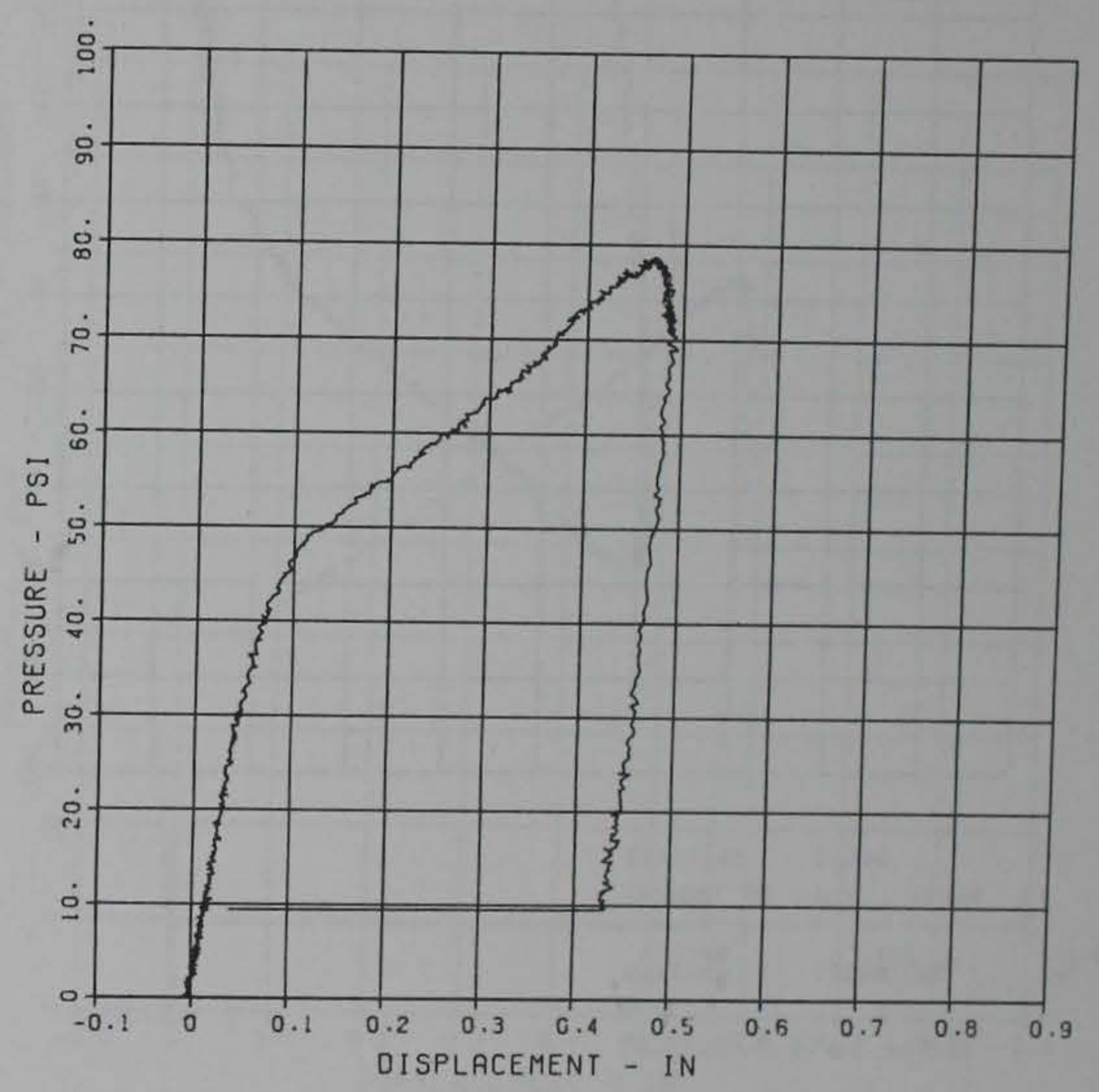


Figure A. 5

UPGRADED FLAT PLATE

$D-3$

MAXIMUM SIGMACALL CAL YAL

CHANNEL NO. $5 \quad 169562$

$02 / 11 / 82 \quad R 0339$

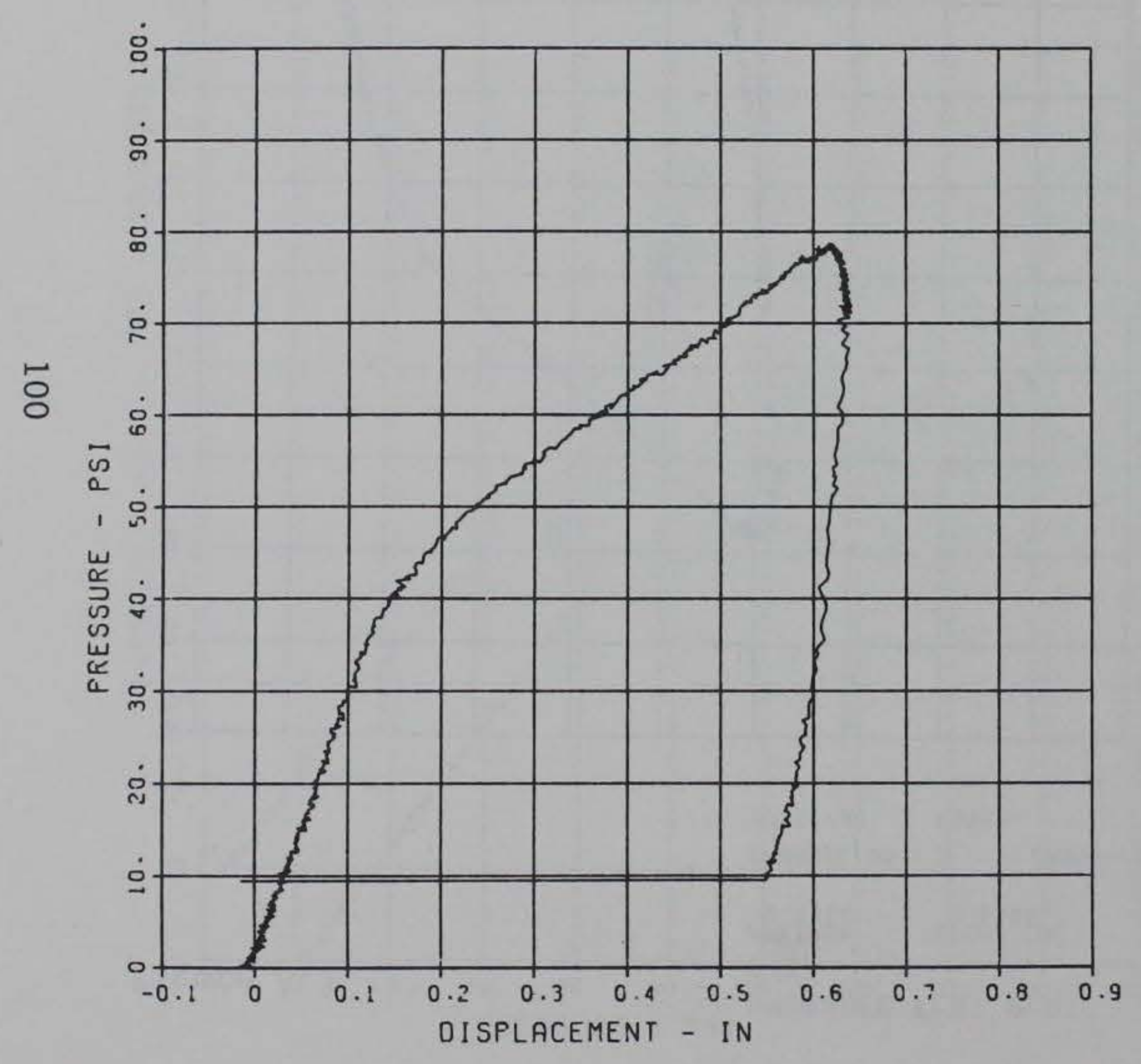

Figure A. 6

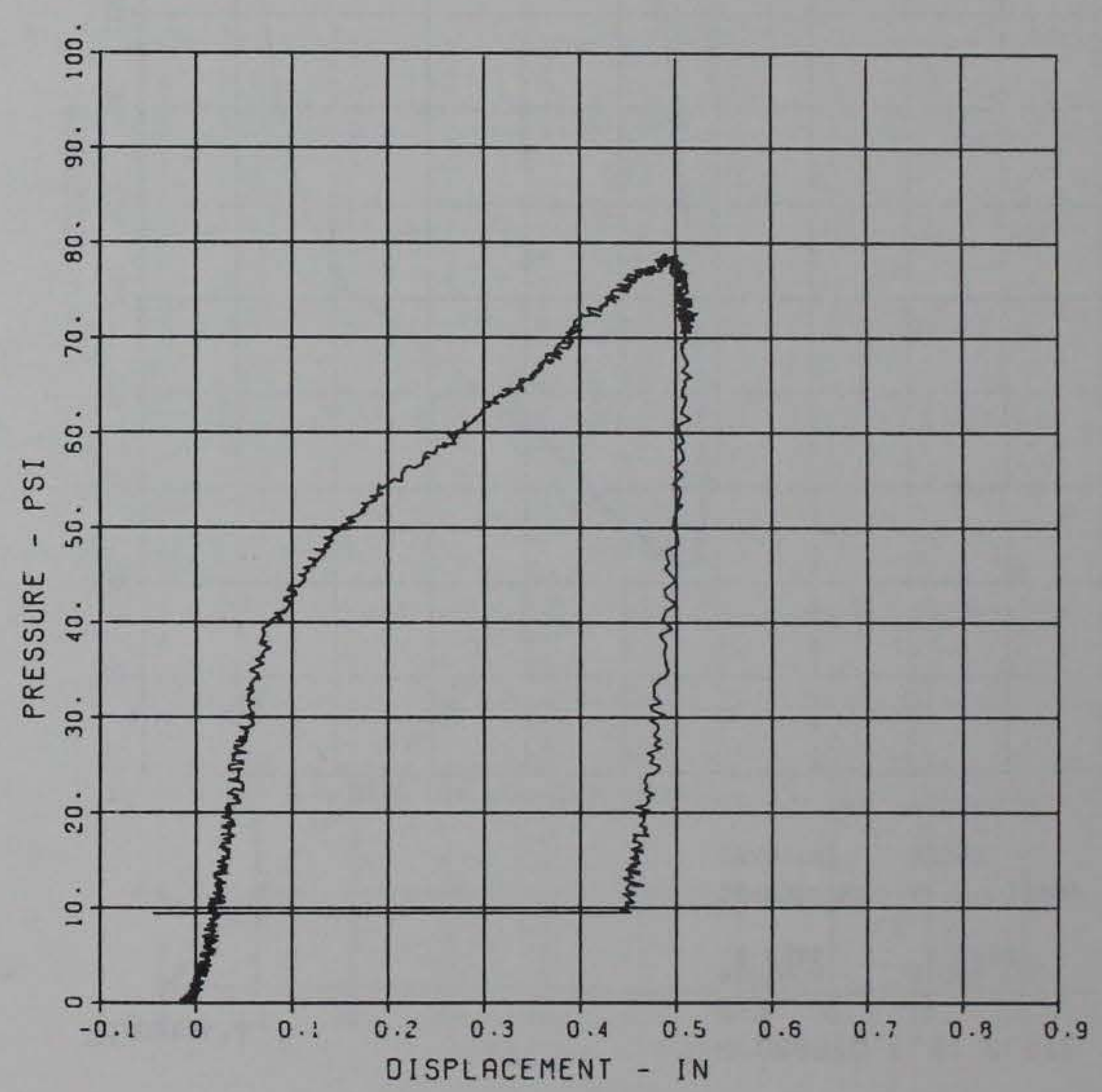

$\mathrm{D}-4$

MAXIMUM SIOMA CAL CAL VAL

CHANNEL NO. $5 \quad 169562$

02/11/82 R0399

UPGRADED FLAT PLATE

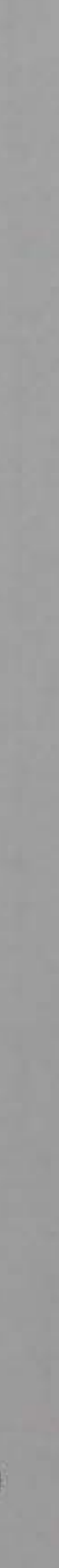


Figure A.7

UPGADED FLAT PLATE

D-5

MAXIMUM SICMA CAL CAL VAL

CHANNEL NO, 7 16955 ?

02/11/82 R0399

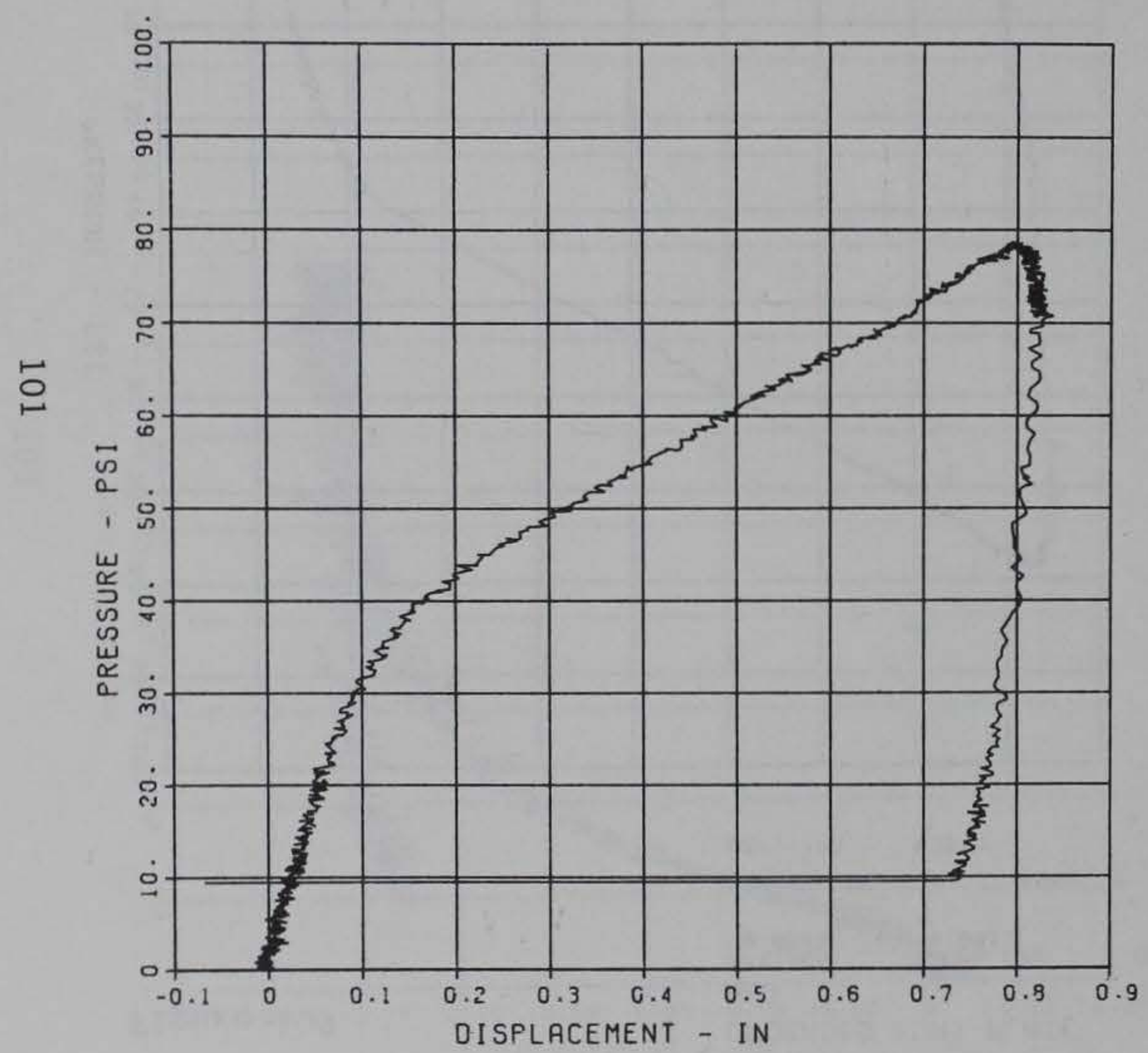

Figure A.8

UPGRADED FLAT PLATE

C-6

MAR IMUM 0.5952 SIGMR CAL CAL VAL

CHANNEL NO. B 169562

02/11/82 R0399

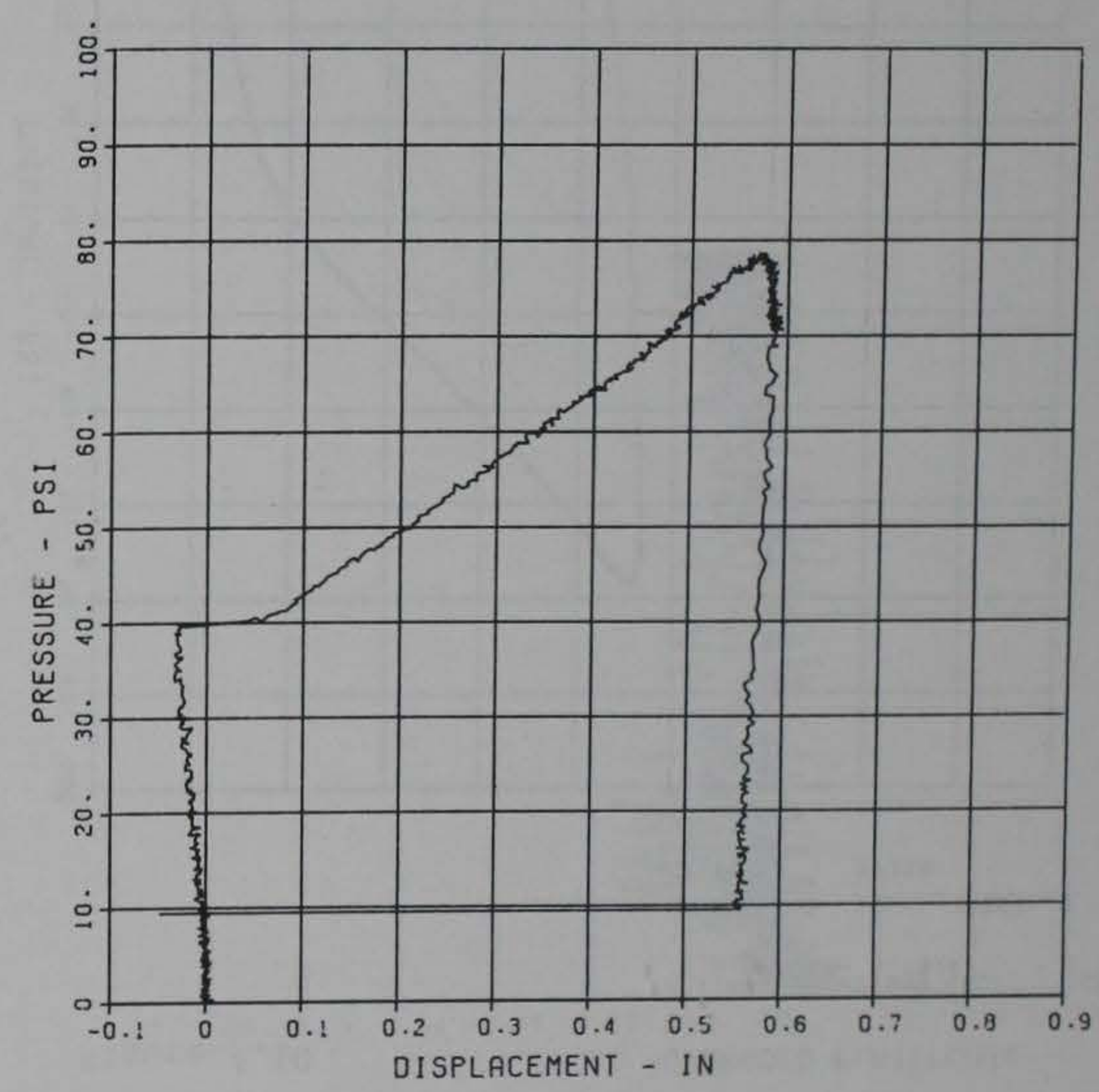


Figure A. 9

UPGRADED FLAT PLATE

D-7

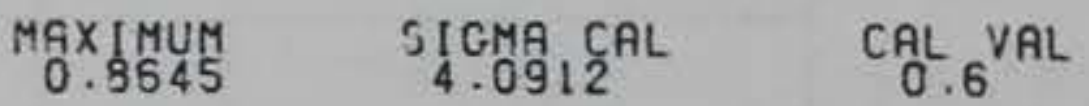

CHANNEL NO. $9 \quad 169562$

02/11/82 R03B9

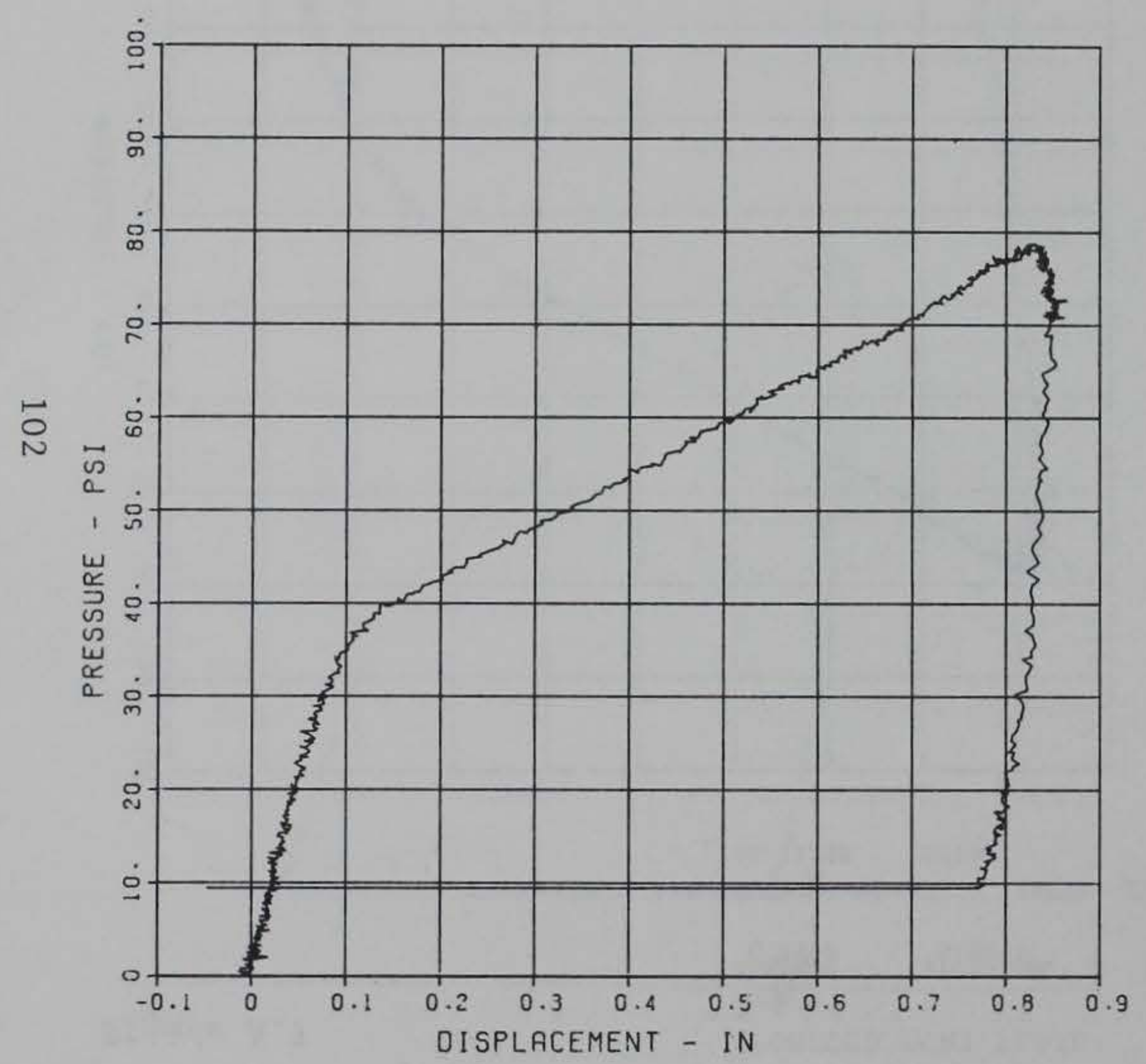

Figure A. 10

UPGRADED FLAT FLATE

D-8

MGX 1 MUM
0.9467 5.7374 CAL $\quad$ CAL VAL

CHANNEL NO. :O 169552

02/11/82 R0399

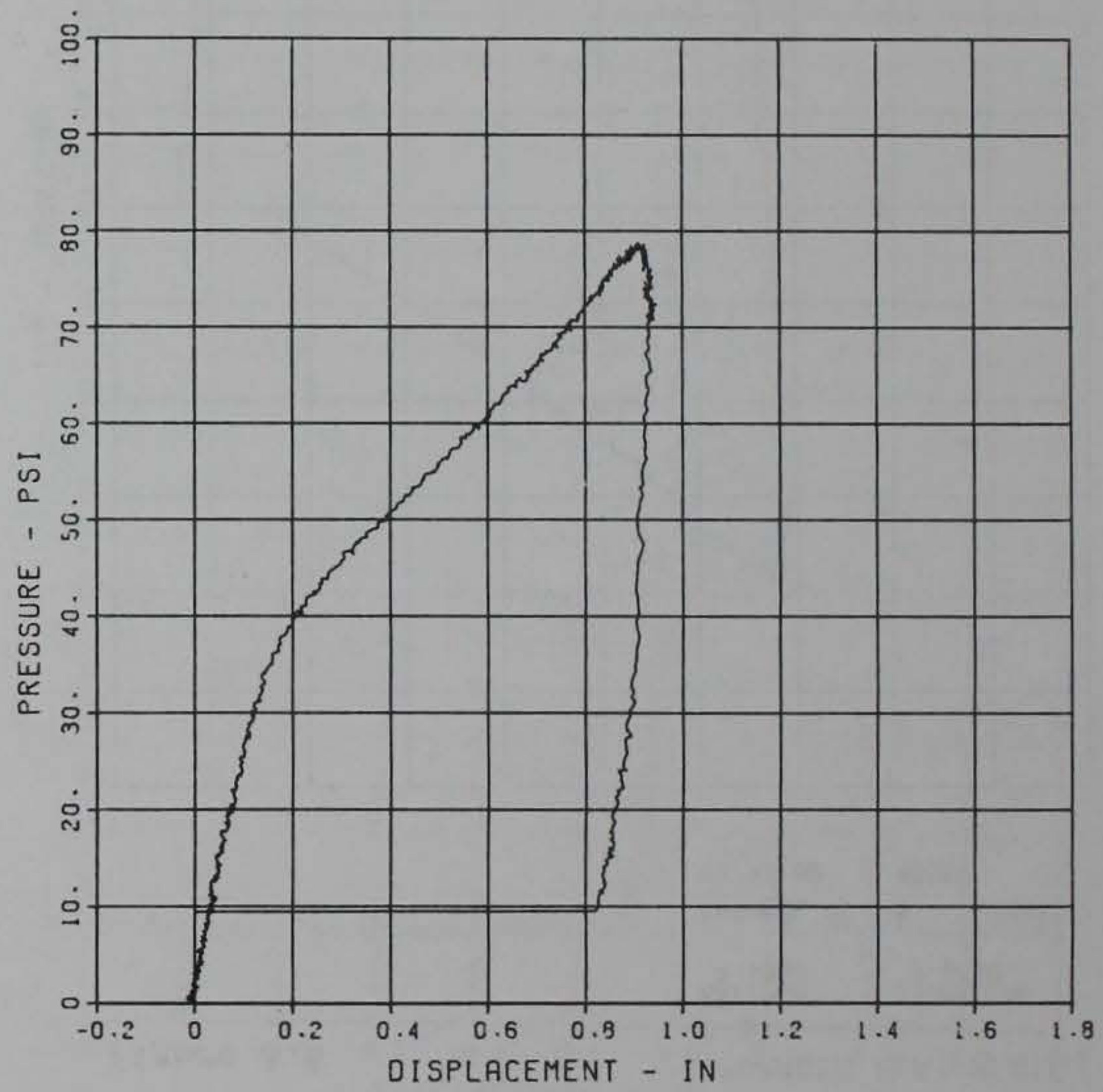


Figure A.11

UPGRADED FLAT PLATE

DW-1

$\begin{array}{lll}\operatorname{MAXIMUM}_{-0.1454} \quad 5 / \mathrm{GMG} \text { CAL } & \text { CAL VAL } \\ 0.4373 & 0.6\end{array}$

CHANNEL NO. $11 \quad 169552$

02/11/82 R0339

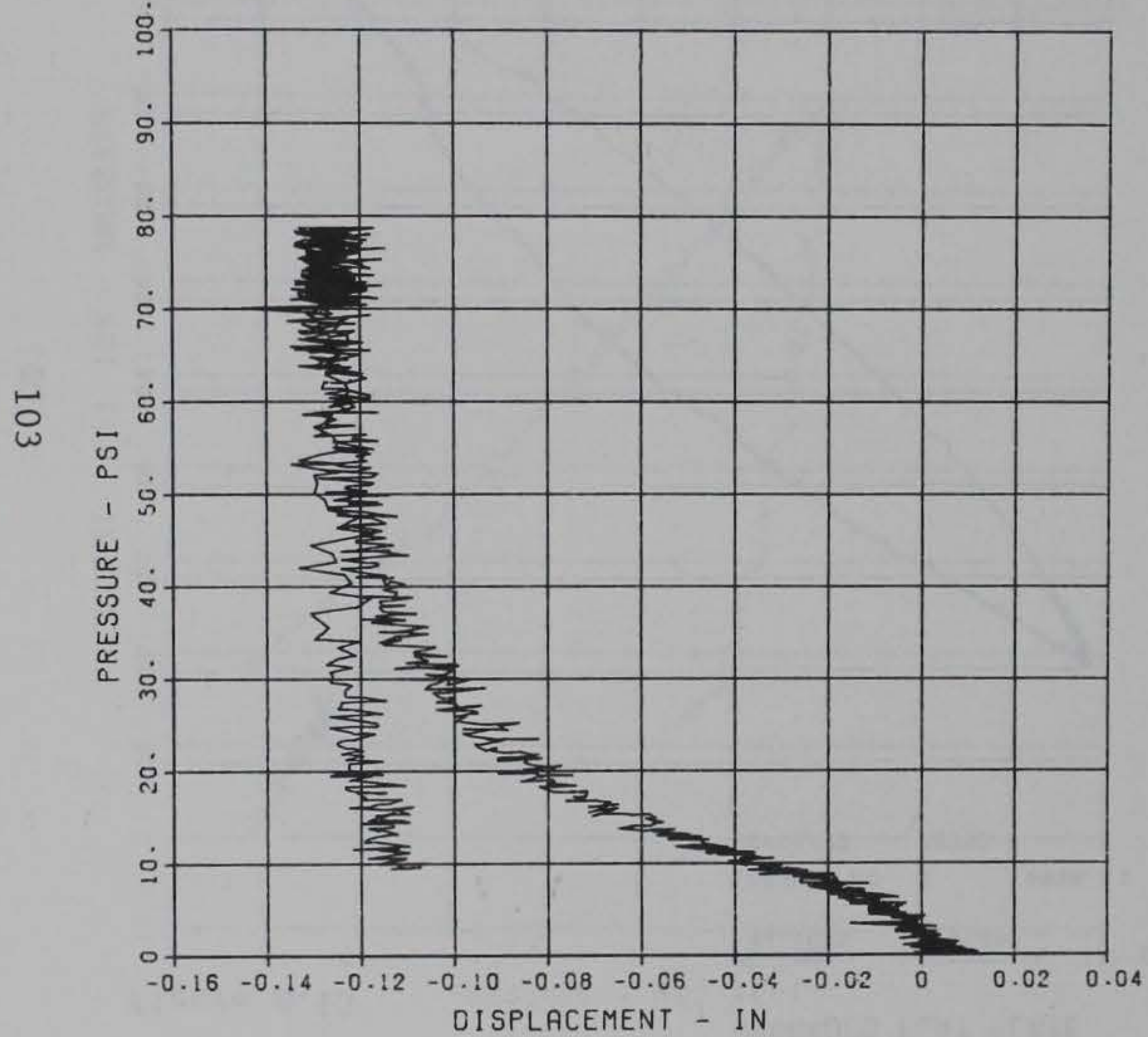

Tigure A.12

UPGRADED FLAT PLATE

DW-2

MaXIMUM
-0.0615
55.4307 $\quad \begin{aligned} & \text { CAL } \\ & 0.5^{\text {VAL }}\end{aligned}$

CHANNEL NO. $12 \quad 169562$

$02 / 11 / 82 \quad$ R0339

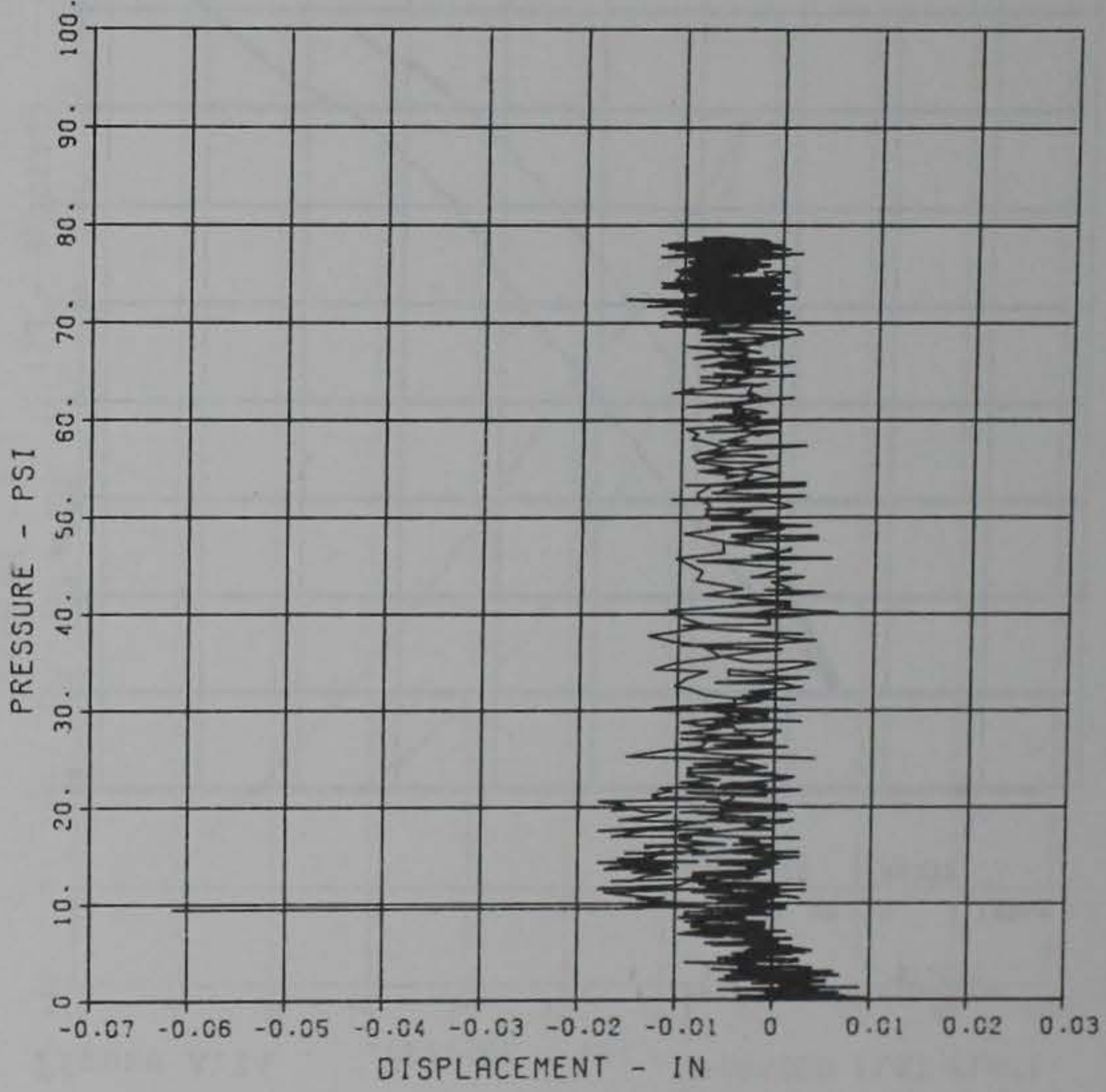


Figure A.13

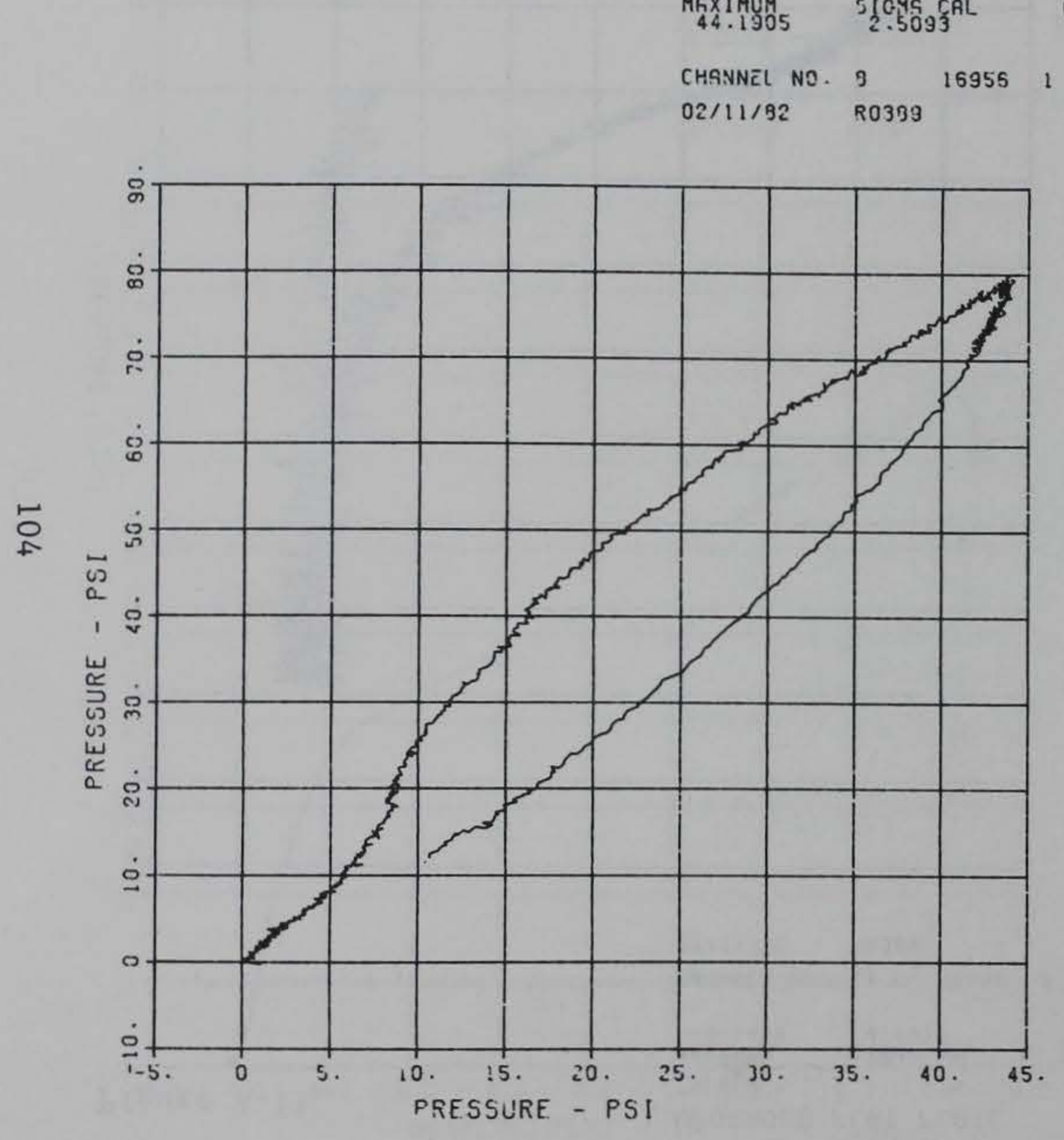

Figure A.14

CAL : : $\mathrm{AL}$

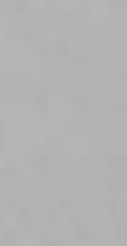

UPGRADED FLAT FLATE.

IF -2

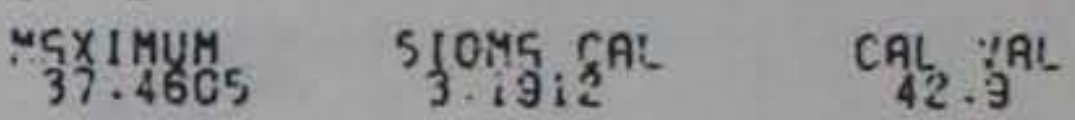

CHANNEI NE 9 I69LS :

O2/11/B2 R0339

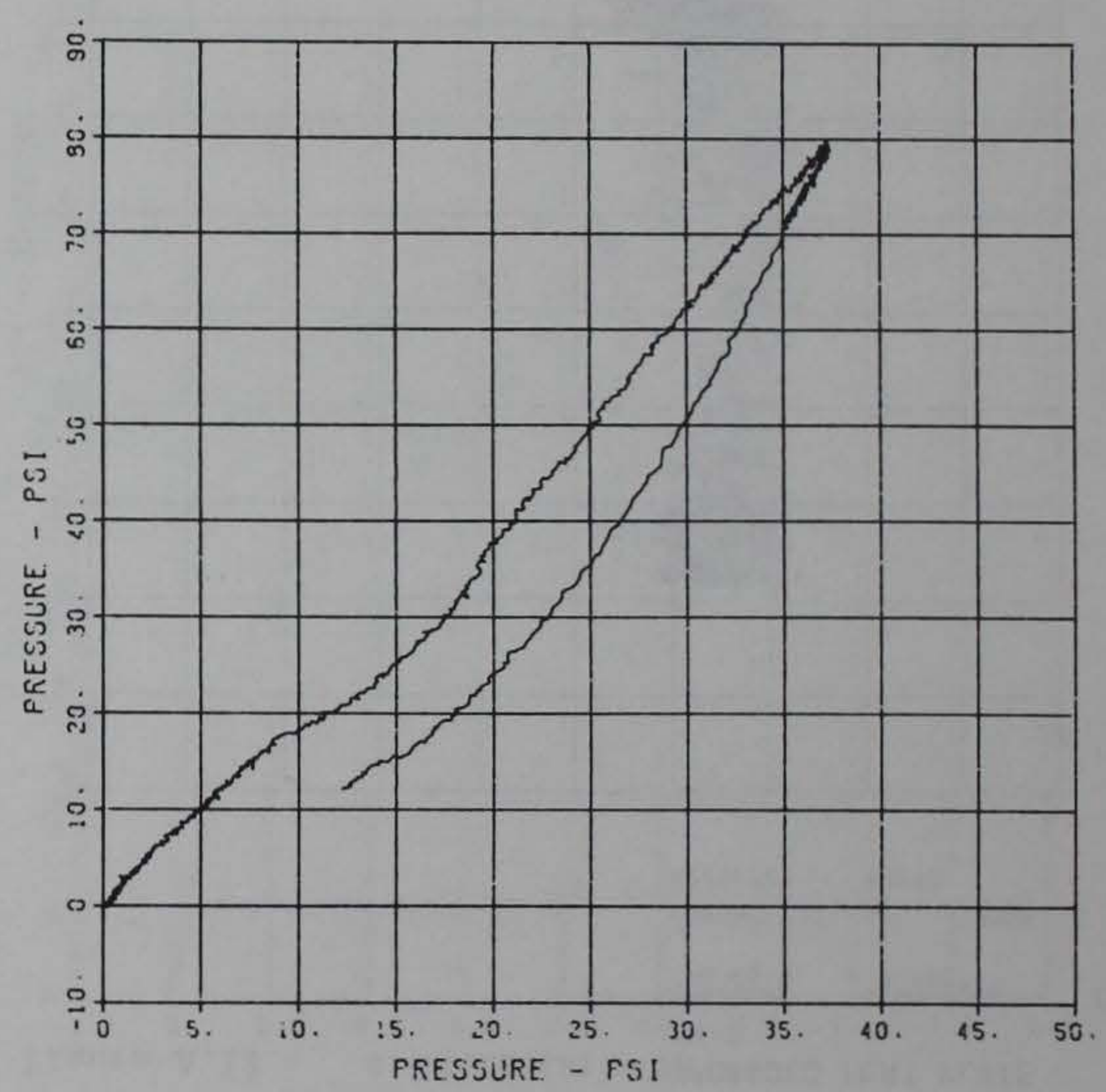


Figure A.15

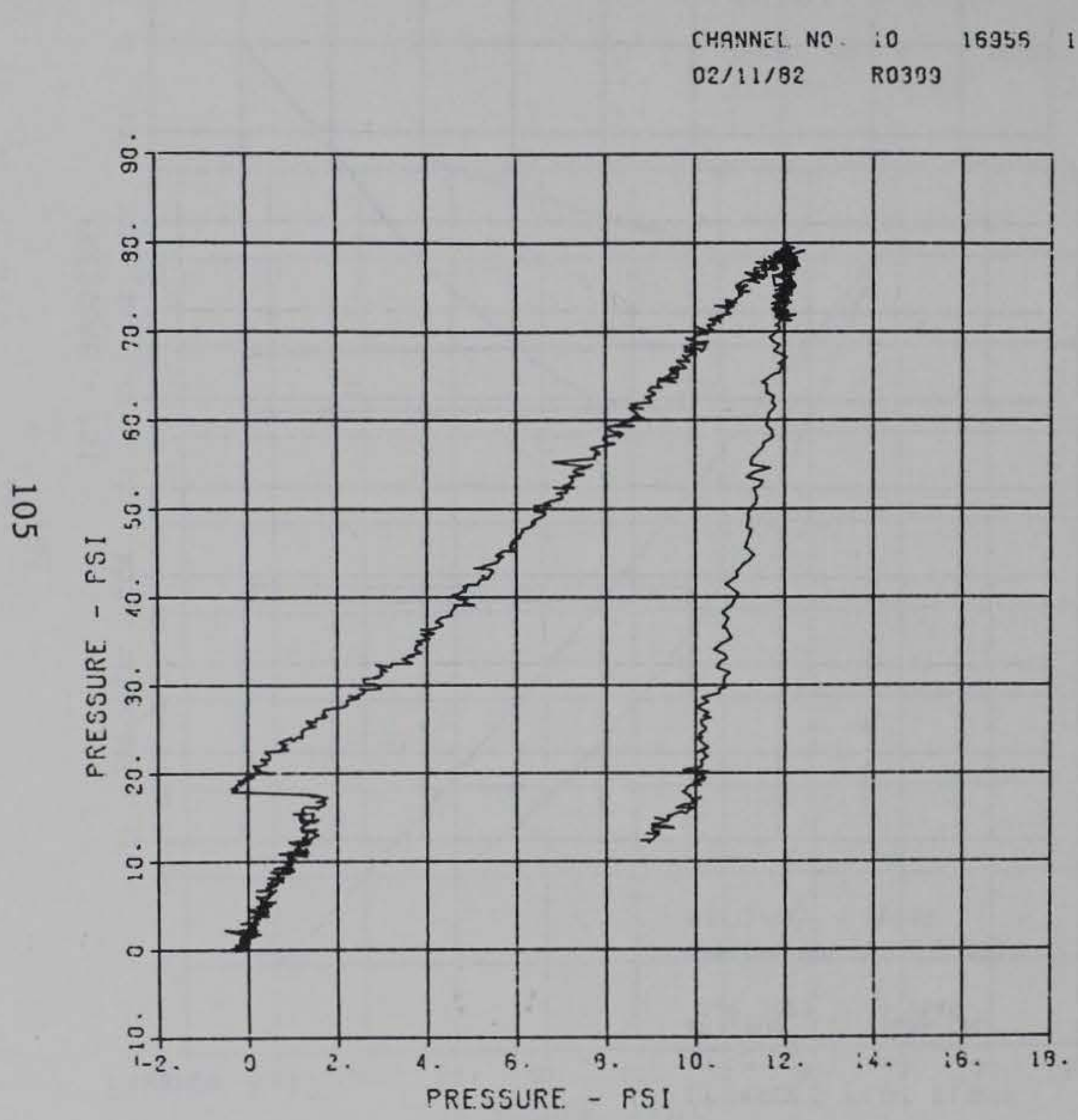

IF - 3

MaxrMuM
12.4571 $\quad 5.534 \mathrm{i}^{\mathrm{AL}}$
Figure A. 16

CAL . ${ }_{44.2}$
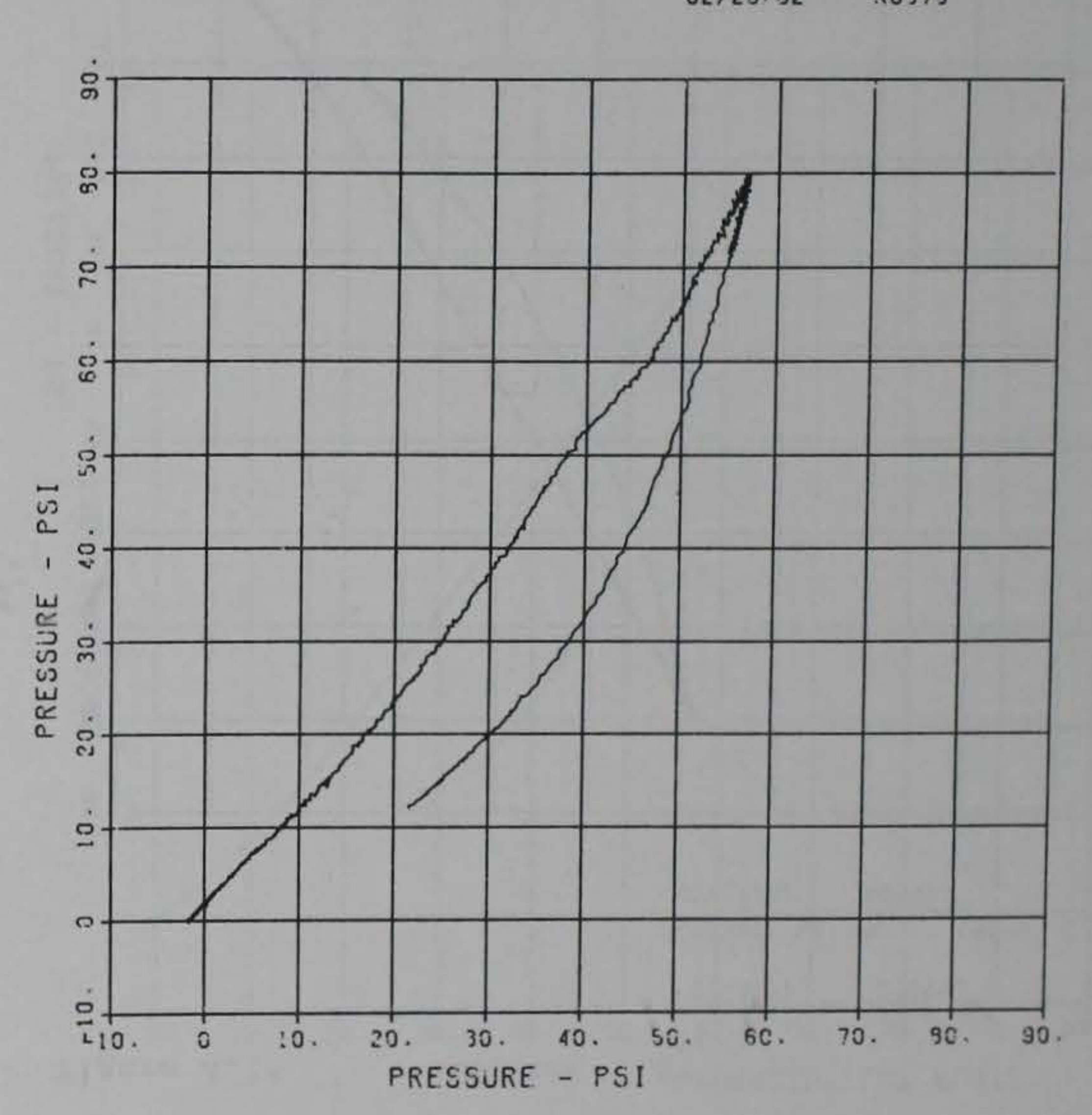
Figure A.17

SPRADED FLA? FLATE

SE- 2

MGXIMUM
100.7223
4.1949

CHQNNEE NO. \& IS95S I

02/11/32 R0399

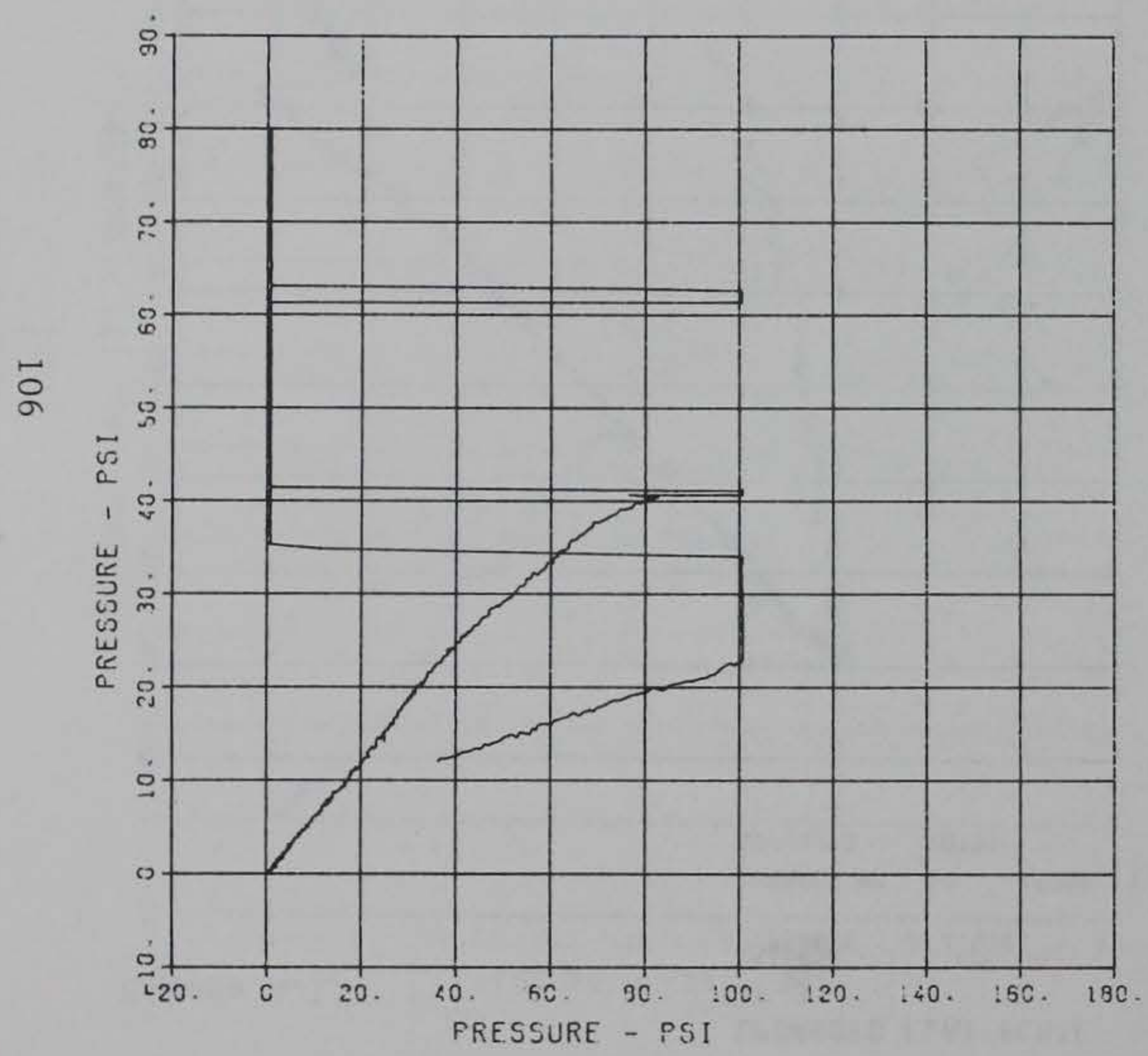

Figure A.18

UPGEDED FLAT PLATE

$S E-3$

MGXIMUM STGMG CAL
$5: .3537$
$2.1550^{\circ}$

CHANNEI NO. 5 1695S 1 02/11/92 R0339

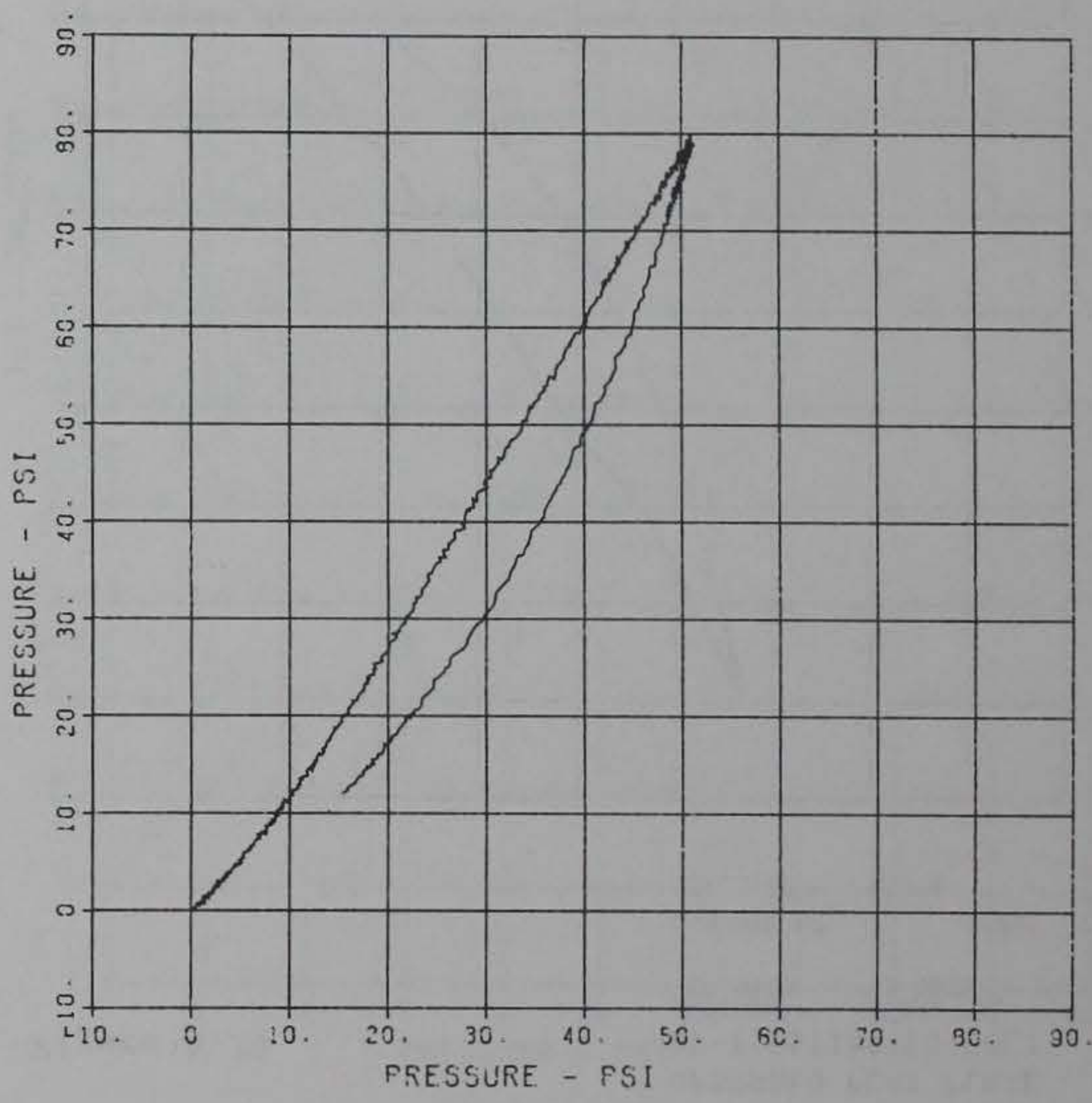


Figure A. 19

UFGRADED FLAT PLATE

FF-SI

MaximuM SIOMG CAL

C8: 2 . AL

CHANNËL NE F 16955 i

O2/1:/82

R0339

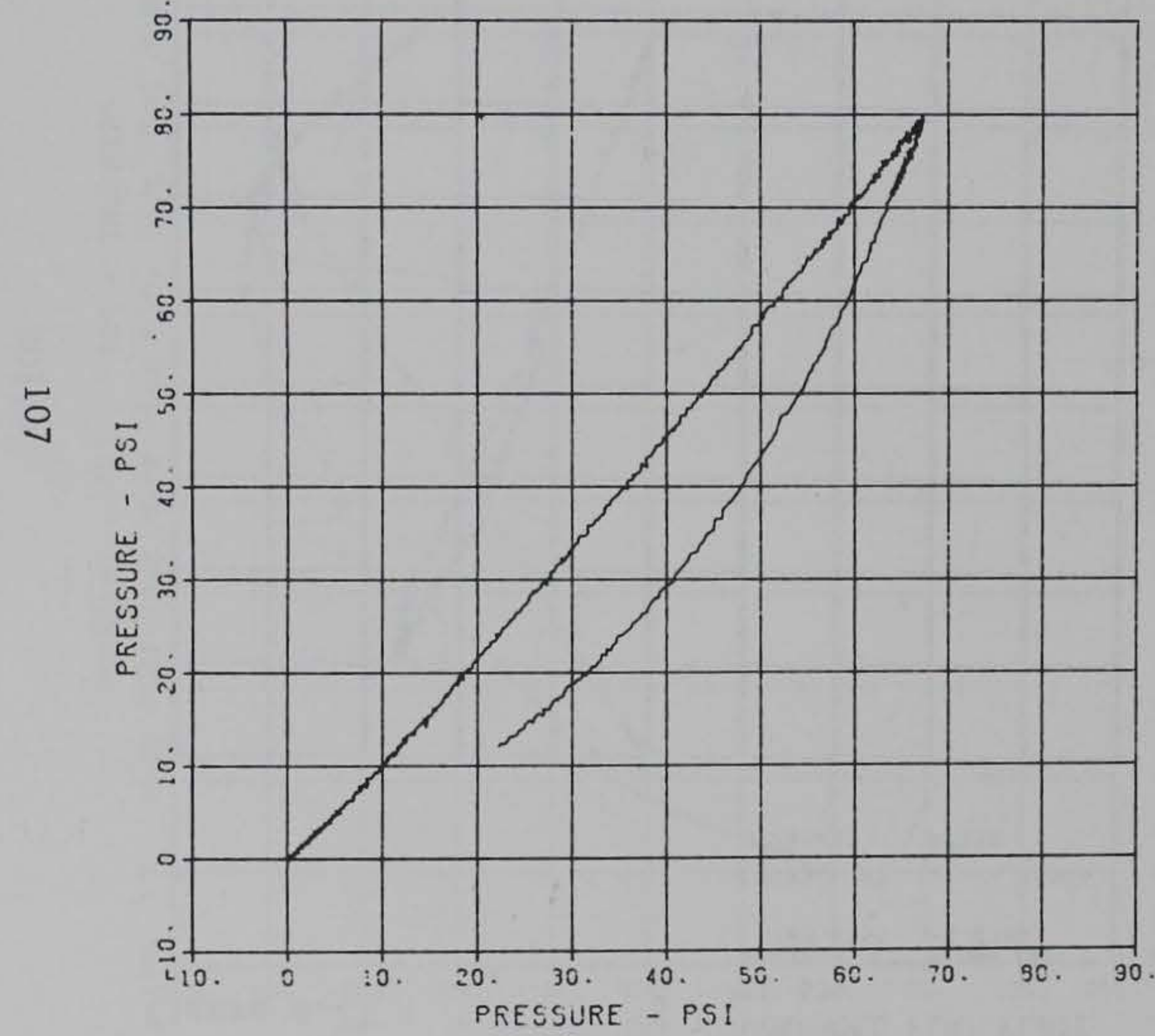

Figure A. 20

UPGRADED FLAT PLATE $\mathrm{FF}-\mathrm{S} 2$

MgXIMUM: SIGMG CAL

CAL $42.7^{A L}$

CHANNEL NO, ? 16955 : 02/11/32 R0339

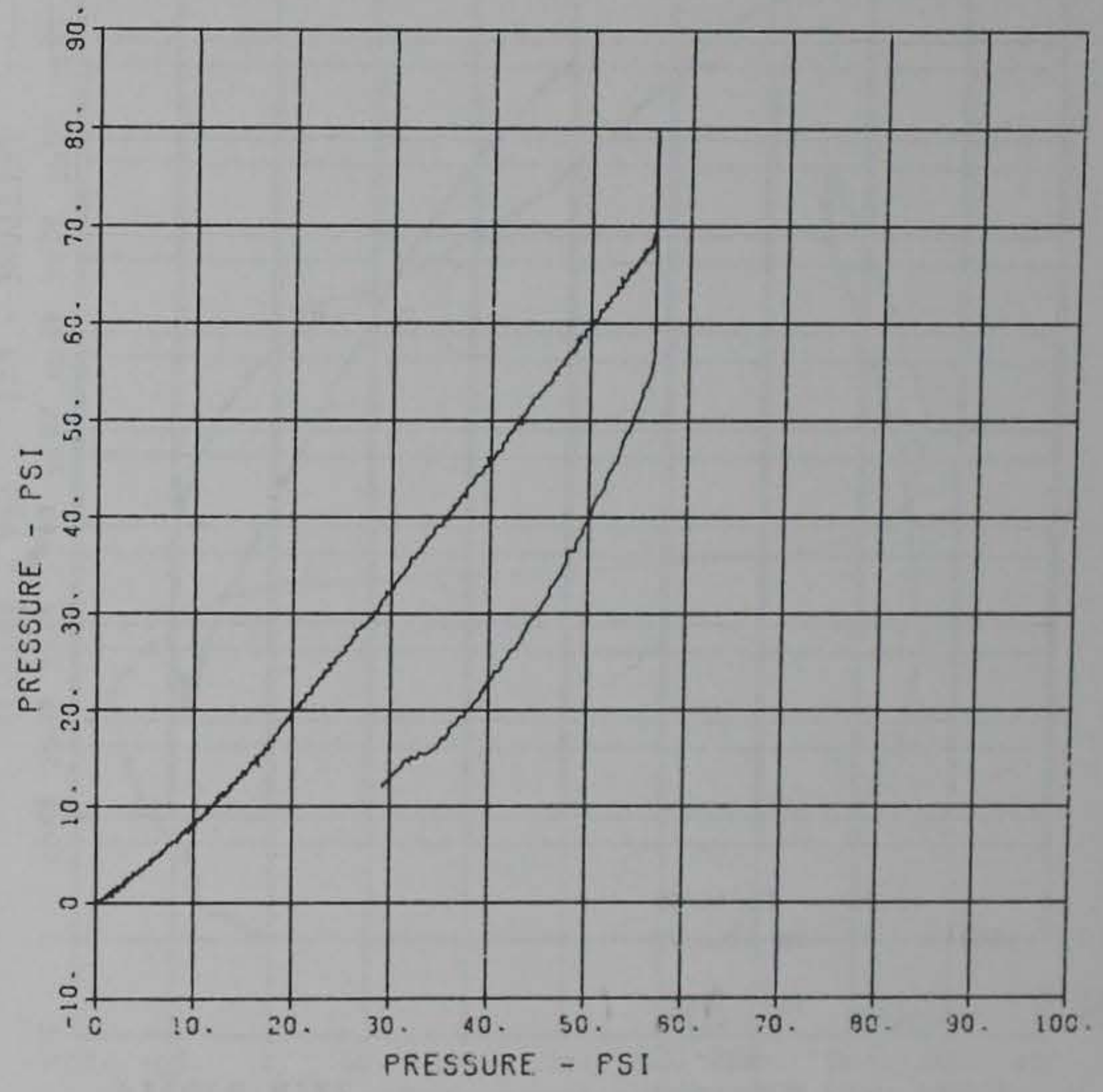


Figure A. 21

UPGRADED FLAT PLATE

SC-SSW

MSXIMUM STGMS CAL
-169.5555
$4.035 E^{2}$

CHONNEL NO A1 16955 ,

02/11/82 R03B9

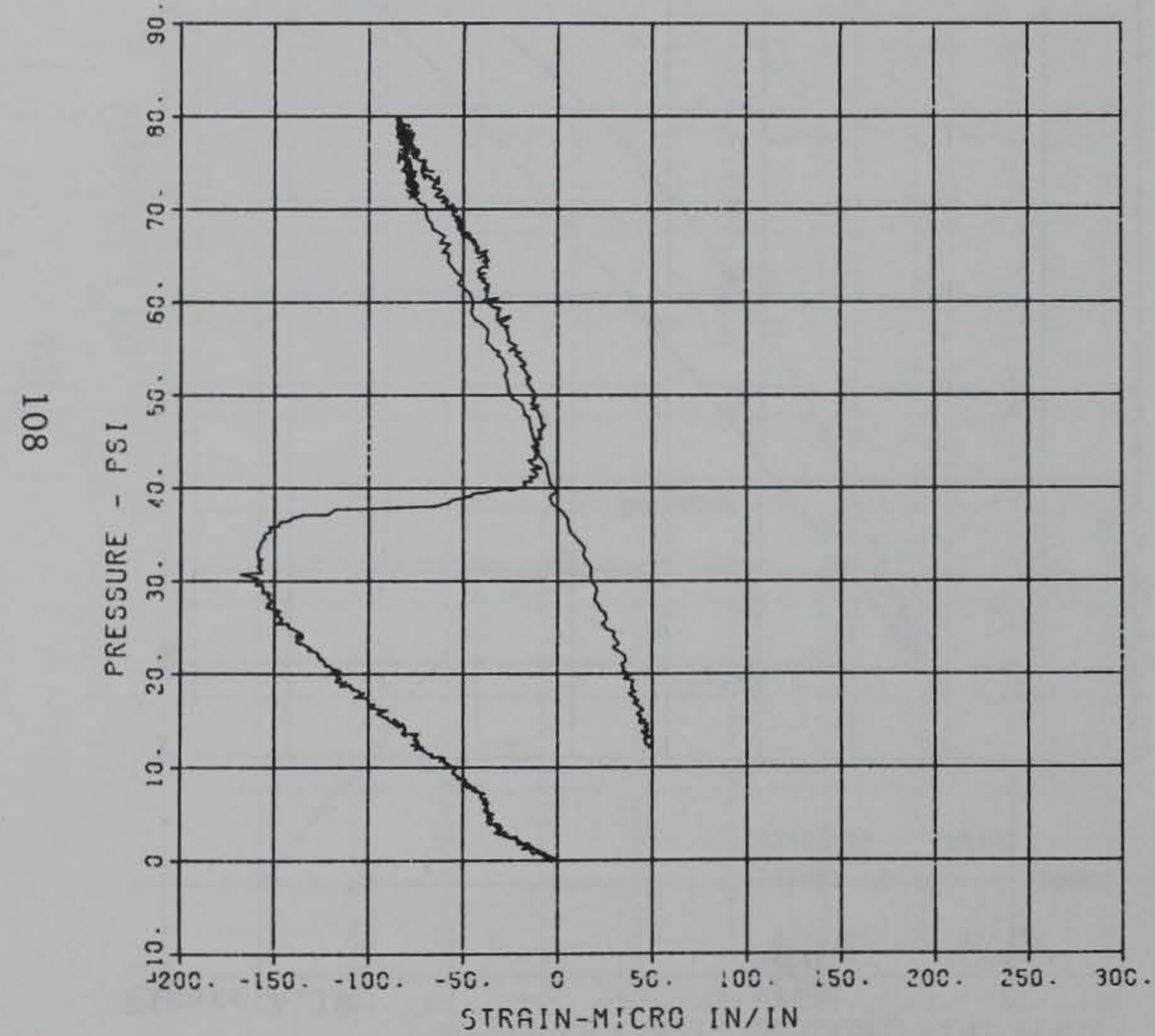

Figure A.22

SG-SSE

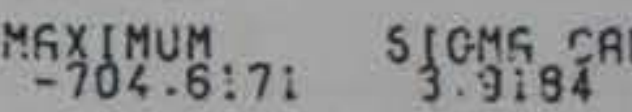

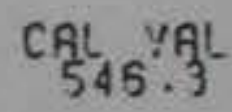

CHANNEI NO. :2 16955 : O2/11/82 R0399

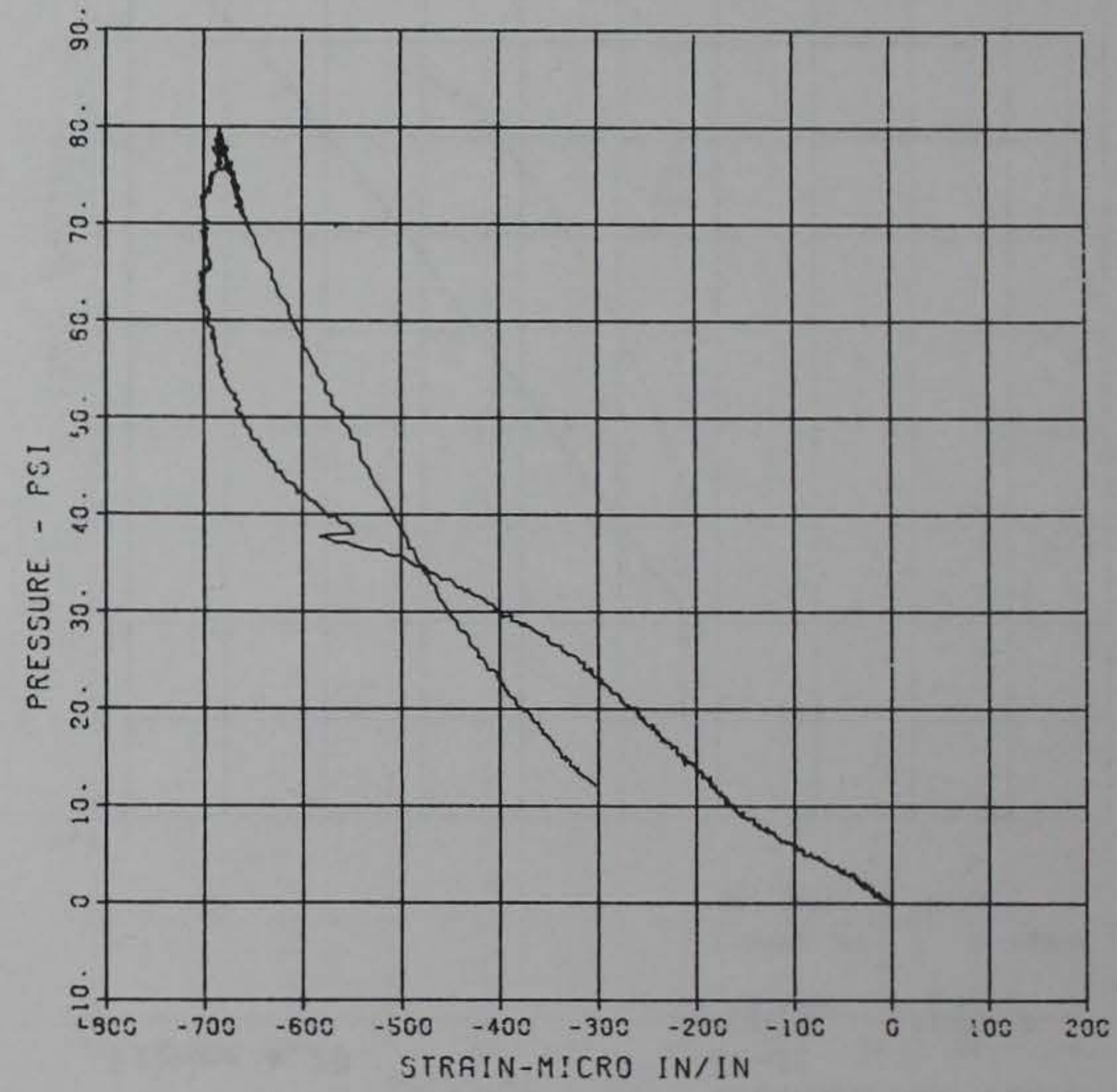


Figure A.23

FGRADED FLAT FLATE

SG-SNE.

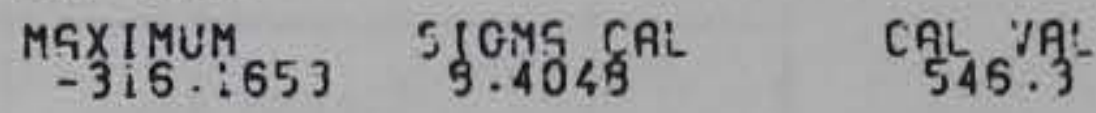

CHANNE: NO :3 15955 :

02/1:/92 R0399

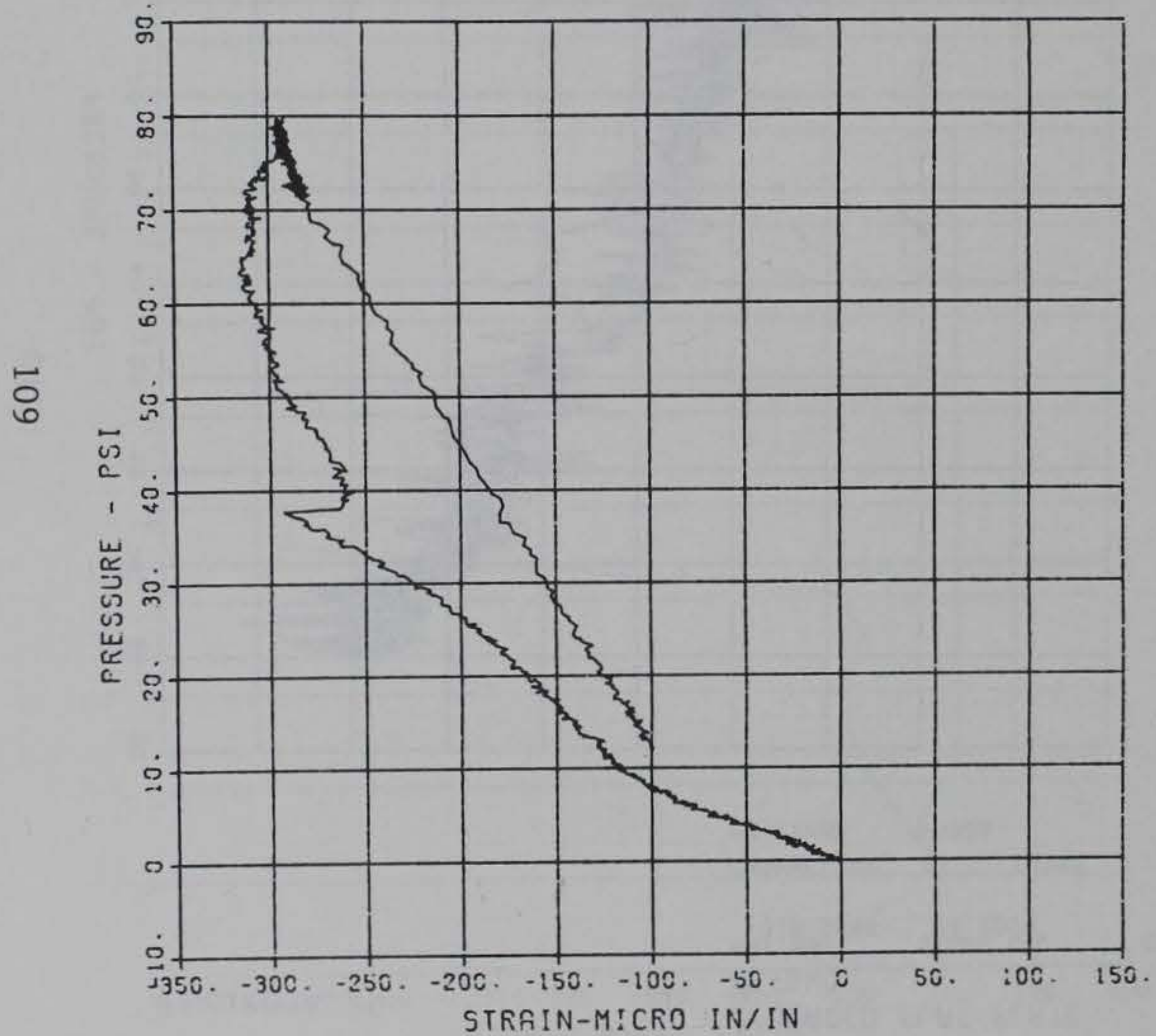

Figure A.24

UPGRADED FLAT PLATE

SG-SNK

MaxiMUM SIOMG CAL

CQLL 546.3 -

CHANNEEI NO 14 ISTSS

O2/11/B2 R03Bg

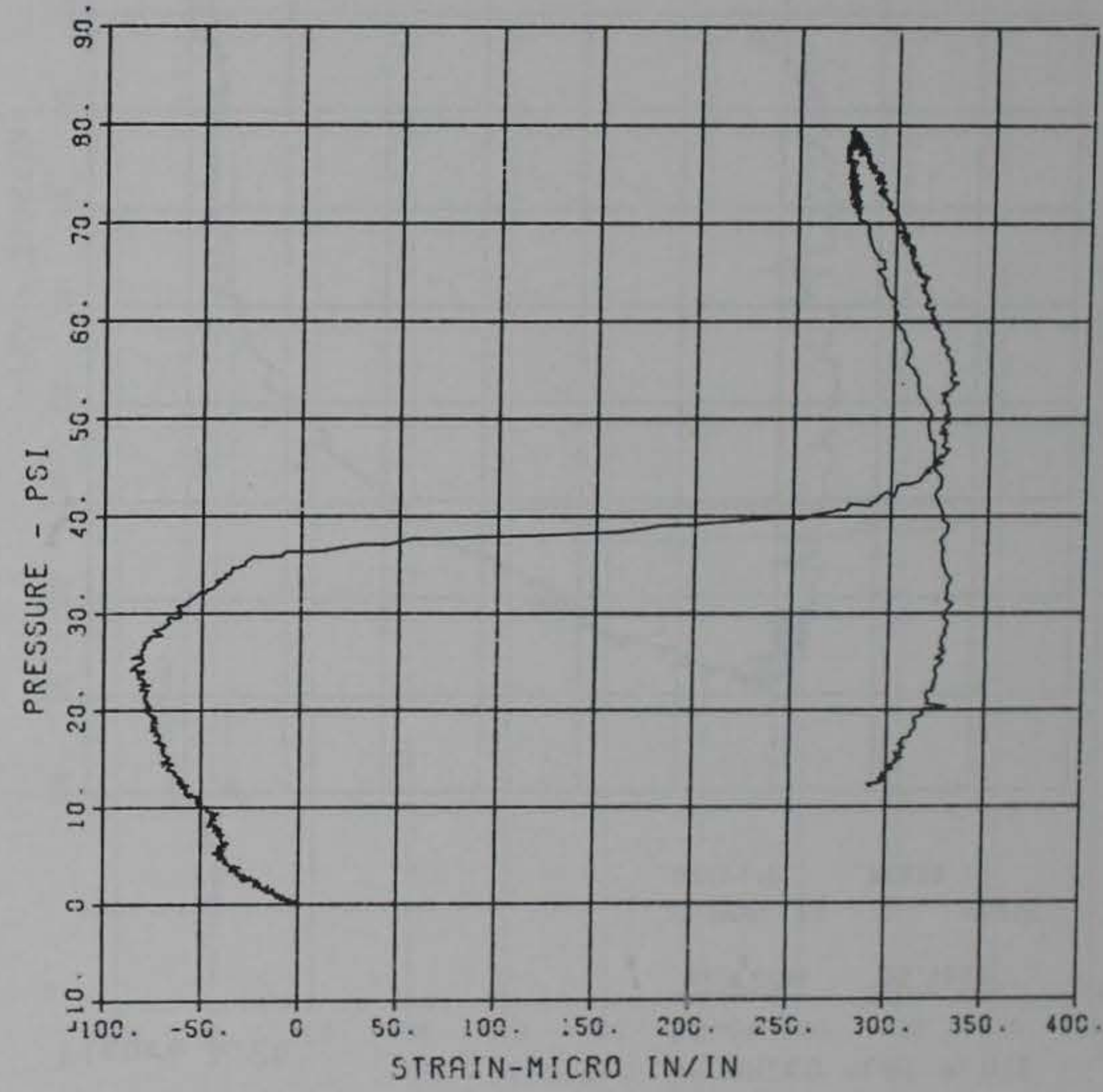


Figure A. 25

UPGRADED FLAT PLATE

SG-SWO

MAXIMUM
-310.9585
SICMA CAL
54.2018

CHANNEL NO. $18 \quad 16956$

02/11/82 R03B9

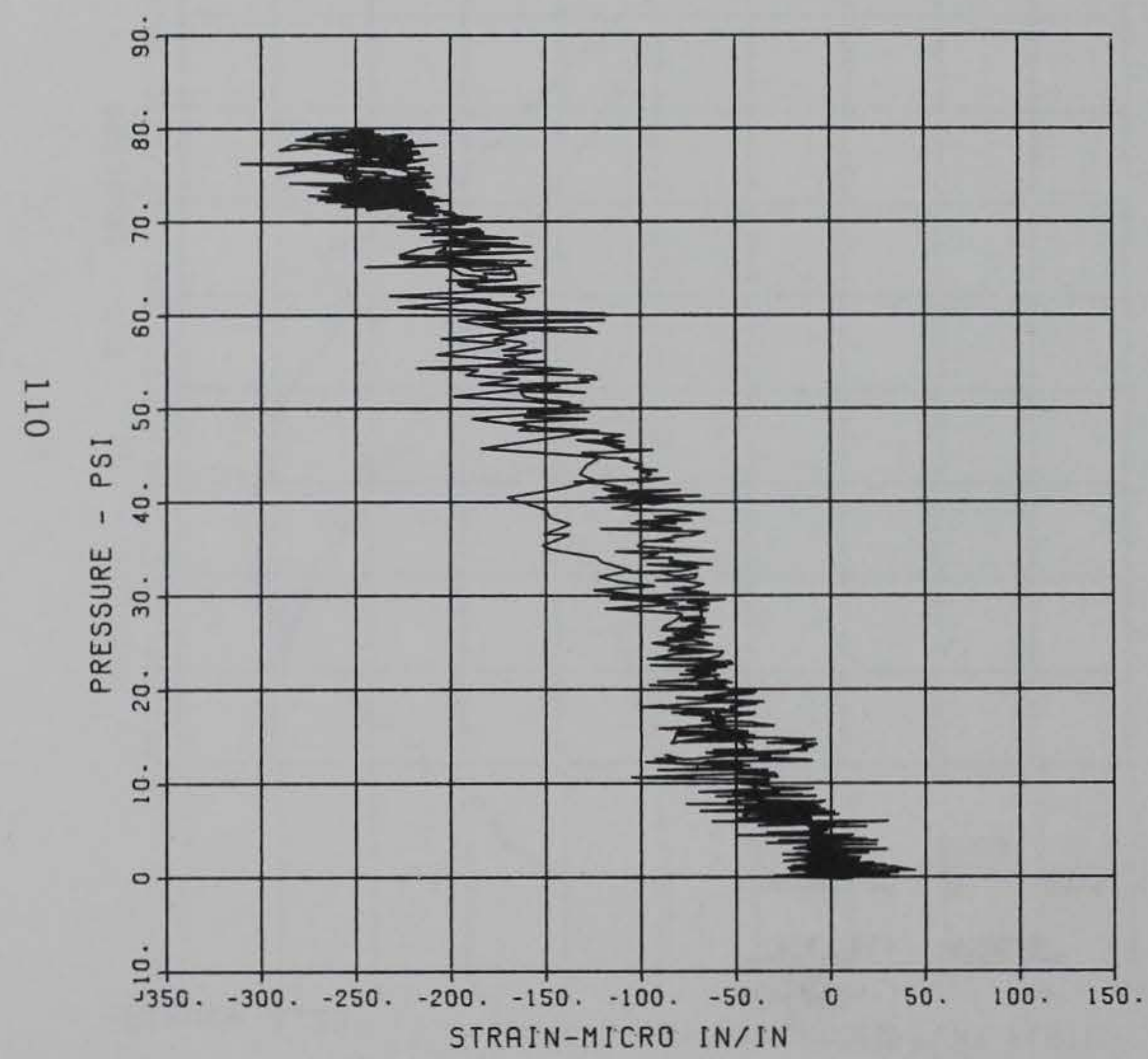

Figure A.26

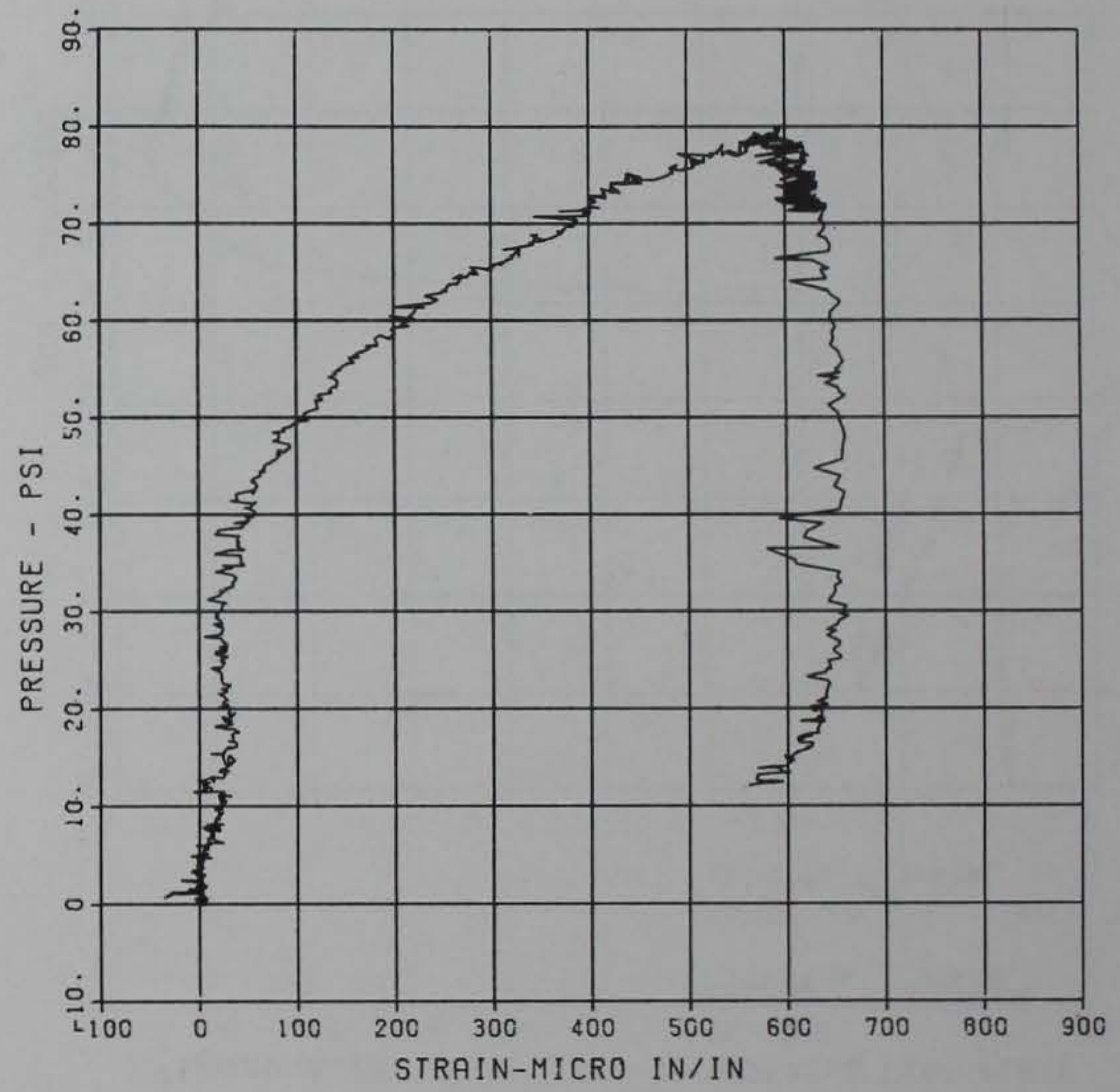

SG-SWI

MGXIMUM
662.4586

CHANNEL NO $\quad 19 \quad 16956$

02/11/82 R0389

UPGRADED FLAT PLATE 
Figure A. 27

UPGRADED FLAT PLATE:

SG-ST 1

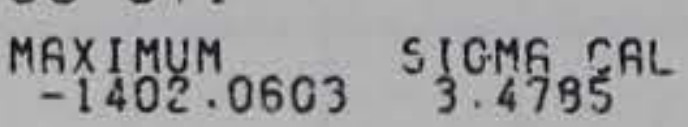

CAุ 970.3

CHANNEL NO I 5 1695S 1

$02 / 11 / 82$

R0339

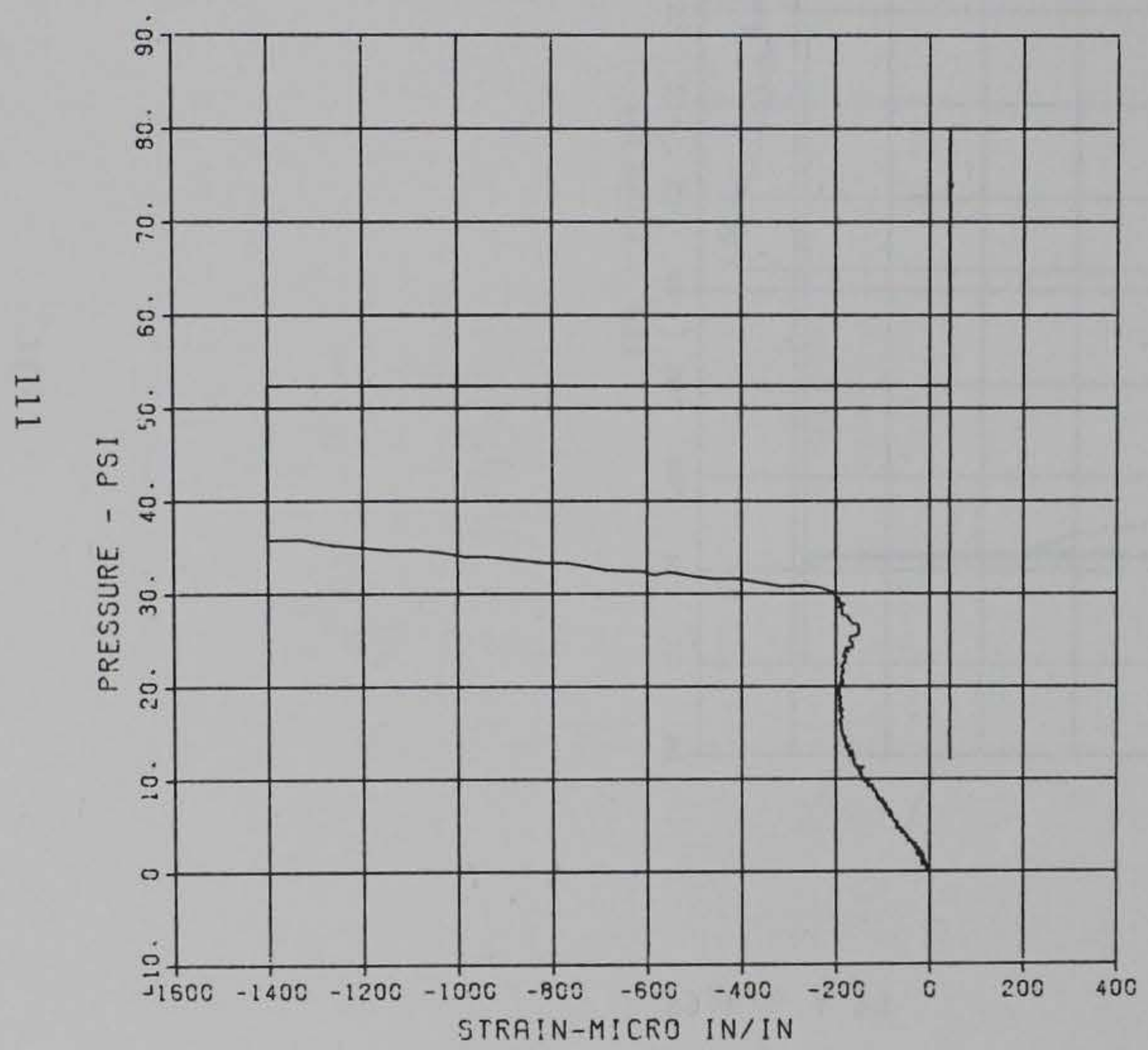

Figure A.28

SG-ST2

MGXIMUM SIOMG CAL

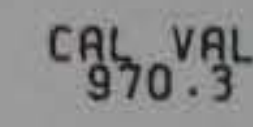

CHANNËL NO :6 16955 I

$02 / 11 / 82$

R0339

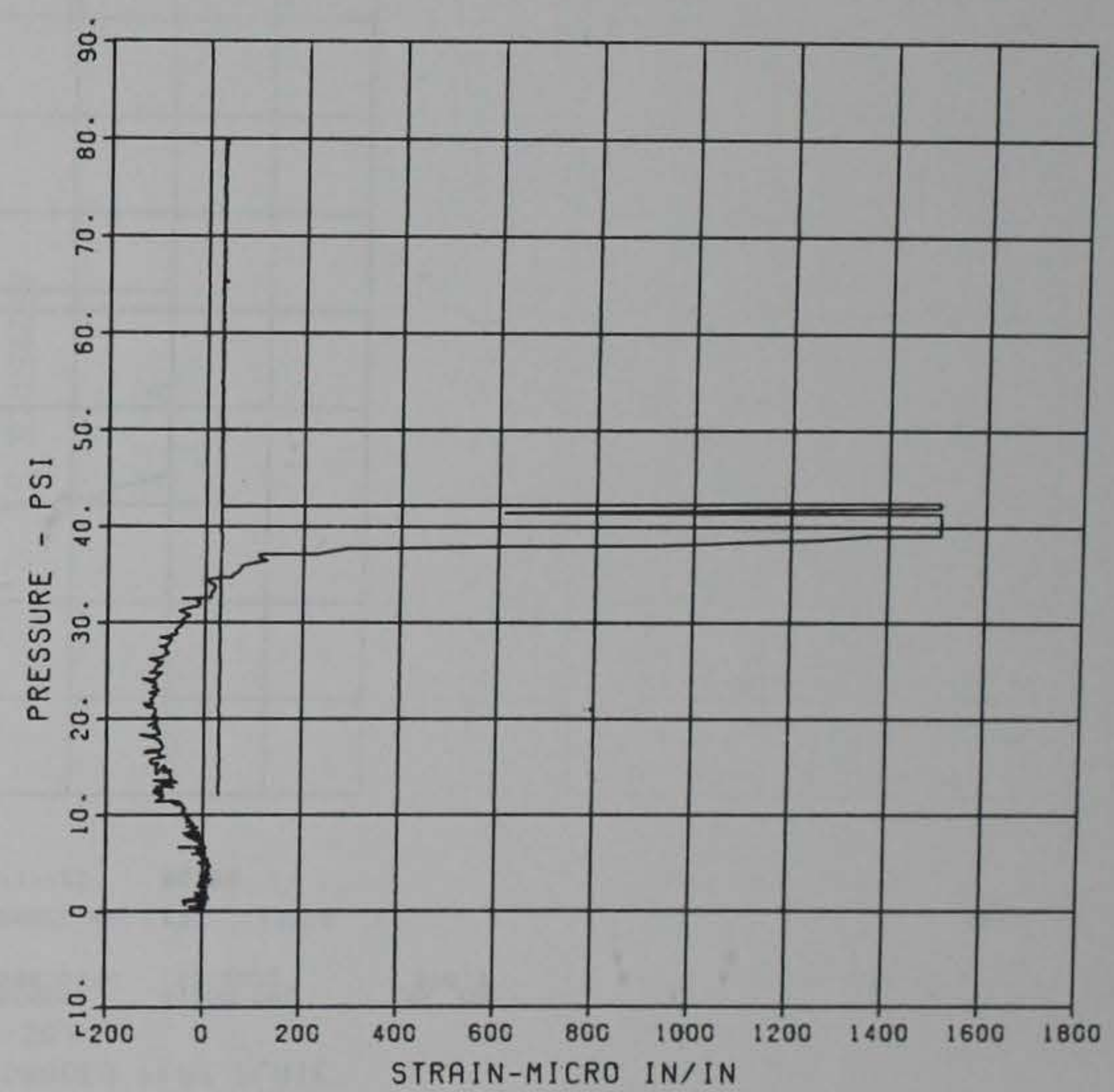


Figure A.29

UPGRADED FLAT PLATE

$S G-S B 2$

$\begin{array}{lll}\text { MAXIMUM } & \text { SIGMA CAL } & \text { CAL VAL } \\ 1398.0474 & { }_{15.2032} & 970.3\end{array}$

CHANNEL NO. $17 \quad 16956$

02/11/82 R0389

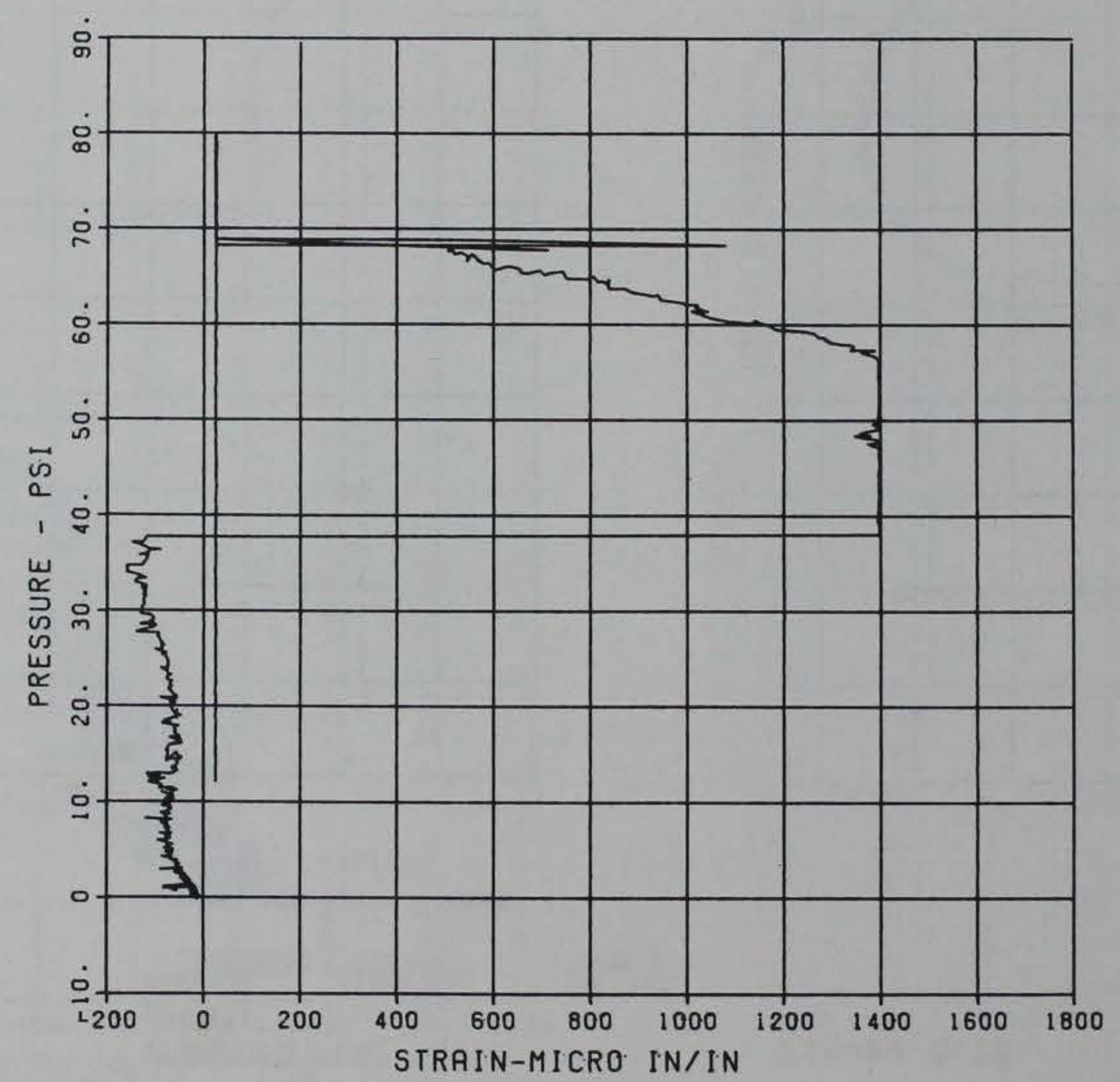


APPENDIX B

DATA FROM THE UPGRADED TWO-WAY SLAB WITH BEAMS MODEL TEST 
Figure B. 1

UPGRADEO 2-WAY SLAG

$P$ - 1

MSXIMUM SIGMG CAL CAL YAL

CHONNE: NG : ISTO 1

$03 / 12 / 82$ ROS21

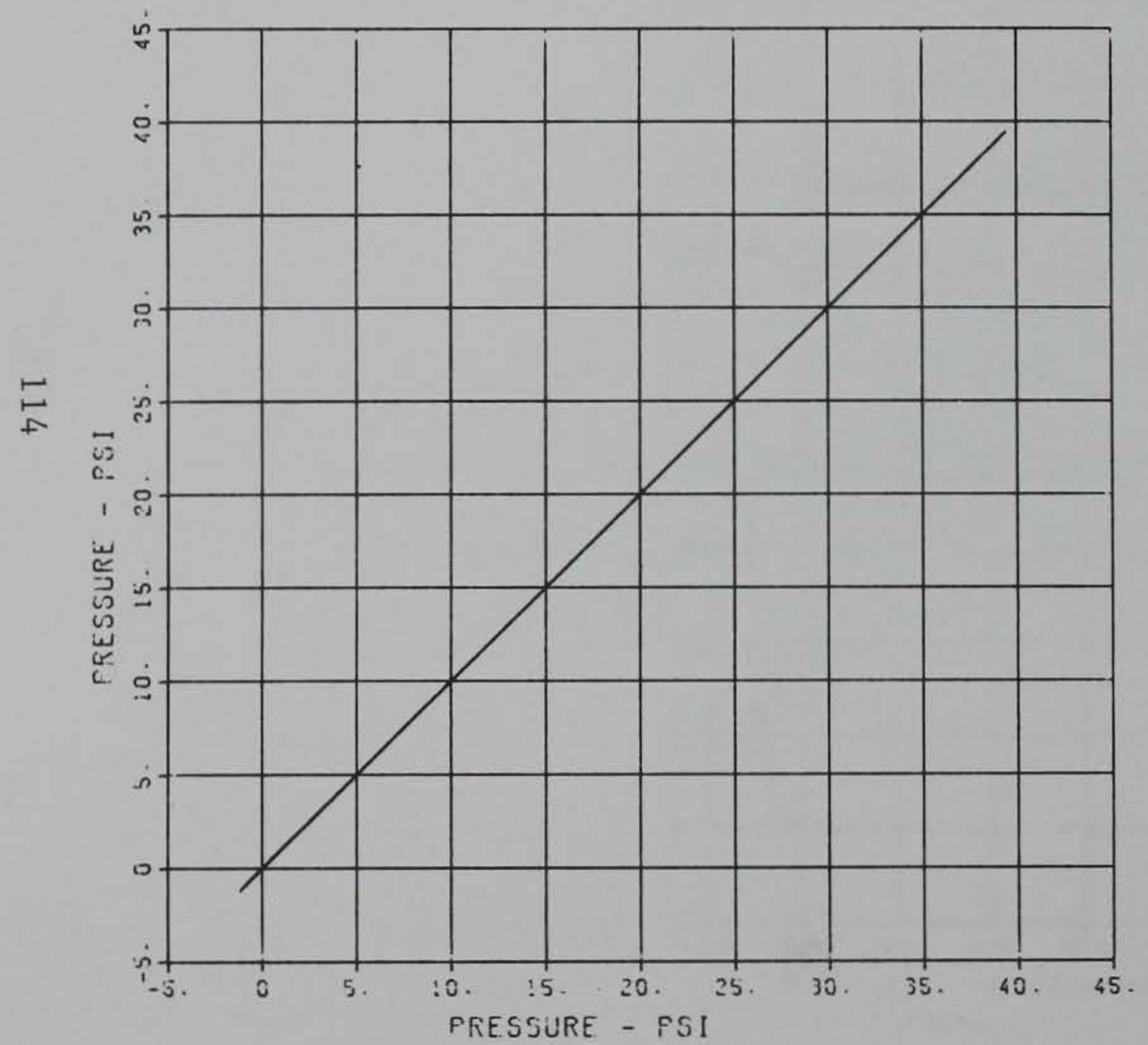

Figure B. 2

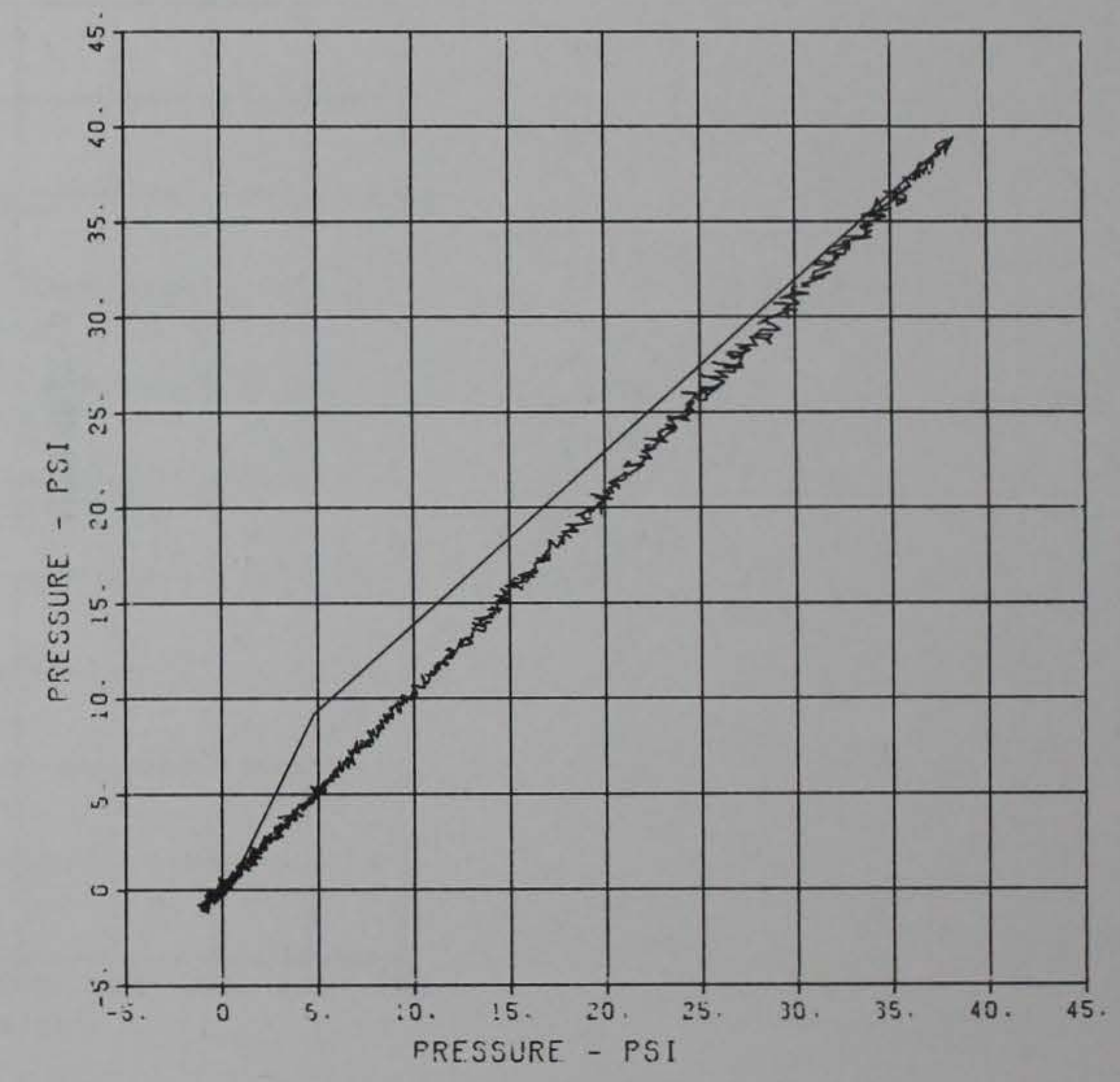

UPGRADED 2-WAY SIAB

$P \cdot 2$

MSXIMUM SICMG CAL

CHANNE: NO. = 19301

03/12/82 R0521 
Figure B.3

UPGRADED 2-WAY SLAS

$D-1$

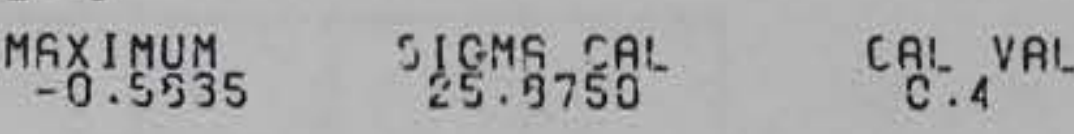

CHANNËL NO. $23 \quad 1990 \quad 1$

$03 / 12 / 82 \quad R 0521$

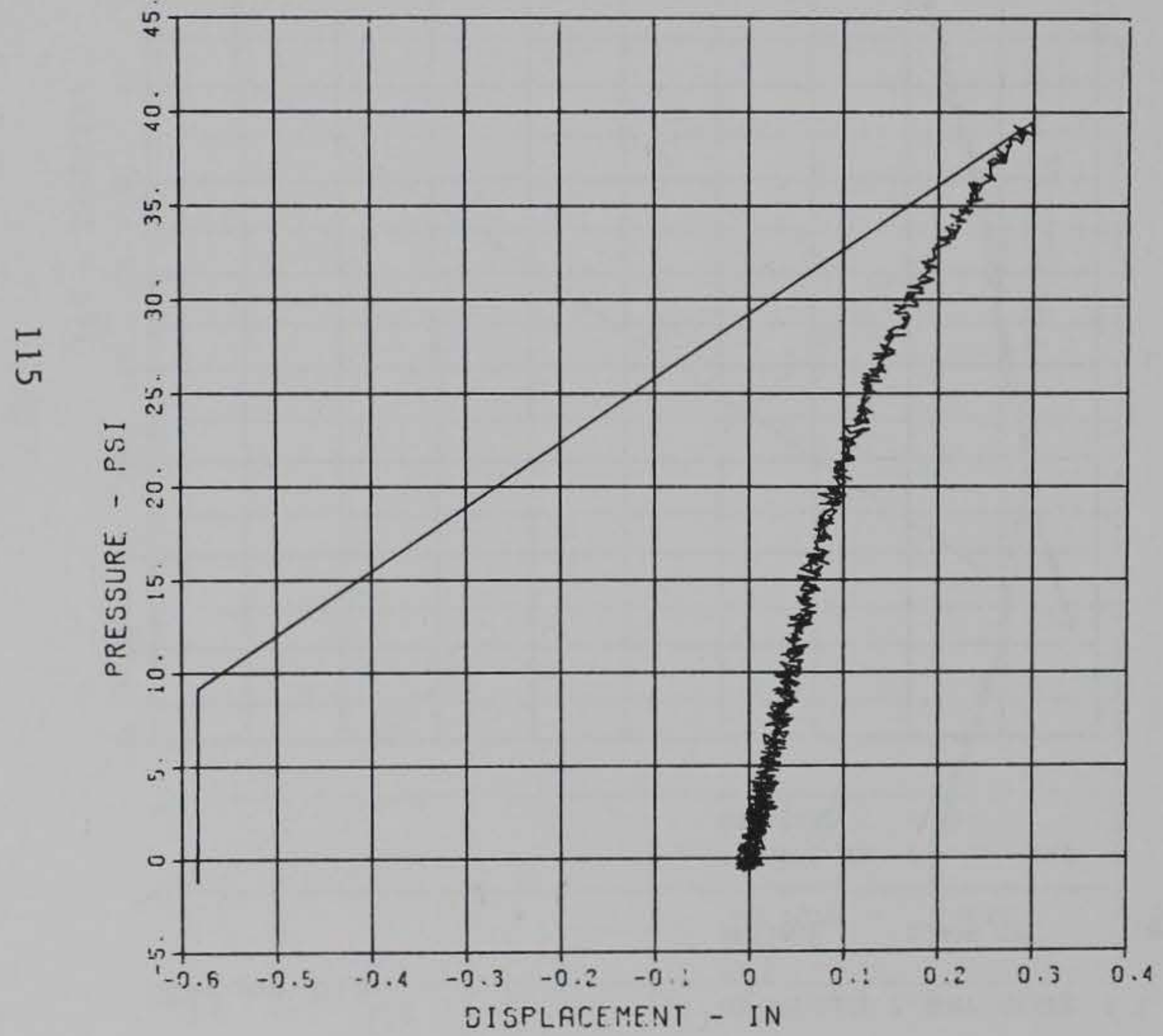

Figure B. 4

(1)

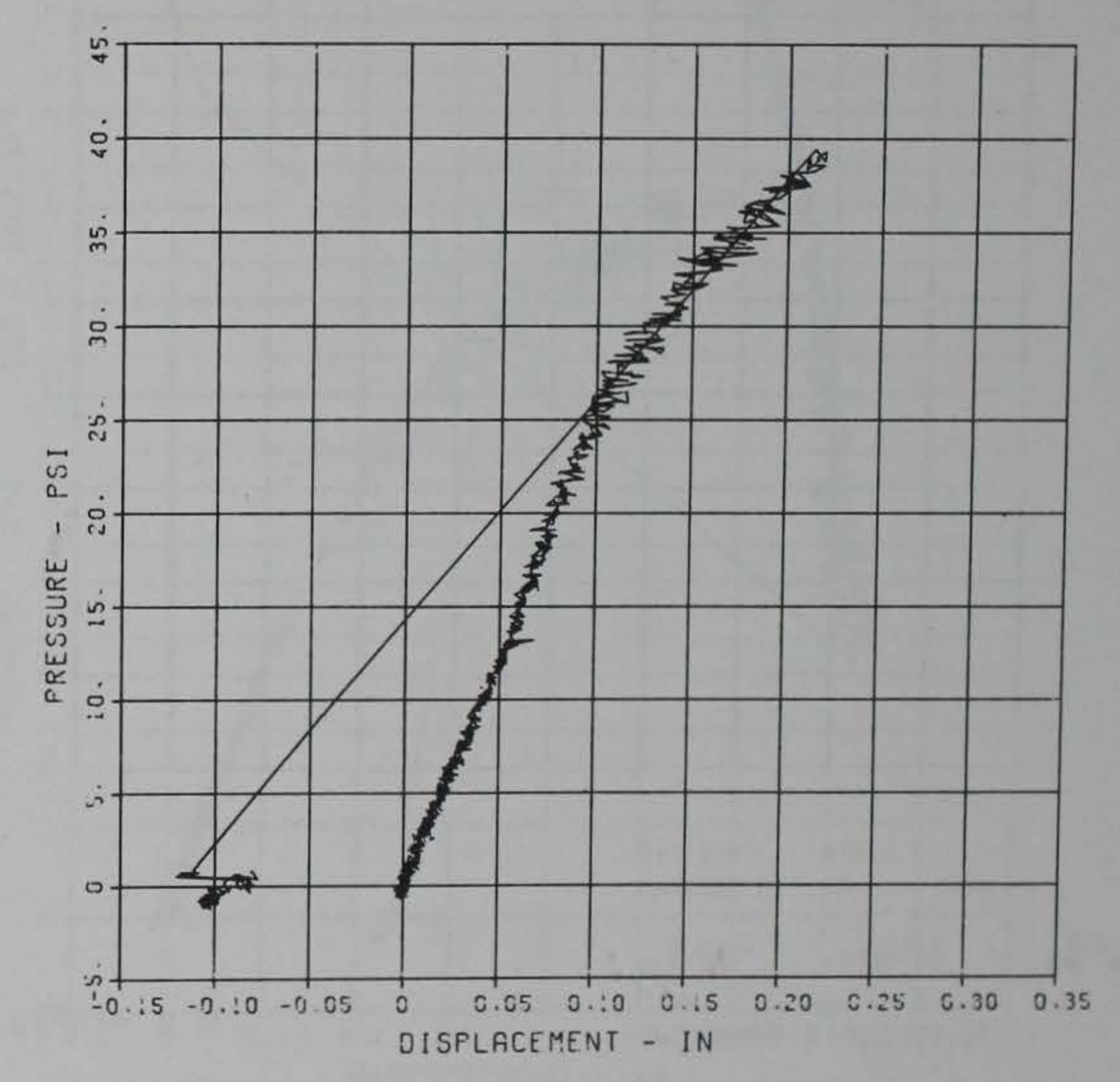

UPGRADED 2-WAY SLAB 
Figure B.5

$0-3$

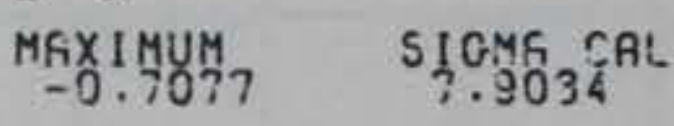

CHGNNE: NO ZS $1990 \quad$

03/12/82 ROS21

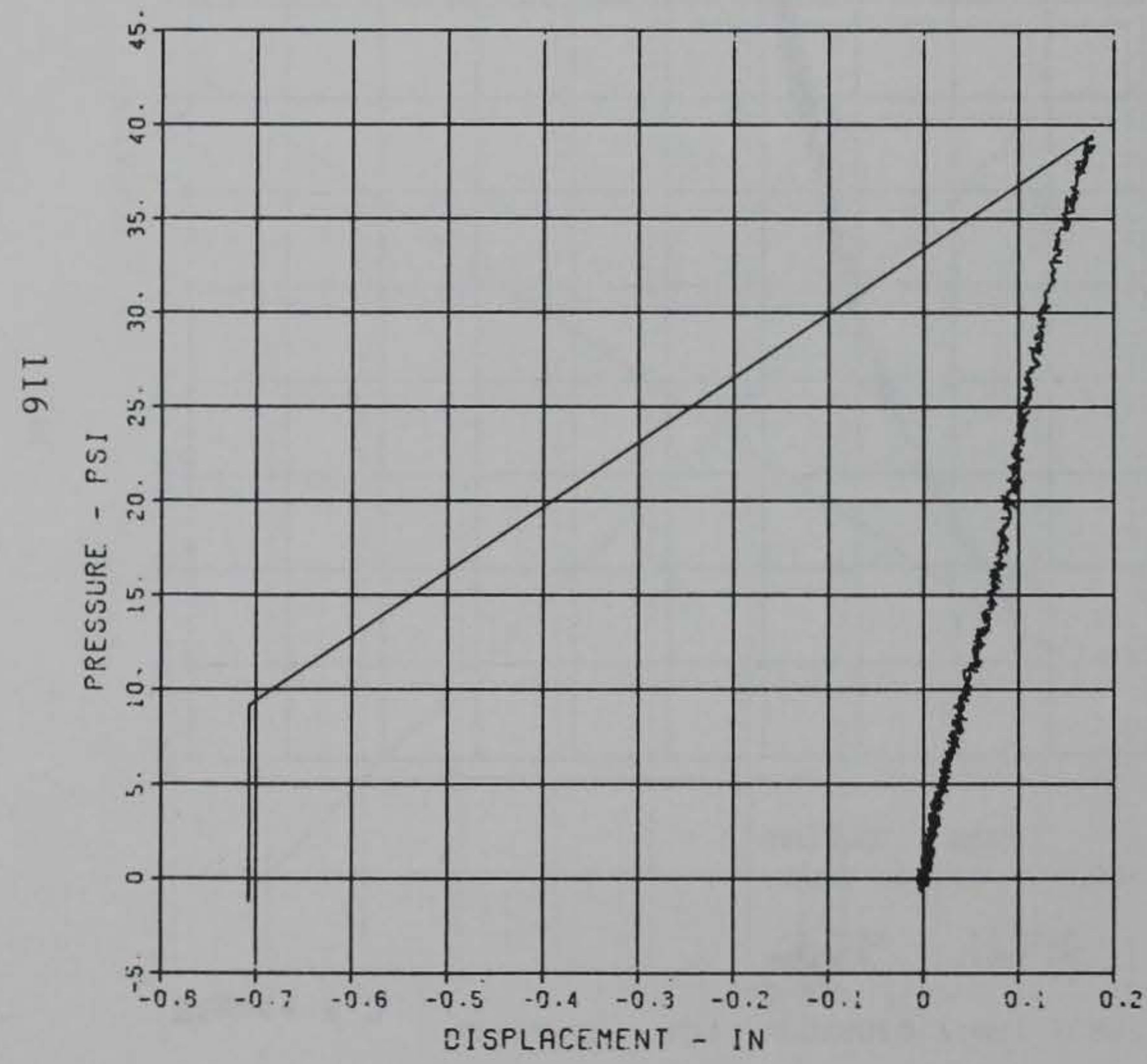

Figure B. 6

รคุ'. ขค'-

UFGRADED 2-WAY SLFB

$\mathrm{S}-1$

MSXIMUM SICMS CRL
-0.5359

CHONNEL NO : $6 \quad 1950 \quad 1$

03/12/82 R0S21

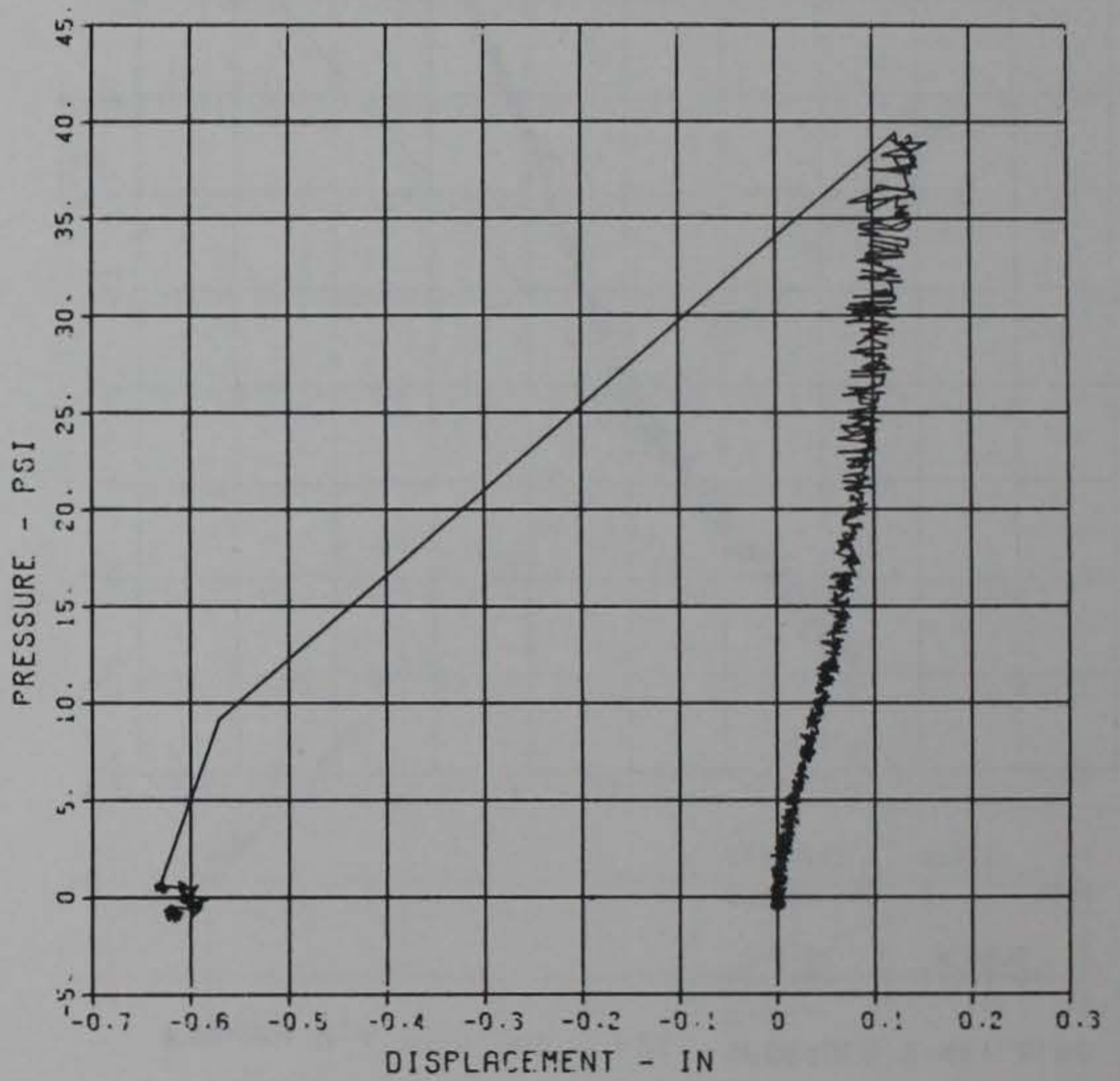


Figure B.7

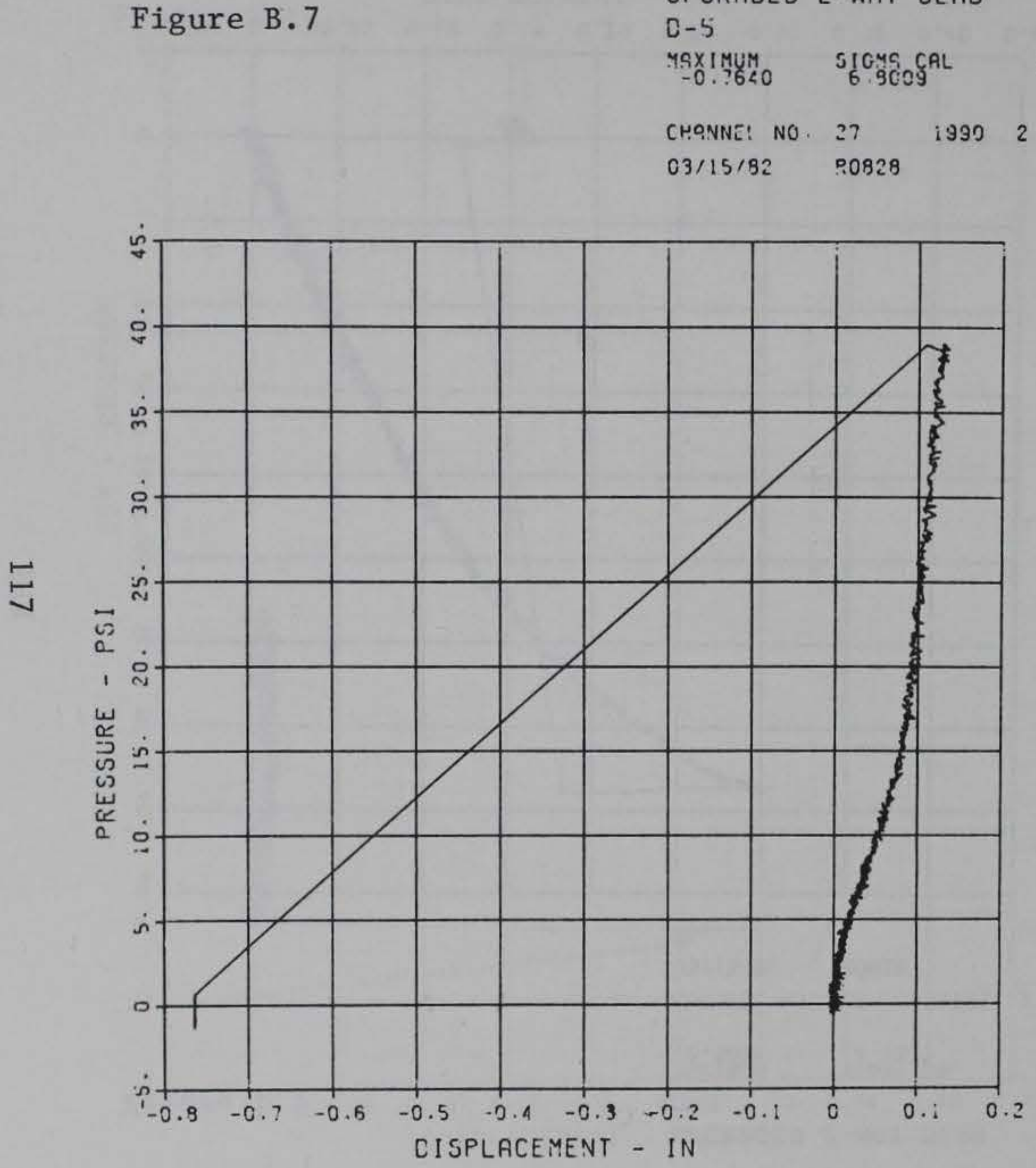

Figure B. 8

CĄL. $s^{\text {YAL }}$

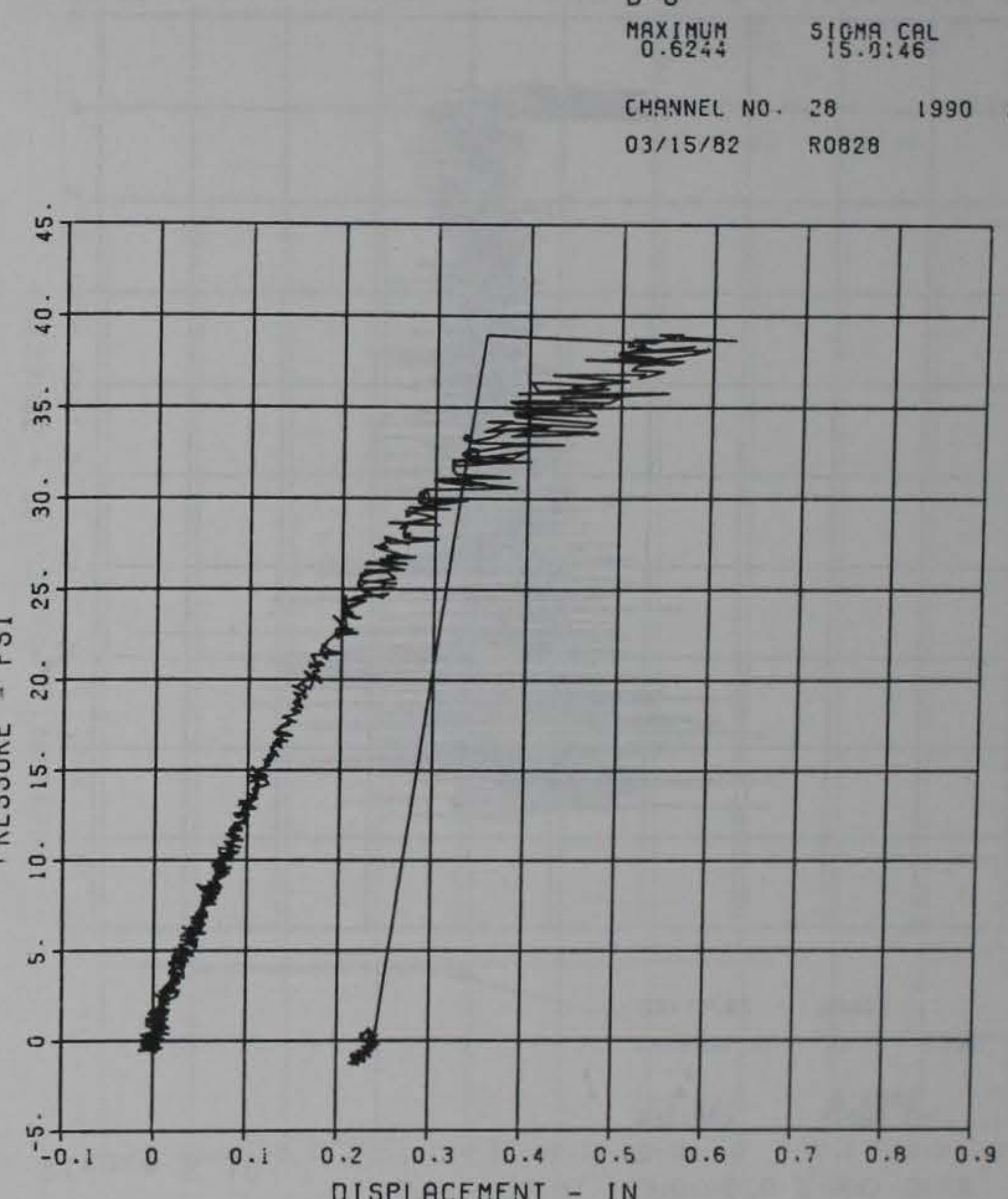

UPGRADED 2-WAY SLAB

D-6

CAL YAL

CHANNEL NO. $28 \quad 1990 \quad 2$

03/15/82 R0828

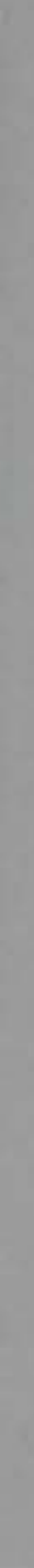


Figure B. 9

UPGRADED 2-WAY SLAB

D-7

MOX.1MUM 51 I.GM9 CAL $\quad$ CRL VAL

CHANNEL. NO. $29 \quad 1990$

03/15/82 R0828

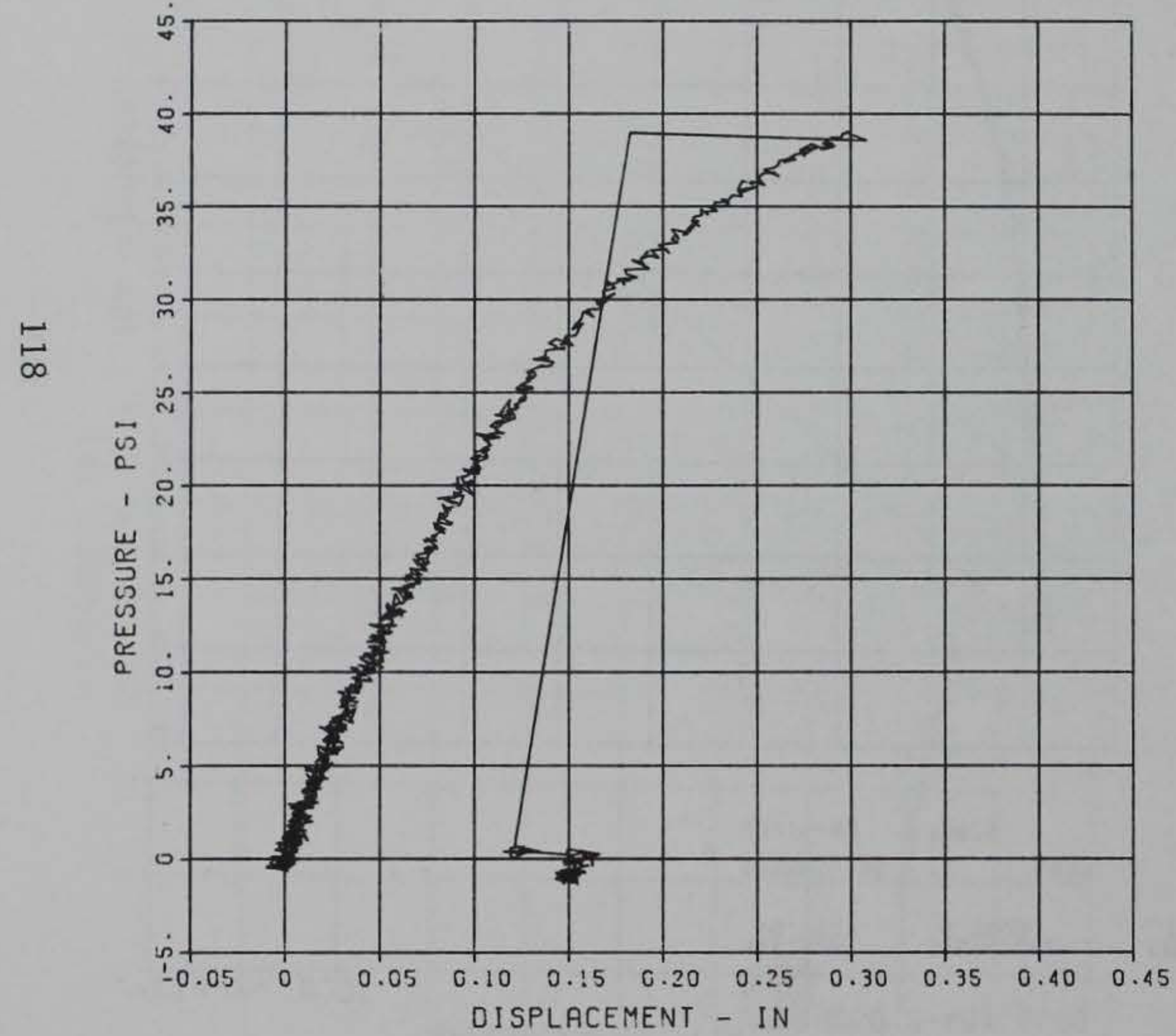

Figure B.10

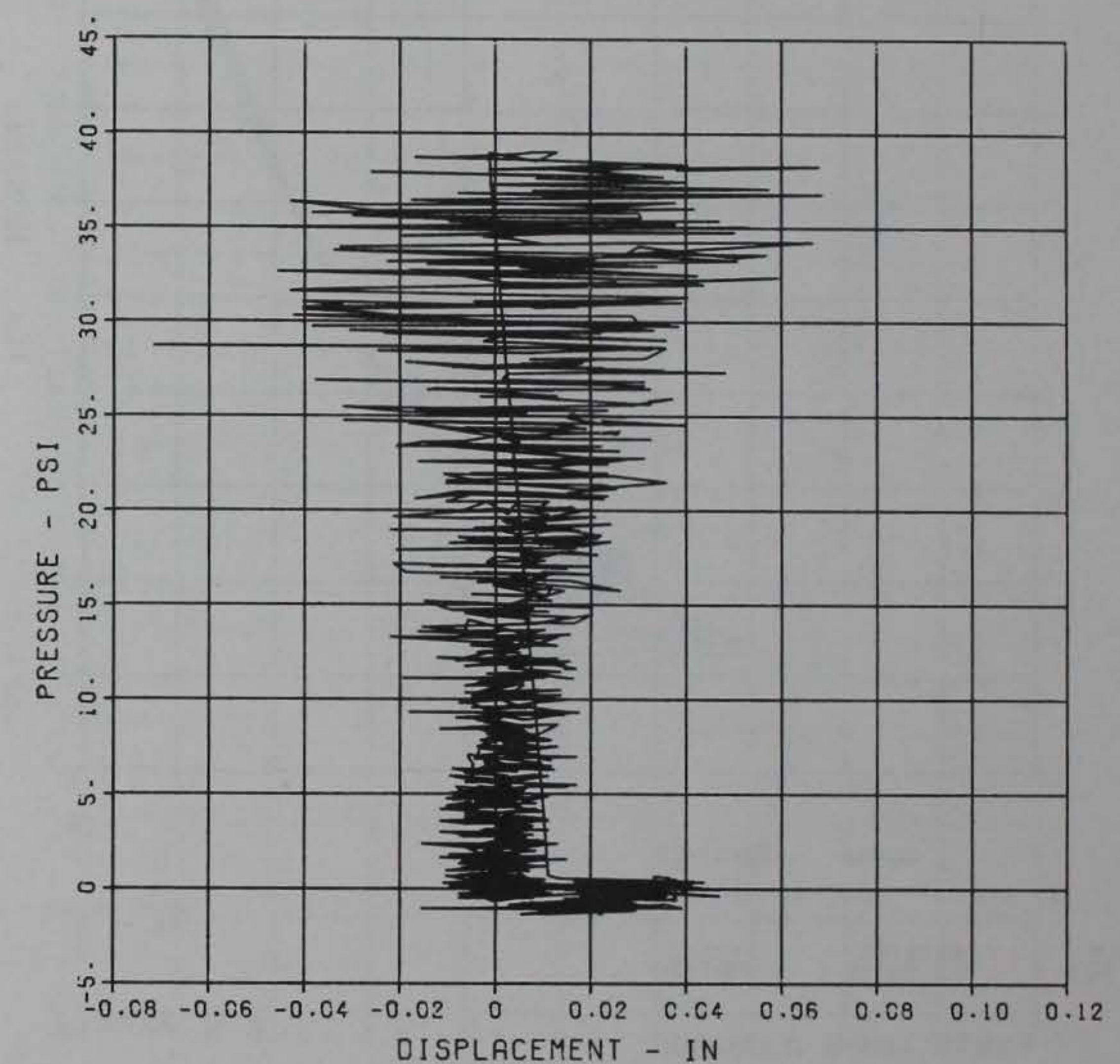

UPGRADED 2-WAY SLAB

$0-8$

MAXIMUM SIGMA CAL
-0.0717 $\quad$ CAL V.5002

CHRNNEL NO. $30 \quad 19902$

03/15/82 ROB28 
Figure B.11

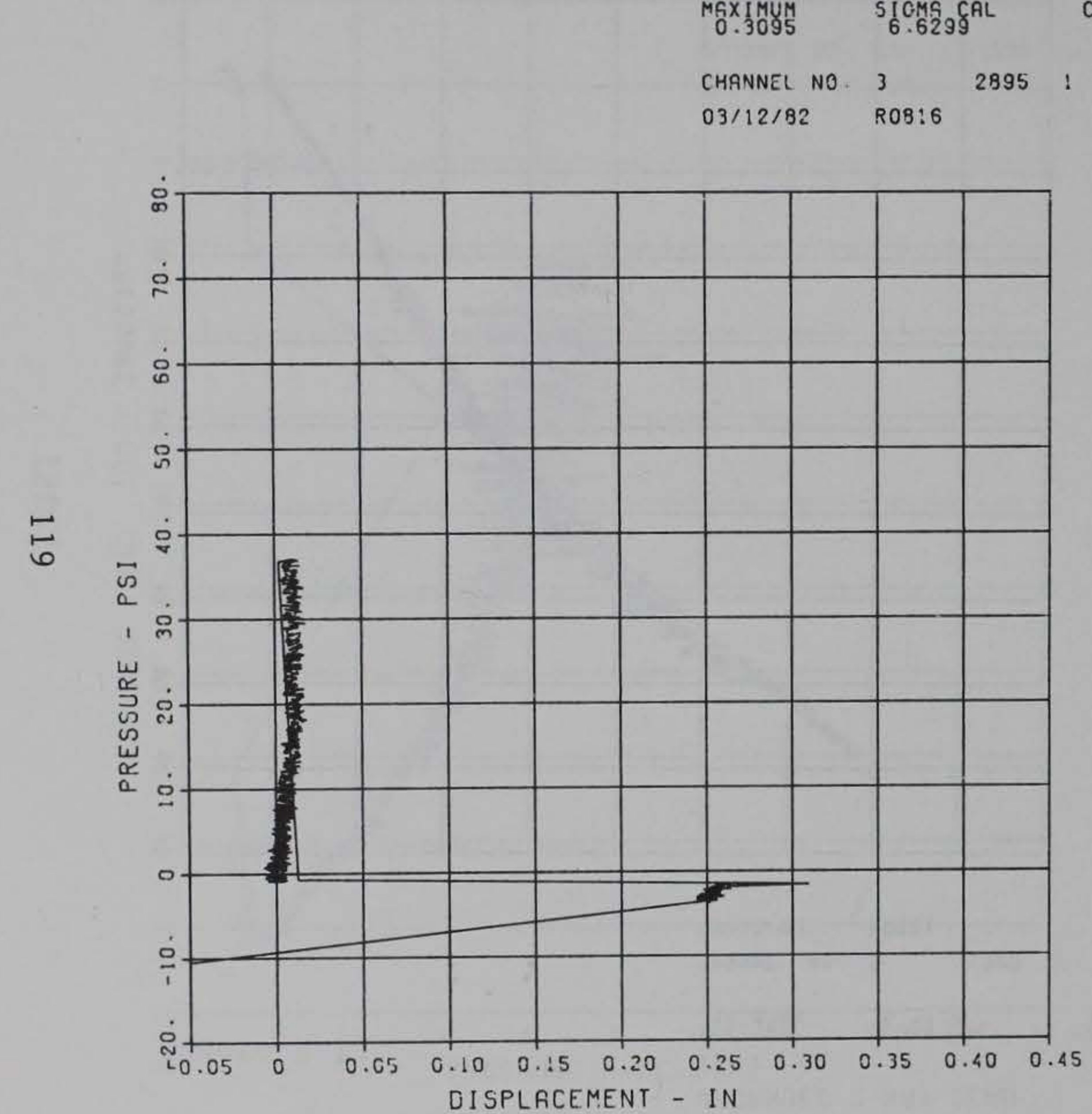

Figure B.12

CAL..$^{\text {YAL }}$

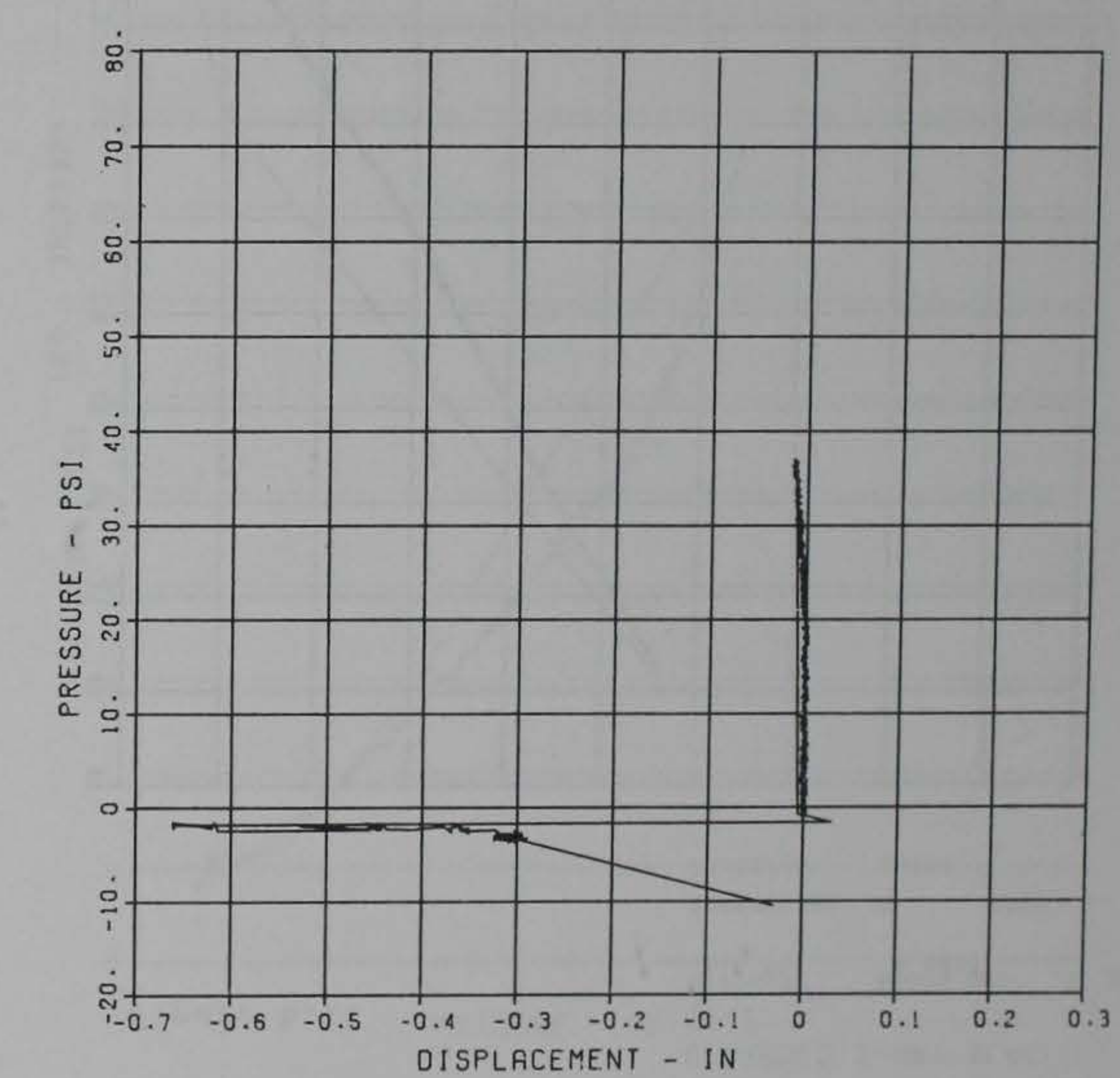

UPGRADED 2-WAY SLAB

$\mathrm{DW}-2$

MAXIMUM SIGMS CAL

CAgL YAL

CHANNEL NO \& 2895 :

03/12/82 ROB!6

DPLACEMENT - IN 


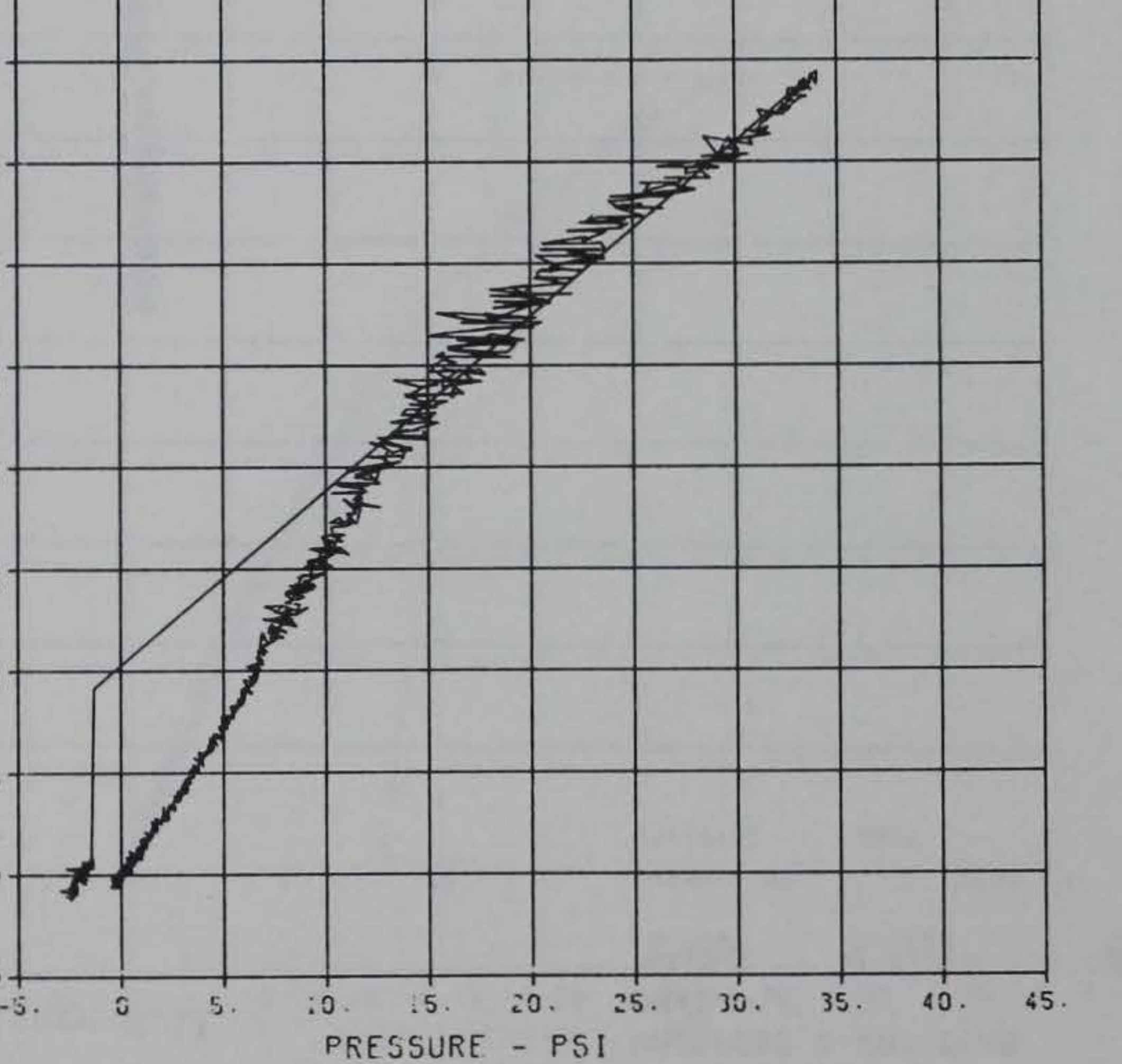<smiles>C1CC1</smiles> 
Figure B. 15

UPGRADED 2-WAY SLAS

IF -3

M.

C6: 42.9 .

CHGNNE! NO $O$ T

$03 / 12 / 82$ P0921

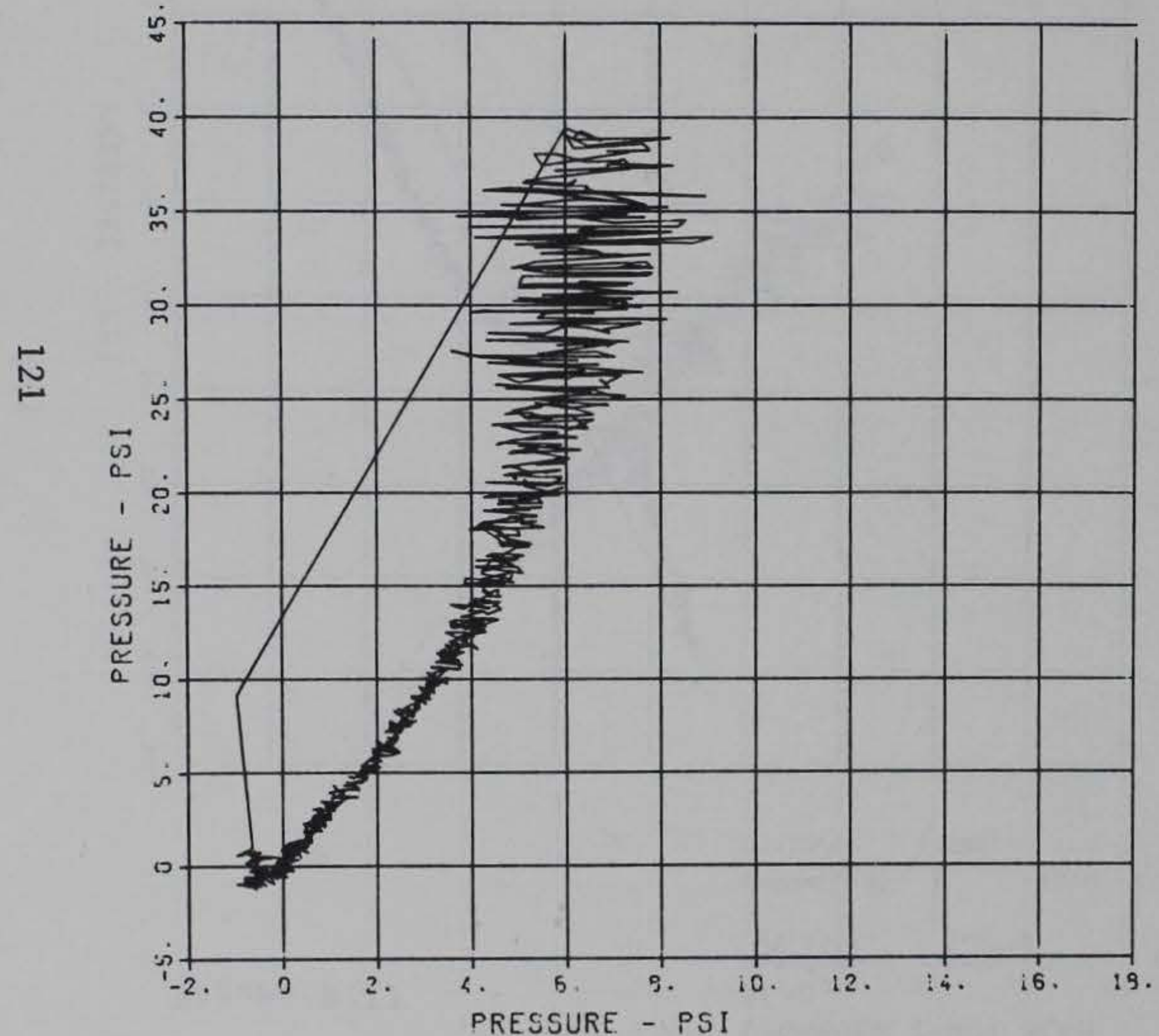

Figure B.16
UPGRADED ¿-WAY SLAS

SE- 1

MAXIMUM SIुGMA CAL

CHANNET. NO $3 \quad 1990 \quad 1$

$03 / 12 / 82$

R0S2:

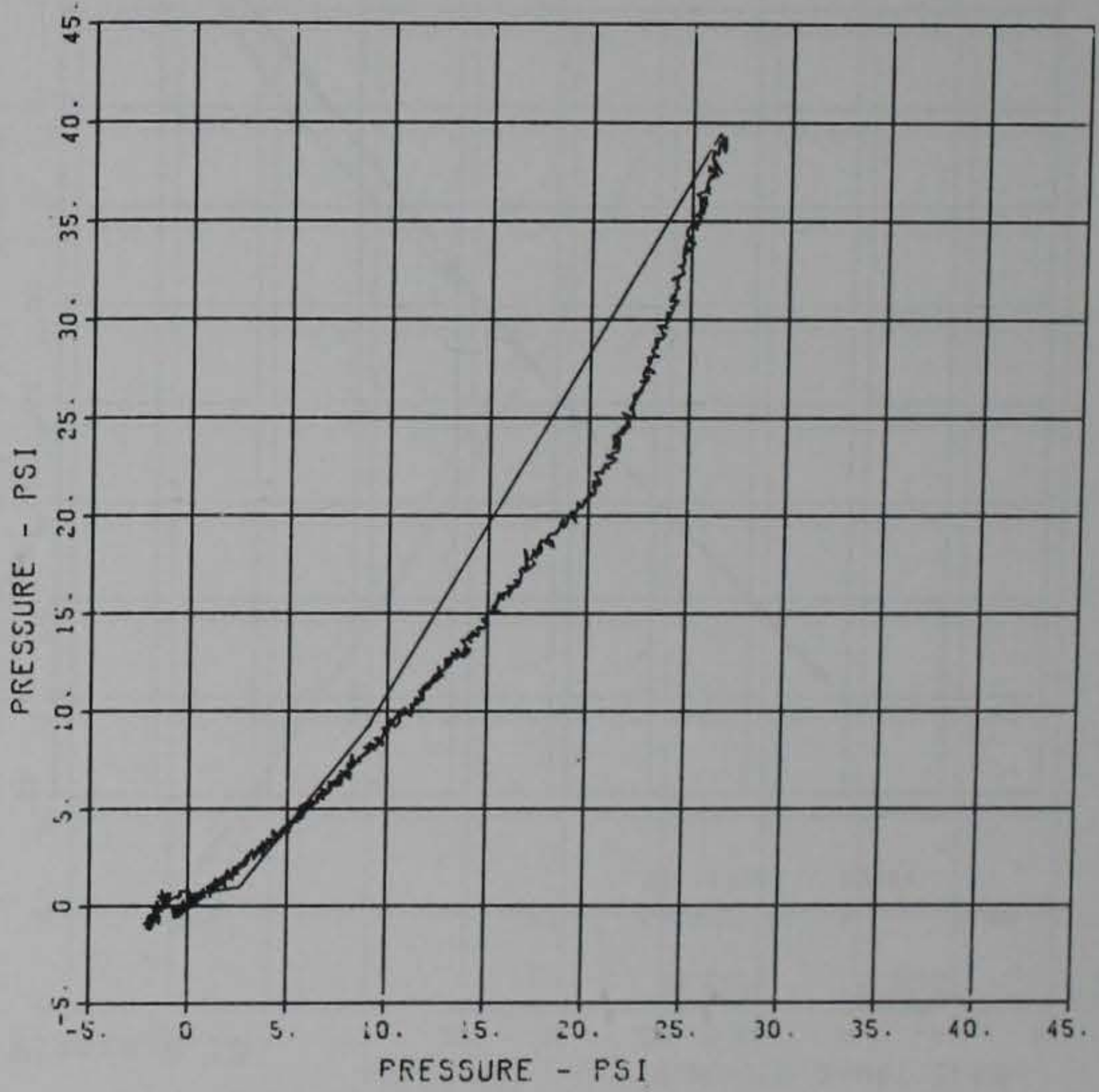


Figure B.17

UPGRADED 2-WAY SLAS

SE - 2

MSXIMUM SIGMG CAL

CHGNNEL NO \& $1330 \quad 1$

03/12/82 R0921

Cค1 132 'ค.

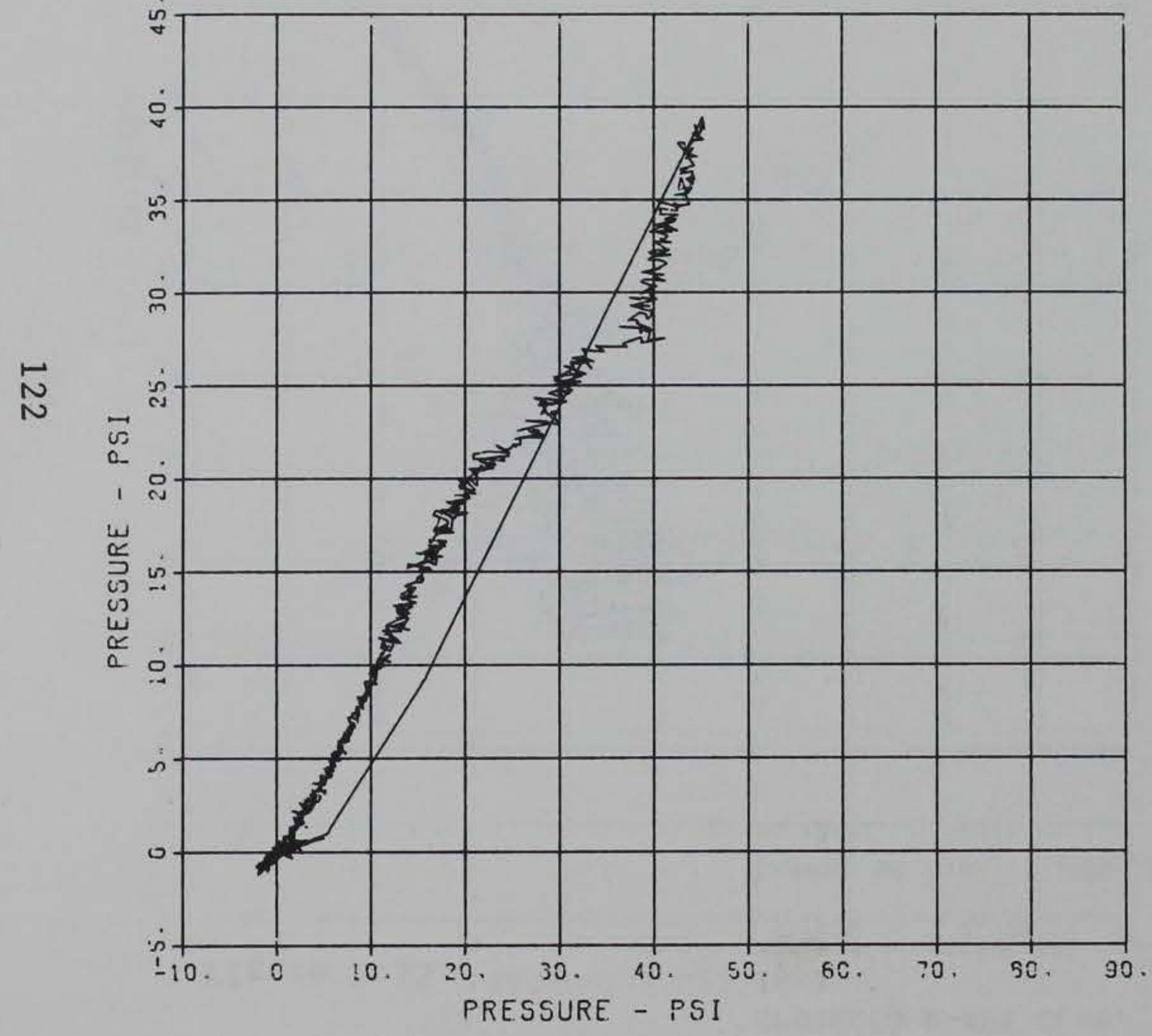

Figure B.18

UPGRADED 2-WAY SLAB

$S E-3$

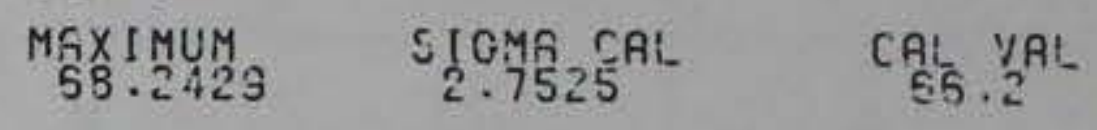

CHANNEL NO. S 13901

03/12/82 R0921

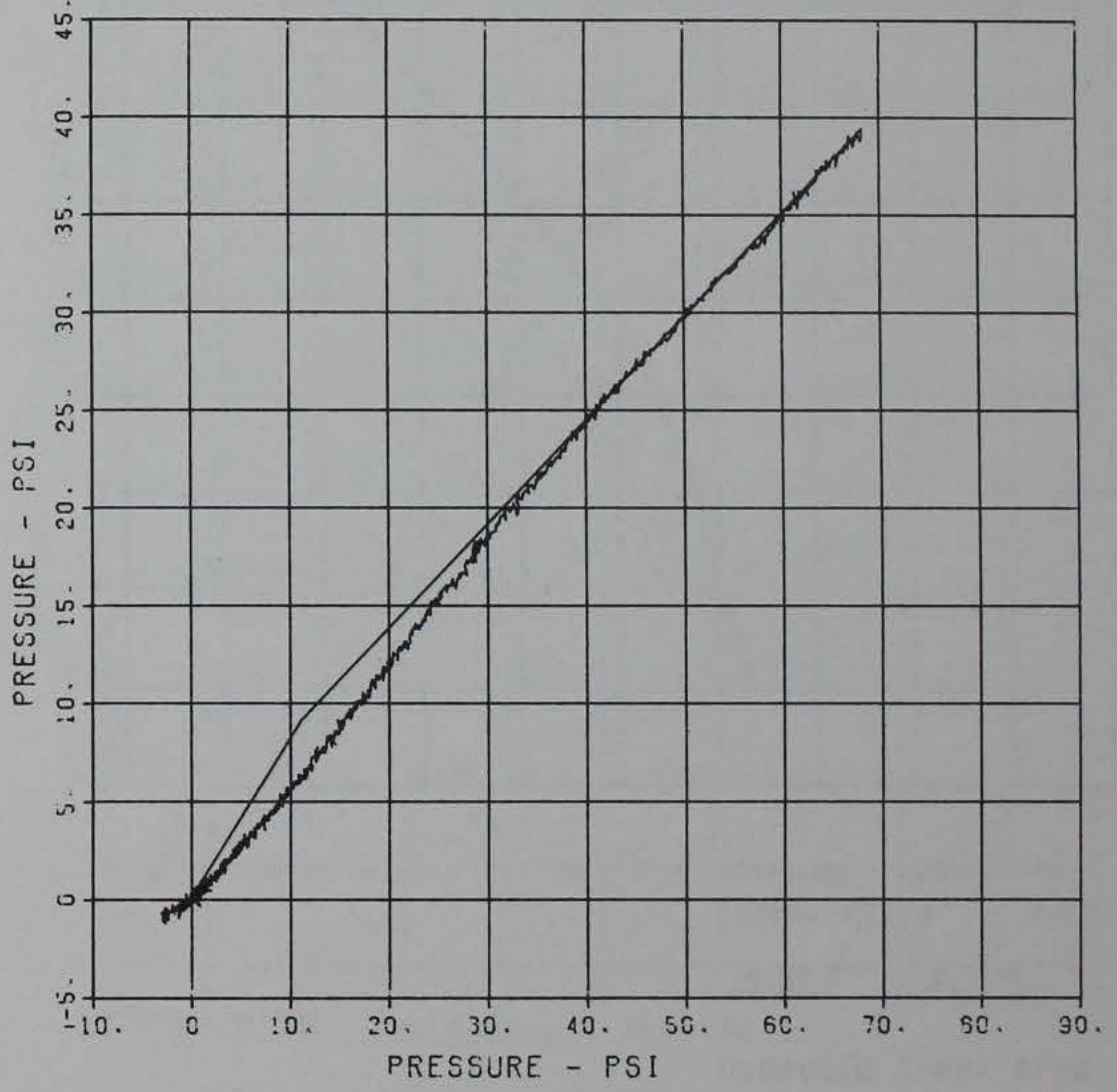


Figure B.19

UFGRADED 2-WAY SLAB

$\mathrm{FF}-\mathrm{Si}$

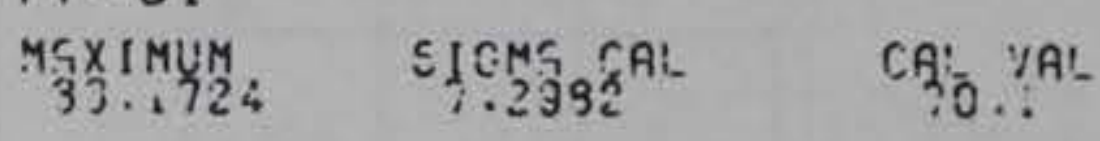

$\begin{array}{llll}\text { CHQNNE: NO } & 5 & 1330 & : \\ \text { O3/12/92 } & \text { ROS21 } & & \end{array}$

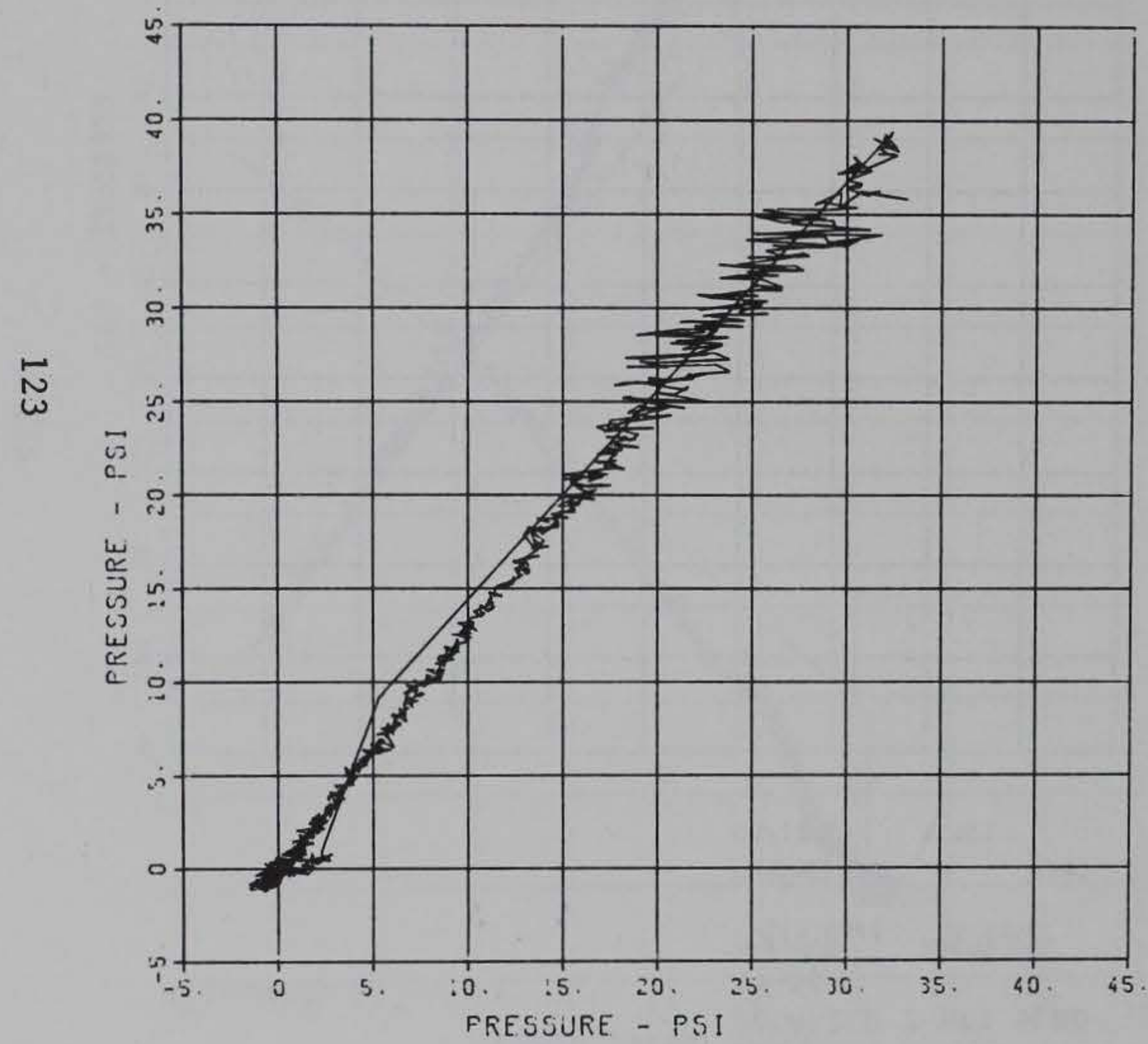

Figure B.20

UFGRADED 2-WAY SLAB

$\mathrm{FF}-\mathrm{S} 2$

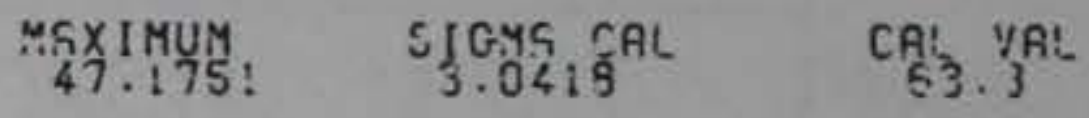

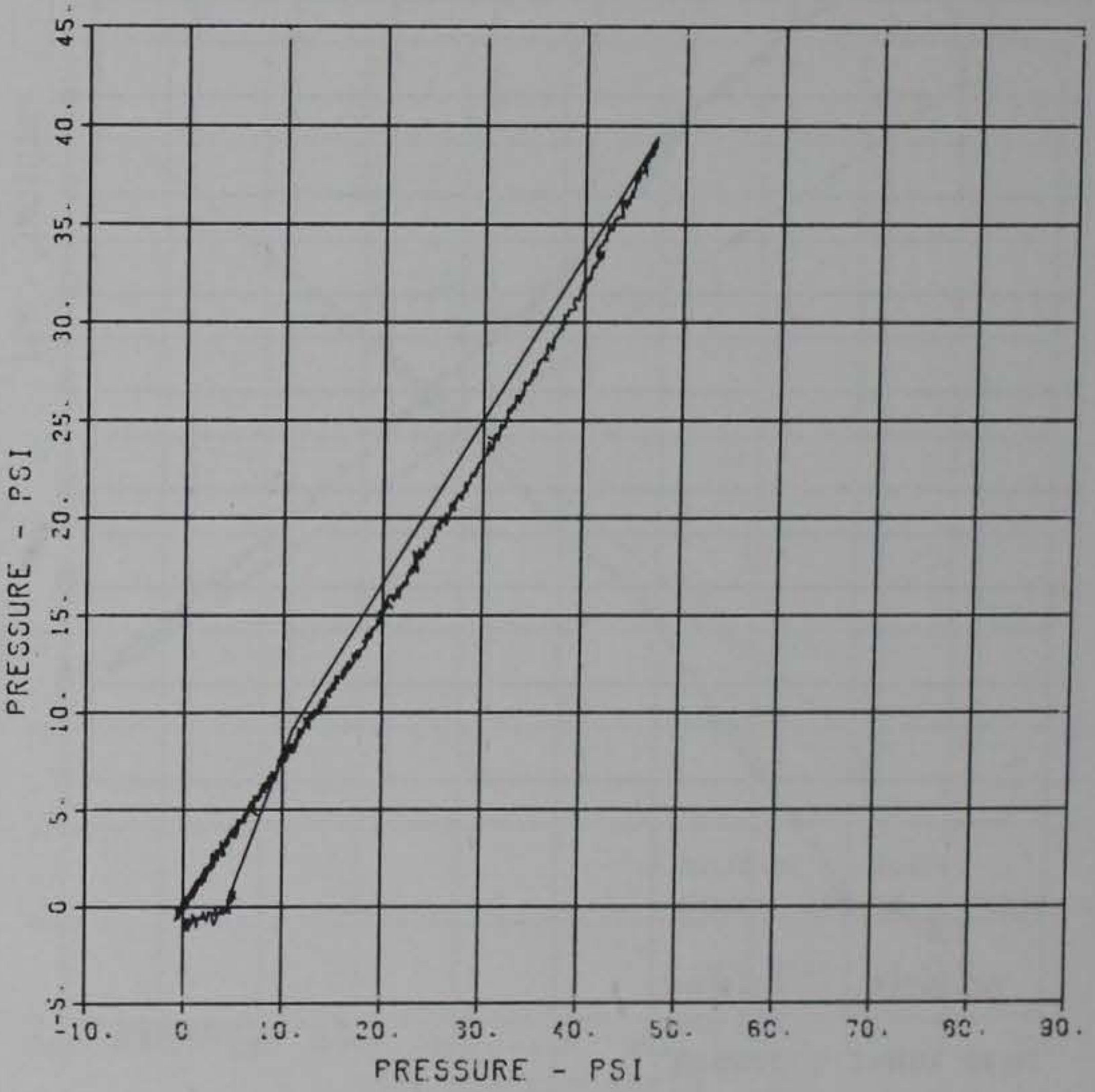


Figure B.21

UPGRADED 2-WAY SLAB

SG-SSW

MGXIMUM
$-5 ! 2.6542$ SIGMG

CHANNELL NO :6 1390

03/12/92 ROS21

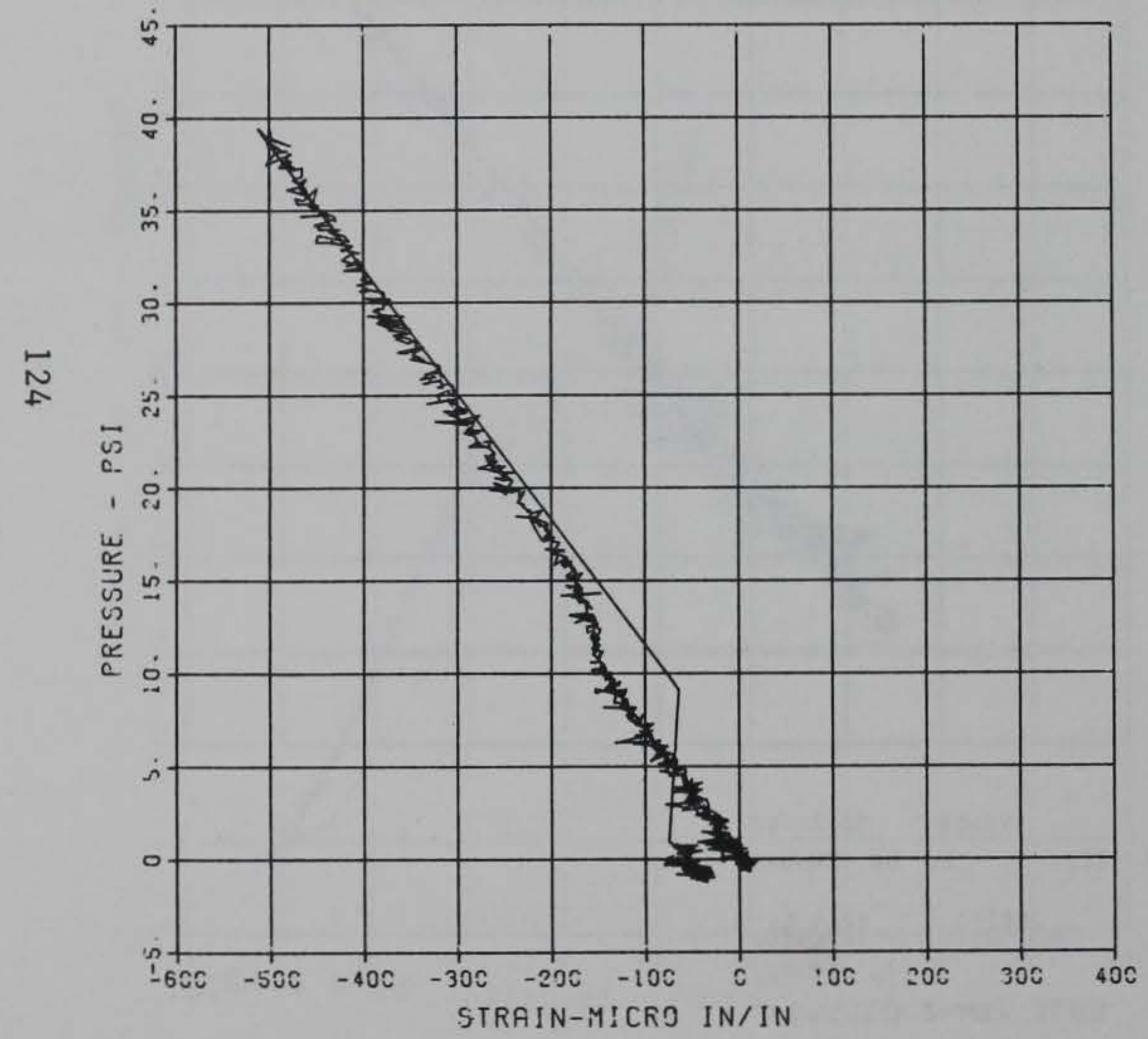

Cค: 546.3 Y

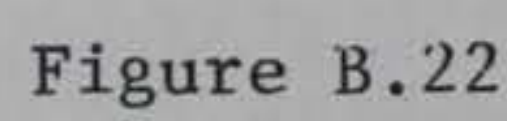

Figure B.22

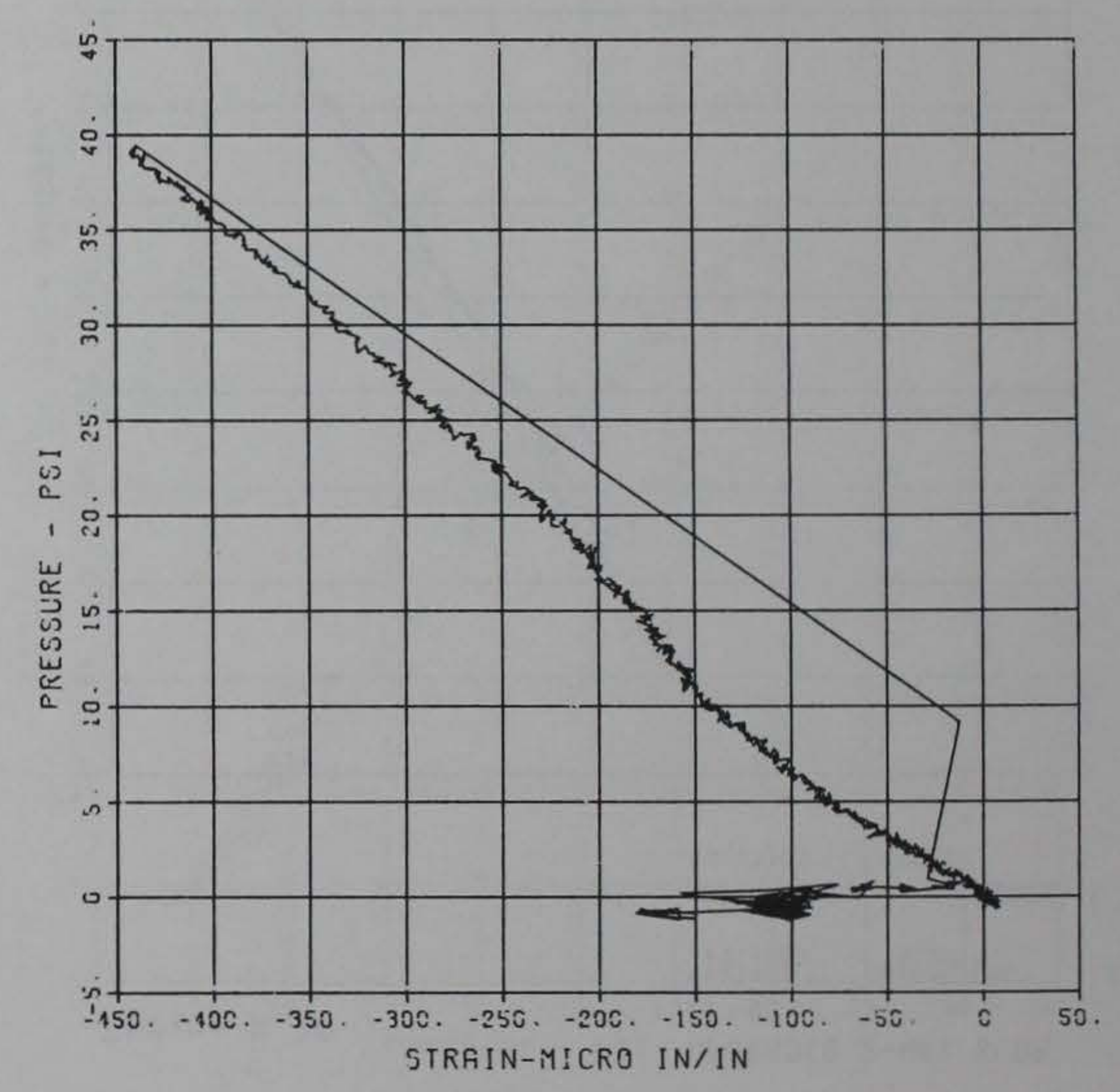


Figure B. 23

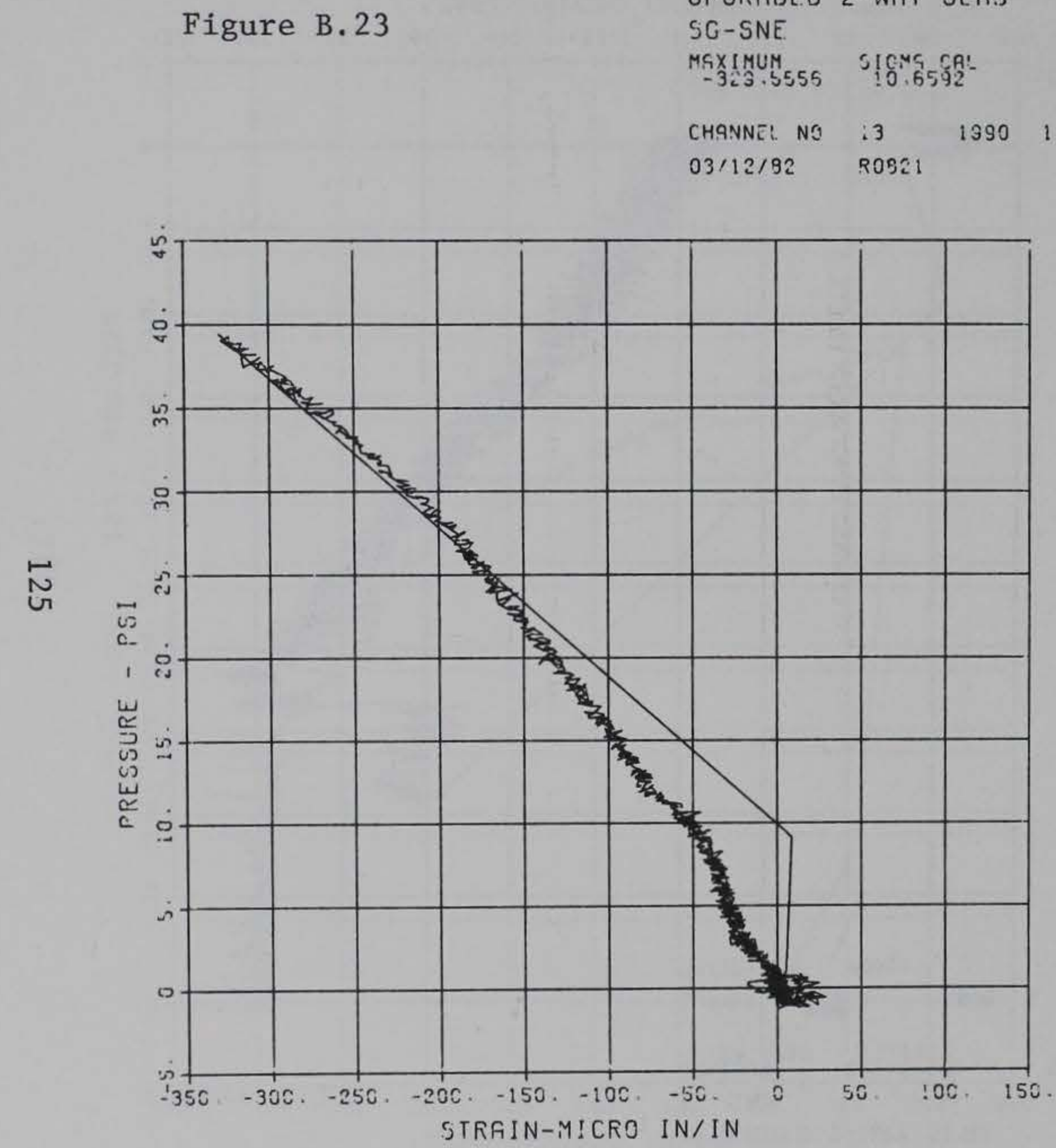

Figure B.24

CA: 54 ' 1 . 3 L
UPGRADED Z -WAY SLAS SG-SNE:

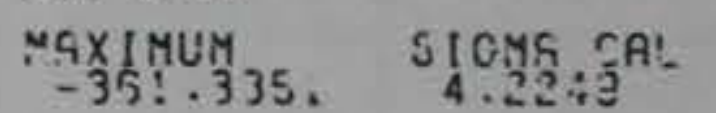

CHGNNE: NO : 4 S $1390 \quad$ ।

03/12/82 R0321

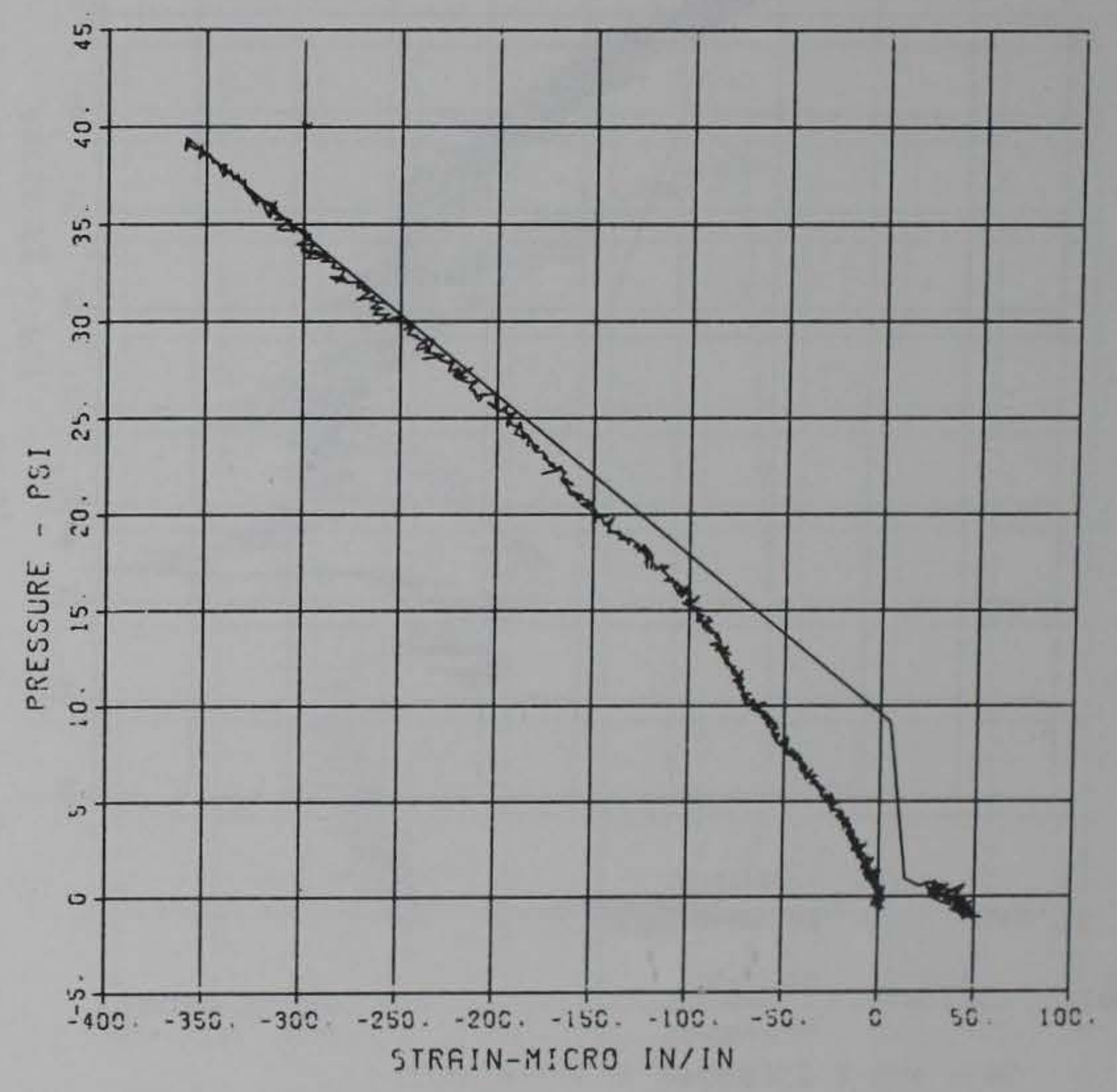


Figure B.25

UPGRADED 2-WAY SLAS

SC-SWO

MGXIMUM
$-109 .: 1757 \quad$ S[GMG CA:
$4.65: 7$

CHaNNäL Ne. A1 $1390 \quad$ i

03/12/82 ROS21

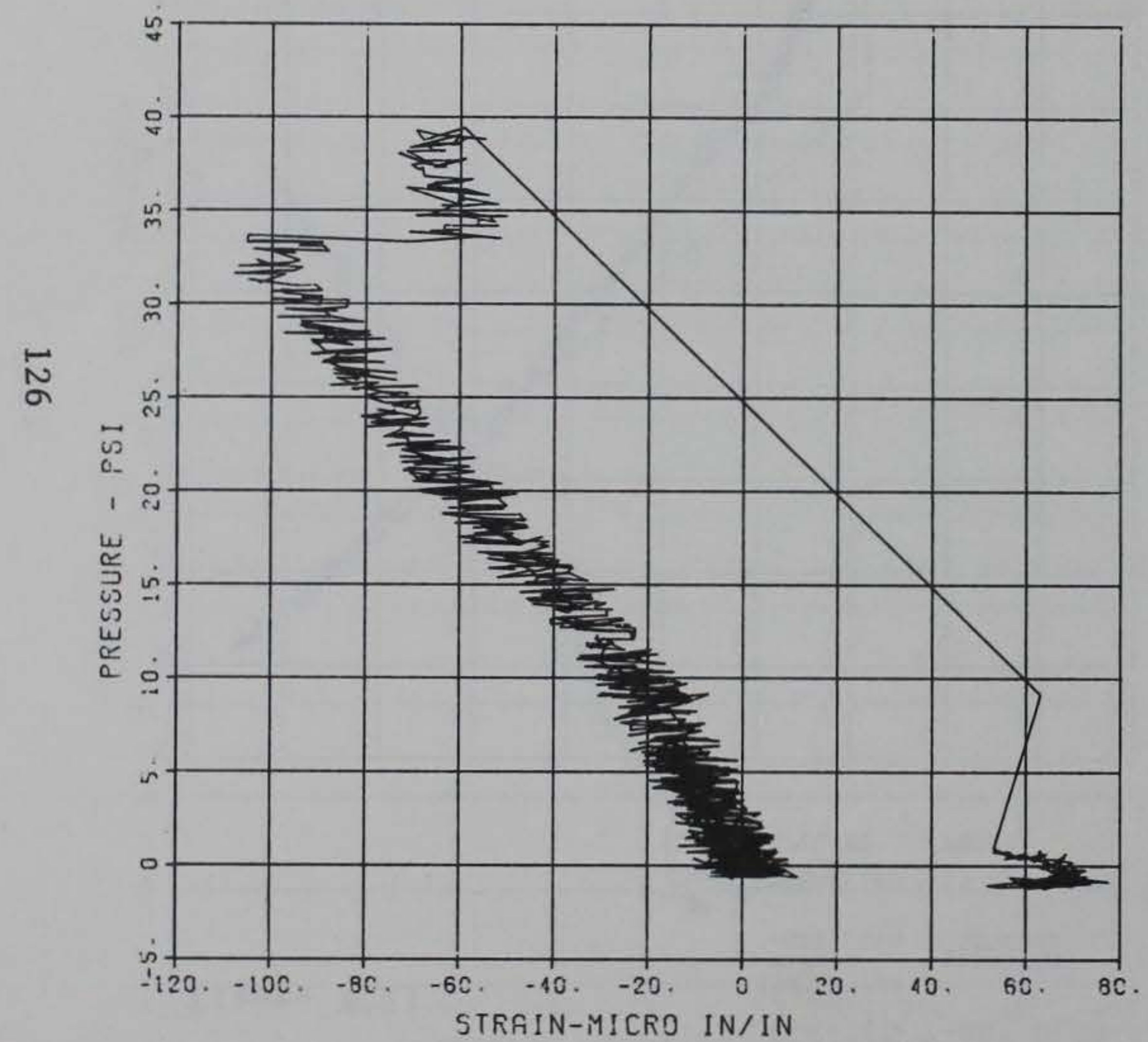

Figure B.26

UPGRADED 2-WAY SLAG

SG-SWI

MSXIMUM SIGMS

CHQNNEL NO : :2 $1390 \quad 1$

03/12/82 R0821

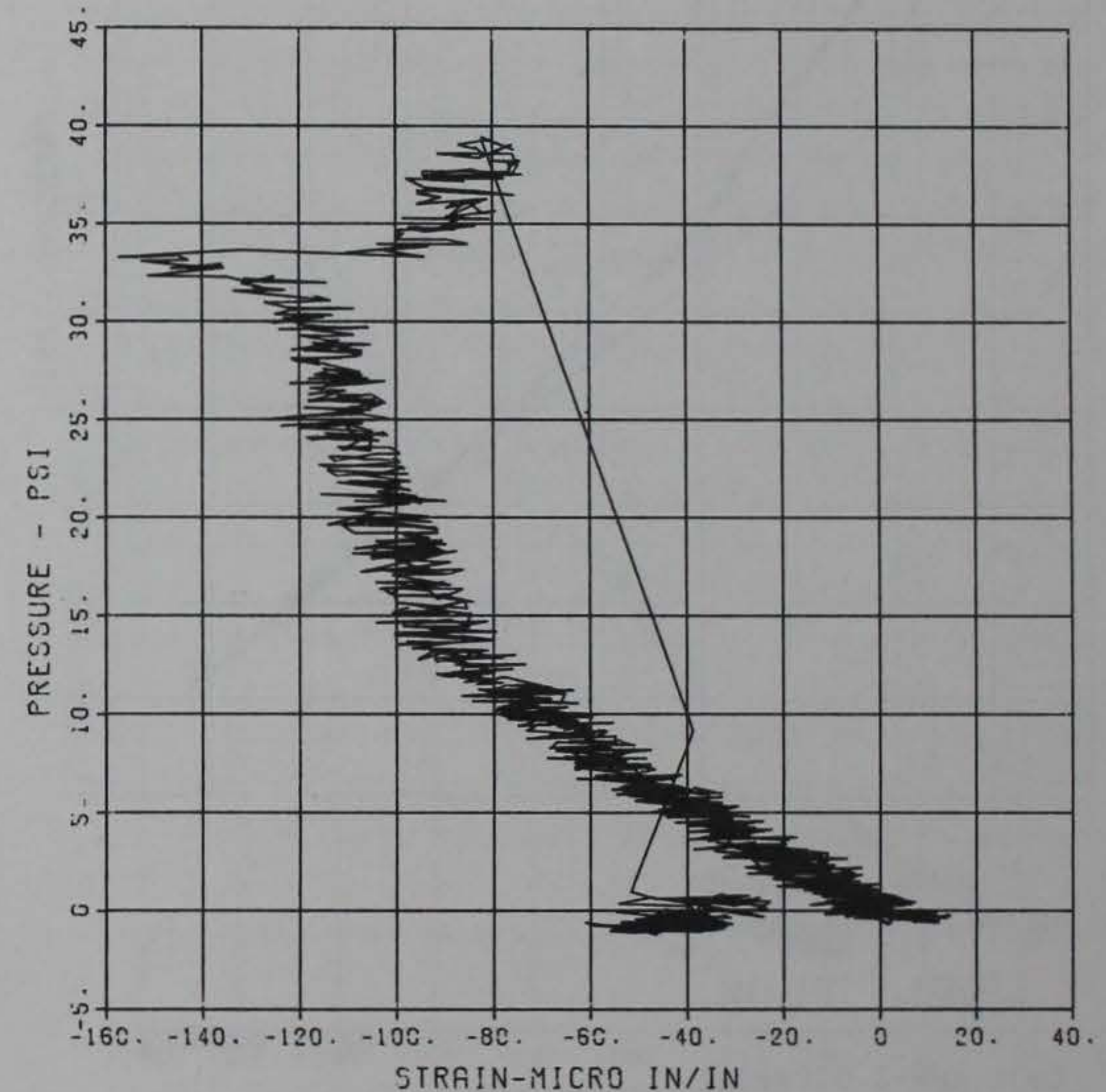


Figure B.27

$$
\begin{aligned}
& \text { UPGRADED 2-WAY SLAS } \\
& \text { SG-ST } 1 \\
& \text { MGXIMUM SIGMG CAL CAL } \\
& \text { CHGNNËL NO. :7 } 1390 \quad 1 \\
& \text { 03/12/82 R0B21 }
\end{aligned}
$$

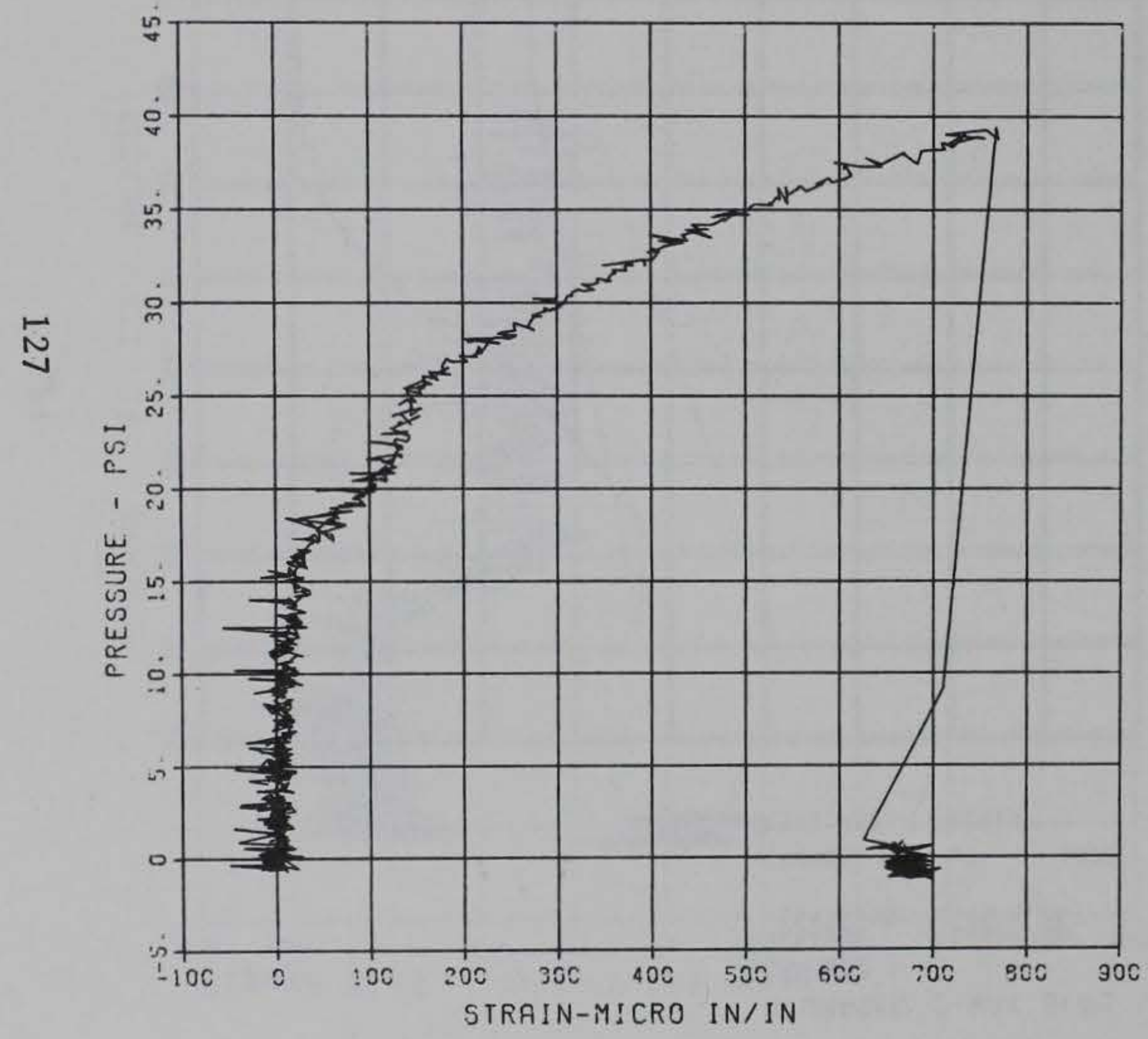

Figure B. 28

$$
\begin{aligned}
& \text { UPGRADED 2-NAY SLAB } \\
& \text { SG-SB } 1
\end{aligned}
$$

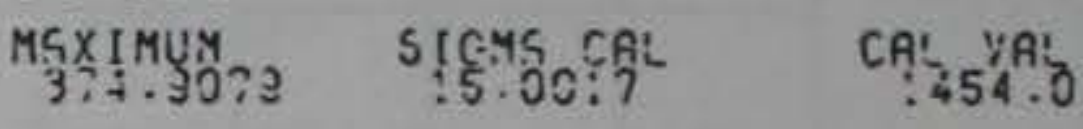$$
\begin{array}{llll}
\text { CHANNE: NO } & \text { : } & \text { 1330 } & 1 \\
\text { O3/12/82 } & \text { ROSEI } & &
\end{array}
$$

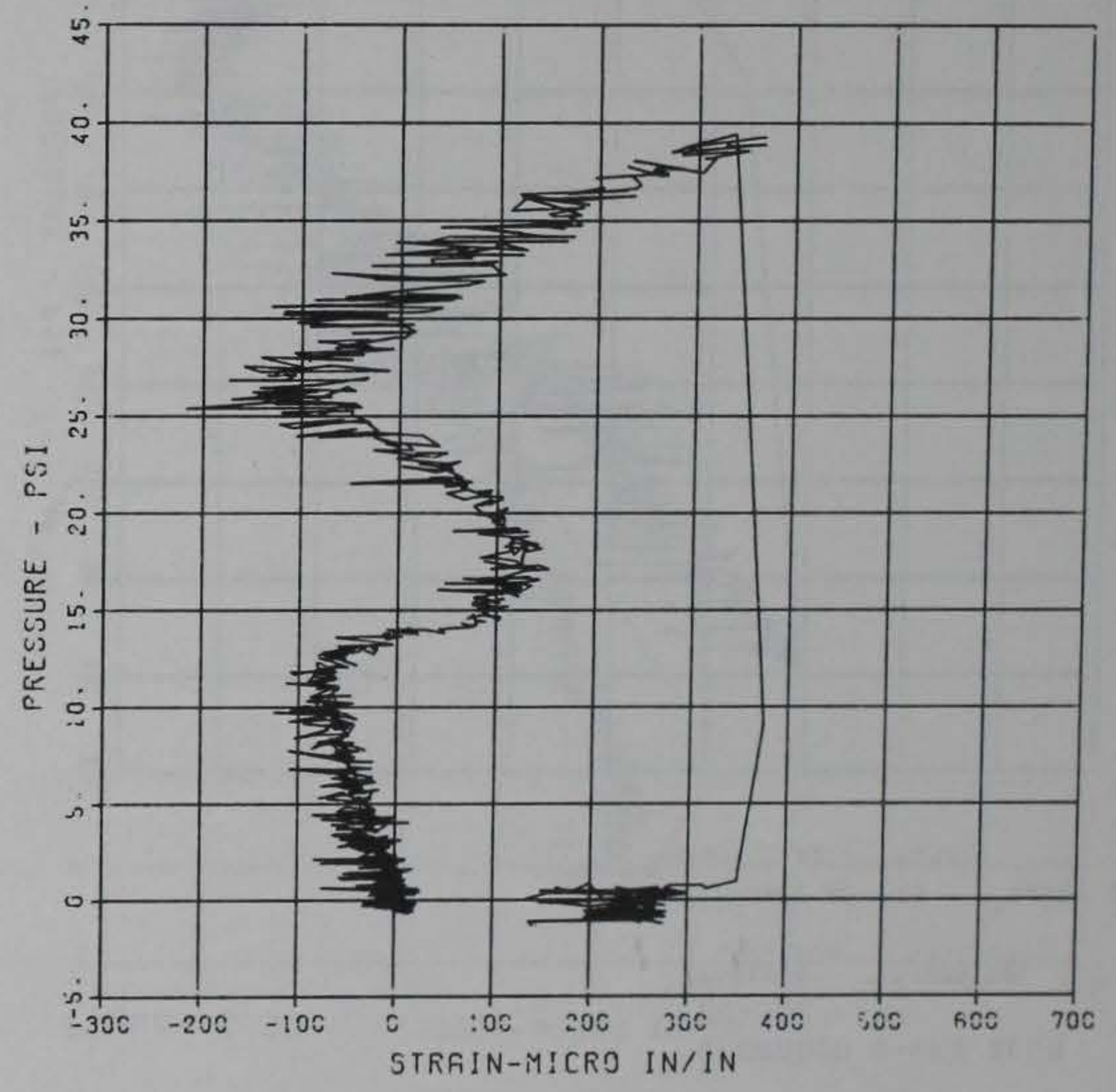


Figure B.29

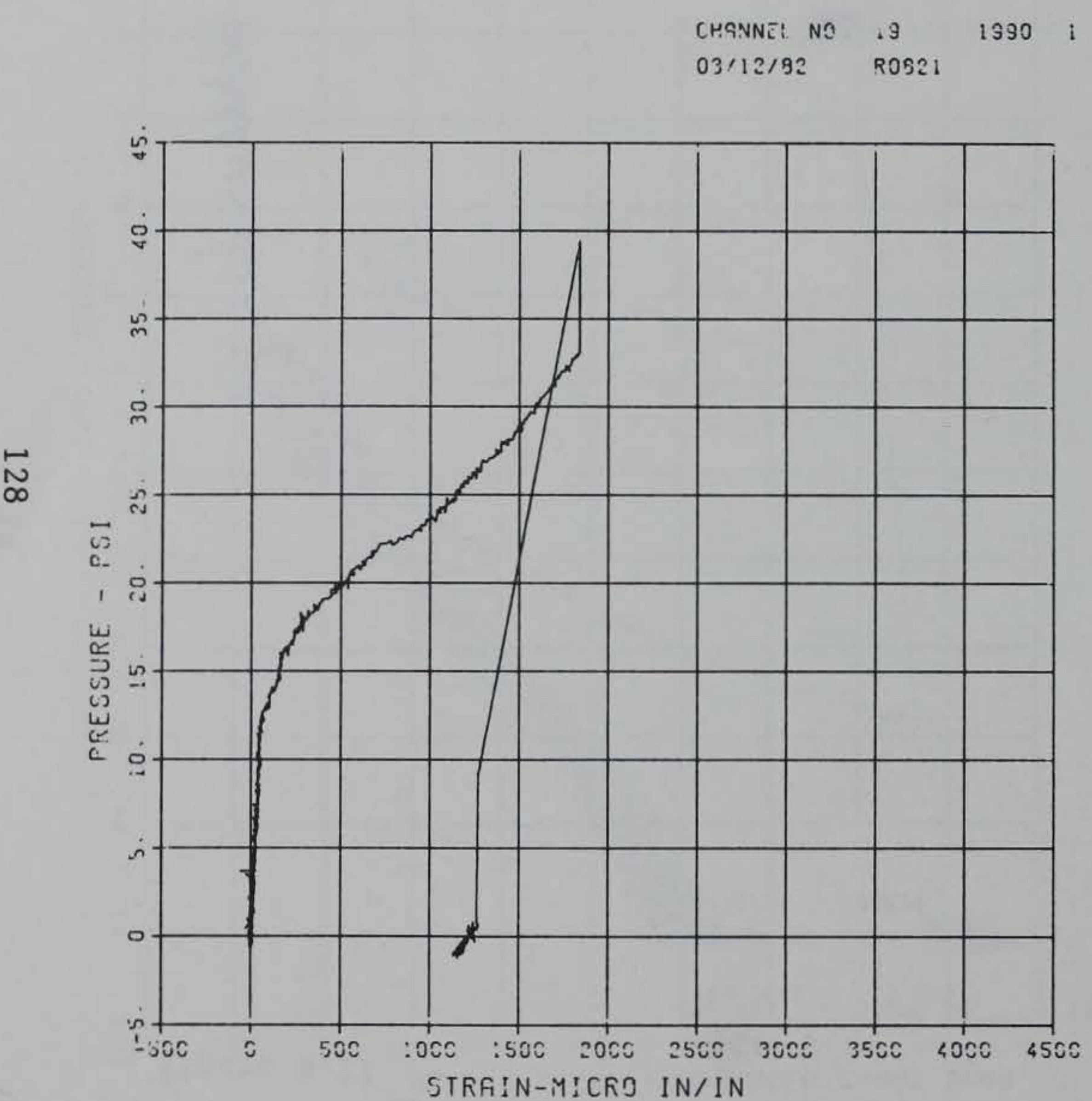

Figure B. 30

(9:) $)^{\text {An: }}$

SG-ST2

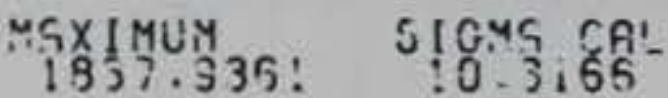

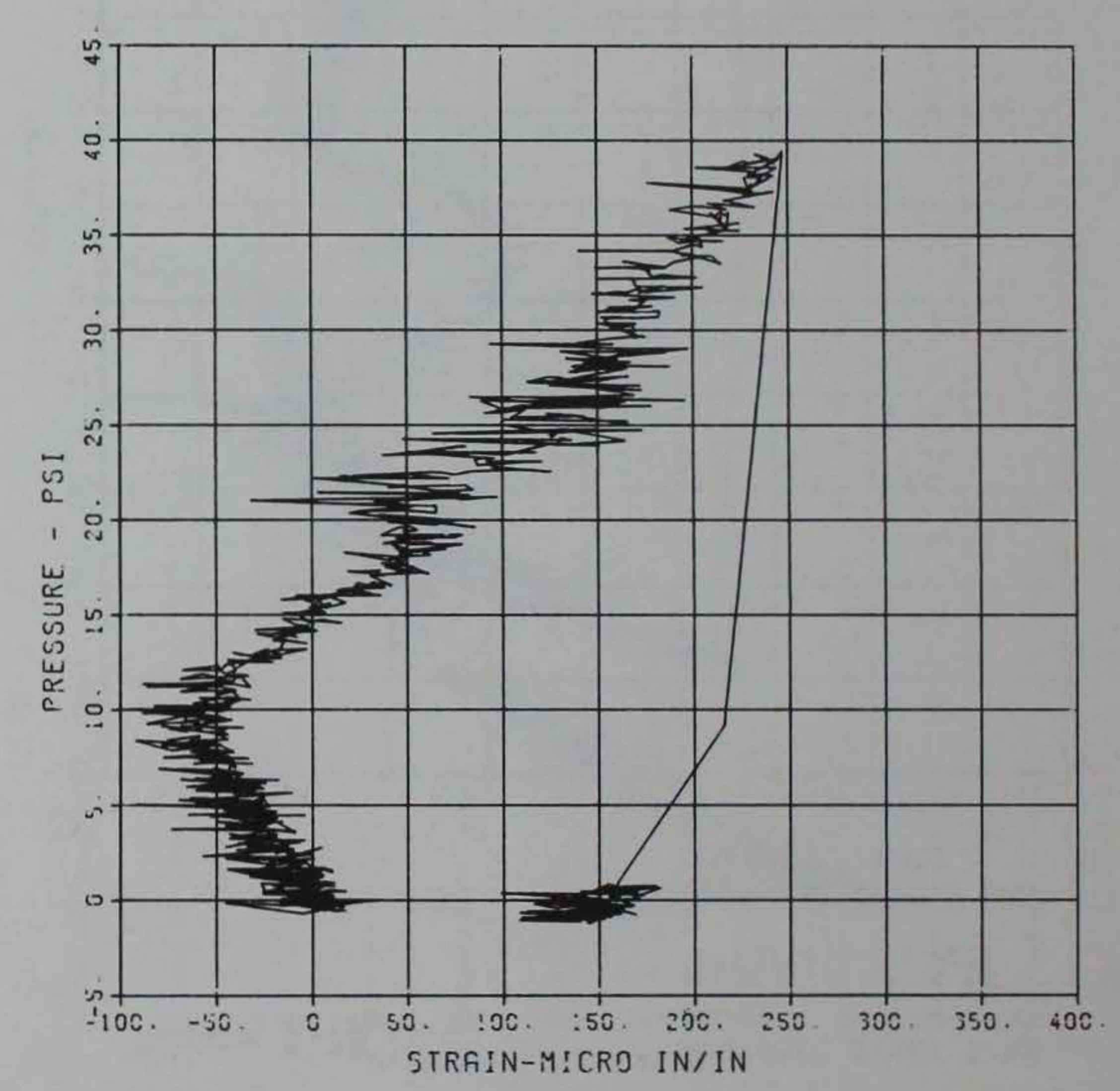

UPGRADED 2-WAY SLAS

SG-SB2

MgXIMUM

CHANNĒL NO . $20 \quad 1990$

03/12/82 R0521 
Figure B. 31

UFGRADED 2-WAY SLAS

SG-ST3

MaXIMUM $210.35: 4$ IEMG

CHANNE: NO. 21 1390

03/12/82 R0521

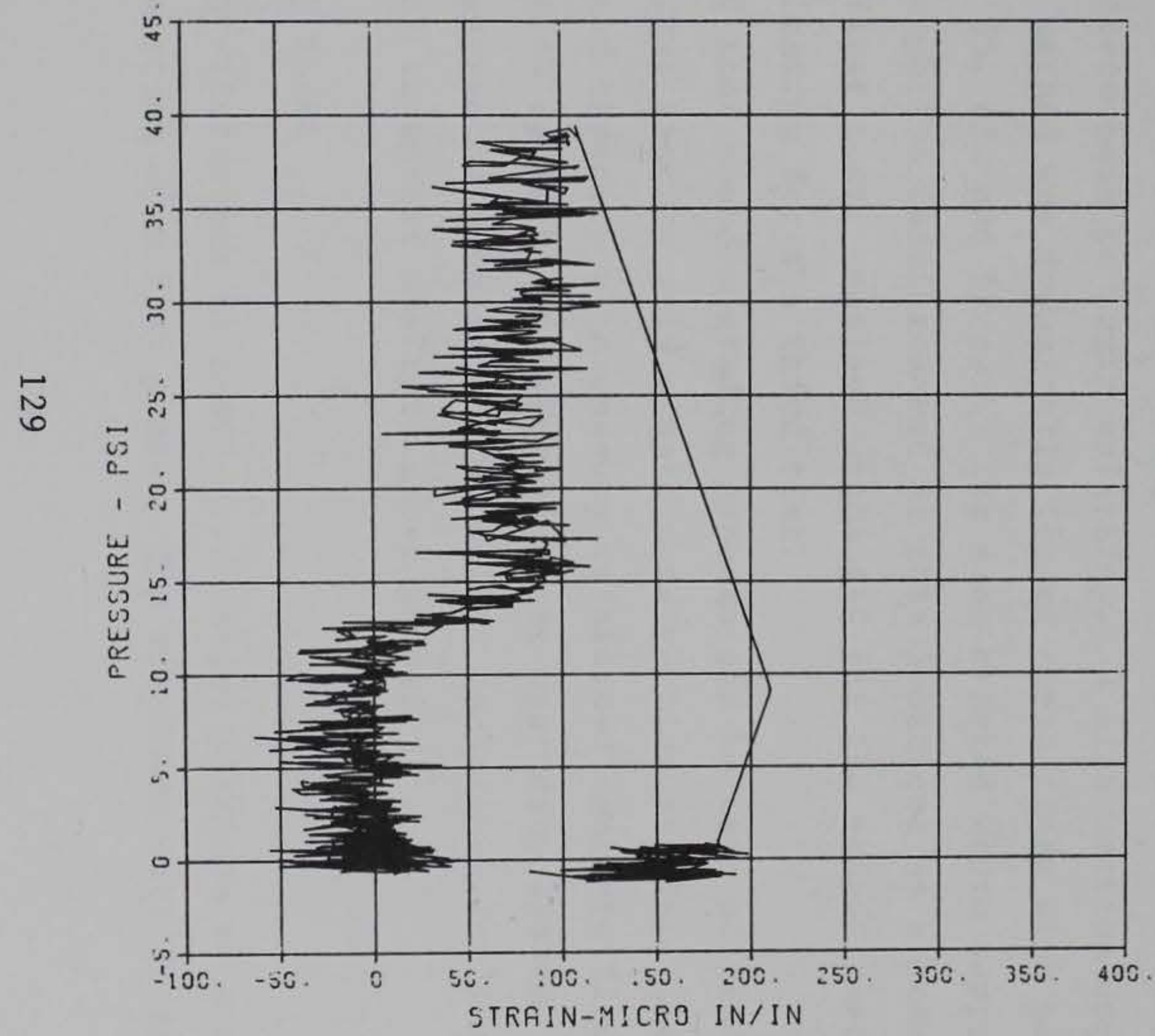

Figure B.32

UFGRADED 2-WAY SLAS

SG-SB3

MSXIMUM GIGYG FAL

(fị)

CHANNË! NO $22 \quad 1990 \quad 1$

$03 / 12 / 82$

ROB21

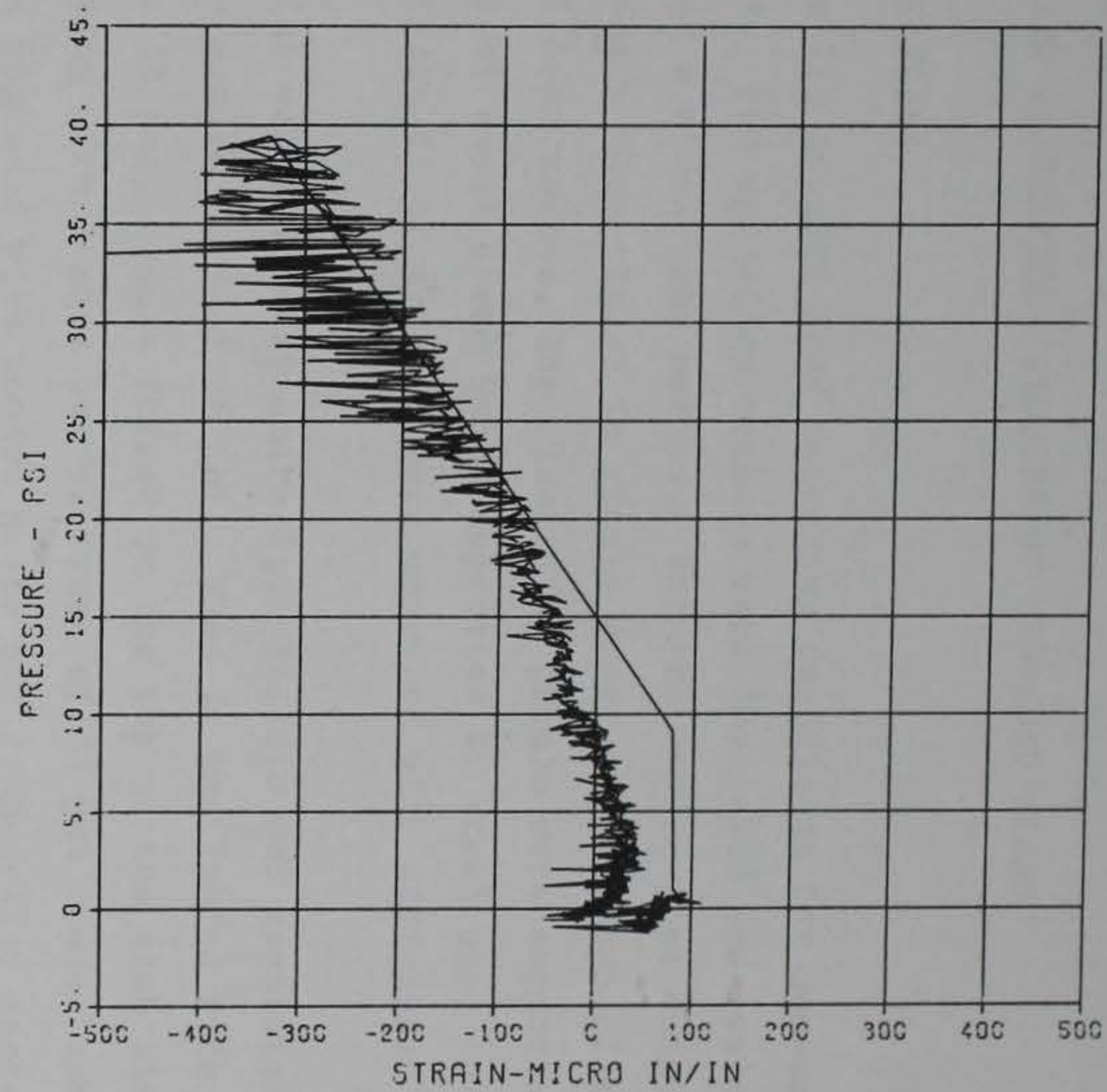




\section{APPENDIX C}

\section{REVIEW OF PREVIOUS STUDIES OF UPGRADED SLABS}

\section{1 UPGRADED ONE-WAY SLABS}

McVay (Reference 11) investigated upgrading techniques for one-way reinforced concrete slabs. Two upgrading methods were developed and evaluated: a wooden post method and a steel beam method. For the wooden post method, several 4- by 4-inch timbers were placed in groups under the midspan of the slabs. For the steel beam method, the floor slab panels were supported at midspan with a series of small steel beams supported by steel pipe columns. The concrete beams of the floor systems were upgraded with additional posts in both methods.

A nonupgraded slab was tested dynamically. Failure was predicted to occur at a peak overpressure load of $16 \mathrm{psi}$. When it was loaded with a peak overpressure of about $15 \mathrm{psi}$, cracks formed in the top of the slab along the beams. A second loading with a peak overpressure of 33 psi caused complete collapse. A slab was upgraded with wooden posts and dynamically tested five times. The fifth test loaded the slab with a peak overpressure of 113 psi, causing two timbers to begin punching through the slab and several timbers under the center concrete beam to begin splitting. A slab section upgraded using the steel beam method was dynamically loaded three times with peak overpressure loadings of 35, 63, and 92 psi. The slab cracked where supported by the steel beams (no negative reinforcement at this location) as a result of the loading for the first test, remained unchanged for the second test, and collapsed under the loading for the third test.

It was concluded that sound upgrading systems can be made of readily available materials that require only simple construction skills. The tests indicated that the load capacity of a one-way reinforced concrete floor system can be increased five to seven times using a proper upgrading system. It was concluded that both upgrading methods are excellent techniques for increasing the load capacities of keyworker shelters above 50 psi.

\section{2 UPGRADED TWO-WAY SLABS}

Woodson and McVay (Reference 6) tested two center portions of a waffle slab and the center portion of a flat plate. The specimens were designed 
with the maximum diameters that would allow placement inside the 22-foot 10inch-diameter Large Blast Load Generator at WES. The test specimens were also constructed to include the positive moment area from 22-foot-square slabs designed according to the Third Edition of the CRSI Handbook (Reference 12). An 8-inch-thick wall, 8-feet tall, supported the slabs along their perimeters, and wooden posts were wedged in place under each specimen. It should be noted that the test specimens were not under boundary conditions similar to those in actual structures.

Due to buckling of upgrading columns, the maximum static and dynamic load-carrying capacities of the waffle slab system were near 44 and 34 psi, respectively. Collapse of the wooden columns allowed the slabs to shear along the rigid boundary. Similarly, the wooden upgrading columns in the flat plate center portion test buckled at an average static overpressure of 38 psi. The slab did not shear along the boundary. Large flexural deflections occurred, causing a loss in water pressure that was statically loading the specimen.

The tests supplied encouraging results that implied that two-way reinforced concrete slabs may be upgraded without the occurrence of punching shear failure at upgrading columns. 